\title{
THE SYNTHESIS OF CARBOHYDRATE PROBES FOR THE DIAGNOSIS OF MULTIPLE SCLEROSIS
}

BY

KRISTIANA SANTOSO

\author{
A thesis \\ submitted to the Victoria University of Wellington \\ in partial fulfilment of the requirements for the degree of \\ Masters in Science
}





\section{Table of Contents}

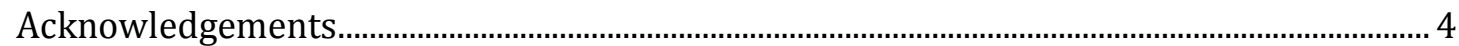

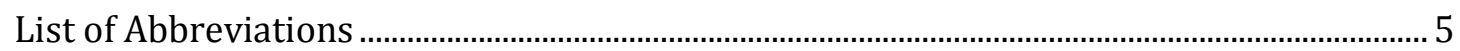

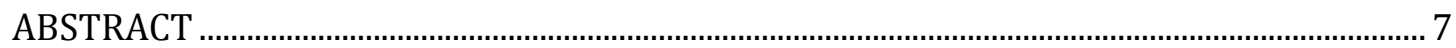

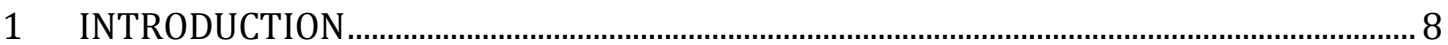

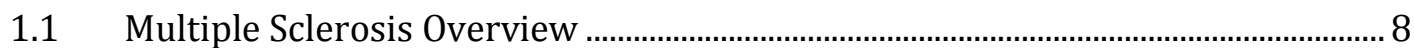

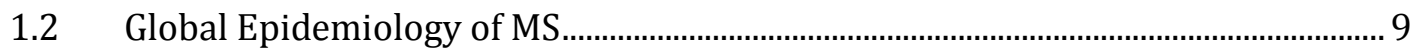

1.2.1 Environmental contributions ...........................................................................10

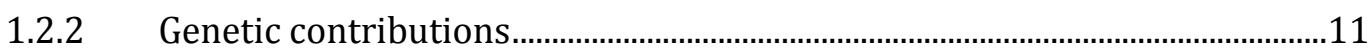

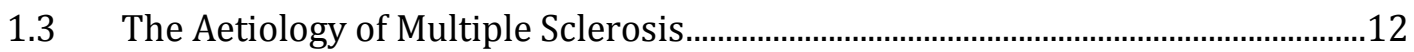

1.3.1 Neurodegeneration in Multiple Sclerosis ...........................................................14

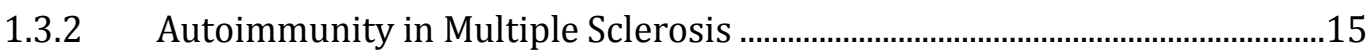

1.4 Types of Multiple Sclerosis.......................................................................................

$1.5 \quad$ Treatments for Multiple Sclerosis …………………………………….....................18

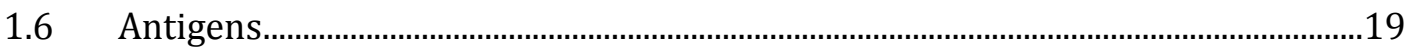

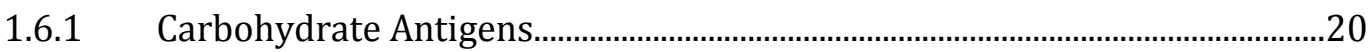

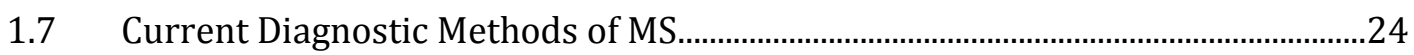

1.8 Anti-Glycan Antibodies in MS Patients ...................................................................25

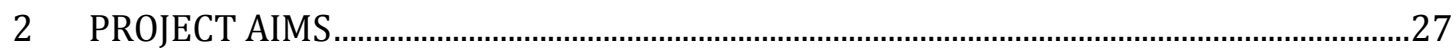

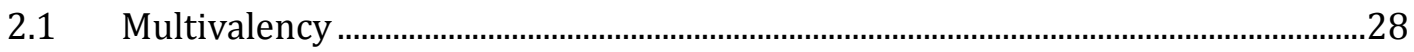

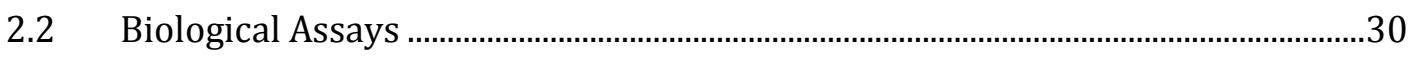

2.2.1 Enzyme-Linked Immunosorbent Assay (ELISA) ...............................................30

2.2.2 Double-Immunodiffusion Assay (The Ouchterlony Method)..........................31

2.3 Synthetic Strategy: Biotinylated Glucosides ……………............................................32

2.4 Synthetic Strategy: Branched Glycosides ..................................................................3

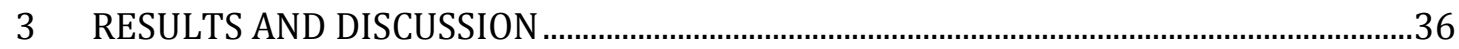

3.1 Synthesis of Linear Saccharides ………………….................................................

3.1.1 Perbenzylated Phenyl Thioglucoside as Donor..................................................36

3.1.2 Benzylidene Protected Thioglucoside Donor......................................................4

3.1.3 Di-O-Benzoyl Phenyl Thioglucoside Donor..........................................................50

3.1.4 Perbenzylated Thioethyl Glucose as Donor ........................................................53 
3.1.5 Using Perbenzylated Thioethyl Maltose as Donor .............................................59

3.1.6 The Synthesis of Biotinylated Glycosides ............................................................62

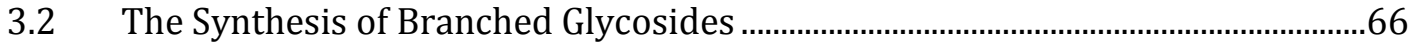

3.2.1 Dendron Synthesis ...........................................................................................66

3.3 ELISA Results ...........................................................................................................

3.3.1 Coating ELISA Plates with Streptavidin.................................................................74

3.3.2 Establishing a Positive Control and Plasma Concentration .............................75

3.3.3 Prevention of Non-Specific Interactions ..............................................................79

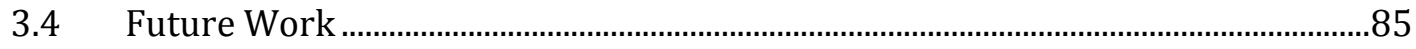

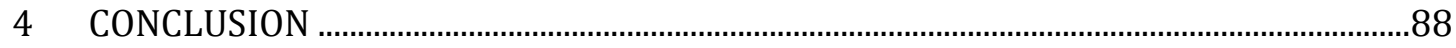

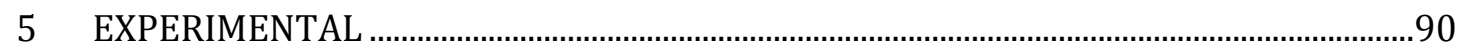

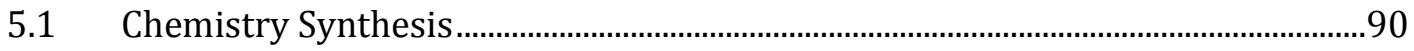

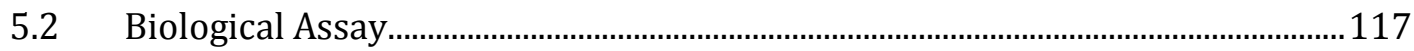

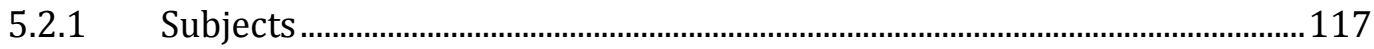

5.2.2 Preparation of Plasma Samples ………………................................................117

5.2.3 General ELISA Method...................................................................................117

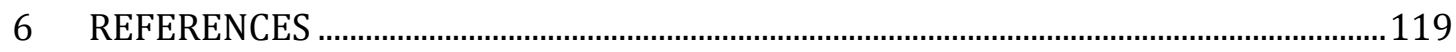

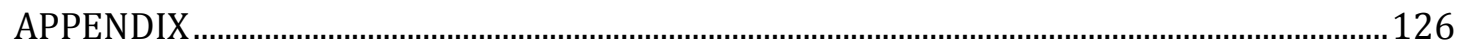




\section{Acknowledgements}

There are many who have contributed to this thesis, and I wish to thank each of you. Firstly, my supervisors Drs. Mattie Timmer and Bridget Stocker, thank you for always having or making time for me, for educating me, for putting things into perspective, for allowing me to park my car at your place, for instilling in me great working habits, and for laughing at my jokes. To my secondary supervisor, Assoc. Prof. Anne LaFlamme, thank you for sharing with me your biological expertise.

To my family, thank you for being patient when I haven't had time for chats, and for being ever so supportive. Grant and Tania, thank you for constantly checking up on me, for always knowing exactly what I need, and looking after me even from across the ditch.

To my research group, you truly have seen the worst of me, I do apologise for that. To Stefan, thank you for sharing with me your time. You are incredibly knowledgeable, and I have enjoyed (and will actually miss) our late night lab sessions. Janice, you have also taught me a lot, both in life and in chemistry and I have missed having you around in the lab. To Amy and Jessie, thank you for putting up with my singing, and Amy for letting me sleep at your house at random hours of the day. Alex, thank you for making me seem funny for having lamer jokes than mine. To the rest: Steph, Hilary, Jaimé, Rhia, Ben, Kristel, Charlotte, Billy, Chriselle, thank you for making the lab a fun place to work.

To my second research group - the biologists: Nikki, Pirooz, Vimal. Thank you for all your help and for letting me invade your space for the last few months. To Ian, Sally, Teresa, Jackie, Dan, thank you for your constant readiness to help.

Special mention to those who I've been blessed to call friends: Stevie, Chas, Natalie J, Natalie S, Katherine, Lynne, Caleb, Ash, Erin - cheers for getting me away from the world of chemistry every now and then; Emma, Claire, Ethan, Sarah, Brad, Lucy, Tat thanks for hanging about being geeks with me; Loïc for your generous hospitality and support (which extend to your amazing flatmates - Mike, Millie, Georgia), for appreciating my sense of humour, and for making me feel tiny, even on fat days. 


\section{List of Abbreviations}

AIDS

ALS

ATP

BSA

BTIB

CDMS

CIS

CNS

COSY

CSA

CSF

DCC

DMF

DMTST

EAE

EBV

FCS

FDA

Glc

GlcNAc

HBTU

HLA

HMBC

HOBt

HRP

HSQC

$\mathrm{Hz}$

IgA

IgD

$\operatorname{IgE}$

IgG

Acquired Immune Deficiency Syndrome

Amyotrophic Lateral Sclerosis

Adenosine Triphosphate

Bovine Serum Albumin

Bis((trifluoroacetoxy)iodo)benzene

Clinically Definite Multiple Sclerosis

Clinically Isolated Syndrome

Central Nervous System

Correlation Spectroscopy

Camphor Sulfonic Acid

Cerebrospinal Fluid

Dicyclohexyl Carbodiimide

Dimethyl Formamide

Dimethyl(methylthio)sulfonium Triflate

Experimental Allergic Ecephalomyetis

Epstein-Barr Virus

Foetal Calf Serum

Food and Drug Administration

Glucose

N-Acetyl Glucosamine

O-(Benzotriazol-1-yl)-N,N,N',N'-Tetramethyluronium

Hexafluorophosphate

Human Leukocyte Antigen

Heteronuclear Multiple Bond Correlation

1-Hydroxy-Benzotriazole

Hydrogen Peroxidase

Heteronuclear Single Quantum Coherence Spectroscopy

Hertz

Immunoglobulin A

Immunoglobulin D

Immunoglobulin $\mathrm{E}$

Immunoglobulin $G$ 


\begin{tabular}{|c|c|}
\hline IgM & Immunoglobulin $\mathrm{M}$ \\
\hline IR & Infrared \\
\hline LSDMS & Laboratory-Supported Definite Multiple Sclerosis \\
\hline MAG & Myelin-Associated Glycoprotein \\
\hline MBP & Myelin Basic Protein \\
\hline МOBP & Myelin-associated Oligodendrocyte Basic Protein \\
\hline MOG & Myelin-Oligodendrocyte Glycoprotein \\
\hline MRI & Magnetic Resonance Imaging \\
\hline MS & Multiple Sclerosis \\
\hline $\mathrm{NAb}$ & Natural Antibodies \\
\hline NBS & N-Bromo Succinimide \\
\hline NHS & N-Hydroxy Succinimide \\
\hline NIS & N-Iodo Succinimide \\
\hline NMR & Nuclear Magnetic Resonance \\
\hline OSP & Oligodendrocyte-Specific Glycoprotein \\
\hline PAMAM & Poly(amidoamine) \\
\hline PBS & Phosphate Buffer Saline \\
\hline PhSOTf & Phenyl Sulfenyl Trifluoromethanesulfonate \\
\hline PLP & Proteolipid Protein \\
\hline PML & Progressive Multifocal Leukoencephalopathy \\
\hline PPMS & Primary Progressive Multiple Sclerosis \\
\hline RRMS & Relapsing Remitting Multiple Sclerosis \\
\hline $\mathbf{R}_{f}$ & Retardation Factor \\
\hline SEM & Standard Error of the Means \\
\hline SPMS & Secondary Progressive Multiple Sclerosis \\
\hline TAL & Transaldoase \\
\hline TBAI & Tetra Butyl Ammonium Iodide \\
\hline TFA & Trifluoroacetic Acid \\
\hline TfOH & Trifluoromethanesulfonic acid \\
\hline TLC & Thin Layer Chromatography \\
\hline TMB & 3,3,5',5'-Tetramethylbenzidine \\
\hline TMSOTf & Trimethyl Silyl Trifluoromethanesulfonate \\
\hline TPABr & Tetra Propyl Ammonium Bromide \\
\hline WHO & World Health Organisation \\
\hline
\end{tabular}




\section{ABSTRACT}

Multiple sclerosis (MS) is a neurologically debilitating disease which typically affects people in the age bracket of 27-40 years old. Currently, little is known about the mechanism of the disease, which is partly due to the lack of a reliable diagnostic test. There are two common ways of diagnosing MS, neither of which are specific to MS. One is the detection of IgG antibodies in the cerebrospinal fluid (CSF), a painful and invasive test, and the other involves obtaining MRIs of the brain to locate and monitor plaques in brain, which can be expensive and harmful. Early detection of the disease could not only lead to better symptom management, but would also allow for better monitoring of disease progress and, accordingly, lead to a better understanding of MS pathology. To this end, a reliable and non-invasive diagnostic test for the early detection of MS is required.

In 2006, it was reported that antibodies against $\alpha$-Glc and $\alpha$-Glc $(\alpha-1,4)$ Glc were found at elevated levels in the sera of MS patients when compared to healthy patients' sera, and it has been proposed that the presence of these two carbohydrates in patient serum might serve as a way to detect the onset and prognosis of MS. Accordingly, this Masters project sought to explore this hypothesis via the synthesis of $\alpha$-Glc and $\alpha$-Glc $(\alpha-1,4)$ Glc, both glycosides and glycodendrons, which could then be used to potentially detect MS-specific antibodies in sera. To this end, both glycans were prepared and coupled to biotin, ready to be used to bind streptavidin-coated enzyme-linked immunosorbent assay (ELISA) plates. An ELISA protocol is to be established by the optimisation of the negative control in order to test such glycans against plasma samples. In the hope to achieve a multivalent system, a dendrimeric scaffold was also prepared that can be used to prepare larger glycan structures for the immunodiffusion assay. Ultimately, this could lead to a new diagnostic test for MS. 


\section{INTRODUCTION}

\section{$1.1 \quad$ Multiple Sclerosis Overview}

Multiple sclerosis (MS) is a common chronically debilitating disease among young adults in the developed world. ${ }^{1}$ The disease was first described in 1868 by the French neurologist Jean-Martin Charcot who observed lesions containing a buildup of inflammatory cells in the brains of patients exhibiting neurological dysfunction. Accordingly, the disease was termed "sclérose en plaques disseminées", or MS. ${ }^{2}$ Since its first discovery, much effort has been spent in trying to identify the underlying cause of MS. Prior to the 1980s, little was known about the disease, and during that time the acquisition of MS was thought to be based solely on environmental and geographical factors. This was due to the higher prevalence of MS observed in northern and southern latitudes than around the equator. $^{3}$ Although this trend is still relevant today, there is also growing evidence for genetic susceptibility to MS., ${ }^{3,4}$

The age of onset for progressive MS is typically from 27-40 years and the disease reduces life expectancy by five to ten years compared to the unaffected population. Thus, MS causes a significant reduction in the quality of life for sufferers. Symptoms of MS vary from patient to patient, which makes the disease difficult to detect. Typical symptoms range from physical disabilities such as speech difficulties, lack of bowel control, and vision impairment, to mental deficiencies such as depression and mood changes. Most patients also suffer stabbing pains around the face, neck, and back. The symptoms will gradually worsen until patients completely lose control of their movements. 


\subsection{Global Epidemiology of MS}

MS is unequally distributed around the world, and accordingly, prevalence studies of MS have long been of interest in order to establish the global epidemiology of the disease. From such studies, it was suggested that MS prevalence had a latitudinal gradient trend, where disease incidence was higher in countries further away from the equator. ${ }^{5-7}$ For example, countries with remarkably high prevalence rates of 170-350 per 100000 people include Canada, Sweden, Finland, and Scotland - all at approximately $60^{\circ}$ north of the equator. On the other hand, countries with low prevalence rates of MS (13 or less per 100,000 people) are much closer to the equator and include Nicaragua, Panama, Thailand, and Singapore. Recently, Wade conducted a spatial analysis of previous prevalence studies dating back from 1950 to present. $^{5}$ From this analysis and a similar study by Taylor in $2011{ }^{7}$ the latitudinal gradient is evident. The same deduction was also reached by the World Health Organisation (WHO) from data collected between 2005 and 2008 (Figure 1), while recognising the low accessibility to diagnosis in low-income countries.

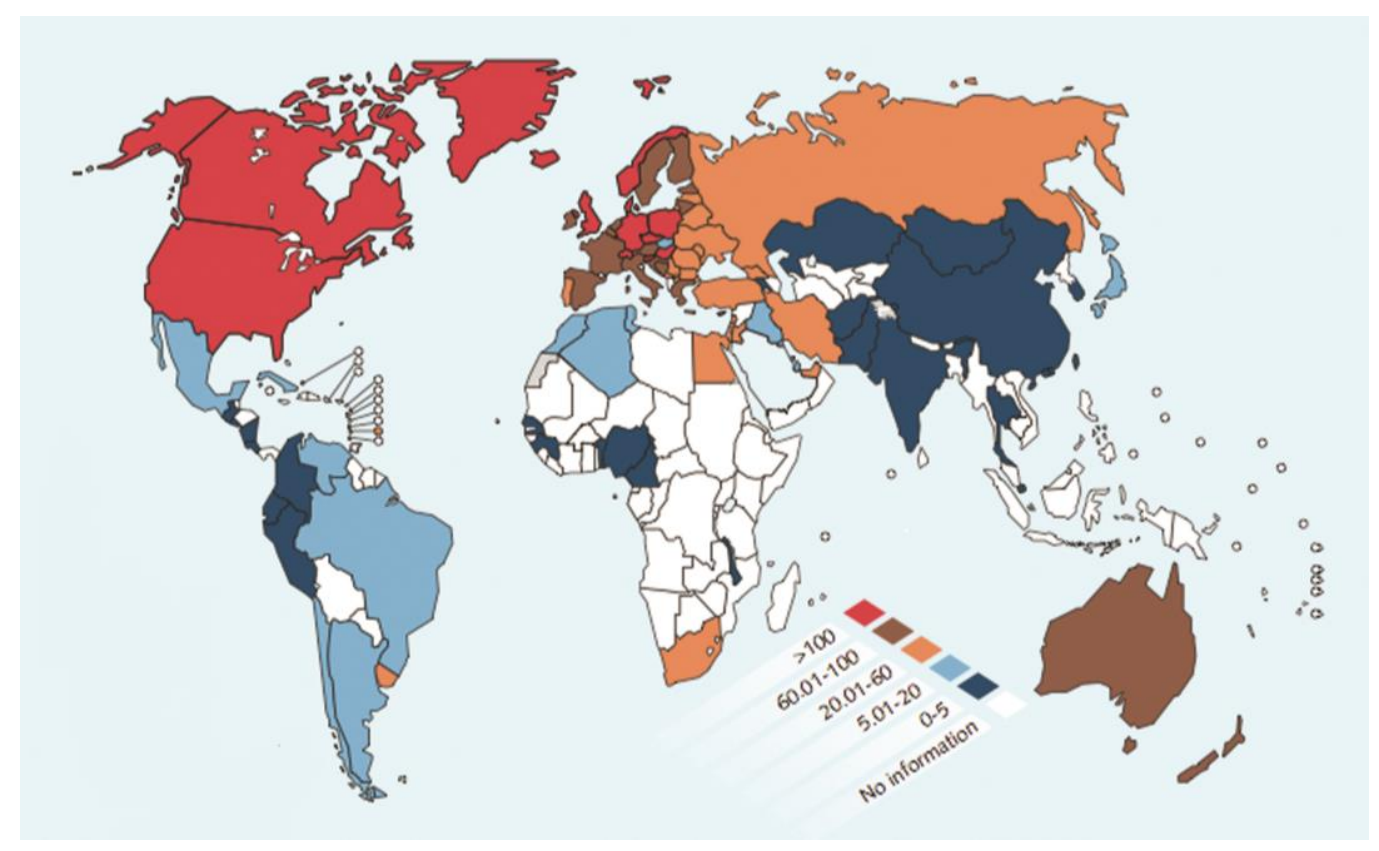

Figure 1. The global distribution of MS based on the data collected by the WHO in 2008, showing the disease prevalence per 100000 people $^{6}$ 
The latitudinal trend, however, has been contended by other researchers, who argue that a genetic rather than an environmental influence could lead to the observed distribution. In 1994, Rosati argued that attributing MS epidemiology to latitudinal factors is an oversimplified and unsupported conclusion. For example, it was observed that over a similar latitude range in Sardinia of $40^{\circ} \mathrm{N}$ to $41^{\circ} \mathrm{N}$, there was a vast difference in prevalence rates. This ranged from 11 afflicted people per 1000 population in Macomer, to 287 per 1000 people in North-West Sardinia. ${ }^{3}$ Rosati later confirmed the importance of genetic triggers on MS acquisition and reported on the rarity of MS among many ethnic groups, including Samis, Turkmen, Uzbeks, Kazakhs, Kirghizis, North and South Amerindians, Chinese, Japanese, and New Zealand Māori. ${ }^{4}$ This is consistent with WHO's finding that people of Northern European origin are the most susceptible to MS. $^{6}$ Furthermore, meta-analysis studies carried out in 2010 and 2011 by Sorensen and Koch-Henriksen dismissed any latitudinal trends and pointed to a uniform and global increase in the incidence of MS over the last decade., 9

Recently, a study was carried out in New Zealand in the hope of establishing genetic and environmental influences on MS acquisition. ${ }^{10,11} \mathrm{New}$ Zealand is a suitable sample study due to its ethnic diversity and large latitude spread of $35^{\circ} \mathrm{S}$ to $48^{\circ} \mathrm{S}$. From this work, a significant latitude-gradient was found, and the prevalence of MS was observed to be three times higher in the south than the north. The gradient was notable below $37^{\circ} \mathrm{S}$, where the Northland-Auckland region is situated. This prevalence gradient was also evident in the Māori population, though the gradient was notable at higher latitudes. Moreover, the latitudinal dependence was greatly affected by gender, with the gradient being three times more evident in females than in males. The much higher risk of MS for females suggests a genetic influence, though environmental factors must also be present for the risk to increase with latitude. From this, it seems that both genetic and environmental factors contribute to the acquisition of MS, though the extent of each contribution is yet to be determined. ${ }^{11}$

\subsubsection{Environmental contributions}

The most common environmental factors associated with MS are vitamin D production and infection. The correlation between latitude and MS attainment has 
previously been associated with shorter sunlight hours away from the equator and the subsequent reduction in vitamin $\mathrm{D}$ production. This was supported by the lower MS incidence rates in countries where vitamin D-rich foods like raw fatty fish are often consumed. In a study in 2004, a 41\% lower MS incidence rate was found in women who took vitamin D supplements daily. ${ }^{12}$ Although the influence of other nutrients cannot be excluded, there is no other micronutrient that has this association with the disease. Furthermore, many MS patients were found to have a variant in the gene that codes for an enzyme responsible for the conversion of an inactive form of vitamin $\mathrm{D}$ to its active form. This variant leads to the loss of enzyme activity and thus further reduction in vitamin $\mathrm{D}$ production. ${ }^{13}$

Another common environmental factor often correlated to the cause of MS is infection through molecular mimicry. Molecular mimicry could lead to autoimmune disorders if pathogens have similar molecular fragments to selfpeptides. ${ }^{14}$ This phenomenon has been used to explain the strong correlation between MS and the Epstein-Barr virus (EBV). The two diseases are very similar in epidemiology, and the primary infection of EBV is often strongly associated with MS. In 2007, Serafini et al. demonstrated that there was consistently higher seropositivity for EBV in MS patients than in healthy individuals and also found EBV-infected cells in 21 of 22 post-mortem MS brains. ${ }^{15}$ The relevance of this observation, however, still needs to be understood. For example, antibodies against EBV are present before the development of MS, which means that this association cannot be a consequence of MS, nor can it be used to predict disease development. ${ }^{16}$

\subsubsection{Genetic contributions}

Although MS is not an inherited disease, there is a slight genetic predisposition to the disease. For example, the risk in acquiring the disease from a parent increases from $0.1 \%$ to $2-3 \%$ in high-risk populations (North America and Europe). ${ }^{17}$ Furthermore, a study of MS in twins saw a 20-30 times greater likelihood in acquiring the disease for a fraternal twin of an MS patient, and a 150-300 times higher risk for an identical twin. ${ }^{2}$ On the contrary, non-biological relatives with the same environmental exposure (e.g. adopted sibling) have the same likelihood as the background population of having the disease. ${ }^{18}$ There is also a correlation between 
the risk of acquiring MS and the age of pubescence. A study conducted by Dean and Elian ${ }^{19}$ showed an increased risk of acquiring MS when children from a lowrisk country under the age of puberty moved to a high-risk country. Conversely, when children from a high-risk country moved to a low-risk country for MS, their risk of acquiring the disease decreased. ${ }^{5}$

One gene that is often associated with genetic susceptibility to MS is the HLA-DRB1 haplotype on chromosome 6p21. This gene is in the human leukocyte antigen (HLA) region, though its influence is largely unknown. ${ }^{17}$ An increase in the extent of demyelination in HLA-DRB1-positive patients has been observed in recent post-mortem studies, however, the presence of the haplotype did not correlate to axonal loss as would be expected in the event of the disease. Moreover, there was no significant difference in the number of brain plaques found in the brain between HLA-DRB1-positive and negative patients. ${ }^{20}$ As demyelination, axonal loss, and brain plaques all occur in MS, these findings suggest that HLA-associated alleles alone are not sufficient to cause MS and the search for nonHLA genes associated with MS has been ongoing. ${ }^{13}$

\subsection{The Aetiology of Multiple Sclerosis}

The gradual decline in neurological function for MS sufferers has been attributed to the degeneration of neurons, however, the definitive cause of this neurodegeneration is unknown. Neurons are nerve cells that transmit information from the central nervous system (CNS) to the rest of the body in the form of electrical signals. These signals travel through the long, thread-like structures at the ends of the neurons, called axons (Figure 2). Most axons are surrounded by bundles of myelin sheaths, making up what is known as the white matter of the CNS. Myelin sheaths provide insulation around the axons, increasing the speed at which these signals travel, much like the insulation of wires. In MS, the myelin sheaths are dismantled through immune responses in a process known as demyelination. During inflammatory demyelination, the myelin sheaths, axons and oligodendrocytes (myelin-forming cells in the CNS) are destroyed. Demyelination leads to the rapid deceleration of electrical signals and ultimately signal blockage. ${ }^{21}$ 


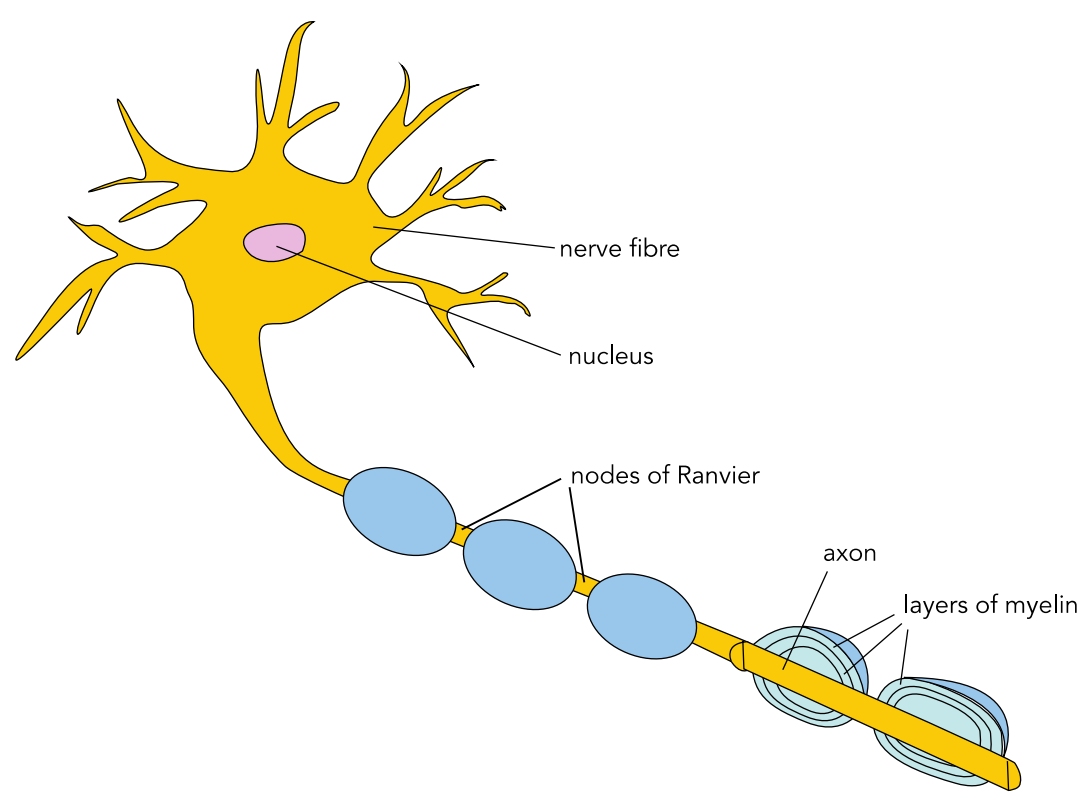

Figure 2. The structure of a neuron. Electrical signals move along the long thread-like structure to and from the nucleus. The layers of myelin insulate the neuron, increasing the speed at which these signals travel. In MS, the myelin is destroyed in a process called demyelination

Although it is still unknown what causes the initial inflammatory attack on the myelin sheath, the continual degradation of the sheath is thought to be caused by the decline of the small energy carrier molecules adenosine triphosphate (ATP). ATP production is necessary for the energy-dependent ion channels that are responsible for signal conduction in axons. Myelination of axons leads to the concentration of the energy-dependent $\mathrm{Na}^{+} / \mathrm{K}^{+}$ion channels at the nodes of Ranvier, where signals are transmitted (Figure 2). This allows the signals to be effectively and repetitively sent. Without myelin sheaths, the ion channels are spread along the axon and the ATP-production cannot keep up with the resulting energy demand. Thus, $\mathrm{Ca}^{2+}$, from the energy-independent $\mathrm{Na}^{+} / \mathrm{Ca}^{2+}$ channels is used. Accumulation of $\mathrm{Ca}^{2+}$ leads to many deleterious effects including the activation of degradative enzymes and the impairment of mitochondrial operation. ${ }^{17}$

Traditionally, MS was deemed an autoimmune disorder, whereby inflammatory processes gradually attacked the body's blood-brain barrier. This enables immune cells to infiltrate the brain, which ultimately causes neurodegeneration. More 
recently, however, this view has been challenged with MS being primarily considered a neurodegenerative disease causing secondary inflammatory demyelination. 17, 22 Thus, there are two key factors that play a role in MS.

\subsubsection{Neurodegeneration in Multiple Sclerosis}

There is substantial evidence to suggest that neurodegeneration is the primary dysfunction in MS, and, nowadays, it is generally thought that the blood-brain barrier must first be compromised through a neurodegenerative process before it becomes more permeable to allow serous fluid containing demyelination-causing immune cells to enter the brain. ${ }^{17}$ Thus, it is likely that the demyelination process does not cause the degeneration of axons, but rather, the two processes are independent of each other. Murine studies have shown that axonal degeneration and swellings can occur with compact myelin sheaths, while there was no sign of axonal pathology in mice lacking the major structural component of the myelin sheath - the myelin basic protein (MBP). ${ }^{23,24}$ This supports the hypothesis that MS is primarily a degenerative disease, rather than an autoimmune disease because axonal degeneration is somewhat independent of the autoimmune response that causes demyelination. ${ }^{23,25}$

There are several factors that are thought to contribute towards neurodegeneration. One such factor is nitric oxide (NO), a free radical with cytotoxic activity that is produced by the enzyme nitric oxide synthase. Nitric oxide synthase has been found to be upregulated in the astrocytes of actively demyelinating regions of MS brains when compared to healthy brains. ${ }^{26,27}$ This can result in elevated NO levels in the cerebrospinal fluid (CSF), blood, and urine of MS patients. ${ }^{28} \mathrm{NO}$ can cause axonal injury by disturbing ionic homeostasis through the modification of key ion channels, ${ }^{29-31}$ as well as reacting with $\mathrm{O}_{2}^{-}$to produce peroxynitrite (ONOO-), a strong oxidant that can cause DNA damage, induce lipid peroxidation, and inhibit mitochondrial respiration. ${ }^{32}$

Another causative agent of neurodegeneration is glutamate, the anionic derivative of the amino acid glutamic acid. Glutamate can be produced by active immune cells in the brain, such as macrophages ${ }^{33}$ and T cells. ${ }^{34}$ Moreover, myelin-associated cells such as oligodendrocytes have glutamate-receptors that can be overactivated, 
leading to $\mathrm{Ca}^{2+}$ accumulation and ultimately cell damage and death. ${ }^{35}$ This effect has been detected by MRI in $\mathrm{MS}^{36}$ and in other chronic neurodegenerative diseases such as stroke, Huntington's disease, the acquired immunodeficiency syndrome (AIDS) dementia complex, and amyotrophic lateral sclerosis (ALS) ${ }^{37}$

\subsubsection{Autoimmunity in Multiple Sclerosis}

The adaptive immune response has been found to be responsible for demyelination. This type of immune response is mediated by $\mathrm{B}$ and $\mathrm{T}$ lymphocytes, which are produced in the bone marrow and thymus, respectively, and is induced when the lymphocytes are exposed to certain molecules known as antigens. Here, immune cell receptors such as antibodies bind to specific parts of the antigens, known as the antigenic determinants, or epitopes. ${ }^{38}$ Antigens have multiple epitopes, allowing for a highly specific interaction with antibodies. B cells are involved in the humoral immune response, while immunity induced by $\mathrm{T}$ cells is cell-mediated. When activated by antigens, $\mathrm{T}$ cells can stimulate $\mathrm{B}$ cells to produce antibodies, or immunoglobulins ( $\operatorname{IgM}, \operatorname{IgD}, \operatorname{IgG}, \operatorname{Ig} A$, and $\operatorname{IgF}$ ) that are employed for specific inflammatory activities. ${ }^{39}$ The functioning of the immune response is highly complex, but a key result is that antigen-antibody binding leads to the activation of an immune response and subsequent destruction of pathogens. In this way, immune cells work together to fight off infections by pathogens such as bacteria in a process known as inflammation (A, Figure 3). ${ }^{38}$ 


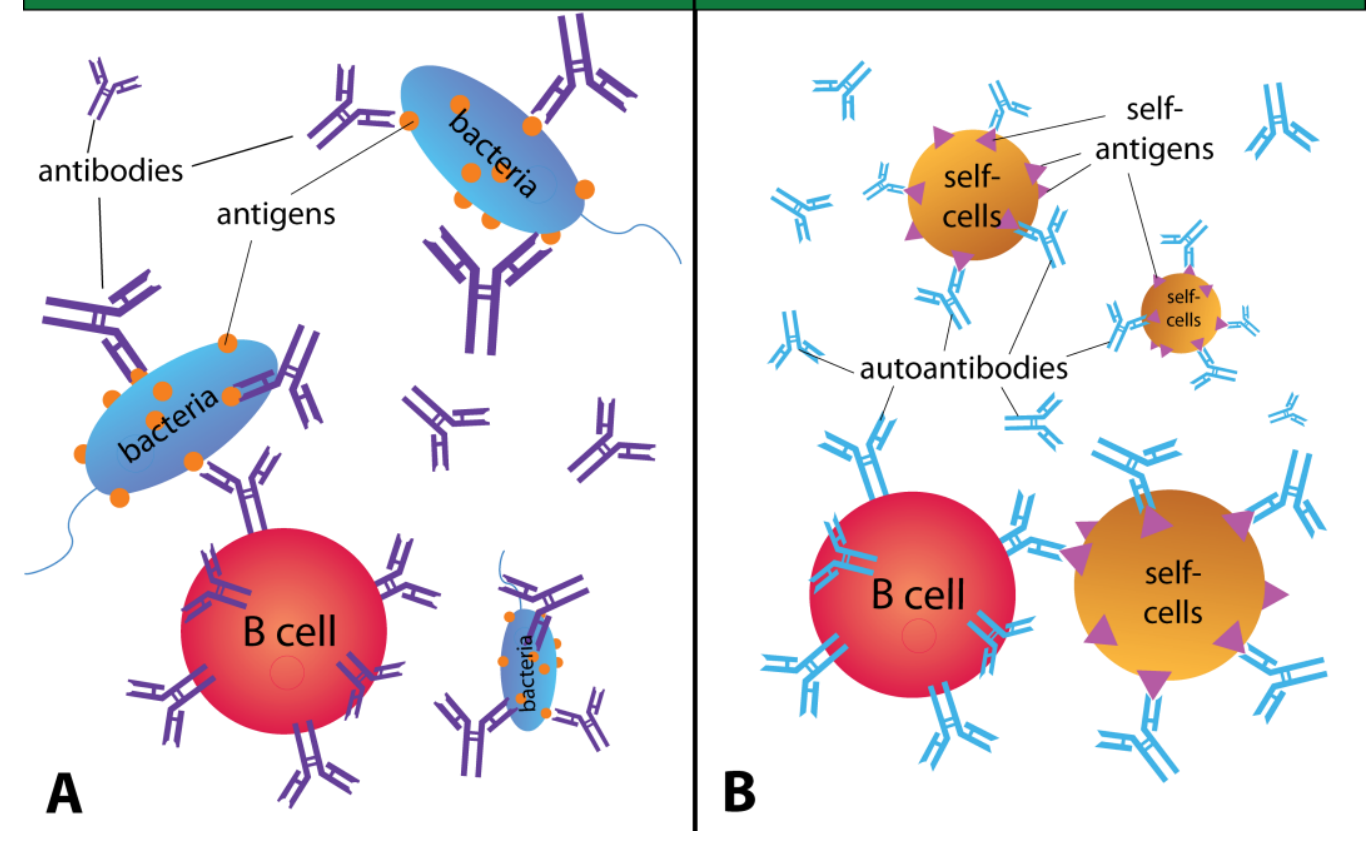

Figure 3. The response of antibodies to A) pathogens, where antibodies bind to epitopes found on the cell surface of bacteria; and B) self-cells in autoimmune diseases, where the epitopes on the surface of self-cells are perceived as harmful, causing an immune response against self-cells ${ }^{38}$

Autoimmunity occurs when the immune system of the body attacks its own tissues because the immune cells recognise self-antigens as harmful, foreign, and pathogenic (B, Figure 3). Immune cells that have this defect are said to be autoreactive, while autoantibodies are antibodies that recognise epitopes on selfcells. The presence of autoreactive cells and autoantibodies is due to a defect in the maturation of immune cells, which normally become "insensitive" to self-antigens by a process known as tolerance. ${ }^{39}$ That said, most healthy individuals have some autoreactive lymphocytes, which are kept in check by the action of other regulatory immune cells. MS patients have the same number of regulatory immune cells as healthy individuals, however, the regulatory activities of these cells is impaired. ${ }^{40,41}$

The autoimmunity of MS is apparent by the presence of immune cells in MS lesions. For example, $\mathrm{CD}^{+}$cytotoxic $\mathrm{T}$ cells that cause axonal injury have been found in MS lesions at higher concentrations than other subsets of $\mathrm{T}$ cells. ${ }^{17}$ Although most of the influx of inflammatory cells occurs after the blood-brain barrier is damaged, there has been evidence of inflammatory infiltration where this 
barrier remains intact. ${ }^{22}$ Another major immune cell found in MS patients is the $\mathrm{CD}^{+}$helper $\mathrm{T}$ cell. $\mathrm{CD} 4^{+}$cells have been found to interact with myelin-associated antigens such as MBP, proteolipid protein (PLP), ${ }^{42,43}$ and myelin-associated glycoprotein (MAG), ${ }^{44}$ and may bind to myelin-oligodendrocyte glycoprotein (MOG), ${ }^{45}$ myelin-associated oligodendrocyte basic protein (MOBP), ${ }^{46}$ and oligodendrocyte-specific glycoprotein (OSP) ${ }^{47}$ Furthermore, experimental allergic encephalomyelitis (EAE) - an animal model of MS - can be induced in a healthy mouse by the in vitro transfer of autoreactive $\mathrm{CD} 4^{+} \mathrm{T}$ cells. ${ }^{48}$

The involvement of B cells was previously only attributed to the production of autoantibodies that lead to the attack of myelin, however, further analyses have shown their involvement in the initiation of the demyelination process. ${ }^{16}$ For example, autoantibodies that have induced demyelination, oligodendrocyte death, and neuronal injuries have been found in EAE. ${ }^{49}$ In addition, high concentrations of IgG antibodies are found in the cerebrospinal fluid (CSF) of MS patients. This is consistent with other autoimmune diseases, such as herpes simplex virus-1 encephalitis and subacute sclerosing panencephalitis, however, unlike many other autoimmune disorders, a single exogenous antigen has not been identified for the IgGs found in the CSF of MS patients. ${ }^{2} \mathrm{~B}$ cells, plasma cells, and myelin-specific antibodies have also been found in MS plaques and areas of active demyelination. ${ }^{50 \text {, }}$ 51

\subsection{Types of Multiple Sclerosis}

The onset of MS is marked by a clinical presentation of neurological symptoms such as speech disorders, emotional changes, and bladder and bowel dysfunctions that can last a few weeks. For some patients, these symptoms only last 24 hours before they cease and the condition is known as a clinically isolated syndrome (CIS). Patients with CIS may or may not develop MS and thus the progress of symptoms must be monitored and diagnosed accordingly. ${ }^{52}$ There are four categories of MS according to the stages of the disease, with the most common category being relapsing-remitting multiple sclerosis (RRMS). RRMS affects around $85 \%$ of MS patients and is characterised by a series of neurological dysfunctions followed by inconsistent periods of remission. ${ }^{22,53}$ 
The periods of complete recovery in RRMS are caused by the body's compensatory mechanisms to repair the damage caused by inflammation. However, for around 30\% of RRMS patients, these repair mechanisms cannot keep up and the demyelination process continues. For such patients, the RRMS stage will inevitably progress to secondary progressive multiple sclerosis (SPMS), where there are no periods of remission. Neurological symptoms in SPMS patients will continue to worsen without distinct attacks and often leaves the MS patient wheelchair-bound. For $10 \%$ of MS patients, the disease begins with this chronic phase. This is known as primary progressive multiple sclerosis (PPMS) and is unremitting from the beginning, though there are occasional plateaus of symptom severity before they worsen. The least common form of MS, known as progressive-relapsing multiple sclerosis (PRMS), affects less than $5 \%$ of patients. Like PPMS, PRMS is also progressive from the beginning and is without remission periods, but involves intermittent episodes of flare-ups where the symptoms worsen. ${ }^{17,54,55}$

The reversibility of demyelination in RRMS has attracted much attention over the years as a potential way to diagnose the disease by monitoring neurological symptoms. However, the intensity and frequency of relapsing episodes are not good indicators of how quickly MS is progressing. This is because the body's compensatory mechanisms for neuronal loss can be more effective in certain areas of the brain or in certain patients than others. Moreover, lesions in some areas of the brain could have no serious physical or neurological effect, thereby allowing the disease to progress silently. The often undetectable symptoms of the disorder as it progresses means that it is difficult to confidently diagnose a patient with MS over other neurological disorders.

\subsection{Treatments for Multiple Sclerosis}

Due to the unknown underlying cause of MS, there are no effective cures. Instead, disease treatment aims to slow the progression of the disease by decreasing the frequency and duration of relapses or to aid in symptom management. Though research is currently being undertaken on the use of anti-psychotic drugs to treat MS, ${ }^{56}$ normal treatment consists of steroids. Generally, a course of corticosteroids 
are administered to treat acute relapses in RRMS patients as the steroids have short-term anti-inflammatory activities and can reduce the permeability of the blood-brain barrier to immune cell infiltration. ${ }^{57}$ For long-term treatment, eight FDA-approved drugs are available to reduce disease activity and progression in relapsing forms of MS (RRMS and early SPMS). These therapeutic agents are: $\beta$ interferons (Avonex, Betaseron, Rebif, Extavia), Glatimar acetate (Copaxone), Mitoxantrone (Novantrone), a monoclonal antibody Natalizumab (Tysabri), and Fingolimod (Gilenya). ${ }^{54}$ Although the mechanisms of action of these drugs are unknown, all have immunomodulatory effects.

Glatiramer acetate and $\beta$-interferons are typically administered at the beginning of RRMS, with the preference of one drug over the other being based on intolerance. Glatiramer acetate has milder side effects (injection-site reactions, or a rash) than $\beta$-interferons which can cause liver function abnormalities, thyroid disease, and depression. ${ }^{54}$ At later stages of the disease, more potent immunosuppressive agents such as mitoxantrone and natalizumab are administered. Inevitably, higher drug potency leads to more serious side effects. For example, mitoxantrone was originally developed to treat certain cancers by inhibiting the DNA repair process and using mitoxantrone as an anti-inflammatory can lead to serious drug effects, particularly cardiotoxicity and myelosuppression. Natalizumab is also very effective in significantly improving all measures of symptom severity, ${ }^{54}$ however, patients on natalizumab become severely immunocompromised and are susceptible to viruses commonly harboured in the human body. Patients using natalizumab have an increased risk of progressive multifocal leukoencephalopathy (PML), a viral infection that typically leads to death or severe disability. ${ }^{58}$

\section{$1.6 \quad$ Antigens}

There are two main classes of antigens thought to have a role in MS: those recognised by $\mathrm{T}$ cells and others that stimulate antibody production by $\mathrm{B}$ cells. Numerous studies have confirmed the involvement of myelin-reactive $\mathrm{T}$ cells in the pathogenesis of MS, $2,17,54,59$ with antigens of myelin-reactive T cells often being postulated to be MBP and MOG, both of which are important proteins in the myelination process of nerves. The recognition of multiple epitopes by the same $T$ 
cell subset suggests that epitope spreading can occur, where the T cells recognise multiple epitopes on that same protein, thus expanding the number of epitopes they bind to. ${ }^{2}$

For decades it was thought that B lymphocytes did not have a significant role in the pathogenesis of MS. This was because very few B lymphocytes were found in MS lesions compared to T cells, ${ }^{17,22}$ however, B cells have an undeniable role in the pathogenesis of MS, as evident by the presence of IgG bands in the CSF. Identifying the antigen to which $\mathrm{B}$ cells bind has proven difficult, though a list of $\mathrm{B}$ cell antigens has been suggested which include myelin-associated antigens such as MBP, PLP, MOG, the enzyme transaldoase (TAL), and OSP; ${ }^{2}$ as well as nonmyelin proteins such as $\alpha \beta$-crystallin, and neurofascin. ${ }^{16}$ Some antigens such as TAL and OSP are present in viral peptides, which supports the molecular mimicry theory in causing autoimmunity in $\mathrm{MS}^{2}{ }^{2}$ That said, $\alpha \beta$-crystallin has antiinflammatory activity and neurofascin is concentrated at the nodes of Ranvier, though the presence of antibodies against these proteins has not led to any conclusions about the autoimmune response observed in MS. ${ }^{16}$

\subsubsection{Carbohydrate Antigens}

All cells are covered by complex carbohydrates (or glycans), which are present in different glycoconjugate forms, such as glycoproteins and glycolipids. Glycoconjugates are important in cellular processes including differentiation, recognition, adhesion, and pathological developments, ${ }^{39}$ and carbohydrate-binding antibodies are ubiquitous in the immune system, playing a key role in the body's defense against pathogens. In addition, there are certain carbohydrate-binding antibodies that are present in all healthy human sera from birth. Such antibodies are known as natural antibodies (NAb), as they arise spontaneously without exposure to specific antigens, and consist mostly of IgM antibodies. ${ }^{60-62}$

Due to the innate nature of IgM NAbs, they are polyreactive towards structurally conserved antigens, which include phospholipids and nucleic acids as well as carbohydrates. ${ }^{60}$ In NAbs, the antibody binding site was formed before antigenic exposure and the antigen-antibody binding affinity is relatively low, though it is somewhat compensated by the pentameric nature of the IgM antibodies. ${ }^{60,63}$ The 
function of NAbs has been attributed to the cellular housekeeping role of efferocytosis - the removal of dead cell debris after apoptosis has taken place. In this way, NAbs offer protection against potentially harmful substances from apoptosis. ${ }^{62}$

The carbohydrate-binding nature of NAbs was established by Bovin et al. in $2009^{61}$ when human sera from 106 healthy patients was tested against a range of carbohydrate epitopes. From this study, it was determined that carbohydrate antigens are widely represented in human sera, although some are more common than others. For example, all human sera showed autoantibody-binding to $\alpha$ rhamnose, $\beta-G a l(\alpha 1,4) \mathrm{GlcNac}$, and $\beta-\mathrm{Gal}(\alpha 1,6) \mathrm{Glc}$, whereas only around $6 \%$ of patient serum showed autoantibody-binding to $\alpha$-Glc, $\beta-3-O-$ sulfate-Gal, and $\beta-\operatorname{Man}(\alpha 1,3)(\operatorname{Man} \alpha 1,6) M a n .{ }^{61}$ Despite the presence of anti-glycan autoantibodies in all healthy sera, it has been hypothesised that the autoreactivity of NAbs could explain the increase in autoimmune diseases. This is supported by the increased levels of autoantibodies in some autoimmune diseases such as rheumatoid diseases, SLE, and Sjögren's syndrome. ${ }^{60}$

The potential of carbohydrate antigens as diagnostic markers for MS was not investigated until the last decade when a comparison between glycosylated and non-glycosylated MOGs was undertaken. ${ }^{64-66}$ An elucidation of the MOG protein structure led to the discovery of an N-glycosylation site on Asn-31 of the protein. Accordingly, when the peptide MOG(35-55), the immunodominant portion of MOG, was $N$-glycosylated at this position, it was specifically bound by autoantibodies, an event that was not seen in the non-glycosylated peptide and it has been proposed that the direct interaction between the sugar moiety and the antibody was essential for effective binding, as glycosylation only resulted in small conformational changes of the protein. ${ }^{65}$ The glycopeptide, later named CSF114(Glc), was used to bind anti-MOG antibodies in $40 \%$ of MS patients, ${ }^{64}$ and more recently, the same glycopeptide was employed to bind and detect the concentration of IgM antibodies in the serum of MS patients. Using this carbohydrate antigen, autoantibodies against MOG were detected in almost one third of all RRMS patients in the study. ${ }^{66}$ Unfortunately, however, the 
autoantibody-MOG binding was seen not only in MS patients, but also in those with other inflammatory diseases such as myelitis/encephalitis and ALS. ${ }^{64}$

In addition to glycosylated MOG peptides, other circulating glycan antigens have also shown promise in the diagnosis of MS. Using a glycan array (GlycoChip ${ }^{\circledR}$ ), Dotan et al. ${ }^{53,67-69}$ immobilised different $p$-aminophenyl-linked glycans (1) onto a solid support bearing a cyanuric chloride-activated 1,8-diamino-3,6-dioxaoctane linker ${ }^{69}$ (Figure 4) and found that IgM antibodies against a range of glucose-based carbohydrates (Figure 5) were upregulated in the sera of MS patients. In particular, the levels of anti- $\alpha$-Glc (2) and anti- $\alpha-G l c(\alpha 1,4)$ Glc (3) antibodies in patients with RRMS and PPMS were significantly higher compared to the levels in healthy patients, or patients with other neurological or autoimmune diseases. Herein, it should also be noted that the concentration of antibodies against $\alpha$-Glc-based glycans (i.e. 2 and $\mathbf{3}$ ) is significantly lower in the sera of healthy individuals compared to antibodies against $\beta$-Glc-containing glycans (5-10). For example, 5.6\% of healthy individuals have anti- $\alpha$-glucose-antibodies compared to $82 \%$ against $\beta$ Glc, and $19 \%$ of healthy patients have antibodies against $\alpha-\operatorname{Glc}(\alpha 1,4) \operatorname{Glc}(\alpha 1,4) G l c$, compared to $88 \%$ with anti- $\beta-G l c(\beta 1,4)$ Glc antibodies. ${ }^{61}$ This suggests that $\alpha$ glucose antigens are highly expressed in MS sera.

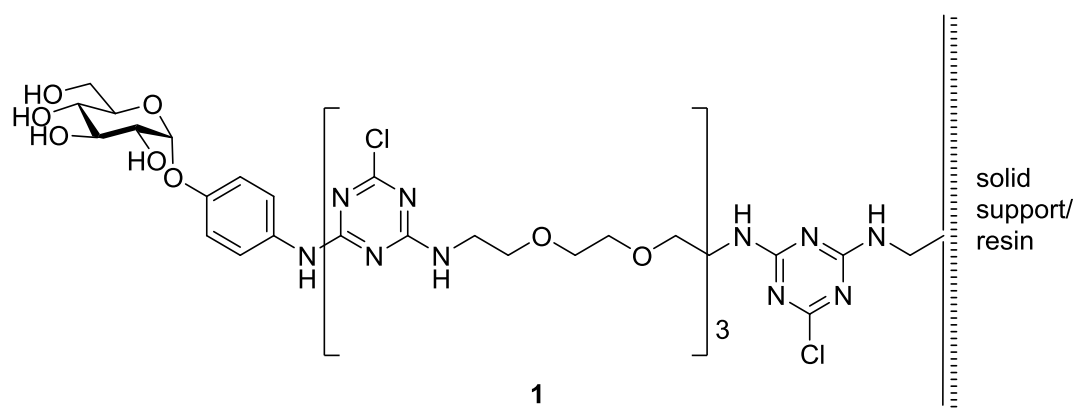

Figure 4. The arrangement of the glycan array, Glycochip ${ }^{\circledR}$, used to immobilise different $g$ glycan antigens, such as p-aminophenyl-linked $\alpha$-Glc (1) ${ }^{69}$ 

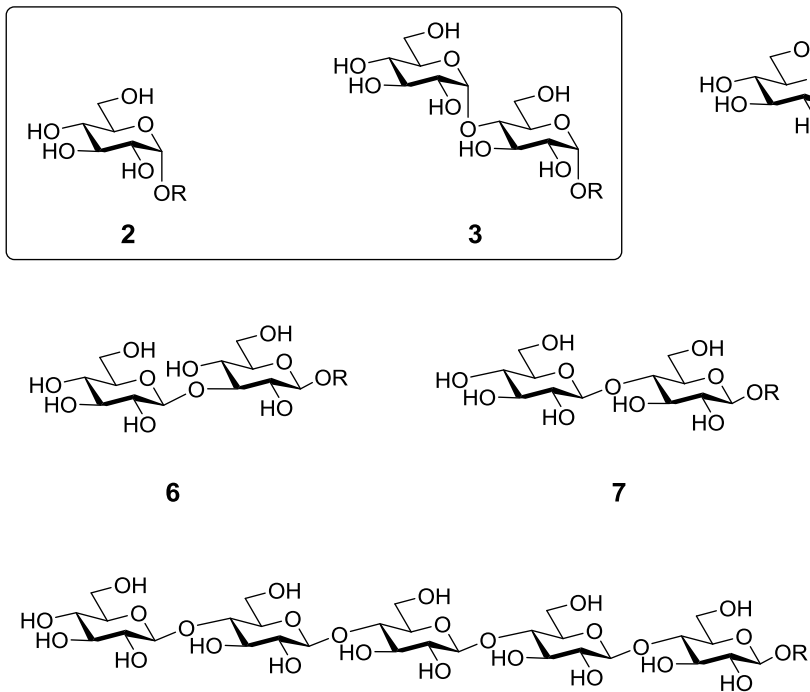

9
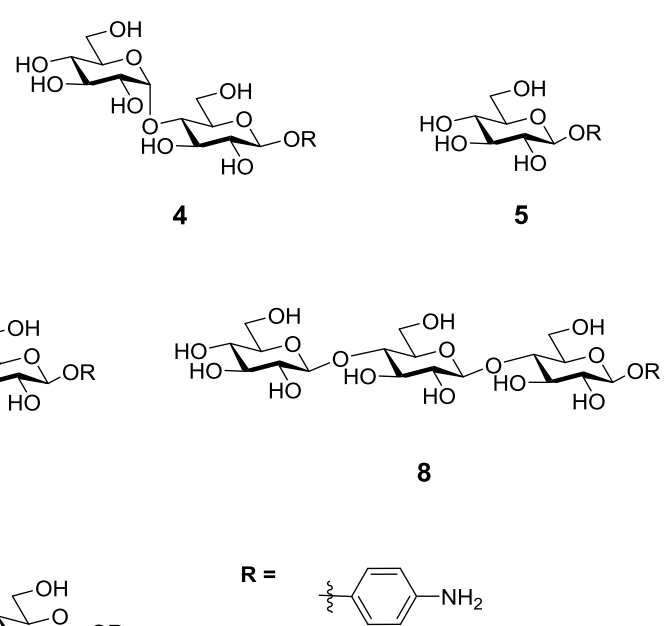

Figure 5. Structures of carbohydrate antigens bound to antibodies found in serum of MS patients only: $\alpha$-Glc (2), $\alpha$-Glc $(\alpha 1,4)$ Glc (3), and other carbohydrate antigens found in MS patients' sera, as well as healthy sera: $\beta$-GIc $(\alpha 1,4) G \mid c(4), \beta-G I c(5)$, $\beta-G I c(\beta 1,3) G l c \quad(6), \quad \beta-G l c(\beta 1,4) G l c \quad(7), \quad \beta-G l c(\beta 1,4) G l c(\beta 1,4) \quad$ Glc $\quad(8)$, $\beta-G I c(\beta 1,4) G I c(\beta 1,4) G I c(\beta 1,4) \operatorname{Glc}(\beta 1,4) G \mid c(9)^{53}$

The high concentration of anti-glycan antibodies in patients with the first presentation of MS symptoms correlated with a higher likelihood of the patient having a second MS attack within 24 months. Also, higher levels of IgM antibodies were found in the CSF of patients that were further along in the disease ${ }^{67}$ and in the sera of RRMS/SPMS patients compared to both PPMS patients and patients with other neurological disorders. Similar levels of the antibodies, however, were found in RRMS and SPMS patients. ${ }^{52}$ While targeting these glycan antigens has shown promise in the diagnosis of MS, the current diagnostic test lacks robust verification, for although the gMS $\mathrm{Dx}^{\circledR}$ test has a $93.8 \%$ positive predictive value, it also has a relatively high negative predictive value of $68.1 \% .^{52}$ The lack of specificity may be due to the non-native linkers ( $p$-aminophenol, cyanuric chloride, and 1,8-diamino-3,6-dioxaoctane) used to attach the sugar onto a solid support, which may lead to non-specific binding of the IgM antibodies to the aromatic residues in the linker. Thus, there is potential for improvement by employing a more immunologically compatible cross-linker onto glycans to target autoantibodies. $^{52}$ 
The association between $\alpha$-glucose and its derivatives with MS is not well understood, however, $\alpha$-glucose has been found within type IV collagen matrix of the blood-brain barrier, ${ }^{67}$ and the type IV collagen matrix itself has been found in MS lesions. ${ }^{70}$ Accordingly, it has been proposed that $\alpha$-Glc antigens are released upon the breakdown of the blood-brain barrier, which in turn induces an immune response by the IgM antibodies. ${ }^{55}$ The presence of $\alpha$-Glc-based polysaccharides on the cell walls of microbes may also lead to the production of IgM auto-antibodies through molecular mimicry. ${ }^{67}$

\subsection{Current Diagnostic Methods of MS}

Although the inflammation-mediated chronic neurodegeneration in MS has been known for decades, its cause remains unknown and, consequently, designing a diagnostic test and preventative treatment for MS has been challenging. Diagnostically, clinicians can look for brain lesions using an MRI scan of patients that present neurological dysfunctions, however, MRI alone cannot be used to diagnose MS. The differentiation of MS from other neurological disorders is difficult, not always conclusive, and requires a series of MRI scans and sometimes additional tests such as CSF analyses. Though non-invasive, MRI cannot be used to monitor disease activity closely, nor can it be used for disease management due to concerns over long-term exposure to electromagnetic fields and cost. ${ }^{53}$ Moreover, the presence of brain lesions is suggestive of a neurological disorder, though the type cannot be specified as a biopsy of brain tissue is normally not performed. $^{71}$ The detection of elevated levels of $\operatorname{IgG}$ antibodies in the CSF is also used to diagnose MS. Here, the CSF IgG levels have increased sufficiently to produce oligoclonal bands, thereby providing evidence for the proliferation of $\mathrm{B}$ cells in the CNS. ${ }^{59}$

Accordingly, the diagnosis of MS involves eliminating other neurological disorders that have more definite diagnoses. Initially, the Poser criteria were used to diagnose either clinically or laboratory-supported definite multiple sclerosis (CDMS and LSDMS, respectively). Poser et al. monitored the number and placements of lesions in the brain, as well as the elevated $\operatorname{IgG}$ oligoclonal bands in the CSF that are absent in the serum, so as to arrive at either of two outcomes: "definite" and 
"probable" MS. ${ }^{72}$ Before long, however, the Poser criteria were superseded by the McDonald criteria. The McDonald criteria include clearly defined categories for abnormal brain activities detected by MRI (e.g. lesions must be gadoliniumenhancing, or be larger than $3 \mathrm{~mm}$ ), and uses clinical evidence (e.g. CSF) wherever possible to reach an outcome of "possible MS" and "no MS"."71,73

Despite the high diagnostic sensitivity in detecting $\operatorname{IgG}$ oligoclonal bands in the CSF (over 90\%), this technique has a low specificity to MS of around 35\% because elevated $\operatorname{IgG}$ bands are also found in infectious diseases ${ }^{1}$ and other autoimmune disorders (e.g. herpes simplex virus-1 encephalitis and subacute sclerosing panencephalitis). ${ }^{2}$ Moreover, the invasive and painful nature of withdrawing CSF means that the procedure isn't typically repeated. ${ }^{53}$ Accordingly, much effort has been spent in searching for other CSF biomarkers. One such biomarker thought to have a correlation with MS progression is MBP. ${ }^{74}$ The detection of MBP can indicate myelin destruction, although significantly elevated levels of MBP in the CSF are typically only evident during relapse. ${ }^{1}$ As MBP-reactive T cells are known to recognise MOG, these proteins also have potential as diagnostic biomarkers. Thus, the observation of MBP and MOG and their autoantibodies in the CSF could effectively confirm diagnoses, ${ }^{75-77}$ however, more recent studies have found a lack of association between these proteins and the progression to MS. ${ }^{78,79}$ There was no increase in the risk of acquiring CDMS in patients who were positive for anti-MOG and anti-MBP antibodies according to the McDonald criterion. Furthermore, neither biomarker induced a convincing MS-specific immune response to self-antigens. ${ }^{1}$ Thus, there remains the need for reliable diagnostic methods for the early detection and monitoring of MS.

\subsection{Anti-Glycan Antibodies in MS Patients}

Glycans are useful antigens to target antibodies to because the dense distribution of carbohydrates on cell surfaces allows for high anti-glycan antibody responses. ${ }^{39}$,

${ }^{53}$ This has been observed in other autoimmune diseases, including the GuillainBarré syndrome, whereby a high concentration of anti-glycolipid antibodies to the disease has been found. Targeting disease-specific antibodies could be useful in diagnosing diseases with a number of non-telling symptoms like MS. Accordingly, 
there has been much recent interest in the potential of anti-glycan $\operatorname{IgM}$ antibodies as a diagnostic means for MS, however, to date, only the GlycoChip ${ }^{\circledR}$ probe, as discussed earlier, has shown some promise in the early detection of MS. ${ }^{52,53,68}$ 


\section{PROJECT AIMS}

The aim of this Masters project is to synthesise carbohydrate probes based on MS antigens so as to develop a reliable diagnostic test for MS. It is envisioned that MSspecific anti-glycan IgM antibodies can then be detected in patient serum using the synthetic glycan probes.

The glycan probes will be designed so that $\alpha$-linked glucose-based antigens are coupled to both D-Biotin (15) and a biotinylated multivalent scaffold (Figure 6). The most easily accessible probe will be the monoglycosylated biotin adducts 11, which can be immobilised on streptavidin-coated enzyme-linked immunosorbent assay (ELISA) plates to achieve multivalent presentation and effective antibody binding. Target probes $\mathbf{1 2}$ will have inherent multivalent presentation and thus can be used in other bioassays, such as the immunodiffusion assay where antigenantibody binding can be visualised as a precipitate. ${ }^{80} \mathrm{In}$ addition, another advantage of the glycosylated dendron is that functionalities other than biotin can be incorporated onto the dendron core. For example, the biotin on the dendron can be substituted for a fluorophore ${ }^{81,82}$ or a toxin ${ }^{82,83}$ so as to allow for the selective imaging or destruction of glycan-reactive B cells, respectively. These latter objectives are outside the scope of this research project, however, they do illustrate the scope of this work. 


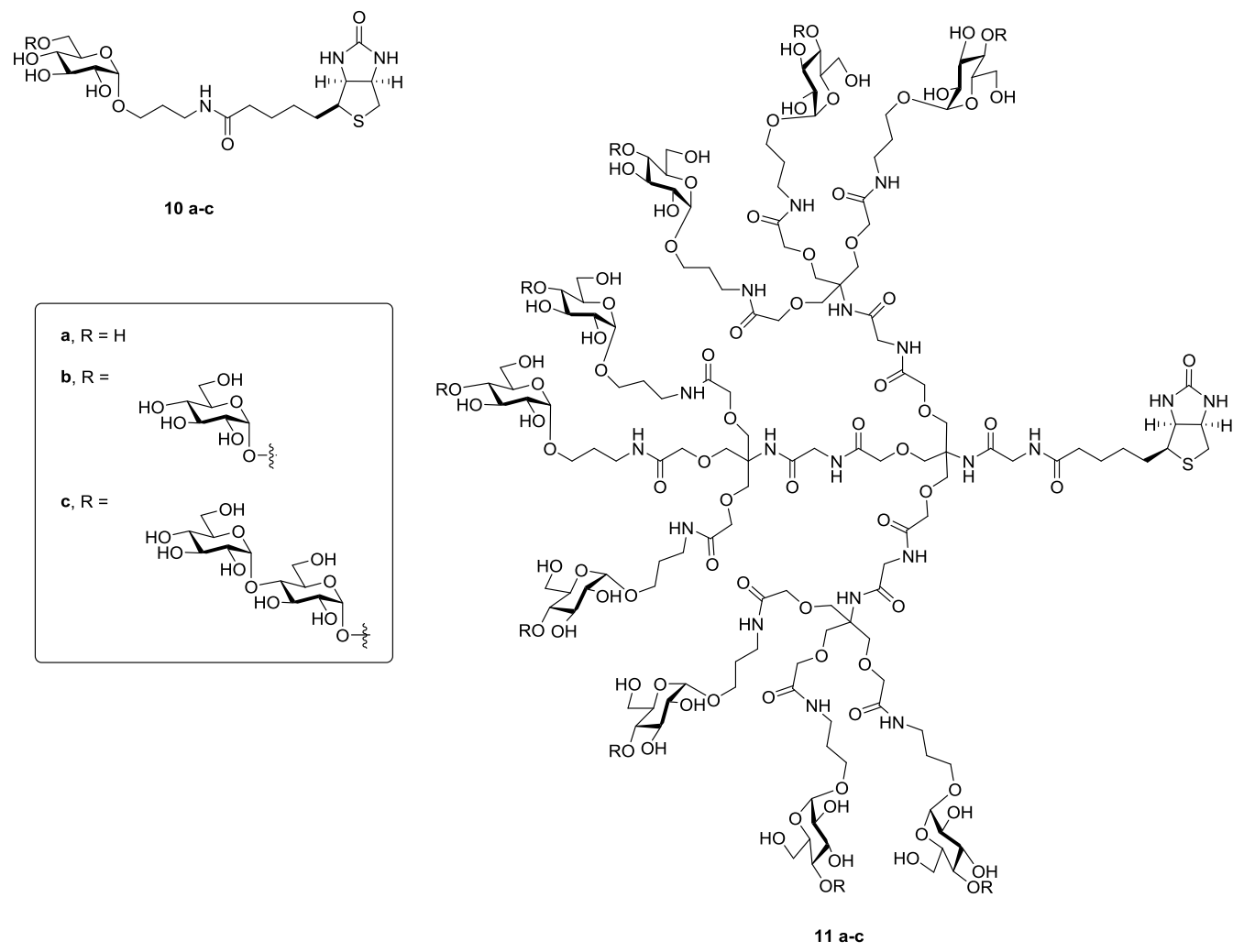

Figure 6. Synthetic glycan targets to be analysed for anti-glycan IgM antibody binding: biotinylated carbohydrates $\alpha$-Glc (10a), $\alpha$-Glc( $\alpha 1,4) \mathrm{Glc} \quad(\mathbf{1 0 b})$, and $\alpha-G|c(\alpha 1,4) G| c(\alpha 1,4) G \mid c(10 c)$; and biotinylated glycodendrons bearing $\alpha$-Glc (11a), $\alpha-G|c(\alpha 1,4) G| c(11 b)$, and $\alpha-G|c(\alpha 1,4) G| c(\alpha 1,4)$ Glc (11c)

The target glycans that will be synthesised are $\alpha$-Glc, $\alpha$-Glc $(\alpha 1,4) G l c$, and $\alpha$-Glc $(\alpha 1,4) \operatorname{Glc}(\alpha 1,4)$ Glc. The focus on $\alpha$-Glc- over $\beta$-Glc-based antigens is due to the significantly higher and more specific antibody response initiated by $\alpha$-Glc based antigens, ${ }^{52,53,68}$ as well as the lower concentration of $\alpha$-Glc based glycans than $\beta$-Glc antigens in healthy sera. ${ }^{61}$ In the case of $\beta$-Glc-based carbohydrates, the longer glycans (e.g. 9, Figure 5) demonstrated higher binding specificities than the shorter disaccharide (e.g. 6, Figure 5), suggesting possible chain length effects. ${ }^{53}$ To this end, mono-, di-, and trisaccharides of $\alpha$-Glc will be used as carbohydrate antigens to provide insight into this effect.

\subsection{Multivalency}

To successfully bind carbohydrate-reactive IgM antibodies, a multivalent system is required. Monovalent antigens have previously been shown to have lower affinities and specificities in binding antibodies than multivalent antigens. This may be due 
to the "cluster effect" - an effect where multivalent antigens have higher binding affinities as they interact with more than one binding site simultaneously and favourably. ${ }^{84}$ Because the higher antigenic exposure leads to a higher binding affinity, a multivalent system thus enhances the cellular responses when compared to a monovalent system. ${ }^{85,86}$ The present study aims to bind only the low-affinity antibodies $(\operatorname{IgM})$, without further activation of high-affinity antibodies $(\operatorname{Ig} G)$. Thus, multivalent antigen presentation is essential. As alluded to previously, one way to generate multivalency is by the coating of ELISA plates with the antigens in such a way that the carbohydrate moieties will be exposed, ready for antibody binding (Figure 7). Here, the plates will first be coated with streptavidin, which has a high affinity for biotin. ${ }^{87}$ The carbohydrate antigens will then be coated onto the plate via their biotin linker.
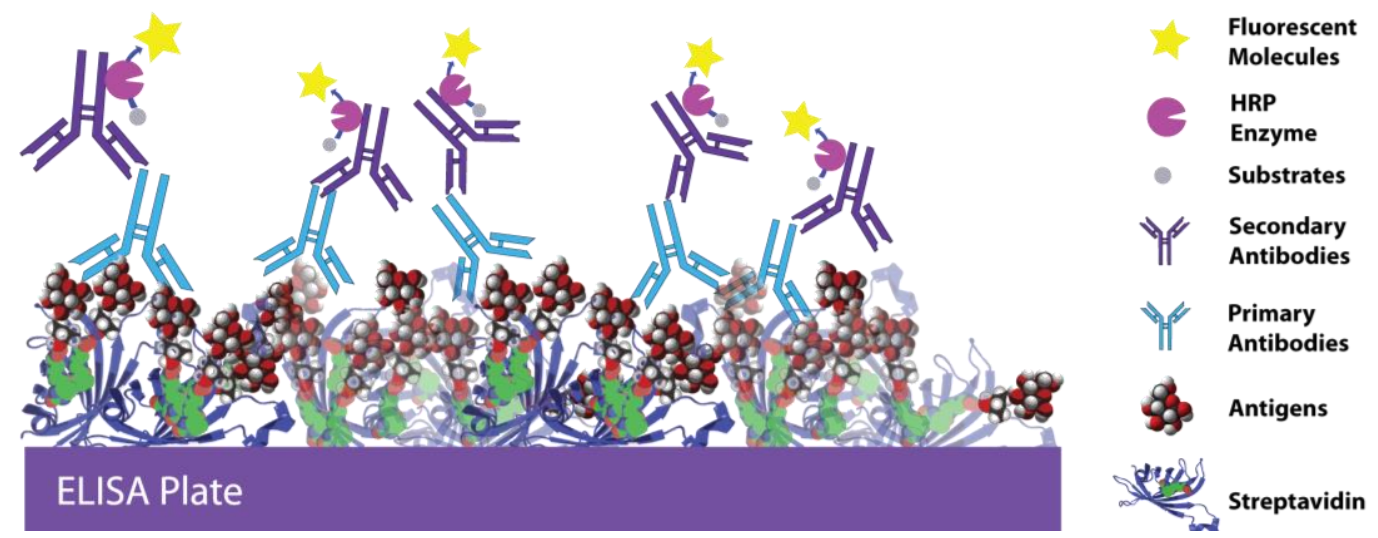

Figure 7. An ELISA to measure antigen-antibody binding in MS patient serum. The plate is coated with streptavidin, onto which the biotinylated carbohydrate antigens will bind. $^{88}$ The anti-glycan antibodies in the serum will in turn bind the carbohydrate heads. This binding can be visualised through a secondary antibody bearing the enzyme HRP. HRP catalyses the formation of a fluorescent molecule

Alternatively, dendrons can be used to allow for multivalent antigenic presentation. Dendrons (from the Greek word meaning "tree”) are characterised by well-defined and repetitive layers of chemical structures known as generations, with the innermost part of the dendron being known as the initiator core, while the outermost portion provides multivalency (Figure 8 ). ${ }^{89}$ The advantages of using dendrons as a mode of antigenic presentation include their monodispersity, nanoscale range, reasonable cost of production, and biocompatibility. ${ }^{89}, 90$ 
Moreover, the use of dendrons can allow for the bifunctionalisation of the multivalent scaffold, whereby different functional groups (e.g. biotin, a fluorophore or a toxin) can be installed at the dendron core.

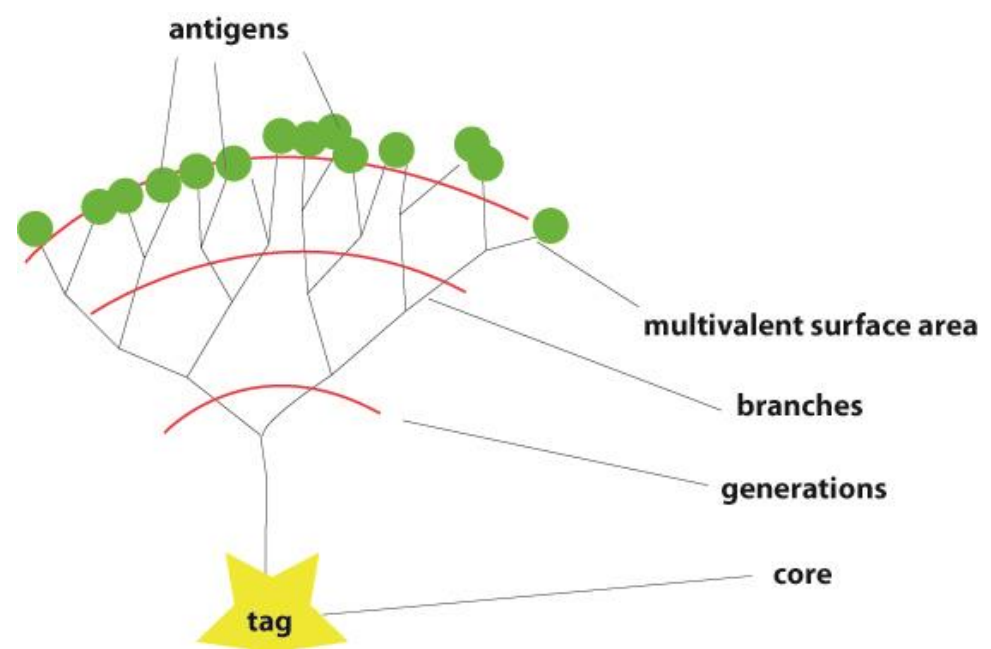

Figure 8. The structure of dendrons showing three generations, with two functionalities: the first being the multivalent presentation of antigens and the tags (e.g. biotin, fluorophore, toxin)

\subsection{Biological Assays}

Once the target glycosides and glycodendrons are synthesised, several biological assays will be performed to measure the MS diagnostic potential of the probes. For the thesis, the assays performed will be ELISA and the double-immunodiffusion assay. Ethics approval for the use of sera samples from both healthy donors and MS patients has been attained.

\subsubsection{Enzyme-Linked Immunosorbent Assay (ELISA)}

ELISA will be used for the detection of anti-glycan specific IgM antibodies in the serum of patients. To this end, a streptavidin-coated plate will be used to immobilise the biotin-functionalised antigens (11a-c), and the patients' serum will then be added to the plate. Anti-glycan IgM antibodies in the serum will bind to 
the carbohydrate epitopes, the plates will be washed and secondary anti-humanIgM antibodies conjugated with horseradish peroxidase enzymes (HRP) will be added (Figure 7). HRP catalyses the redox reaction between 3,3',5,5'tetramethylbenzidine (TMB) (12) and hydrogen peroxide whereby TMB is oxidised into a fluorescent molecule 3,3',5,5'-tetramethylbenzidine diimine (13), thereby allowing for the visualisation of bound antibodies (Scheme 1). Sera from consenting MS patients $(\mathrm{n}=8)$ who have presented with different stages of MS will be used for this assay, with sera from healthy age- and sex- matched individuals $(\mathrm{n}=6)$ as controls.

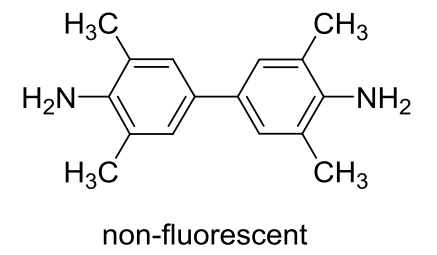

TMB (12)
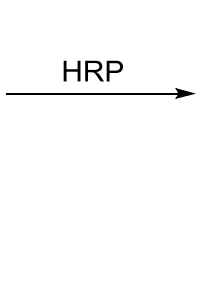

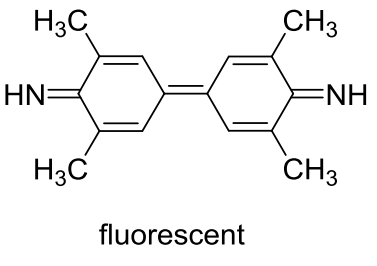

13

Scheme 1.

The HRP-catalysed reaction of TMB (12)

\subsubsection{Double-Immunodiffusion Assay (The Ouchterlony Method)}

The double-immunodiffusion assay is a gel-diffusion technique where solutions of antigens and antibodies are placed in adjacent wells in an agar gel. Each solution is then allowed to diffuse through the gel. As antigens are bound by antibodies, a precipitate will form between the wells, which indicates successful binding between the antibody and antigen. ${ }^{80,91}$ This assay requires high concentrations of both antigen and antibody, because it relies on the formation of antibody-antigen complexes that precipitate from solution when the concentration is sufficiently high (Figure 9). ${ }^{80}$ Accordingly, to enhance antigen-antibody binding and the formation and precipitation of larger multi-molecular complexes, the dendron scaffold will be used to present the antigens. 


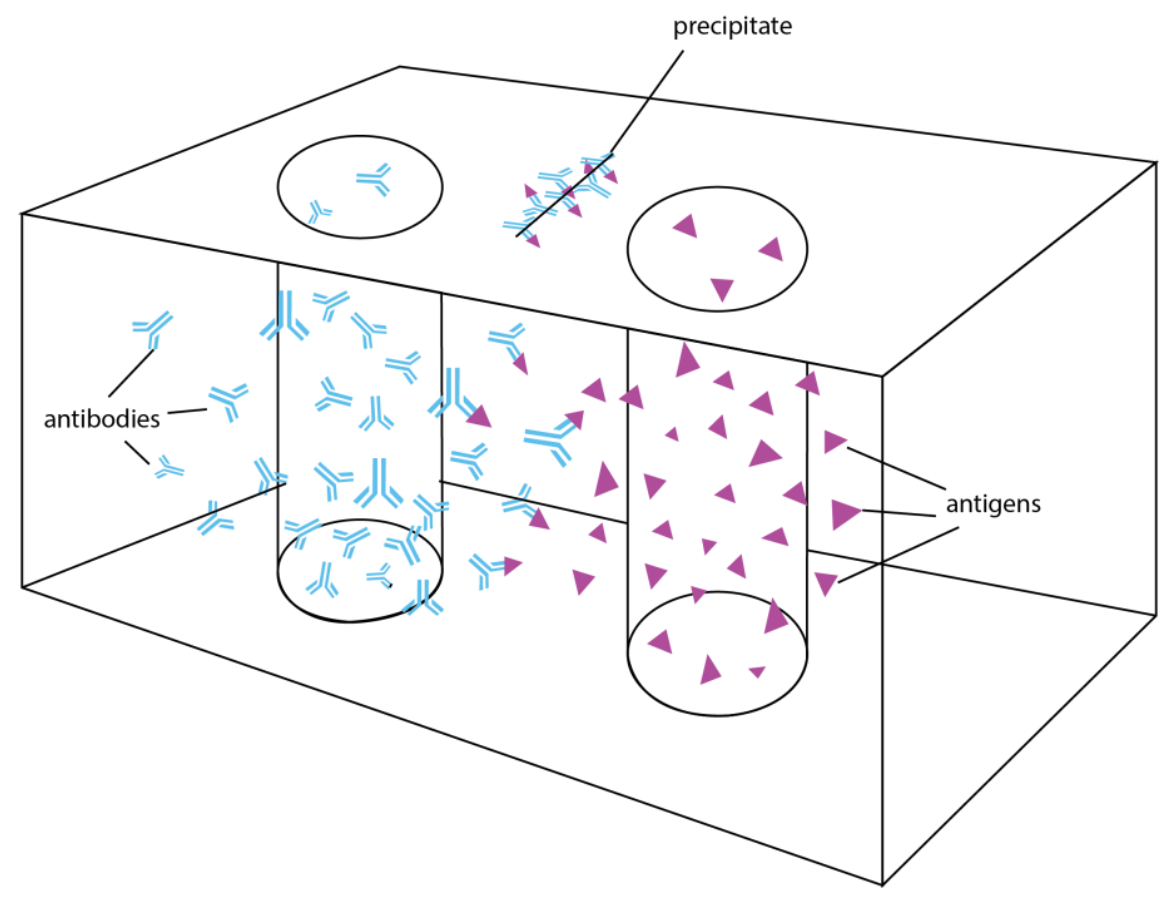

Figure 9. Cartoon depicting the basic principles of the double-immunodiffusion assay. ${ }^{80,91}$ Here, antibodies and antigens are placed in adjacent wells in an agar gel. The antigens and antibodies will diffuse through the gel, bind to one another, and form a precipitate

\subsection{Synthetic Strategy: Biotinylated Glucosides}

The retrosynthetic route for the preparation of the biotin-linked glucosides is shown in Scheme 2. Here, the biotin-linked glucosides 10a-c can be prepared from the fully protected glycosides 14a-c via hydrogenation to remove the benzyl protecting groups and to reduce the azide to an amine, and subsequent coupling with D-Biotin (15) to form the desired amide linkage. The amide bond was chosen as it is stable and soluble in biologically relevant media. Glucosides 14a-c can in turn be prepared by the conjugation of commercially available D-glucose (16a), Dmaltose (16b), or D-maltotriose (16c) with bromopropanol (17). Benzyl protecting groups will initially be explored as this will provide a non-participating group at the 2 - position of the reducing end sugar, thereby discouraging the formation of $\beta$ products. ${ }^{92}$ Glucosyl donors with different anomeric leaving groups will be explored to determine if this has any effect on the stereochemistry of the glycosylation. 

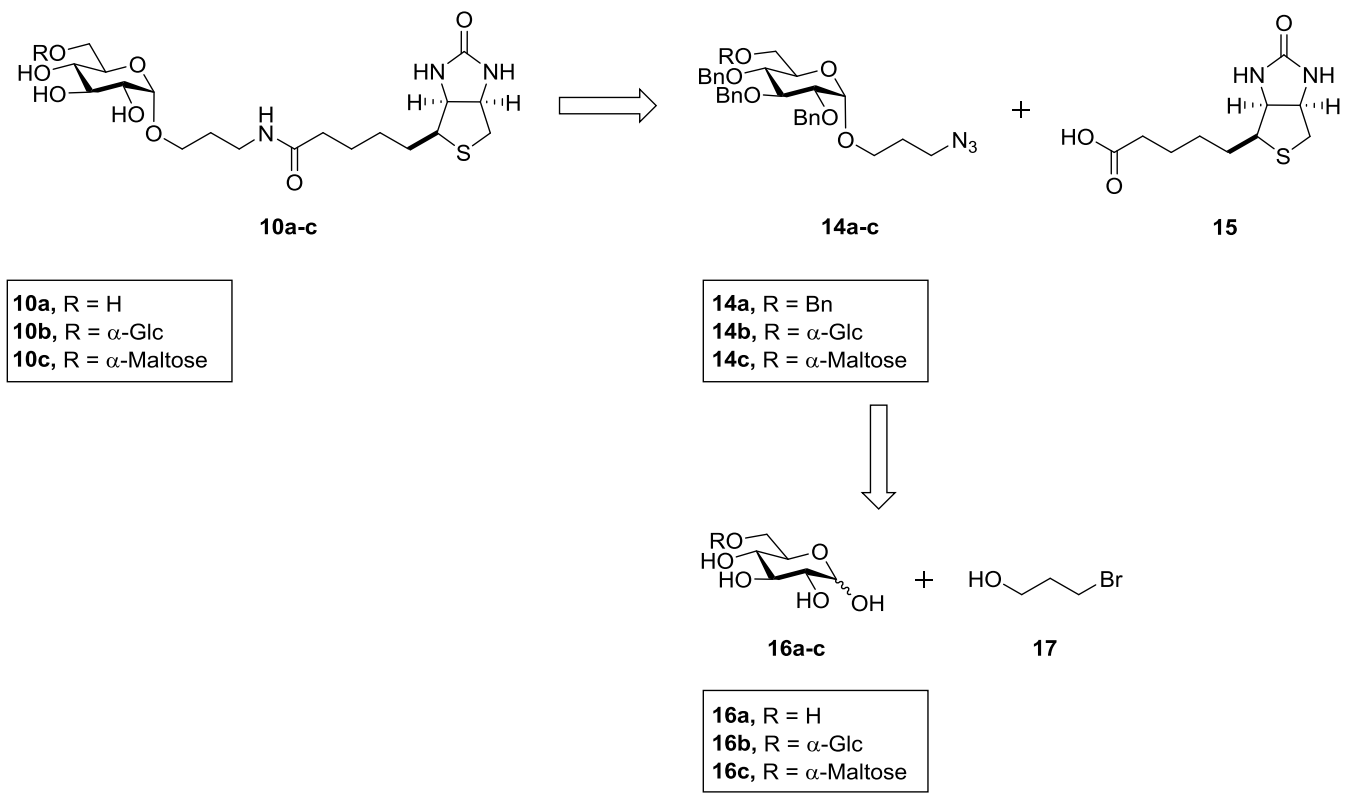

Scheme 2.

\subsection{Synthetic Strategy: Branched Glycosides}

The retrosynthetic analysis for the biotinylated glycodendrons 11a-c is shown in Scheme 3. The glycodendrons will be synthesised through the formation of an amide bond between the carboxylic acid groups of a second generation dendron and the amino functional groups of glycosides 19a-c. The second generation dendron at this stage will be prepared from the tert-butyl deprotection of a biotin-linked dendron, which is in turn prepared by forming an amide bond between the carboxylic acid moiety of D-Biotin (15) with the amine moiety of a second generation dendron which will be prepared via a Staudinger reduction of the azide group in dendron 18. 


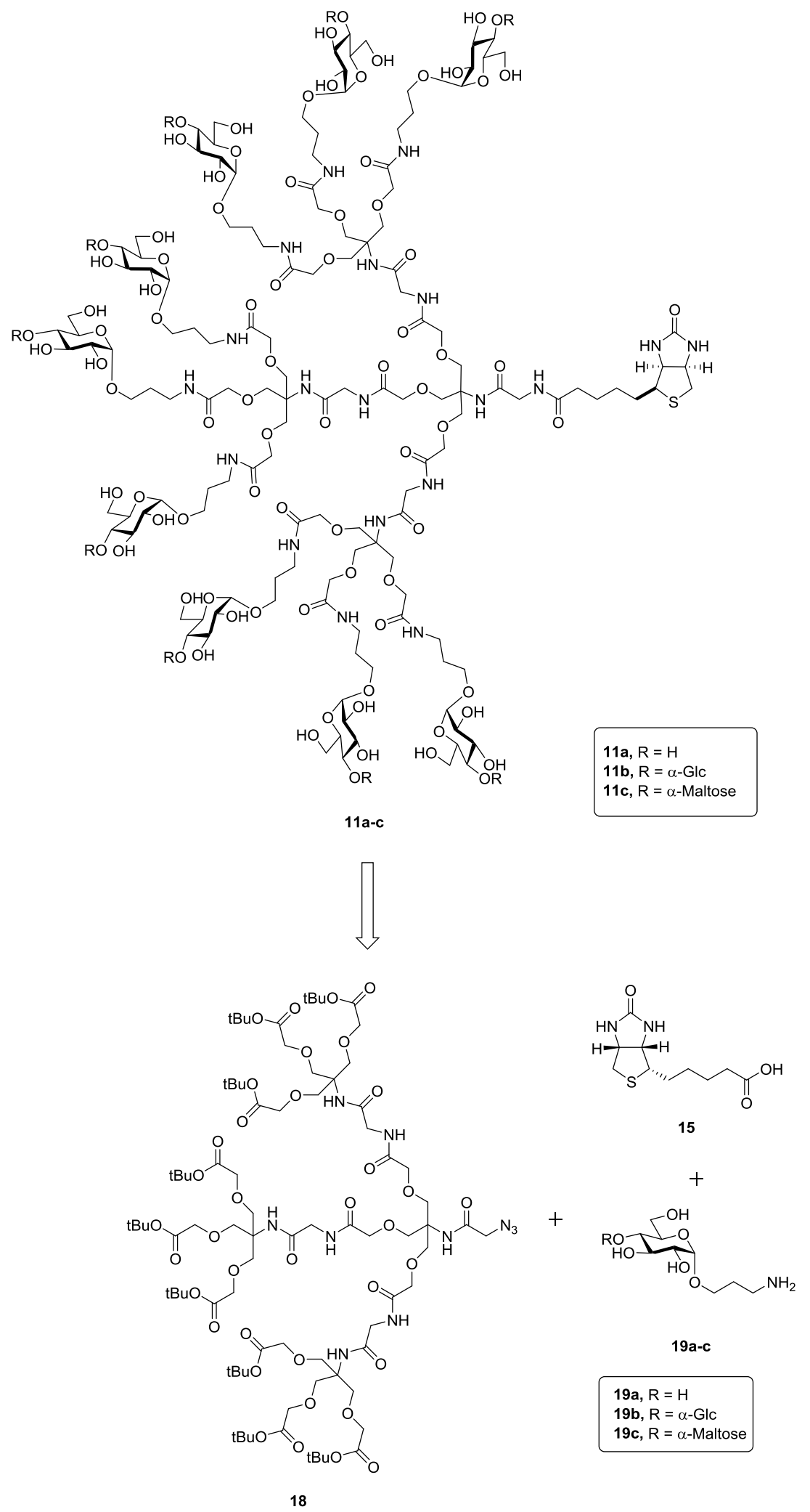

Scheme 3. The retrosythetic analysis of target glycodendrons 11a-c

The second-generation dendron 18 can in turn be synthesised by coupling two first-generation dendrons with different reactive centres, namely a carboxylic acid 
20 and an amine 21 (Scheme 4). Both these first-generation dendrons can be synthesised from the fully protected dendron 22 . The assembly of the secondgeneration dendron thus utilises double exponential growth synthetic methodology, ${ }^{89}$ which is highly efficient as the building blocks are dendrons themselves. The fully protected first-generation dendron 22 can then be made by coupling the commercially available starting materials tris(aminomethane) (24) and bromoacetic acid (23).

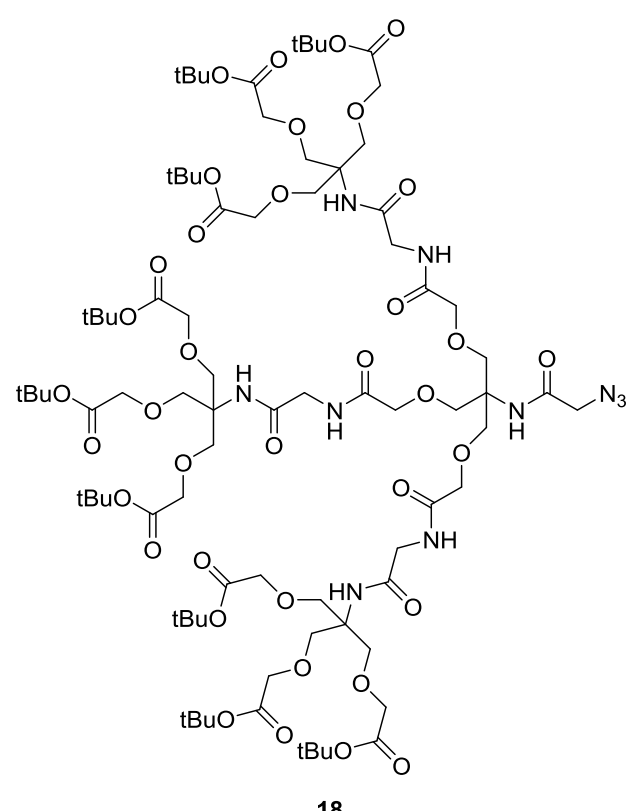

18

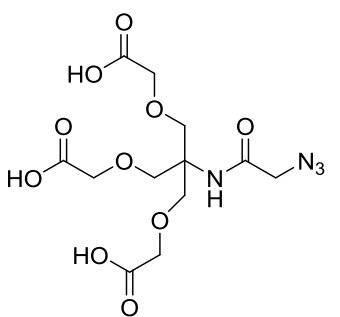

20
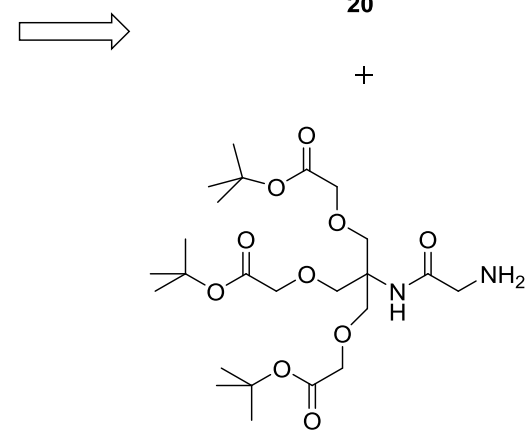

21<smiles>C=CC</smiles><smiles>CC(C)(C)OC(=O)COCC(COCC(=O)OC(C)(C)C)(COCC(=O)OC(C)(C)C)NC(=O)CN</smiles>

22

Scheme 4. The retrosynthetic scheme for the synthesis of second-generation dendron $\mathbf{1 8}$

With this efficient synthetic strategy, target glycosides 10a-c and glycodendrons 11a-c will be synthesised and used in biological assays in order to determine whether the levels of anti-glycan antibodies are elevated in the sera of MS patients in comparison to healthy sera. 


\section{RESULTS AND DISCUSSION}

\subsection{Synthesis of Linear Saccharides}

\subsubsection{Perbenzylated Phenyl Thioglucoside as Donor}

The first donor selected for the synthesis of the target $\alpha$-glucosides was the perbenzylated phenyl thioglucoside 25 (Scheme 6). The benzyl protecting groups were chosen as they are non-participating and should therefore favour the formation of the $\alpha$-anomer in a glycosylation reaction. ${ }^{93,94}$ The arming, or electrondonating, nature of benzyl ethers has also been proposed to increase the reactivity of the glycosyl donor, forming the $\alpha$-glycoside in high yield, as illustrated by the work of Sun et al. (Scheme 5)..$^{95}$ Here, the perbenzylated thioglucoside 25 acts as the donor in a glycosylation reaction with ethanol and (bis(trifluoroacetoxy)iodo)benzene (BTIB) as an activator, giving 26 with a high yield and with excellent $\alpha$-selectivity $(80 \%,>30: 1 \alpha: \beta)$.

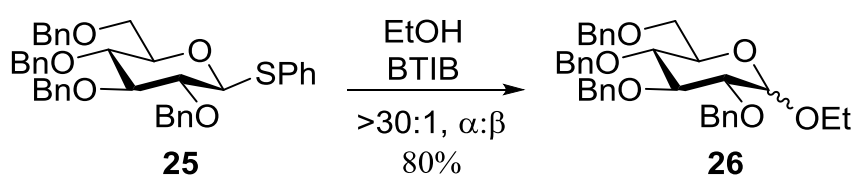

Scheme 5. An $\alpha$-selective glycosylation reaction with perbenzylated donor $25^{95}$

\subsubsection{Synthesis of the Phenyl Thioglucoside Donor}

Synthesis of the thioglucoside donor 25 was readily achieved in four steps from D-glucose (16a) following literature procedures (Scheme 6). ${ }^{96}$ Accordingly, D-glucose (16a) was treated with $\mathrm{Ac}_{2} \mathrm{O}$ in pyridine to give peracetylated glucose 27 as a 7:1 mixture of $\alpha$ - and $\beta$-anomers. Treatment of peracetylated glucose 27 with $\mathrm{PhSH}$ and trifluoroborate etherate then gave phenyl thioglucoside 28 in an $86 \%$ yield. The coupling constants $\left(J_{1,2}=9.5 \mathrm{~Hz}\right)$ in the ${ }^{1} \mathrm{H}$ NMR spectrum is indicative of the $\beta$-thioglucoside formation due to neighbouring group participation, whereby the protons at C-1 and C-2 are in a trans-relationship and therefore have a relatively large coupling constant. ${ }^{97}$ Thioglucoside 28 was then deacetylated via treatment with $\mathrm{NaOMe}$ in $\mathrm{MeOH}$ for $16 \mathrm{~h}$ to provide the tetraol 29 quantitatively. Successful 
deacetylation was shown by the disappearance of the four carbonyl carbons in the ${ }^{13} \mathrm{C}$ spectrum of thioglycoside $28(6-\mathrm{C}=\mathrm{O} 170.8 \mathrm{ppm}, 3-\mathrm{C}=\mathrm{O} 170.4 \mathrm{ppm}, 4-\mathrm{C}=\mathrm{O}$ $169.6 \mathrm{ppm}, 2-\mathrm{C}=\mathrm{O} 169.5 \mathrm{ppm}$ ) as well as the appearance of broad $\mathrm{OH}$ stretches in the IR spectrum at 3409 and $3371 \mathrm{~cm}^{-1}$. Thioglycoside 29 was then subjected to benzylation by reaction with $\mathrm{BnBr}, \mathrm{NaH}$, and tetrabutylammonium iodide (TBAI) to give the desired perbenzylated donor 25 in $40 \%$ yield. Here, the appearance of eight doublets with large coupling constants $(10-12 \mathrm{~Hz})$ in the ${ }^{1} \mathrm{H}$ NMR specrum of $\mathbf{2 5}$ is characteristic of the methylene protons in the $\mathrm{O}-\mathrm{Bn}$ groups, thereby indicating that the benzylation was successful. Using 2D COSY NMR analysis, the methylene protons could also be individually assigned (2-O-Bn 4.72 and 4.88 ppm, 3-O-Bn 4.89 and 4.84 ppm, 4-O-Bn 4.82 and 4.57, and 6-O-Bn 4.60 and 4.54 ppm).

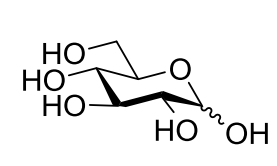

D-Glucose (16a)

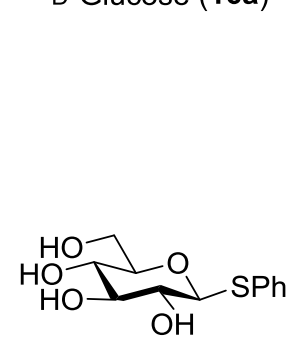

29

$\mathrm{BnBr}, \mathrm{NaH}, \mathrm{TBAI}, \mathrm{DMF}$

$16 \mathrm{~h}, 0^{\circ} \mathrm{C}$ to $\mathrm{RT}$

$40 \%$

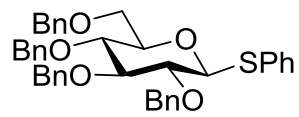

25

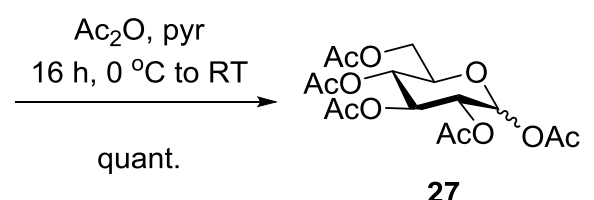

$\mathrm{NaOMe}, \mathrm{MeOH}$

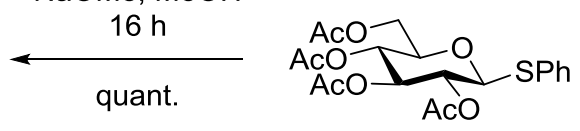

28

Scheme 6. Four-step synthesis of thioglucoside donor $\mathbf{2 5}$

\subsubsection{Synthesis of the Azidopropanol Acceptor}

The azidopropanol acceptor 30 (Scheme 7), which will act as the aglycon in the target glycosides 10a-c and 11a-c, was then prepared in a one-step synthesis by reacting bromopropanol (17) with $\mathrm{NaN}_{3}$ in $\mathrm{H}_{2} \mathrm{O}$, according to a literature procedure. ${ }^{98}$ The reaction proceeded uneventfully to give the acceptor $\mathbf{3 0}$ in $80 \%$ 
yield. The instalment of the azide group was evident by the appearance of a sharp IR absorbance at $2088 \mathrm{~cm}^{-1}$.

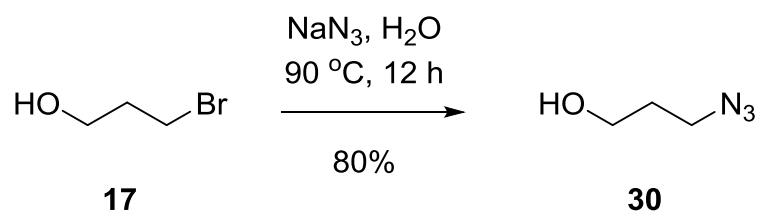

Scheme 7. One step synthesis of azidopropanol (30)

\subsubsection{3 $\mathrm{NIS/TfOH} \mathrm{Activation}$}

With the perbenzylated thioglucoside donor $\mathbf{2 5}$ and the azidopropanol acceptor $\mathbf{3 0}$ in hand, the synthesis of the fully protected glucoside $14 \mathbf{a}$ was then attempted (Scheme 8). The coupling reaction using a 1:3.5 ratio of 25:30 in freshly distilled $\mathrm{CH}_{2} \mathrm{Cl}_{2}$ at $-78{ }^{\circ} \mathrm{C}^{99,100}$ was carried out using TfOH (0.2 equiv.) and NIS (1.3 equiv.) to activate the thioglucoside. Upon the addition of the activating agents the anticipated colour change from orange to a deep red, which indicates the formation of the iodine-sulfur complex during activation, was not observed until the reaction was warmed to $0{ }^{\circ} \mathrm{C}$. Analysis of the reaction mixture by TLC after one hour revealed the absence of donor and the reaction was then quenched by the addition of $\mathrm{NEt}_{3}$. Following work-up and purification, a 44\% yield of glucoside 14a was obtained, yet despite the absence of a C-2 participating group, the major product of the reaction was unfortunately the $\beta$-glucoside $(1: 2.5, \alpha: \beta)$. Upon repeating the reaction, the yield varied only slightly, achieving $57 \%$ at best, with the $\alpha: \beta$ ratio remaining the same.

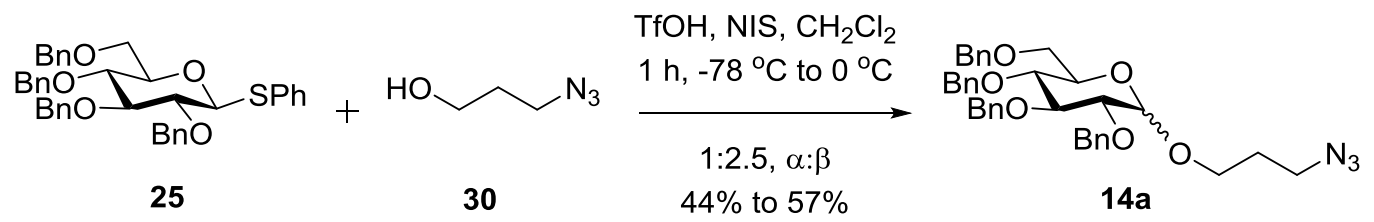

Scheme 8. The reaction between the thioglucoside donor $\mathbf{2 5}$ with azidopropanol $\mathbf{3 0}$ to form the fully protected glucoside $14 a$

The ratio of anomers is typically determined by comparing the integrations of the resonances characteristic of the H-1 protons in the ${ }^{1} \mathrm{H}-\mathrm{NMR}$ spectrum. For the 
$\alpha$-anomer, a small ${ }^{1} \mathrm{H}$ NMR $J_{1^{\prime}, 2^{\prime}}$ coupling of $3-5 \mathrm{~Hz}$ is expected, while a larger $J_{1^{\prime}, 2^{\prime}}$ coupling of $10-12 \mathrm{~Hz}$ is expected for the $\beta$-anomer. ${ }^{97}$ In the case of the perbenzylated glucoside, however, the $\alpha: \beta$ anomer ratio was difficult to determine using the anomeric signals alone as there was overlap between the anomeric signal for the $\alpha$-anomer (at $4.70 \mathrm{ppm}$ ) and the methylene $\mathrm{O}$ - $\mathrm{Bn}$ resonances, as seen in the HSQC (Figure 10). However, after fully assigning the $\alpha$ - and $\beta$-products using 2D NMR, the ratio of anomers could be established by comparing the integral values of the anomeric resonance for the $\beta$-anomer and that of $3-O-B n$ doublet (4.98 ppm) for the $\alpha$ product. This gave an $\alpha: \beta$ ratio of 1:2.5. Furthermore, analysis of the HMBC spectrum confirmed that both $\alpha$ - and $\beta$ - anomers have the desired C1'C1 linkage, as illustrated (Figure 11).

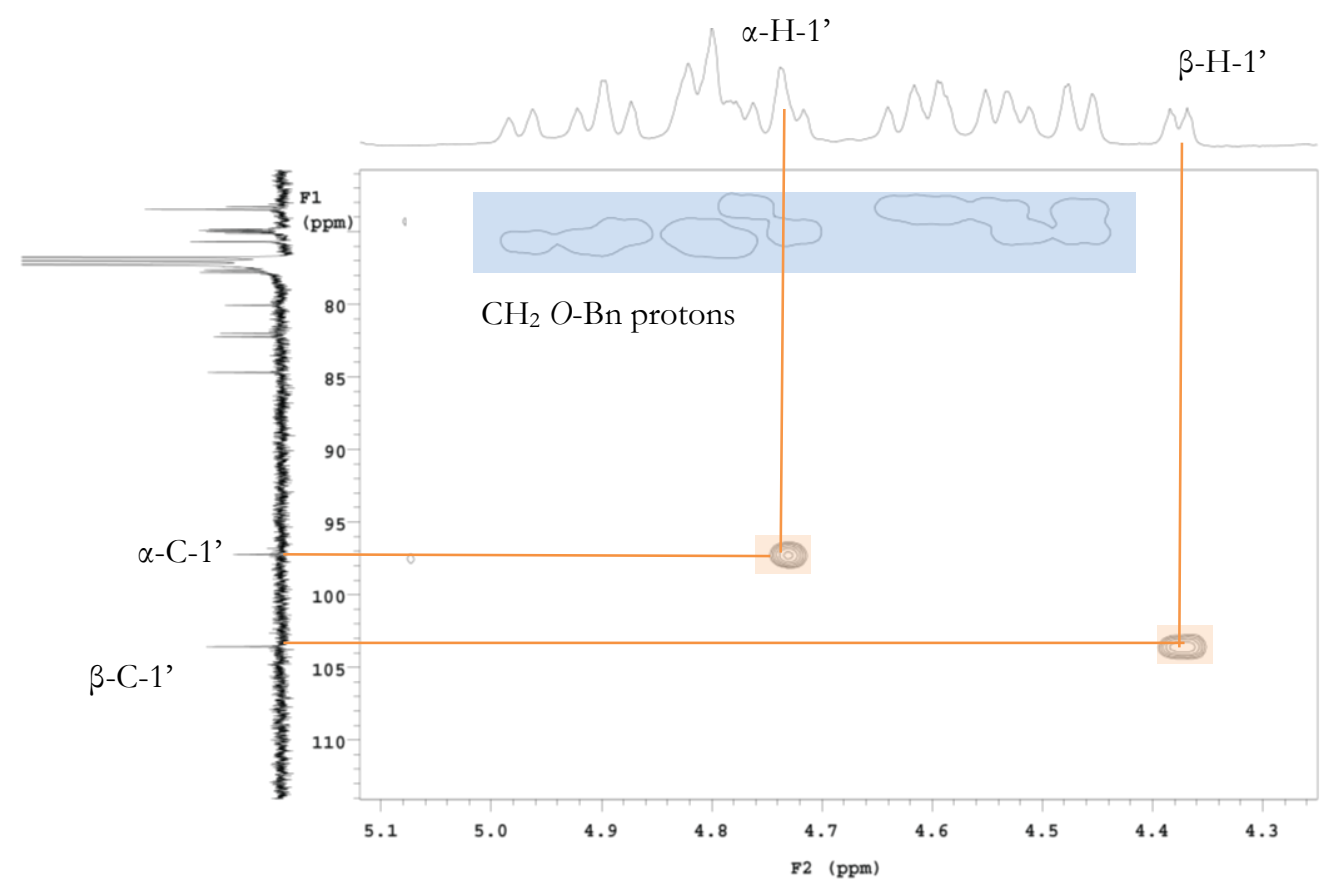

Figure 10. $\mathrm{HSQC}$ spectrum $\left(500 \mathrm{MHz}, \mathrm{CDCl}_{3}\right)$ of $14 \mathrm{a}$ showing the anomeric proton shifts. 


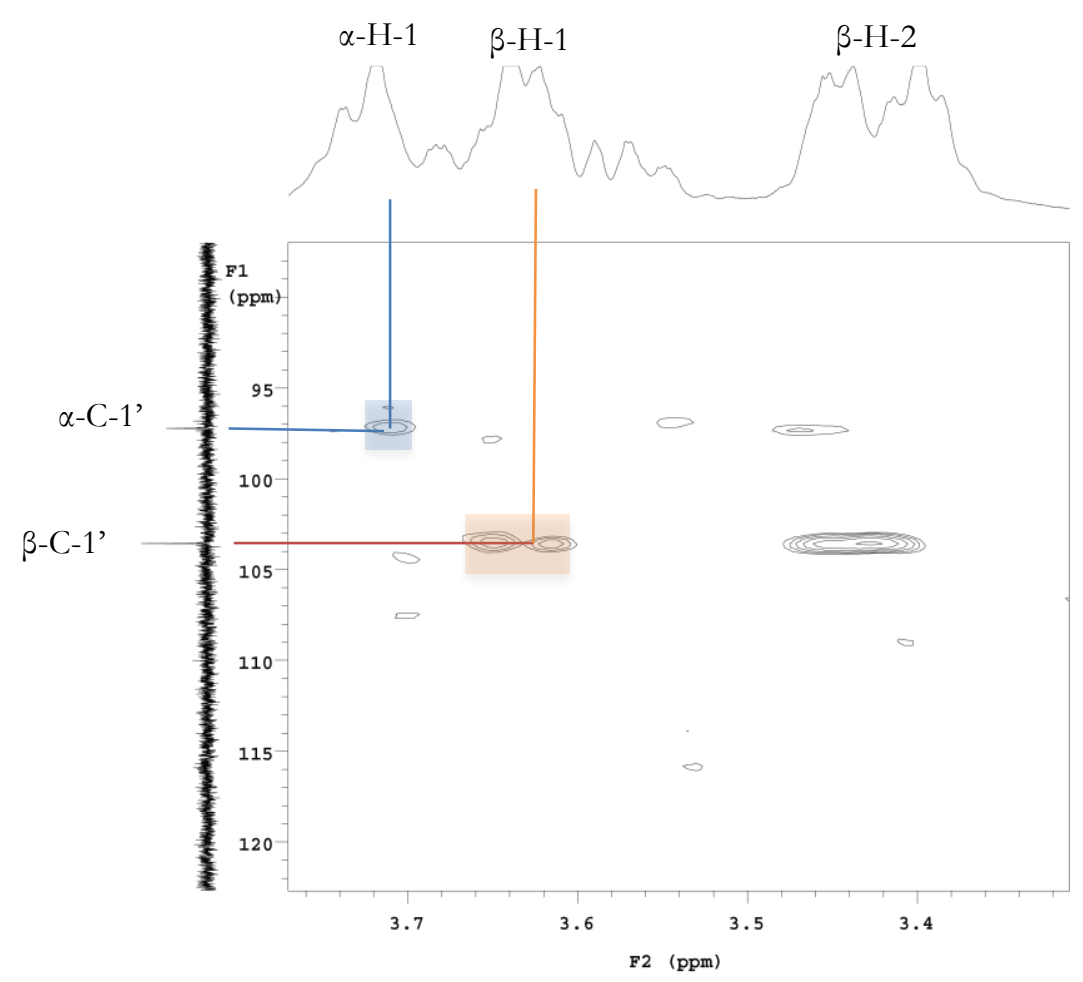

Figure 11. $\mathrm{HMBC}$ spectrum $\left(500 \mathrm{MHz}, \mathrm{CDCl}_{3}\right)$ of $14 \mathrm{a}$ showing interaction between the anomeric carbons $\left(\alpha / \beta-C-1^{\prime}\right)$ and the $-O-\mathrm{CH}_{2}$ protons of the aglycon $(\mathrm{H}-1)$

Given the poor $\alpha$-selectivity of the previous reaction and the slow activation of the donor, the reaction was repeated, this time at $0{ }^{\circ} \mathrm{C}$ and with a higher concentration of TfOH (1 equiv.). TLC analysis after half an hour showed the disappearance of the donor and the presence of product. These conditions led to a faster activation of the thioglucoside donor and improved the $\alpha$-selectivity to a $1: 1 \alpha: \beta$ ratio, though needless to say, the $\alpha: \beta$ selectivity was not sufficient for the purpose of this project. The reaction yield for this slightly modified procedure was also similar to that obtained previously.

While it is generally accepted that the presence of a non-participating group at the 2-position of a carbohydrate favours the formation of the $\alpha$-glycoside, ${ }^{93,101}$ the exact glycosylation conditions (e.g. type of donor, ${ }^{102,}{ }^{103}$ activating agent, ${ }^{104}$ and solvent, ${ }^{105}$ as well as reaction conditions such as concentration ${ }^{106}$ and temperature ${ }^{107,108}$ ) can lead to differences in $\alpha$ - and $\beta$-selectivities. Interestingly, a similar reaction by Heuckendorf et al. involving donor 25 under the same glycosylation conditions with hexanol also gave a 1:2 $\alpha: \beta$ anomer mixture (Scheme 
9). ${ }^{109}$ This $\alpha: \beta$ ratio appears to be consistent when using perbenzylated donors. For example, thioglucoside 25 also favoured the formation of the $\beta$-glycosylation product 34 with the carbohydrate acceptor 33 in a glycosylation reaction done by Dieskau et al. ${ }^{110}$, as was the case when the slightly varied perbenzylated thioglucoside 35 was used (Scheme 9).
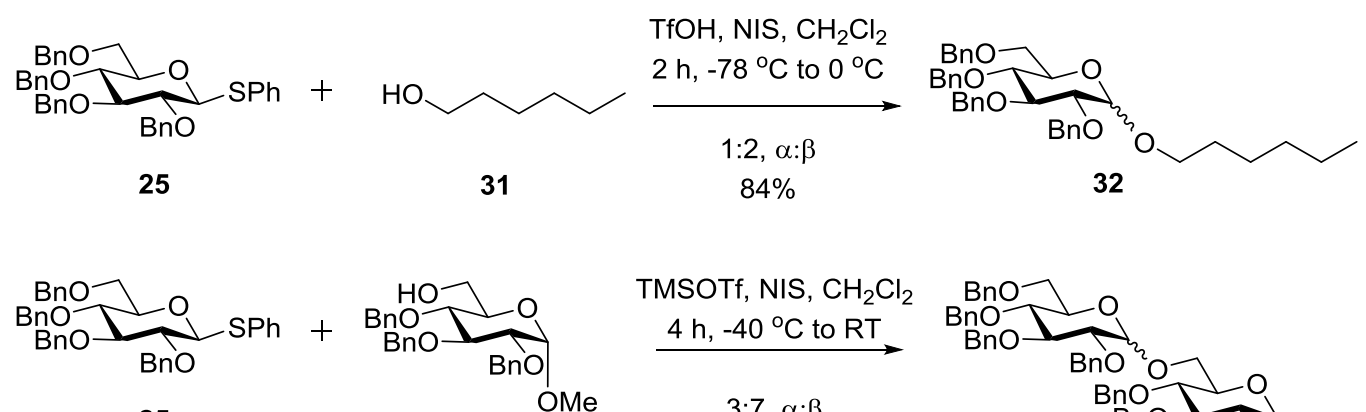

25

33
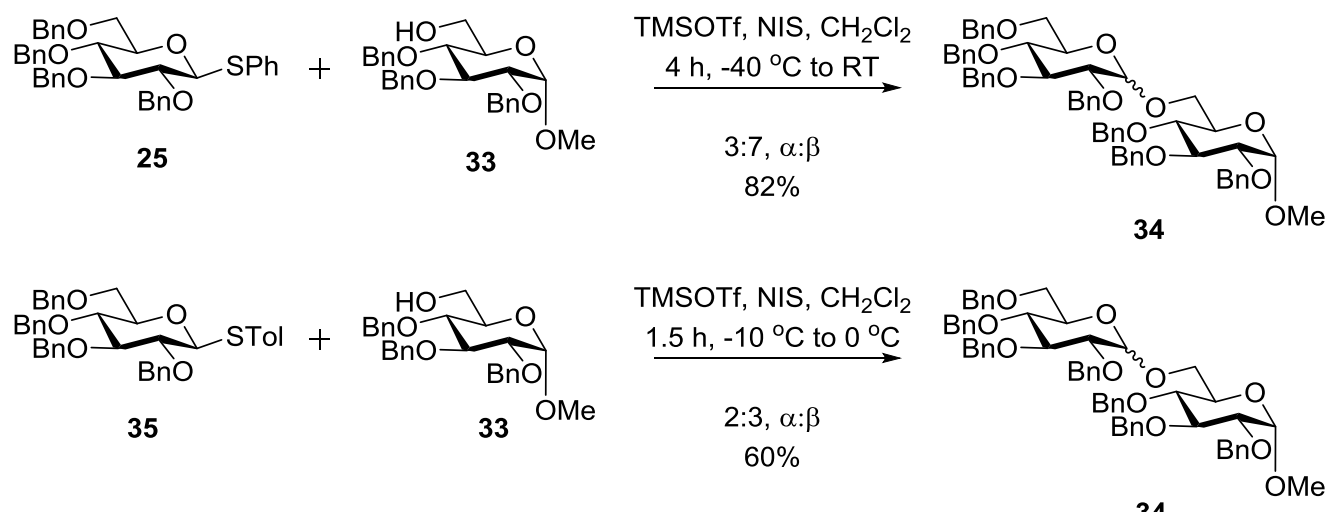

34

Scheme 9. The different $\alpha: \beta$ selectivities achieved in the glycosylation reactions using perbenzylated thioglucosides ${ }^{109-111}$

\subsubsection{Benzylidene Protected Thioglucoside Donor}

In contrast to the perbenzylated donor, the trans-decalin system formed by the incorporation of a benzylidene protecting group has been proposed to result in higher glycosylation selectivities. ${ }^{112,} 113$ The benzylidene group is known to discourage the flattening of the anomeric centre required to stabilise an oxocarbenium ion intermediate due to the torsional strain imposed on the system, which in turn leads to a disarming effect. ${ }^{114}$ Taken together, these effects will therefore encourage an $\mathrm{S}_{\mathrm{N}} 2$-type substitution, which will favour the $\alpha$-glycosylation product from a $\beta$-thioglucoside donor. ${ }^{113}$ Furthermore, glycosylation reactions using the dibenzyl/benzylidene-protected thioglucoside donor has led to excellent $\alpha$-selectivities at $-78{ }^{\circ} \mathrm{C}$ in $\mathrm{CH}_{2} \mathrm{Cl}_{2}$ via glycosyl triflate intermediates using $\mathrm{PhSOTf}$ 
as the activator (Scheme 10). ${ }^{113}$ This procedure was applied with different acceptors, including the acetylated methyl glucoside acceptor 37, the tertiary alcohol 39, and peptide acceptor 41 to give the corresponding glycosides 38, 40, and 42 with excellent $\alpha$-selectivity.

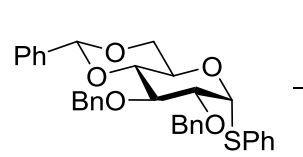

36

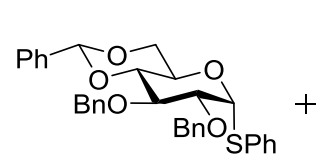

36

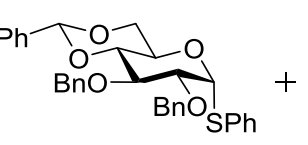

36

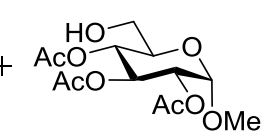

37

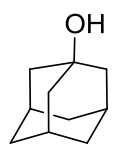

39

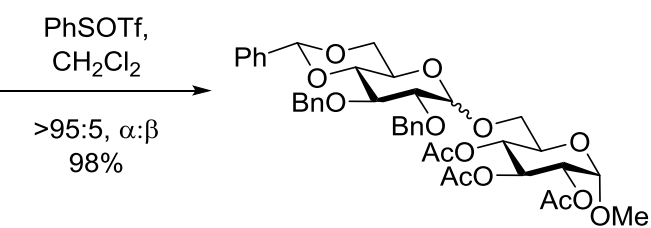

38

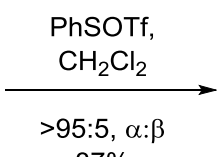

$87 \%$

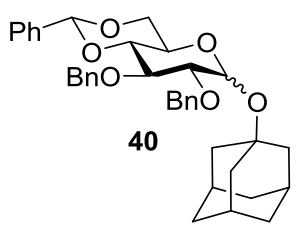<smiles>CC(=O)OC(=O)NC(CO)C(=O)O</smiles>

41
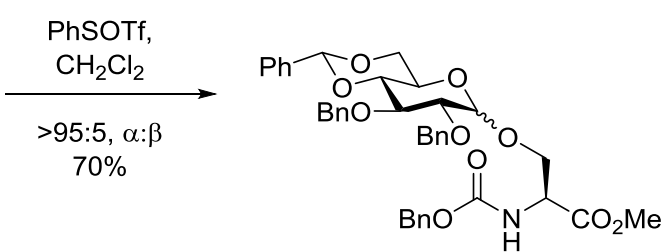

42

Scheme 10. $\alpha$-Glycosylations using a benzylidine-protected thioglucoside donor ${ }^{113}$

\subsubsection{Synthesis of the Benzylidene Thioglucoside}

Benzylidene-protected donor $\mathbf{3 6}$ was prepared in two steps from the previously prepared tetraol thioglucoside $\mathbf{2 9}$ (Scheme 11). The first step was the instalment of the benzylidene group across the 4- and 6-positions using benzaldehyde dimethylacetal in the presence of camphorsulfonic acid (CSA), and under reduced pressure to remove the methanol by-product. ${ }^{115}$ This reaction proceeded smoothly to give diol 43 in $70 \%$ yield, which was then benzylated, according to the procedure previously described, to provide the benzylidene-protected thioglucoside donor 36. Successful addition of the benzylidene protecting group was confirmed by a singlet at $5.59 \mathrm{ppm}\left(\mathrm{PhCHO}_{2}\right)$ in the ${ }^{1} \mathrm{H}$ NMR spectra of both the diol 30 and the thioglucoside donor 36. The instalment of benzyl ether protecting groups was confirmed by the presence of four doublets assigned to $\mathrm{CH}_{2}$ protons for 2-O-Bn and 3-O-Bn with coupling constants of $10.4 \mathrm{~Hz}$ and $11.0 \mathrm{~Hz}$, 
as well as aromatic carbons in the ${ }^{13} \mathrm{C}-\mathrm{NMR}$ (132.5-126.1 $\left.\mathrm{ppm}\right)$. The full characterisation of the thiophenol donor (36) matched that reported in literature. ${ }^{116}$

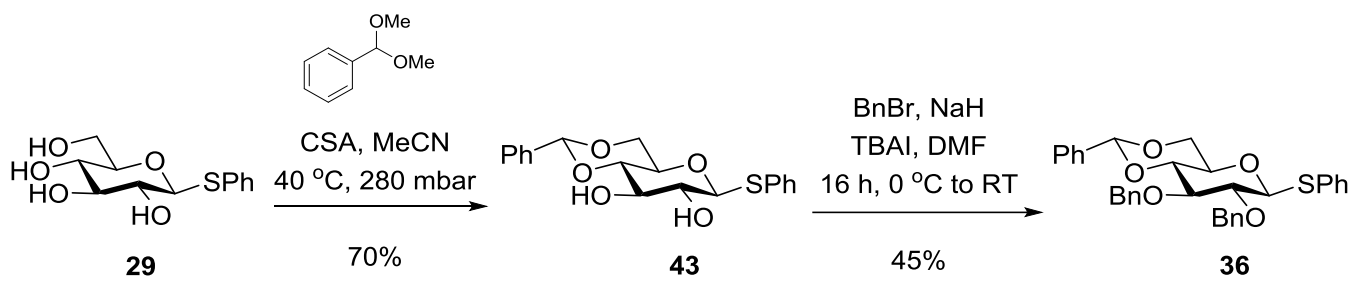

Scheme 11. Two-step synthesis of the benzylidene-protected thiophenol donor $\mathbf{3 6}$

\subsubsection{NIS/TfOH Activation}

Having prepared the benzylidene-protected thioglucoside donor 36, the glycosylation reaction with azidopropanol (30) was performed, again using $\mathrm{NIS} / \mathrm{TfOH}$ (1.3 and 1 equiv., respectively) in freshly distilled $\mathrm{CH}_{2} \mathrm{Cl}_{2}$ (Table 1). Following a literature procedure, ${ }^{117}$ the addition of the activating agents was performed at cold temperatures $\left(-60 \rightarrow 0{ }^{\circ} \mathrm{C}\right)$ before the reaction was warmed to $0{ }^{\circ} \mathrm{C}$ over $1.5 \mathrm{hr}$ (Entry 1). These reaction conditions, however, favoured the formation of the $\beta$-glycoside product 44 . The reaction was then repeated at room temperature (Entry 2). Here, an improvement in the $\alpha$-selectivity of the reaction was observed and a 1:1 $\alpha: \beta$ ratio was obtained. Successful coupling was shown in the $\mathrm{HMBC}$ spectrum in figure 12 which shows the interactions between both $\alpha$ and $\beta-\mathrm{C}-1$ ' with the $\mathrm{H}-1 \mathrm{a}$ and $\mathrm{H}-1 \mathrm{~b}$ of the linker.

Table 1. Glycosylation of thioglucoside $\mathbf{3 6}$ with acceptor $\mathbf{3 0}$
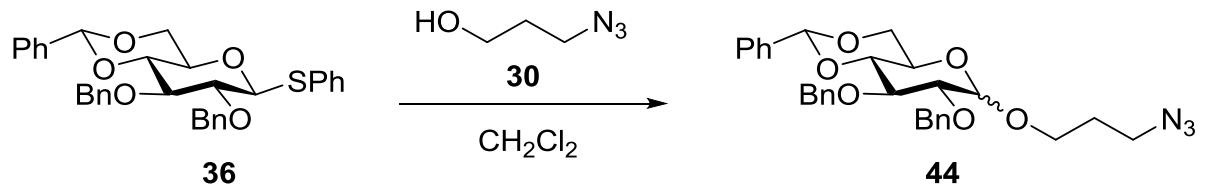

44

\begin{tabular}{llllll} 
Entry & Activator (equiv.) & Time & Temp $\left({ }^{\circ} \mathbf{C}\right)$ & $\alpha: \beta$ & Yield \\
\hline 1 & NIS (1.3)/TfOH (1) & $1.5 \mathrm{~h}$ & $-60 \rightarrow 0$ & $1: 2$ & $45 \%$ \\
2 & NIS (1.3)/TfOH (1) & $1 \mathrm{~h}$ & $\mathrm{RT}$ & $1: 1$ & $36 \%$ \\
3 & NIS (1.3)/TfOH (1) & $1 \mathrm{~h}$ & 40 & - & $0 \%$ \\
4 & NIS (1.3)/TfOH (1) & $0.25 \mathrm{~h}$ & 40 & - & $0 \%$
\end{tabular}




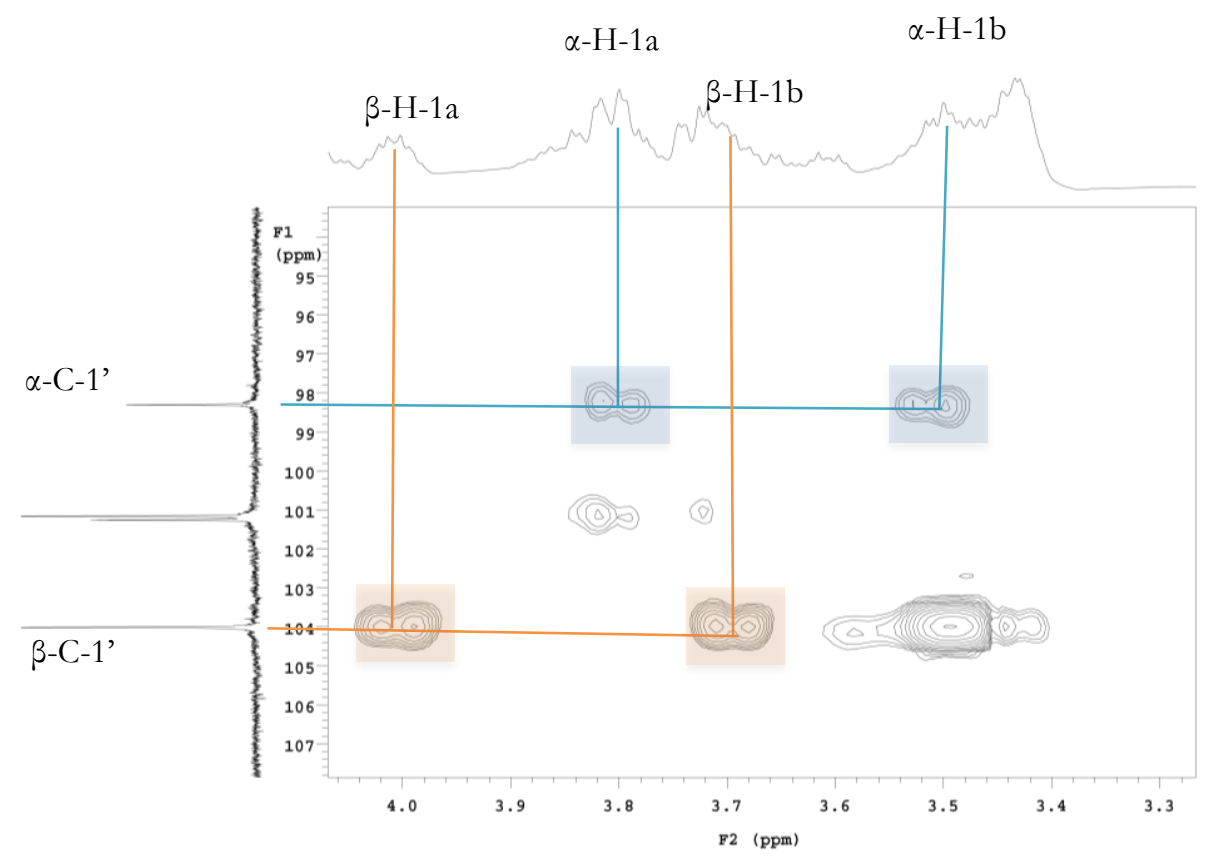

Figure 12. $\mathrm{HMBC}\left(500 \mathrm{MHz}, \mathrm{CDCl}_{3}\right)$ showing glycosylation product 44 , specifically, the interaction between $\alpha-\mathrm{C}-1^{\prime}$ and $\mathrm{H}-1$, as well as $\beta-\mathrm{C}-1^{\prime}$ and $\mathrm{H}-1$

The improvement in $\alpha$-selectivity upon an increase in reaction temperature suggests the involvement of a triflate intermediate in situ. It has been proposed that triflate anions form a tight ion pair with the oxocarbenium cation in situ before the acceptor attacks the anomeric centre, especially when the acceptor is less nucleophilic than the triflate anion. ${ }^{118}$ Moreover, the $\alpha$ - rather than the $\beta$ glycosyltriflate will form due to the anomeric effect (I), which will in turn favour the formation of the $\beta$-product in an $S_{N} 2$-like substitution (Scheme 12). Alternatively, a diastereomeric mixture can be obtained via an $\mathrm{S}_{\mathrm{N}} 1$ substitution reaction. Thus, as temperature is increased, the interaction between the oxocarbenium cation and the triflate anion is weakened (II), which leads to an increasingly $\mathrm{S}_{\mathrm{N}} 1$-like reaction and subsequently the observed 1:1 mixture of $\alpha$ and $\beta$ products. Accordingly, the reaction was repeated under reflux for one hour (Entry 3), however, no product was formed. Refluxing the reaction mixture for a shorter length of time (Entry 4) also did not yield any of the desired product and only product degradation was found in both cases. Using the benzylidene-protected donor did not improve the $\alpha$-selectivity of the glycosylation reaction, thus, different activating agents were explored. 


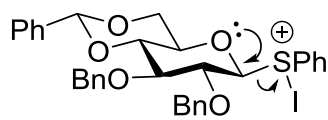

45
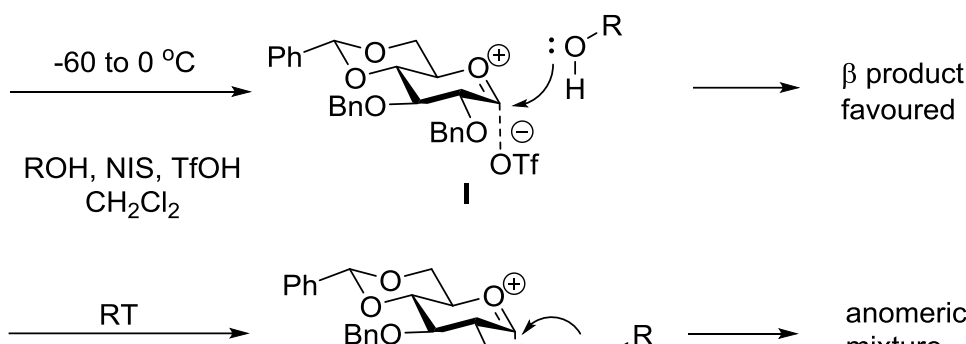

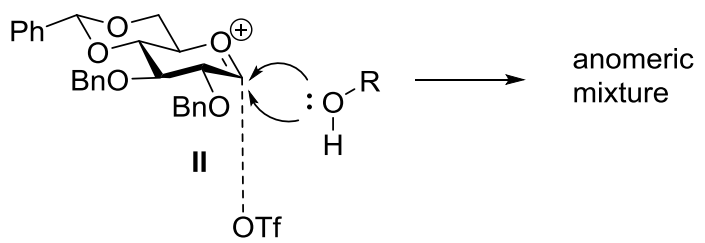

Scheme 12. The effect of temperature on the selectivity of NIS/TfOH-promoted glycosylation reactions

\subsubsection{Bromide Activation}

Next, the ability of glycosyl bromides to favour the formation of the $\alpha$-anomer during glycosylation reactions was explored. The in situ anomerisation of glucosyl bromides, as proposed by Lemieux et al. (Scheme 13), ${ }^{119}$ involves an equilibrium between $\alpha$ - and $\beta$-glycosyl bromides (IV and $\mathbf{V}$, respectively) whereby the decreased stability of the $\beta$-bromide $(\mathbf{V})$ facilitates fast nucleophilic substitution by the acceptor $\left(\mathrm{R}^{\prime} \mathrm{OH}\right)$. In contrast, the increased stability of the $\alpha$-bromide (IV) results in slow nucleophilic substitution. Thus, the fast consumption of the $\beta$ anomer will shift the equilibrium to the formation of the $\beta$-bromide $(\mathbf{V})$ due to Le Chatelier's principle. ${ }^{120}$ This will ultimately result in the formation of the $\alpha$-glycoside (VII) as the major product.

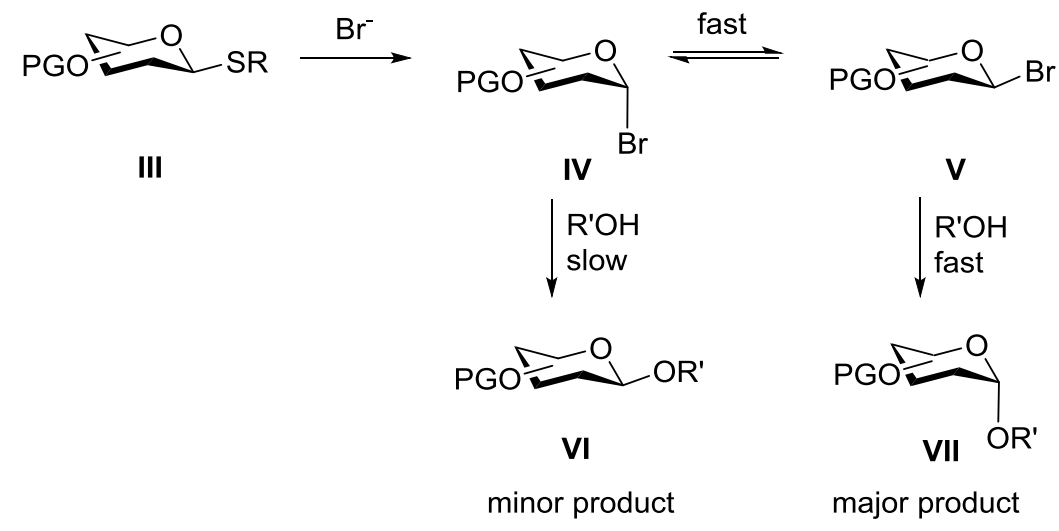

Scheme 13. In situ anomerisation of glycosyl bromides as proposed by Lemieux. ${ }^{119}$ 
Excess bromide anions are required for $\alpha$-selectivity in order for the rate of anomerisation to be greater than the rate of glycosylation. ${ }^{121}$ To this end, brominating agents such as the combination of dimethyl(methylthio)sulfonium triflate (DMTST) and tetrapropylammonium bromide (TPABr), as instigated by Andersson et al., ${ }^{121}$ have been used to activate thioglucosides to obtain $\alpha$-glycosides. Thus, to explore the potential of DMTST as an activator, the glycosylation reaction between the 4,6-O-benzylidene protected donor $\mathbf{3 6}$ and alcohol $\mathbf{3 0}$ was attempted (Table 2). It was envisaged that during the formation of 44 , catalytic DMTST could be used as it could be regenerated in situ from the by-products phenyl methyl sulfide (46) and $\mathrm{SMe}_{2}$ (Scheme 14). For this reason, only 0.2 equivalents of DMTST was used for the initial glycosylation without the use of TPABr (Entry 1). However, after 25 minutes at reflux, the reaction was quenched using triethylamine only to recover the unactivated donor. The reaction was then repeated at reflux using 1.2 equivalents of DMTST (initially 0.6 equivalents were used, with another 0.6 equivalents added after an hour), but again, no activation was observed (Entry 2). Finally, product was formed when 3 equivalents of DMTST were used, and the reaction was refluxed for 5 hours $(18 \%, 2: 1 \alpha: \beta)$ (Entry 3). Here, one equivalent of DMTST was initially added and another equivalent was added every hour after the first two hours when TLC analysis showed no further product formation. 
Table 2. Glycosylations of thioglycoside donor 36 and acceptor 30 in $\mathrm{CH}_{2} \mathrm{Cl}_{2}$.

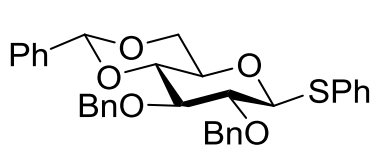

36

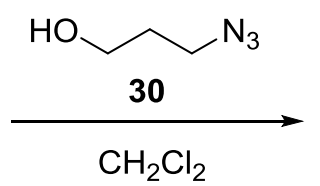

$\mathrm{CH}_{2} \mathrm{Cl}_{2}$

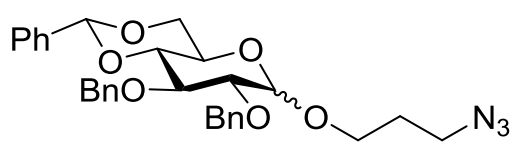

44

\begin{tabular}{lllll} 
Entry & Activator (equiv.) & Time & Temp & Yield \\
\hline 1 & DMTST (0.2) & $0.25 \mathrm{~h}$ & $40{ }^{\circ} \mathrm{C}$ & $0 \%$ \\
2 & DMTST (1.2) & $2 \mathrm{~h}$ & $40{ }^{\circ} \mathrm{C}$ & $0 \%$ \\
3 & DMTST (3) & $5 \mathrm{~h}$ & $40{ }^{\circ} \mathrm{C}$ & $18 \%$ \\
4 & DMTST (3), TPABr (5), NBS (3) & $5 \mathrm{~d}$ & $\mathrm{RT}$ & $<5 \%$ \\
5 & DMTST (3), TPABr (5), NBS (6) & $7 \mathrm{~d}$ & $40{ }^{\circ} \mathrm{C}$ & $0 \%$
\end{tabular}

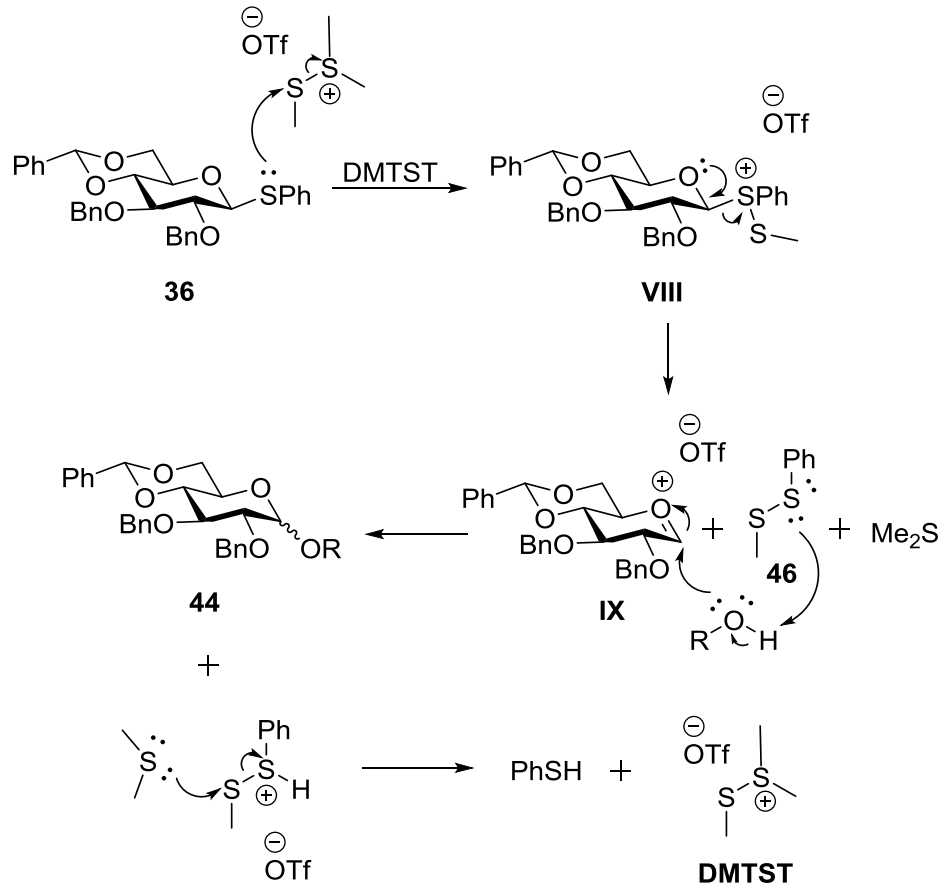

Scheme 14. In situ regeneration of DMTST during a glycosylation reaction 
As this was the first glycosylation reaction that produced the $\alpha$-product as the favoured anomer, the reaction was then repeated at room temperature for a longer period of time. Following a literature procedure, ${ }^{121}$ three equivalents of DMTST and five equivalents of TPABr were added (Entry 4), however, after four days, TLC analysis showed only donor and acceptor, suggesting that no activation of the donor had taken place. In an attempt to activate the donor, 3 equivalents of $N$ bromosuccinimide (NBS) were added to the reaction vessel. After stirring at room temperature for $16 \mathrm{~h}$, TLC analysis (1:3, ethyl acetate : petroleum ether, v:v) showed the disappearance of the donor and the presence of the product $\left(\mathrm{R}_{f}=\right.$ $0.44)$ together with hydrolysed donor $\left(\mathrm{R}_{f}=0.02\right)$. However, following work-up and purification by silica gel column chromatography, very little product $(<5 \%)$ was isolated, and the $\alpha: \beta$ selectivity of the product mixture could not be determined. These conditions were then repeated with the addition of NBS at the same time as DMTST and TPABr, and warming to $40{ }^{\circ} \mathrm{C}$ after 5 days, however, no appreciable product was formed (Entry 5).

While there is no published reaction mechanism for the DMTST/TPABr activation of thioglycosides, it was proposed that in situ formation of $\mathrm{Br}_{2}$ occurs, which in turn activates the thioglucoside donor (Scheme 15). The sluggish nature of the DMTST/TPABr-activated glycosylation reaction could thus be explained by the requirement of the reaction between DMTST and TPABr to first react and form $\mathrm{Br}_{2}$ before the donor was activated. To this end, it was envisaged that the in situ activation of the thioglycosyl donor $\mathbf{3 6}$ could occur much faster in the presence of $\mathrm{Br}_{2}$ than with the more mild activators DMTST and TPABr. ${ }^{122-124}$

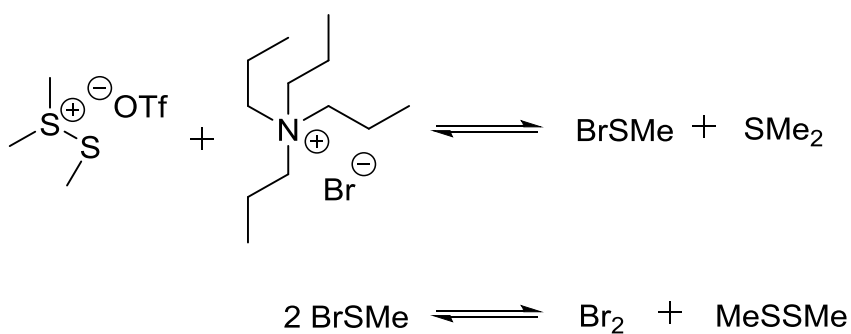

Scheme 15. Proposed in situ formation of $\mathrm{Br}_{2}$ from DMTST and $\mathrm{TPABr}$ 
Accordingly, the glycosylation reaction of benzylidine-protected thioglucoside $\mathbf{3 6}$ with 3-azidopropanol (30) was performed in the presence of $\mathrm{Br}_{2}$ and $\mathrm{TPABr}$ (Table 3). Again, the $\alpha$-product was the major product of the glycosylation reaction and a 3:1 $\alpha: \beta$ ratio of products was obtained when the reaction was performed in $\mathrm{CH}_{2} \mathrm{Cl}_{2}$ at room temperature (Entries 1 and 2). The yields of these reactions, however, were poor. To explore the effect of solvent polarity on the reaction yield and $\alpha: \beta$ selectivity, the reaction was thus repeated using toluene as a solvent (Entries 3 and 4). Here, refluxing conditions in toluene yielded no product (Entry 3), nor did a 1:1 $\mathrm{CH}_{2} \mathrm{Cl}_{2}$ : toluene mixture at room temperature (Entry 4), instead, product degradation was observed. The absence of product when using toluene as a solvent was subsequently attributed to the in situ formation of $\mathrm{HBr}$ via an electrophilic aromatic substitution reaction between toluene and $\mathrm{Br}_{2}$, which may have made the reaction too acidic.

Table 3. Glycosylation reactions between the thioglucosyl donor 36 and alcohol 30 with $\mathrm{Br}_{2}$ and $\mathrm{TPABr}$

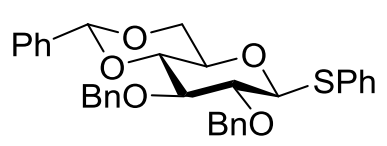

36

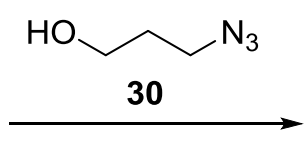

Solvent

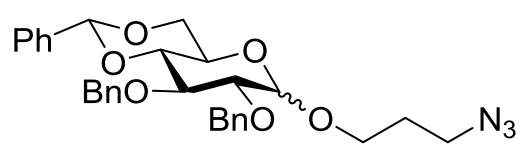

44

\begin{tabular}{lllllll} 
Entry & Activators (equiv.) & Solvent & Time & Temp & $\boldsymbol{\alpha}: \boldsymbol{\beta}$ & Yield \\
\hline 1 & $\mathrm{Br}_{2}(2.5), \mathrm{TPABr}(5)$ & $\mathrm{CH}_{2} \mathrm{Cl}_{2}$ & $3 \mathrm{~d}$ & $\mathrm{RT}$ & $3: 1$ & $13 \%$ \\
2 & $\mathrm{Br}_{2}(3.5), \mathrm{TPABr}(5)$ & $\mathrm{CH}_{2} \mathrm{Cl}_{2}$ & $1 \mathrm{~d}$ & $\mathrm{RT}$ & $3: 1$ & $8.4 \%$ \\
3 & $\mathrm{Br}_{2}(2), \mathrm{TPABr}(5)$ & $\mathrm{Toluene}$ & $3 \mathrm{~h}$ & $110{ }^{\circ} \mathrm{C}$ & - & $0 \%$ \\
4 & $\mathrm{Br}_{2}(3), \mathrm{TPABr}(5)$ & $1: 1$, & $4 \mathrm{~d}$ & $\mathrm{RT}$ & - & $0 \%$ \\
& & $\mathrm{CH}_{2} \mathrm{Cl}_{2}:$ toluene & & & &
\end{tabular}

In each of the glycosylation reaction with the benzylidene donor $36,{ }^{1} \mathrm{H}-\mathrm{NMR}$ and 2D NMR were used to confirm product formation, where the integration of anomeric proton signals of $\alpha$ - and $\beta$-products was determined using ${ }^{1} \mathrm{H}$-NMR. 


\subsubsection{Di-O-Benzoyl Phenyl Thioglucoside Donor}

After observing only poor yields and modest $\alpha$-selectivity when using the benzylidene-protected glucose donor, next the reactivity of a glucose donor containing electron-withdrawing benzoyl groups was explored. Higher $\alpha$-selectivity with a more disarmed donor was seen in the work by Demchenko et al., ${ }^{124}$ whereby a $>25: 1 \alpha: \beta$ product ratio was observed when using the superdisarmed donor 2-Obenzyl 3,4,6-O-tribenzoyl thioglucoside (47) in a bromine-activated glycosylation reaction with 33 to yield $\mathbf{4 8}$. The more arming perbenzylated thioglucoside donor (49) gave 2.2:1 $\alpha: \beta$ when subjected to the same reaction conditions (Scheme 16). The reason for the different $\alpha: \beta$ selectivities, however, is not clear, though it can be argued that the electron-withdrawing nature of the benzoyl group discourages the formation of the oxocarbenium ion. This in turn will favour the formation of the $\alpha$-product due to in situ anomerisation.

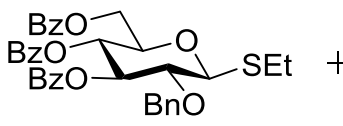

47

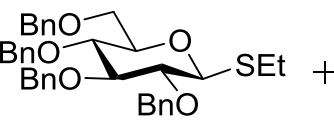

49

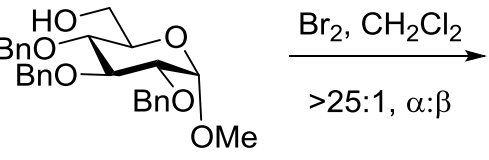

33

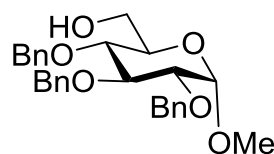

33

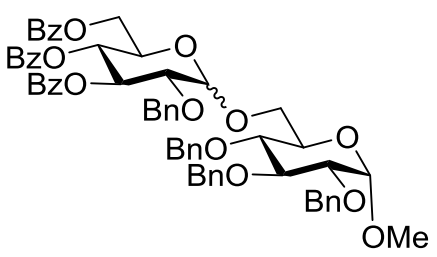

48

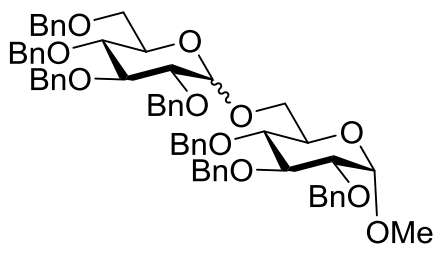

34

Scheme 16. Different $\alpha: \beta$ selectivities in bromine-activated glycosylation reactions achieved between disarmed donor $\mathbf{4 7}$ and armed donor $\mathbf{4 9 ^ { 1 2 4 }}$

\subsubsection{Synthesis of the di-O-Benzoyl di-O-Benzyl Phenyl Thioglucoside}

To explore the effect of disarming protecting groups, a di-O-benzoyl di-O-benzyl phenyl thioglucoside was synthesised for its ease of synthesis from the previously 
prepared 4,6-benzylidene glucoside 36. To this end, the benzylidene protecting group was removed under acidic conditions ${ }^{125}$ to obtain diol $\mathbf{5 0}$ in $70 \%$ yield, which was then reacted with $\mathrm{BzCl}$ in pyridine to give the di-O-benzoyl thioglucoside donor 51 (Scheme 17). ${ }^{126}$ The addition of benzoyl protecting groups was evident by the appearance of aromatic protons in the ${ }^{1} \mathrm{H}-\mathrm{NMR}$ spectrum at around $8 \mathrm{ppm}$, which are downfield from the benzyl ether aromatic protons found between 7.20 and $7.50 \mathrm{ppm}$ due to the electron-withdrawing nature of the carbonyl in the benzoyl groups. Two carbonyl carbons were also observed at 166.2 and $165.3 \mathrm{ppm}$ in the ${ }^{13} \mathrm{C}-\mathrm{NMR}$ spectrum for the benzoylated donor $\mathbf{5 1}$.

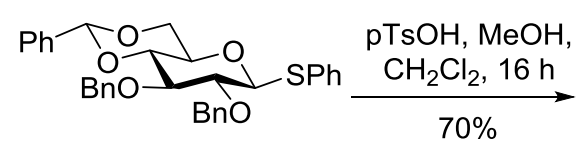

36

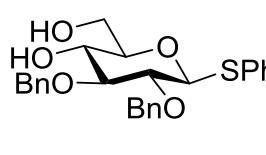

50

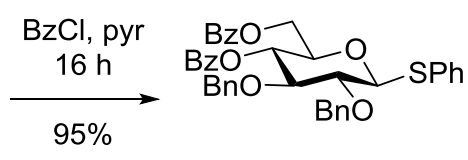

51

Scheme 17. Synthesis of the di-O-benzoyl di-O-benzyl phenyl thioglucoside $\mathbf{5 1}{ }^{126}$

\subsubsection{Glycosylation via Glycosyl Bromide}

With the more disarmed thiophenol donor $\mathbf{5 1}$ in hand, a glycosylation reaction with acceptor $\mathbf{3 0}$ and $\mathrm{Br}_{2}$ as the activator was explored (Table 4). Initially, a small scale NMR experiment was carried out (Entry 1). Here, following the addition of $\mathrm{Br}_{2}$ at $0{ }^{\circ} \mathrm{C}$, the ${ }^{1} \mathrm{H}$ NMR showed degradation of the donor, which was indicated by the loss of resonances between $3 \mathrm{ppm}$ and $5 \mathrm{ppm}$, as well as loss of some of the aromatic resonances attributable to donor 51 . The reaction was then repeated on a larger scale, under dry conditions as it was proposed that the presence of $\mathrm{H}_{2} \mathrm{O}$ in the $\mathrm{CDCl}_{3}$ may have led to hydrolysis of donor 51. With the addition of TPABr, TLC analysis showed the disappearance of the donor after half an hour of activation, and following work-up, mostly the $\alpha$-product was obtained $(4.5: 1, \alpha: \beta)$, albeit in a modest yield of $25 \%$ (Entry 2). The formation of the product was evident through an $\mathrm{HMBC}$ between the anomeric proton and $\mathrm{O}-\mathrm{C}-1$ of the acceptor (30) (Figure 13). Degradation of the donor was still occurring, however, as no hydrolysed or unactivated donor was recovered from the reaction, instead isolating only uncharacterised degradation products, indicated by the loss of aromatic protons as evident in the ${ }^{1} \mathrm{H}-\mathrm{NMR}$ spectrum. In an attempt to prevent degradation and thus improve the reaction yield, the solution was cooled to $-60{ }^{\circ} \mathrm{C}$ 
before $\mathrm{Br}_{2}$ was added (Entry 3). This time, the disappearance of the donor occurred over one hour as gauged by TLC analysis. Upon work-up and purification using silica gel flash column chromatography, however, very little product $(<5 \%)$ was obtained, and the $\alpha: \beta$ selectivity of the product mixture could not be determined. Accordingly, it was decided that the use of $\mathrm{Br}_{2}$ proved too harsh for an effective glycosylation reaction to take place.

Table 4. Glycosylation reactions with di-O-benzoyl di-O-benzyl donor $\mathbf{5 1}$

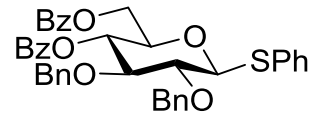

51

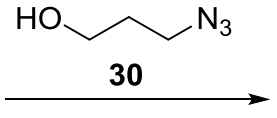

Solvent Time

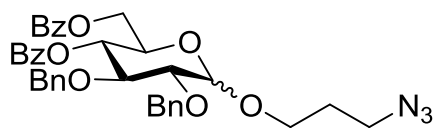

52

\begin{tabular}{lllllll} 
Entry & Activators (equiv.) & Solvent & Time & Temp & $\alpha: \beta$ & Yield \\
\hline $1^{\mathrm{a}}$ & $\mathrm{Br}_{2}(3.5)$ & $\mathrm{CDCl}_{3}$ & $5 \mathrm{~min}$ & $0{ }^{\circ} \mathrm{C}$ & - & $0 \%$ \\
2 & $\mathrm{Br}_{2}(3.5), \mathrm{TPABr}(5)$ & $\mathrm{CH}_{2} \mathrm{Cl}_{2}$ & $30 \mathrm{~min}$ & $0{ }^{\circ} \mathrm{C}$ & $4.5: 1$ & $25 \%$ \\
3 & $\mathrm{Br}_{2}(3.5), \mathrm{TPABr}(5)$ & $\mathrm{CH}_{2} \mathrm{Cl}_{2}$ & $1 \mathrm{~h}$ & $-60{ }^{\circ} \mathrm{C}$ & - & $<5 \%$
\end{tabular}

a Performed in an NMR tube

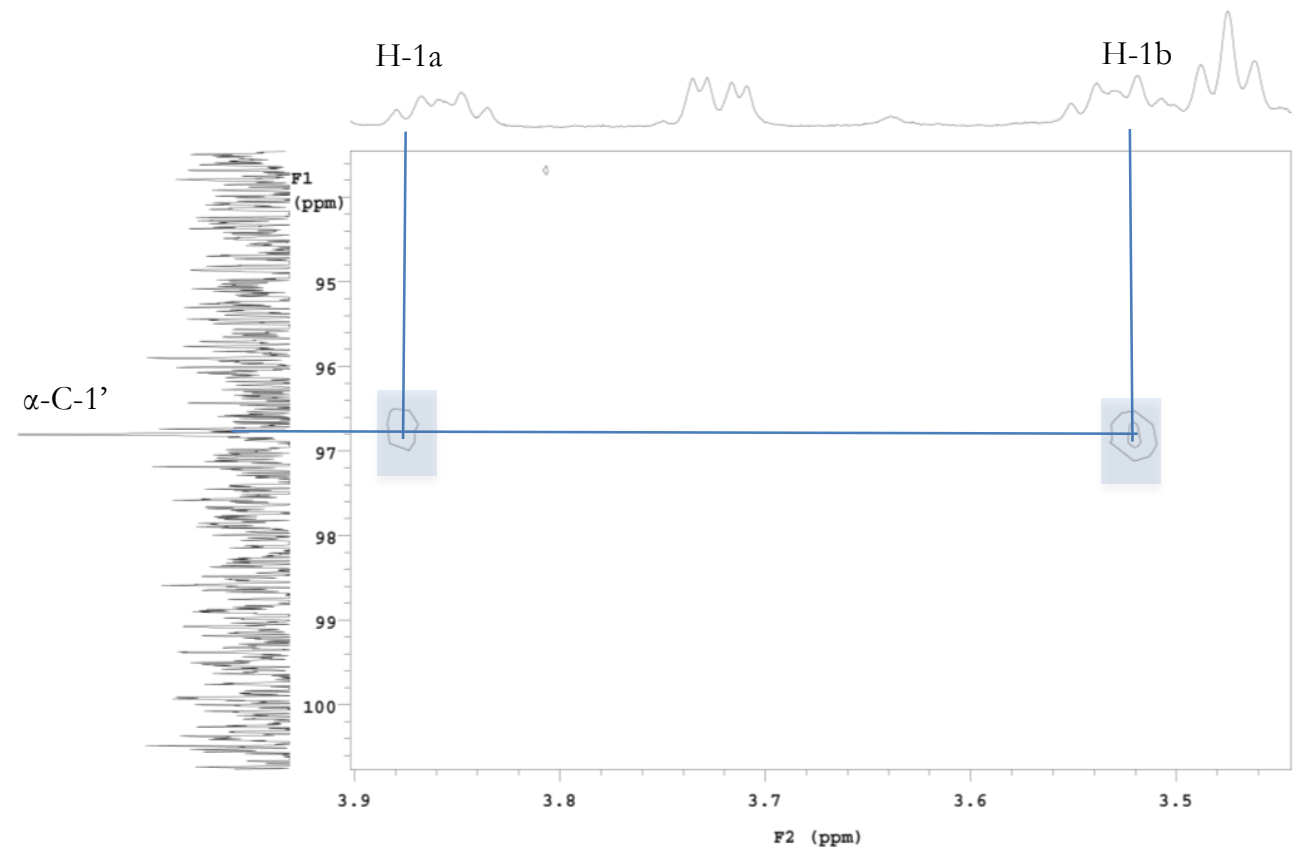

Figure 13. $\mathrm{HMBC}\left(500 \mathrm{MHz}, \mathrm{CDCl}_{3}\right)$ showing coupling between $\alpha-\mathrm{C}-1^{\prime}$ and $\mathrm{H}-1 \mathrm{a}$ and $\mathrm{H}-1 \mathrm{~b}$ of the glycosylation product $\mathbf{5 2}$ 


\subsubsection{Perbenzylated Thioethyl Glucose as Donor}

In light of the lack of success in the activation and subsequent glycosylation of thiophenol donors, it was hypothesised that a more readily activated thiol aglycon will improve both the yield and $\alpha$-selectivity for the installation of the azidopropanol linker (30). A study comparing the reactivities of different donors with different thiol groups at the anomeric centres, ${ }^{127}$ such as thiophenyl and thioethyl, revealed that donors with more electron-donating aglycons, such as alkyl groups, were fast-reacting donors and those with electron-withdrawing aglycons, such as phenyl groups, were slower-reacting donors. This is due to the increased nucleophilicity of the sulfur when bonded to electron-donating rather than electron-withdrawing aglycons. Thus, the synthesis of a perbenzylated ethyl thioglucoside was undertaken.

\subsubsection{Synthesis of the Ethyl Thioglucoside Donor}

The ethyl thioglucoside 49 was synthesised in four steps from commercially available D-glucose (16a) in a manner similar to that for the phenyl derivative (Scheme 18). Accordingly, D-glucose (16a) was peracetylated and the thioethyl group introduced using EtSH, with $\mathrm{SnCl}_{4}$ as the Lewis acid. ${ }^{128}$ Although the procedure gave a mixture of $\alpha: \beta$ anomers, recrystallisation of the per-acetylated thioglucoside 53 using 3:1 petroleum ether : ethanol (v:v) resulted in the isolation of only the $\alpha$-thioglucoside $\mathbf{5 3 a}$, as determined by the ${ }^{1} \mathrm{H}$-NMR $J_{1,2}=5.6 \mathrm{~Hz}$. The $\alpha$-anomer of the glycosylation donor is desirable in order to ultimately form the $\alpha$-glycosylation product, as concluded by Kaeothip, et al.. ${ }^{124}$ This is because the $\alpha$ thioglycoside will form the $\beta$-glycosyl bromide in situ (via an $\mathrm{S}_{\mathrm{N}} 2$ reaction), which will then undergo a second $S_{N} 2$ reaction with the acceptor to give the desired $\alpha$ linked product. The $\beta$-thioglycoside, however, will form the much more stable $\alpha$-glycosyl bromide. The stability of the $\alpha$-bromide is such that it can be isolated and thus does not readily undergo an $\mathrm{S}_{\mathrm{N}} 2$ reaction with the acceptor. 


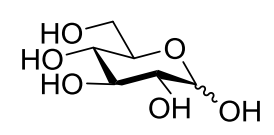

D-Glucose (16a)

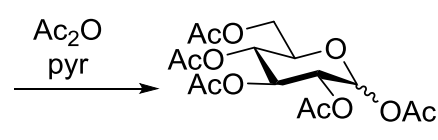

27

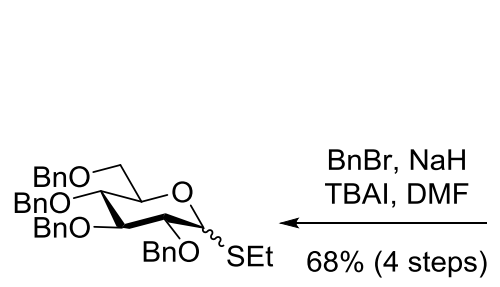

49

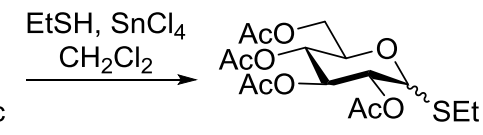

53

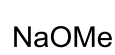

$\mathrm{MeOH}$

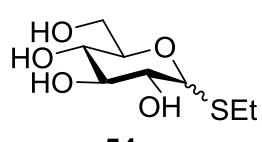

54

Scheme 18. Synthesis of the perbenzylated ethyl thioglucoside 49

The $\alpha$-thioglycoside donor could also be prepared through the anomerisation of per-acetylated $\beta$-thioglycoside $\mathbf{5 3 b}$ through the use of Lewis acids such as $\mathrm{SnCl}_{4}$ and $\mathrm{TiCl}_{4}{ }^{129}$ To this end, anomerisation was performed on the mother liquor containing $\beta$-thioglycoside $\mathbf{5 3 b}$ using $\mathrm{SnCl}_{4}$, which activates the thiol aglycon $(\mathbf{X})$ (Scheme 19) and establishes an equilibrium between the $\alpha$ - and $\beta$-anomers. ${ }^{130}$ Due to the inherent stability of the $\alpha$-thioglycoside compared to the $\beta$-thioglycoside, the anomerisation process will favour the formation of the $\alpha$-thioglycoside (Scheme 19). ${ }^{129}$ Indeed, the $\beta$-thioglycoside anomerisation process proved successful and allowed for an increase in $\alpha$-selectivity from 1:1.5 to $>20: 1, \alpha: \beta$. The $\alpha$ thioglycoside was then separated from the small amount of the $\beta$-anomer via silica gel flash column chromatography, where the $\alpha$-anomer elutes slightly before the $\beta$ product in $0.5 \%$ ethyl acetate in toluene despite the anomers both having the same $\mathrm{R}_{f}$ value (0.47 in 1:2.5 ethyl acetate: petroleum ether $\left.\mathrm{v}: \mathrm{v}\right)$ on TLC. The peracetylated $\alpha$-thioglucoside 53a was then de-acetylated under Zemplén conditions, ${ }^{131}$ followed by perbenzylation with $\mathrm{BnBr}, \mathrm{NaH}$ and $\mathrm{TBAI},{ }^{132}$ to give the target perbenzylated thioglycoside 49. 


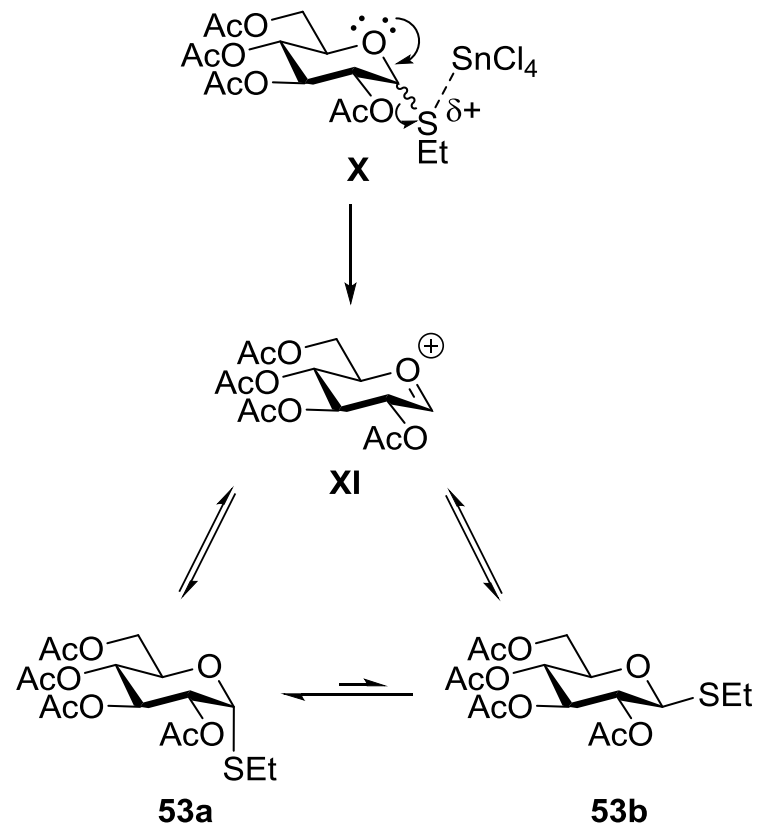

Scheme 19. $\mathrm{SnCl}_{4}$-mediated anomerisation between thioglucosides $\mathbf{5 3 a}$ and $\mathbf{5 3} \mathbf{b}$

\subsubsection{Bromide Activation}

Different bromine-containing activating agents were used for the glycosylation reactions of ethyl thioglucoside $\mathbf{4 9}$ to form the glycosyl bromide intermediate in situ (Table 3). First, donor 49 was reacted with azidopropanol 30 and $\mathrm{Br}_{2}$ in order to establish the difference between the thiophenyl and thioethyl donors. Indeed, the glycosylation reaction proceeded more readily, where TLC analysis after one hour showed complete disappearance of the donor 49. Following work-up and purification via silica gel column chromatography, a $73 \%$ yield was obtained, with a 2:1, $\alpha: \beta$ product ratio (Entry 1$)$. 
Table 5. Glycosylation reactions of ethyl thioglucoside $\mathbf{4 9}$ with alcohol $\mathbf{3 0}$

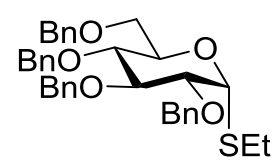

49

Et
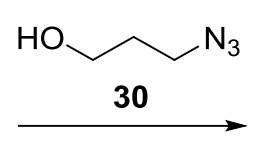

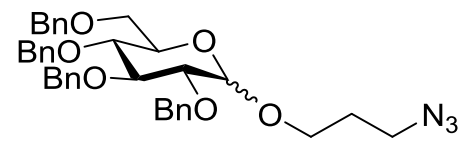

$14 a$

\begin{tabular}{lllllll} 
Entry & Activators (equiv.) & Solvent & Time & Temp & $\boldsymbol{\alpha}: \boldsymbol{\beta}$ & Yield \\
\hline 1 & $\mathrm{Br}_{2}(1.3)$ & $\mathrm{CH}_{2} \mathrm{Cl}_{2}$ & $1 \mathrm{~h}$ & $\mathrm{RT}$ & $2: 1$ & $73 \%$ \\
2 & $\mathrm{CuBr}_{2}(3), \mathrm{TPABr}(3)$ & $1: 2{\mathrm{DMF}: \mathrm{CH}_{2} \mathrm{Cl}_{2}}$ & $10 \mathrm{~d}$ & $\mathrm{RT}$ & $5: 1$ & $90 \%$ \\
3 & $\mathrm{CuBr}_{2}(3), \mathrm{TPABr}(3)$ & $1: 2{\mathrm{DMF}: \mathrm{CH}_{2} \mathrm{Cl}_{2}}$ & $3 \mathrm{~h}$ & $40{ }^{\circ} \mathrm{C}$ & $2.5: 1$ & $30 \%$ \\
4 & DMTST (3), TPABr (5) & $\mathrm{CH}_{2} \mathrm{Cl}_{2}$ & $10 \mathrm{~d}$ & $\mathrm{RT}$ & $7.5: 1$ & $35 \%$
\end{tabular}

Due to the high reactivity of the thioethyl donor 49 , milder bromination conditions were then explored. It has been previously reported that using $\mathrm{CuBr}_{2}$ in conjunction with $\mathrm{TPABr}$ as activating agents leads to the slower activation of thioglycosides, and that a good yield of the $\alpha$-product has been observed when using a per-benzylated donor. ${ }^{133}$ Little is known about the mechanism by which $\mathrm{CuBr}_{2} / \mathrm{TPABr}$ activate thioglucosides, though it is proposed that sulfur and copper, both being of similar softness, form a dative bond before the formation of the glycosyl bromide takes place. Due to the strength of this dative bond, the activation is slower, allowing for in situ anomerisation of the glycosyl bromide to occur before nucleophilic attack of the acceptor. A DMF : $\mathrm{CH}_{2} \mathrm{Cl}_{2}$ mixture was then used as the solvent to aid in solubility (Entry 2), and these conditions resulted in an improved yield and selectivity $(82 \%, 5: 1, \alpha: \beta)$. Disappointingly, when the reaction was heated to $40{ }^{\circ} \mathrm{C}$, a poor yield and $\alpha$-selectivity were obtained due to product degradation (Entry 3). DMTST, being a mild activator, was also used as a promoter in conjugation with TPABr to glycosylate the thioethyl donor 49 (Entry 4). Again, good $\alpha$-selectivity was achieved (7.5:1 $\alpha: \beta)$, albeit with a modest yield of $35 \%$. The reaction with DMTST was more difficult to keep dry due to the volatility of $\mathrm{CH}_{2} \mathrm{Cl}_{2}$ in combination with maintaining an argon atmosphere over the long reaction time. This led to increased donor hydrolysis and thus a lower yield. 
To understand more about the mechanism of the $\mathrm{CuBr}_{2} / \mathrm{TPABr}$-mediated glycosylation reaction, an anomeric mixture of thioglucoside 49 was prepared and subjected to the same glycosylation conditions with azidopropanol 30 (Scheme 20). Interestingly, a similar $\alpha: \beta$ selectivity (5:1) was achieved when starting with this epimeric mixture as compared to that obtained when using only the $\alpha$-anomer. This provides evidence for the in situ anomerisation mechanism taking place during the glycosylation reaction. Thus, an anomeric mixture of the donor 49 can be used for the $\mathrm{CuBr}_{2} / \mathrm{TPABr}$-mediated glycosylation reaction to obtain the $\alpha$-product, which improves the yield and efficiency of the overall synthesis.

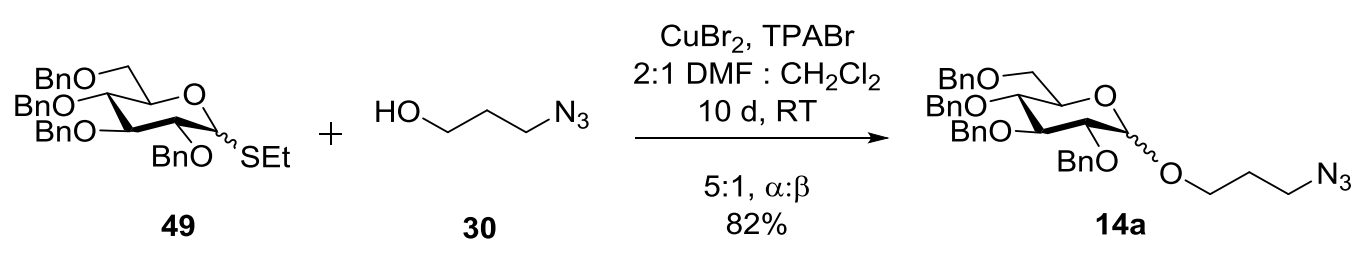

Scheme 20. Glycosylation of $\alpha / \beta$-thioethyl glucoside 49 with azidopropanol (30)

Satisfied with both the yield and ratio of the target glycoside 14a, the anomers were then separated using silica gel flash column chromatography. A slow elution gradient of ethyl acetate in toluene was required as both anomers have, what appears to be, the same $\mathrm{R}_{f}=0.30$ in 1:4 ethyl acetate : petroleum ether (v:v). The $\alpha$ anomer is eluted first with 1:200 ethyl acetate : toluene (v:v), followed closely by the $\beta$-anomer. While this method of anomeric separation is slow and somewhat laborious, on average, $90 \%$ of the total amount of the $\alpha$-product can be obtained in excellent purity, as illustrated by the ${ }^{1} \mathrm{H}-\mathrm{NMR}$ (Figure 14). Full characterisation of the target $\alpha$-glycoside was made using a combination of 2D NMR techniques, including HMBC which confirms the linkage between the anomeric centre and the linker (Figure 15). 


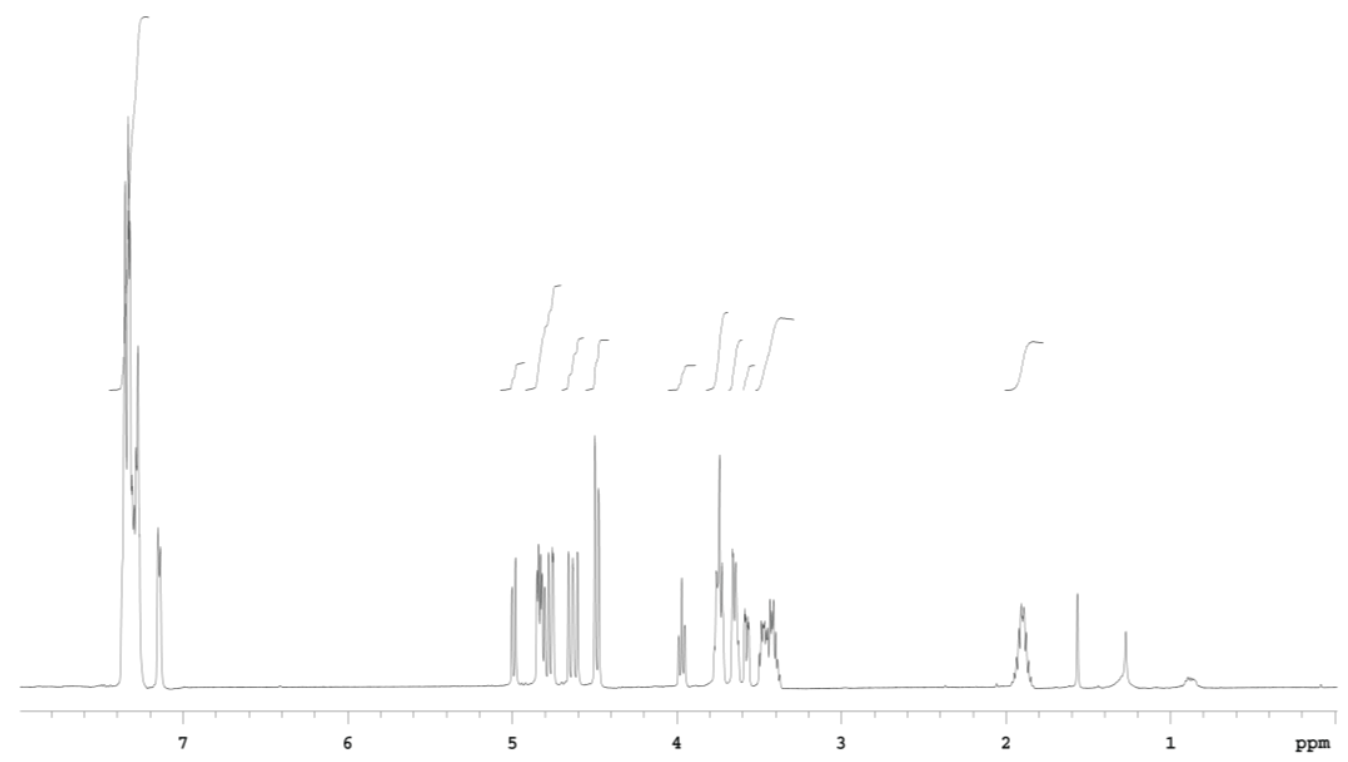

Figure 14. ${ }^{1} \mathrm{H}-\mathrm{NMR}$ spectrum $\left(500 \mathrm{MHz}, \mathrm{CDCl}_{3}\right)$ showing the presence of only the $\alpha$ glycosylation product.

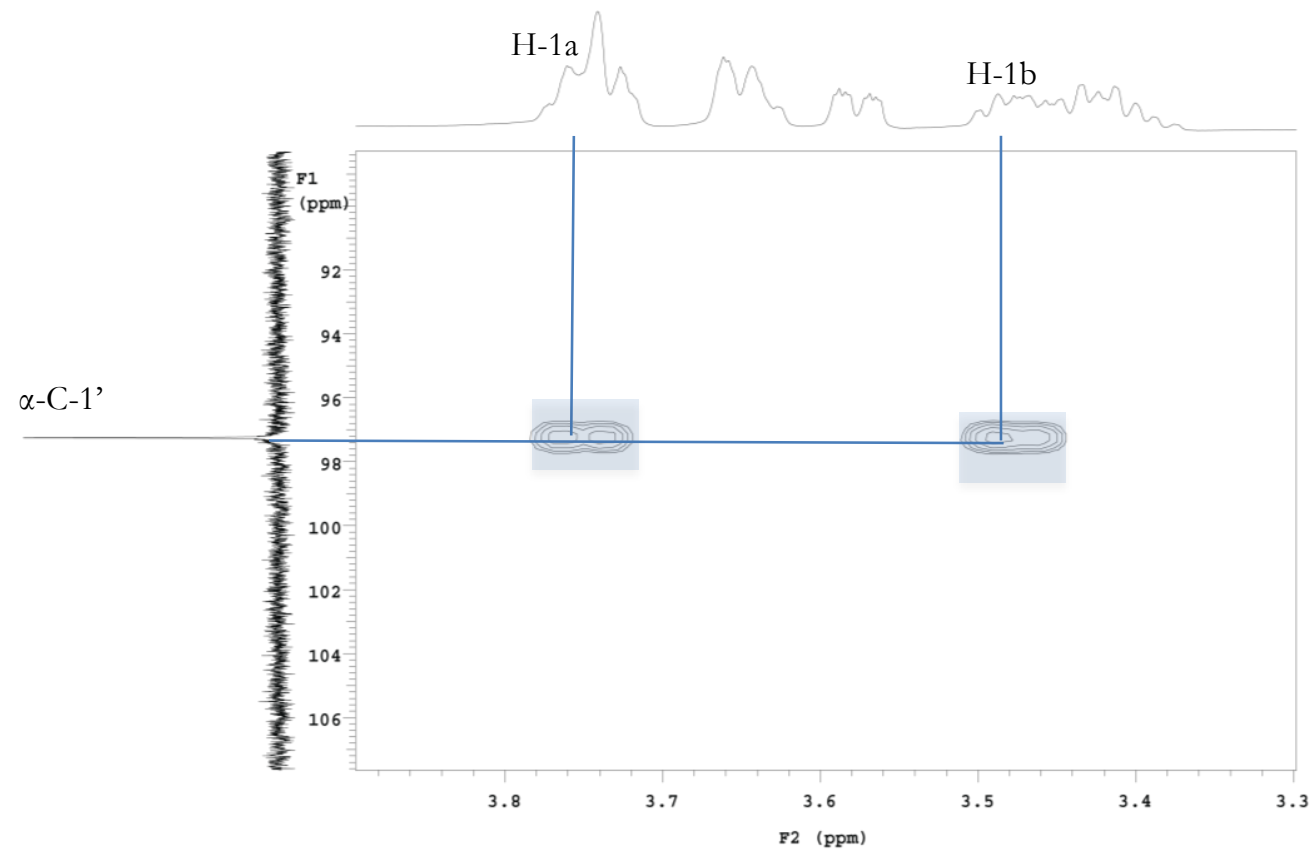

Figure 15. $\mathrm{HMBC}\left(500 \mathrm{MHz}, \mathrm{CDCl}_{3}\right)$ showing the interaction between the anomeric centre $\left(\alpha-\mathrm{C}-1^{\prime}\right)$ and the linker $(\mathrm{H}-1)$ in the glycosylation product $14 \mathrm{a}$ 


\subsubsection{Using Perbenzylated Thioethyl Maltose as Donor}

\subsubsection{Synthesis of the Perbenzylated Thioethyl Maltose}

With the synthetic strategy for the $\alpha$-linked glucoside established, the same reaction sequence was then applied to the synthesis of the second target glycan, the maltose disaccharide $14 b$. To this end, D-maltose (16b) was peracetylated using $\mathrm{NaOAc}$ in $\mathrm{Ac}_{2} \mathrm{O}^{134}$ to form maltose octaacetate 55, which was then reacted with EtSH and $\mathrm{SnCl}_{4}{ }^{135}$ to obtain the peracetylated thioglucoside 56. Deacetylation using Zemplén conditions ${ }^{131}$ provided the septaol $\mathbf{5 7}$, which was in turn subjected to benzylation conditions $(\mathrm{BnBr}, \mathrm{NaH}, \mathrm{TBAI})^{136}$ to obtain the perbenzylated thioethyl maltose donor $\mathbf{5 8}$ in $45 \%$ yield over the four steps (Scheme 21). The $\alpha: \beta$ mixture of donor 58 obtained was not a concern as the $\alpha$-selectivity of the subsequent glycosylation relies on the in situ anomerisation of the glycosyl bromide intermediate rather than the stereochemistry of the donor, as previously described for the monosaccharide derivative.
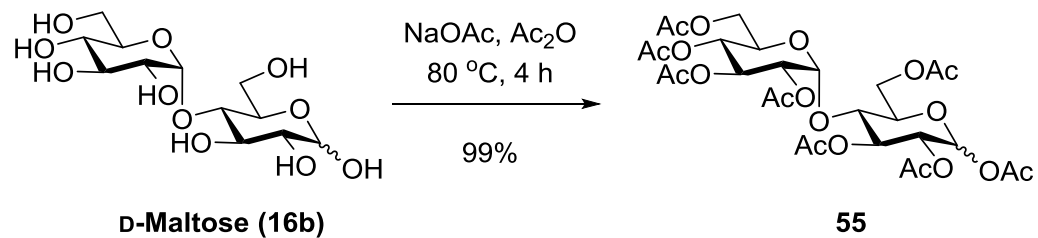

55

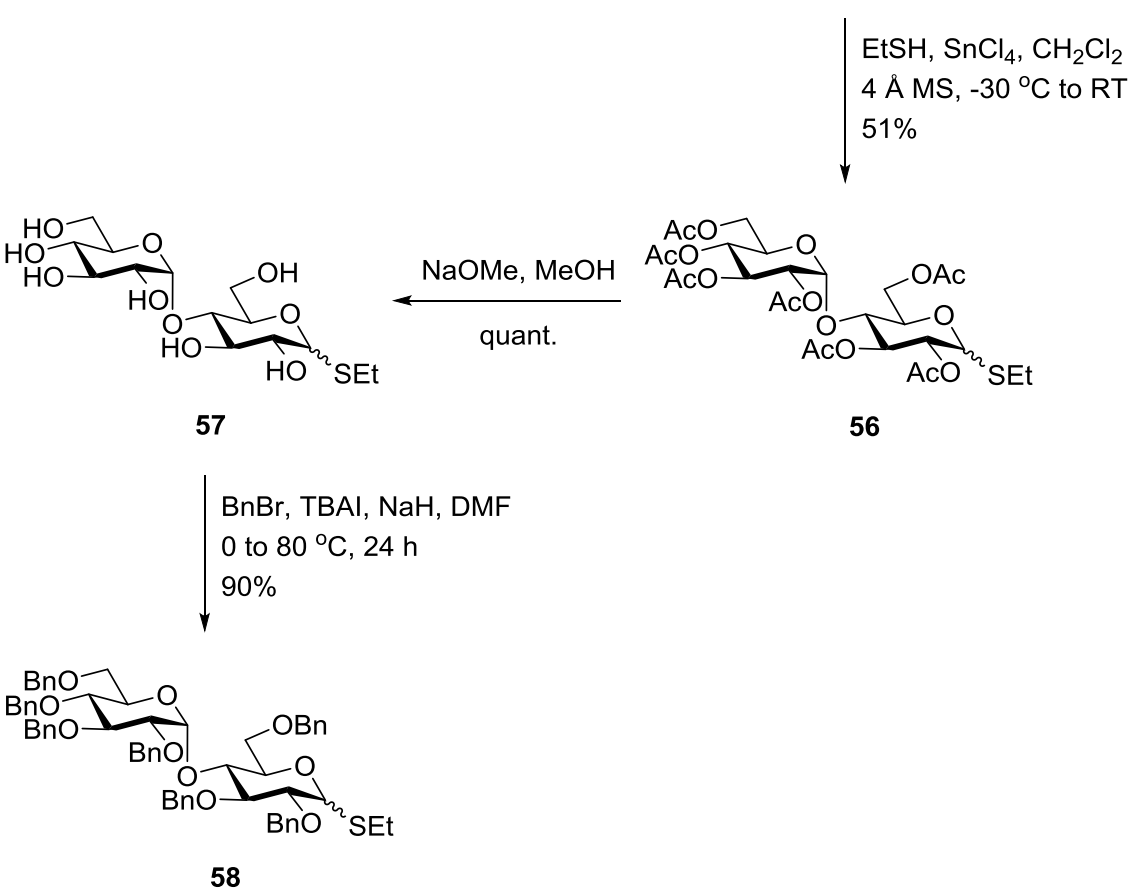

Scheme 21. Four-step synthesis of the perbenzylated thioethyl donor $\mathbf{5 8}$ 


\subsubsection{Bromide Activation}

With the disaccharide thioethyl donor $\mathbf{5 8}$ in hand, a glycosylation reaction was performed with acceptor 30 using $\mathrm{CuBr}_{2}$ and $\mathrm{TPABr}$ as activators in order to synthesise the target $\alpha$-linked disaccharide 14b (Table 6). First, the reaction of disaccharide $\mathbf{5 8}$ with 3-azidopropanol (30) was attempted using the same synthetic route for monosaccharide 57, whereby 3 equivalents each of $\mathrm{CuBr}_{2}$ and $\mathrm{TPABr}$ were added to the reaction vessel. However, after stirring at room temperature for ten days, TLC analysis showed the lack of donor activation and only a small amount of product. Additional activating agents ( 3 equiv. each) were then added, and the reaction was left to stir for a further nine days, after which time the solution was quenched as TLC analysis showed little change. Only a 12\% yield of product was isolated with $5: 1 \alpha: \beta$ selectivity (Entry 1 ). Subsequently, the reaction was repeated at reflux, which led to the degradation of reactants (Entry 2). To explore the effect of $\mathrm{TPABr}$ on both yield and selectivity, two reactions were conducted using either 3 equivalents or 8 equivalents of TPABr while keeping the amount of $\mathrm{CuBr}_{2}$ (5 equiv.) constant (Entries 3 and 4, respectively). As there was no change in either yield or selectivity with the varying amounts of $\mathrm{TPABr}$, it was concluded that a greater excess of bromide does not affect the equilibrium of glycosyl bromides in situ. Finally, an increased yield of 51\% was achieved when a higher concentration $\left(0.08 \mathrm{molL}^{-1}\right)$ of reactants was used (Entry 5). At this stage, this was sufficient to provide the $\alpha$-product for the next reaction, as most of the $\alpha$ anomer could be separated from the 5:1 $\alpha: \beta$ mixture using silica gel flash column chromatography (1:200, ethyl acetate : toluene, v:v), with the $\alpha$-product eluting first $\left(\mathrm{R}_{f}=0.40\right)$. It was envisioned that further increasing the concentration of the reaction mixture may lead to an improved yield, though unfortunately time constraints did not make this objective possible. Nonetheless, an efficient synthesis of the desired disaccharide 14b was developed, and the target disaccharide could be obtained in excellent purity, as illustrated by the ${ }^{1} \mathrm{H}-\mathrm{NMR}$ (Figure 16). Again, full characterisation of disaccharide $\mathbf{1 4 b} \mathrm{b}$ was performed, with the linkage between the anomeric centre and the linker confirmed using HMBC (Figure 17). 
Table 6. Glycosylation reactions of disaccharide 58 and 3-azidopropanol (30)
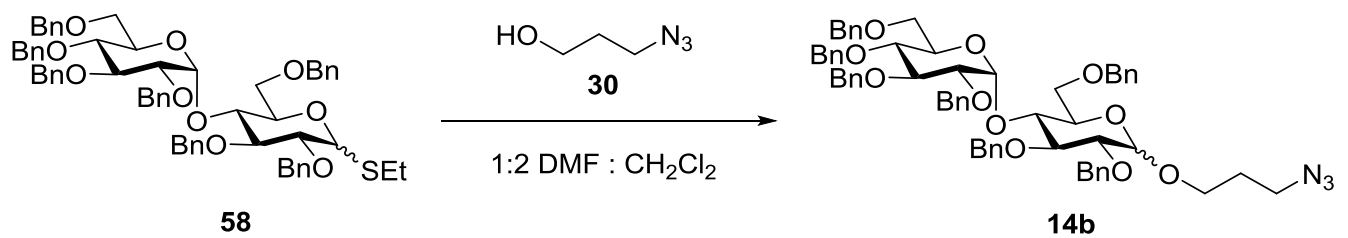

\begin{tabular}{lllllll} 
Entry & Activators (equiv.) & Concentration & Time & Temp & $\alpha: \beta$ & Yield \\
\hline 1 & $\mathrm{CuBr}_{2}(6), \mathrm{TPABr}(6)$ & $0.03 \mathrm{molL}^{-1}$ & $19 \mathrm{~d}$ & $\mathrm{RT}$ & $5: 1$ & $12 \%$ \\
2 & $\mathrm{CuBr}_{2}(3), \mathrm{TPABr}(3)$ & $0.03 \mathrm{molL}^{-1}$ & $10 \mathrm{~h}$ & $110{ }^{\circ} \mathrm{C}$ & - & $0 \%$ \\
3 & $\mathrm{CuBr}_{2}(5), \mathrm{TPABr}(3)$ & $0.03 \mathrm{molL}^{-1}$ & $10 \mathrm{~d}$ & $\mathrm{RT}$ & $5: 1$ & $18 \%$ \\
4 & $\mathrm{CuBr}_{2}(5), \mathrm{TPABr}(8)$ & $0.03 \mathrm{molL}^{-1}$ & $10 \mathrm{~d}$ & $\mathrm{RT}$ & $5: 1$ & $10 \%$ \\
5 & $\mathrm{CuBr}_{2}(3), \mathrm{TPABr}(3)$ & $0.08 \mathrm{molL}^{-1}$ & $10 \mathrm{~d}$ & $\mathrm{RT}$ & $5: 1$ & $51 \%$
\end{tabular}

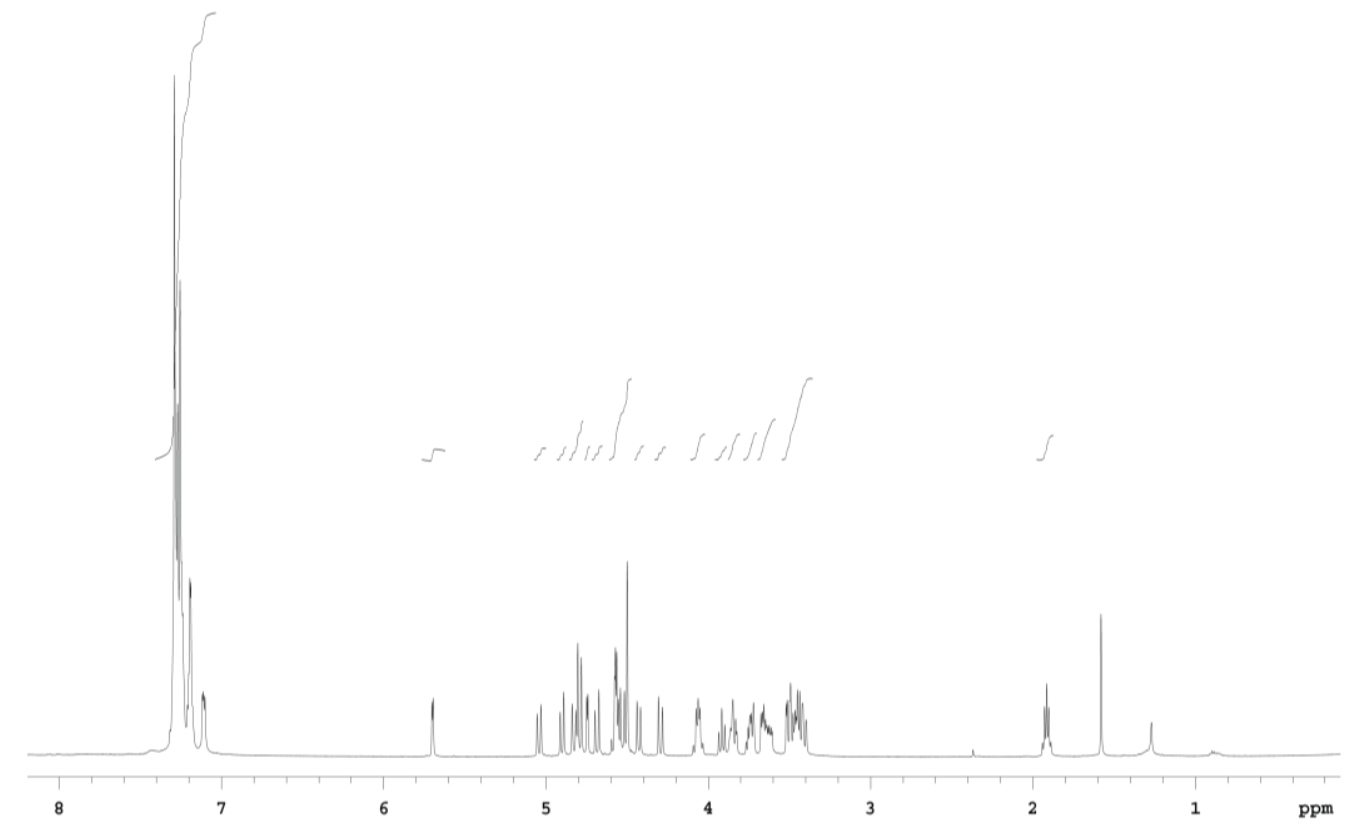

Figure 16. ${ }^{1} \mathrm{H}-\mathrm{NMR}\left(500 \mathrm{MHz}, \mathrm{CDCl}_{3}\right)$ spectrum showing the presence of only the $\alpha$-glycosylation product. 


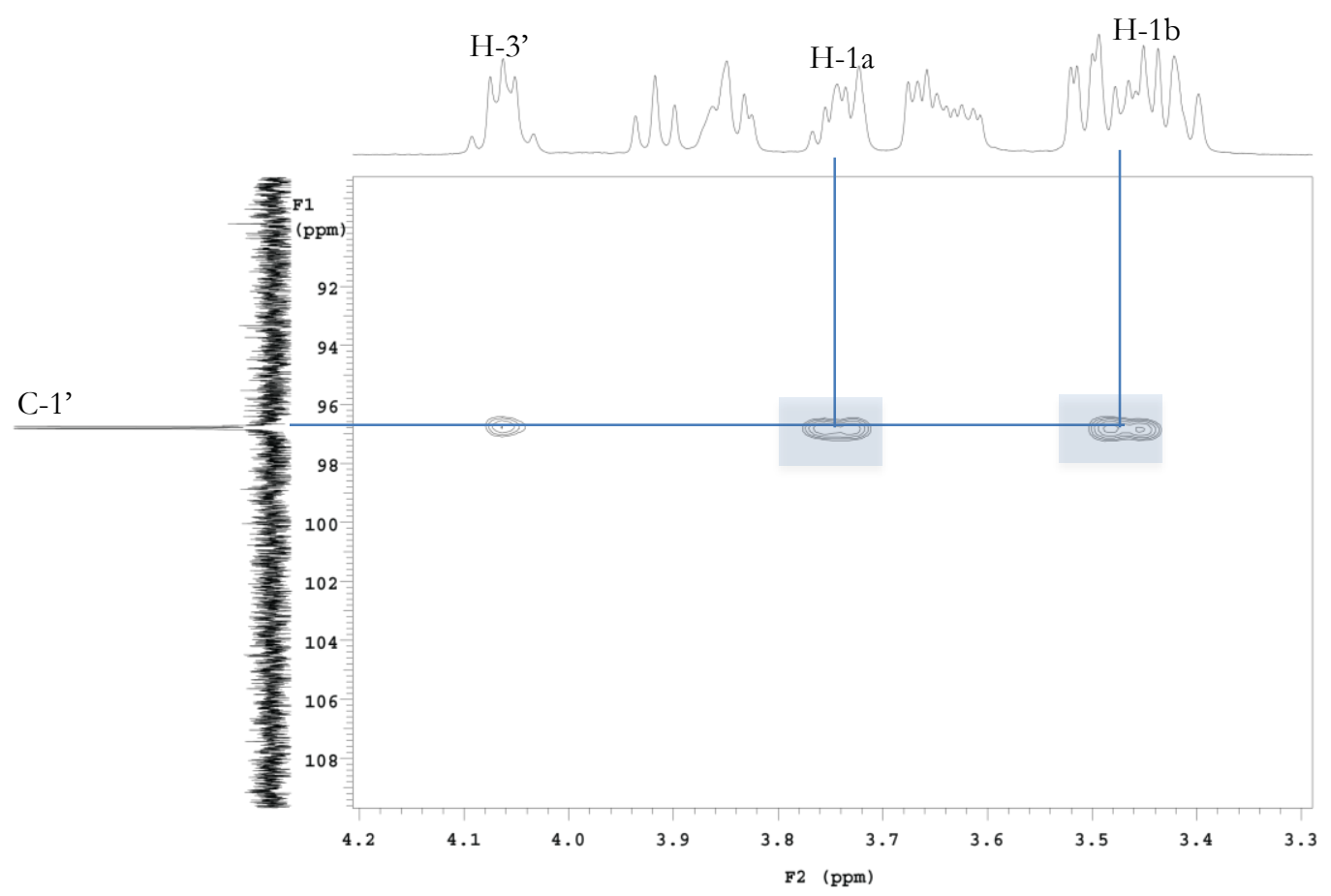

Figure 17. $\mathrm{HMBC}\left(500 \mathrm{MHz}, \mathrm{CDCl}_{3}\right)$ showing the linkage between the anomeric centre and $\mathrm{H}-1$ of the linker in the glycosylation product $\mathbf{1 4 b}$

\subsubsection{The Synthesis of Biotinylated Glycosides}

\subsubsection{Deprotection of $\alpha$-Glycosides}

The global deprotection of $\alpha$-linked saccharide $14 \mathrm{a}$ and disaccharide $14 \mathrm{~b}$ was then achieved using $\mathrm{Pd}(\mathrm{OH})_{2} / \mathrm{C}$-catalysed hydrogenation to remove the benzyl ether protecting groups while simultaneously reducing the azide to an amine to form the $\alpha$-linked glycosides 19a and 19b (Scheme 22). The progress of the reaction could be readily monitored via TLC analysis, whereby remaining benzyl groups could be detected under UV light and the presence of amine was visualised using the ninhydrin stain. ${ }^{137}$ For both $\alpha$-linked mono- and disaccharide $14 \mathrm{a}$ and $\mathbf{1 4 b}$, the hydrogenation occurred quantitatively overnight in $3: 2 \mathrm{CHCl}_{3}: \mathrm{MeOH}$ to give the fully deprotected glycosides 19a and 19b, respectively, which were purified using $C_{8}$ reverse phase chromatography. In terms of characterisation, the characteristic azide asymmetric stretch at $2108 \mathrm{~cm}^{-1}$ in the IR spectra ${ }^{138}$ of protected sugars $14 \mathbf{a}$ and 14b was absent for the deprotected adducts 19a and 19b, replaced instead by stretches at $1634 \mathrm{~cm}^{-1}$, characteristic of N-H bending ${ }^{139}$ and N-H stretching and O- 
$\mathrm{H}$ stretching both under a broad peak between 3500 and $3000 \mathrm{~cm}^{-1}$. The ${ }^{1} \mathrm{H}-\mathrm{NMR}$ spectra for both 19a and 19b also lacked aromatic protons, typically found around $7 \mathrm{ppm}$, and the ring protons shifted upfield from between 4 and $5 \mathrm{ppm}$ in the perbenzylated glycosides to between 3 and $4 \mathrm{ppm}$ in the fully deprotected adducts. Finally, it should be noted that time constraints did not allow for a similar sequence of reaction methodologies to be used for the synthesis of the additional target glycan, the trisaccharide 19c.

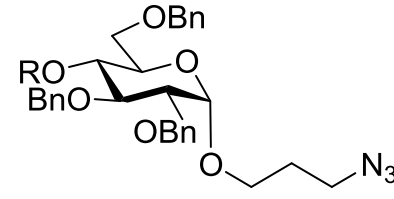

$\mathrm{Pd}(\mathrm{OH})_{2} / \mathrm{C}, \mathrm{H}_{2}$

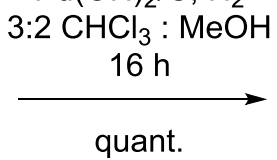

$14 a-b$

$14 a, R=B n$

14b, $R=\alpha-B n_{4}-G l c$

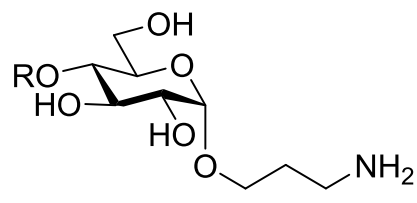

$19 a-b$

19a, $\mathrm{R}=\mathrm{H}$

$19 b, R=\alpha-G l c$

Scheme 22. Global deprotection of $\alpha$-linked glucosides $14 a$ and $14 b$

\subsubsection{Coupling of Linear Saccharides with D-Biotin}

Having prepared the deprotected $\alpha$-linked glucosides $19 \mathbf{a}$ and $\mathbf{1 9} \mathbf{b}$, the synthesis of the target biotin-linked saccharides was undertaken (Scheme 23). The coupling reaction between the amino group of $19 a$ or $19 b$ and the carboxylic acid moiety of D-Biotin (15) was achieved using the coupling reagent O-(Benzotriazol-1-yl)N,N,N',N'-tetramethyluronium hexafluorophosphate (HBTU). HBTU assists in the formation of an amide bond between a carboxylic acid (59) and an amine (60) by converting the carboxylic acid into an active ester benzotriazole (XIV) (Scheme 24). ${ }^{140,141}$ Following deprotonation by triethylamine, the resulting carboxylate anion (XII) performs a nucleophilic attack on the urea of HBTU to form uronium ion XIII. Uronium XIII can then be substituted by a hydroxybenzotriazole to form exter XIV. Now bearing a good leaving group, the activated ester could then undergo a nucleophilic attack by the amine $\mathbf{6 0}$, cleaving the $\mathrm{C}-\mathrm{O}$ bond and forming the desired amide (61) along with by-products 1-hydroxy-benzotriazole (HOBt) and tetramethyl urea. 


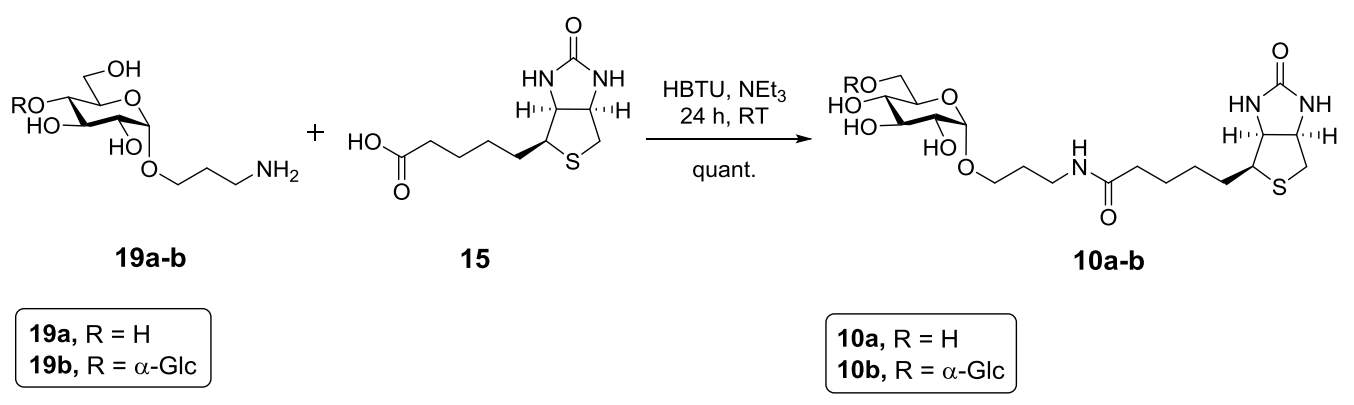

Scheme 23. Coupling reaction between the fully deprotected $\alpha$-glucosides $19 a-b$ with DBiotin (15) to form target glucosides 10a-b

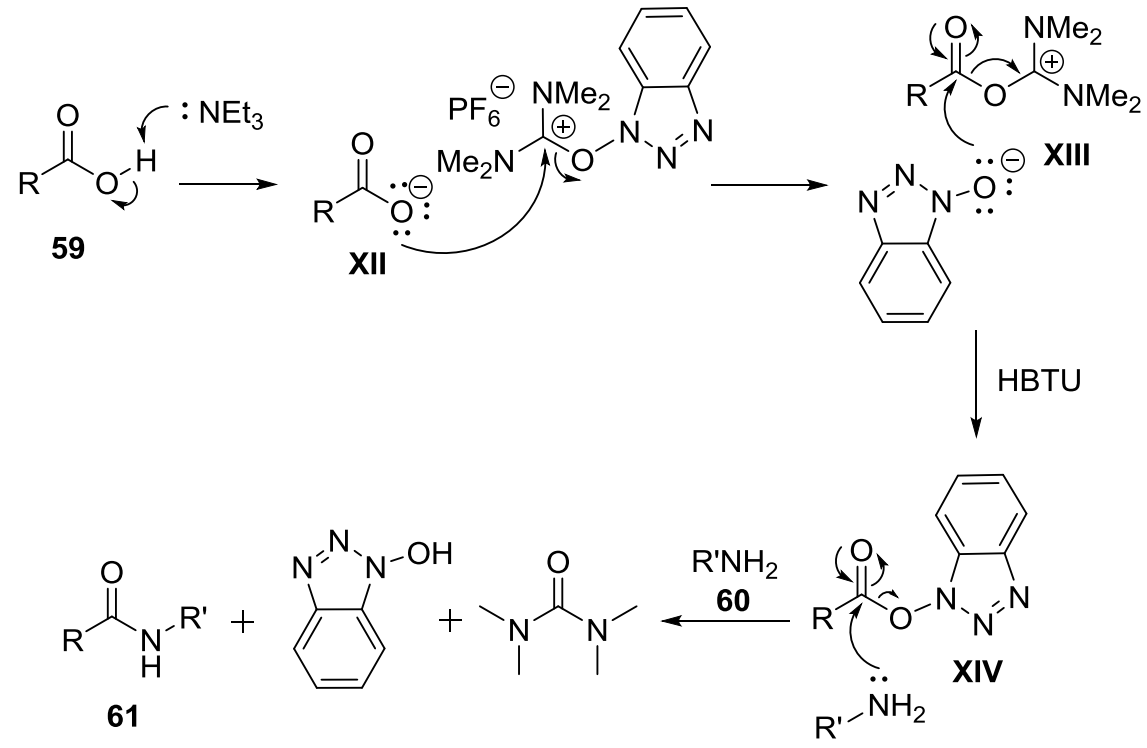

Scheme 24. Mechanism of HBTU peptide coupling ${ }^{140}$

The coupling reaction proceeded smoothly over $16 \mathrm{~h}$ to produce the target saccharides $10 \mathrm{a}$ and $10 \mathrm{~b}$ quantitatively. The presence of the product could be visualised on TLC by exposing the plate to $\mathrm{I}_{2}$ as well as acid $\left(10 \% \mathrm{H}_{2} \mathrm{SO}_{4}\right.$ in $\left.\mathrm{EtOH}\right)$ $\left(\mathrm{R}_{f}=0.29,6: 2: 2: 1, \mathrm{CH}_{2} \mathrm{Cl}_{2}: \mathrm{MeOH}: \mathrm{EtOH}: \mathrm{NH}_{3}(35 \%)\right.$, v:v:v:v). As $\mathrm{I}_{2}$ can be used to visualise sulfide-containing molecules, it also shows the presence of excess D-Biotin (15) in the reaction mixture, though it can be easily distinguished from the product spot as D-Biotin (15) does not appear as a spot when the TLC plate is charred with acid. TLC analysis was also used to detect the by-product HOBt (69), which appeared as a higher running product $\left(\mathrm{R}_{f}=0.74,6: 2: 2: 1, \mathrm{CH}_{2} \mathrm{Cl}_{2}: \mathrm{MeOH}\right.$ : EtOH : $\mathrm{NH}_{3}(35 \%)$, v:v:v:v) under UV light. The products were isolated using silica gel flash chromatography $\left(\mathrm{CH}_{2} \mathrm{Cl}_{2} \rightarrow\right.$ 5:2:2:1 $\mathrm{CH}_{2} \mathrm{Cl}_{2}: \mathrm{EtOH}: \mathrm{MeOH}: \mathrm{NH}_{3}$ 
(35\%)), followed by Sephadex ${ }^{\circledR}$ LH-20 size exclusion column chromatography (eluted with 1:1 $\mathrm{CH}_{2} \mathrm{Cl}_{2}: \mathrm{MeOH}, \mathrm{v}: \mathrm{v}$ ) to separate the products from the smaller compounds such as tetramethyl urea and excess D-Biotin (15). Successful coupling to biotin was confirmed by an HMBC between the carbonyl carbon of biotin and the protons at the end of the linker in both 10a (Figure 18) and 10b (Figure 19).

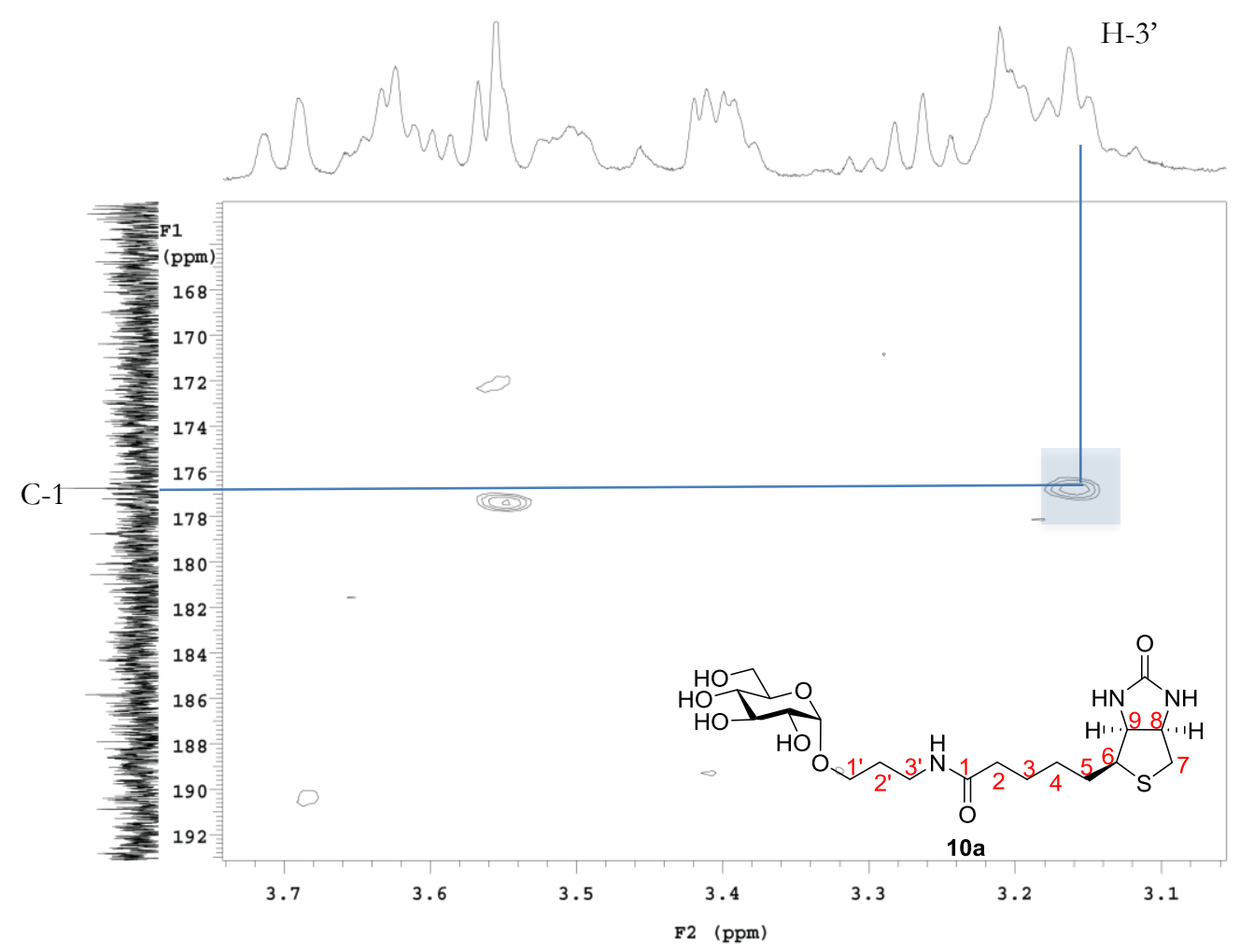

Figure 18. $\mathrm{HMBC}\left(500 \mathrm{MHz}, \mathrm{D}_{2} \mathrm{O}\right)$ showing the interaction between $\mathrm{H}-3^{\prime}$ and $\mathrm{C}-1$ in coupled product 10a 


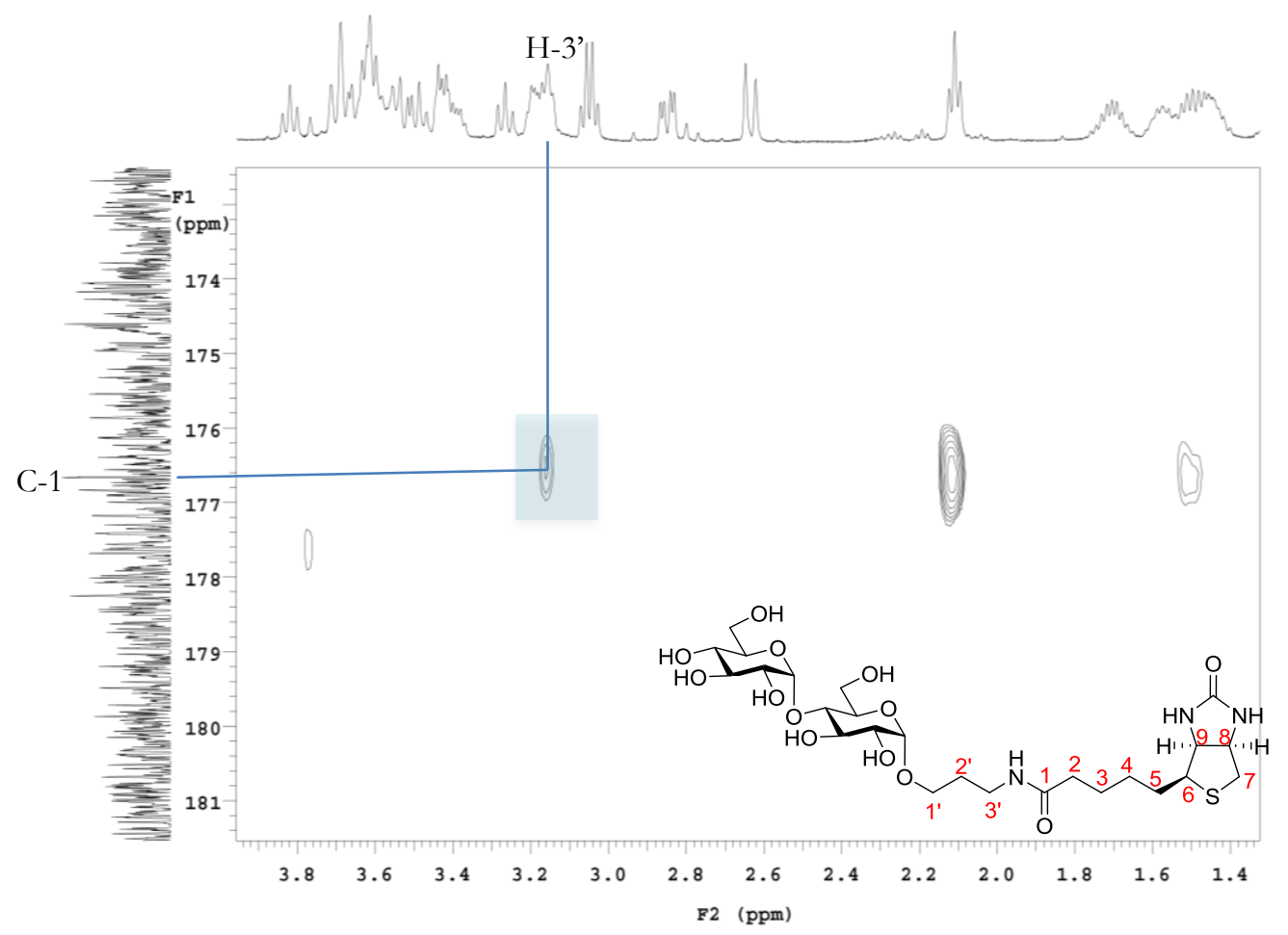

Figure 19. $\mathrm{HMBC}\left(500 \mathrm{MHz}, \mathrm{D}_{2} \mathrm{O}\right)$ showing the interaction between $\mathrm{C}-1$ and $\mathrm{H}-3^{\prime}$ in the coupled product $\mathbf{1 0 b}$.

\subsection{The Synthesis of Branched Glycosides}

\subsubsection{Dendron Synthesis}

To synthesise a glycodendron for multivalent binding in a biological context, a bifunctional dendron first needed to be prepared. There are different strategies that can be employed when preparing multivalent structures. One such strategy is the most widely used in industry, the divergent method, where the dendron assembly begins at the core, followed by radial addition of monomers. ${ }^{89}$ Poly (amido amine) (PAMAM) dendrimers, the most commonly synthesised dendrimers, are assembled using this strategy at industrial scales (Scheme 25). ${ }^{89,142,143}$ Typically, the dendritic core bears a primary amine functionality (62) which can undergo alkylation via Michael addition with methyl acrylate. The methyl ester $\mathbf{6 3}$ can then form an amide (64) through nucleophilic attack by an amine such as ethylenediamine. The alkylation and amidation steps are then repeated to form the first generation dendrimer $65 .{ }^{142,143}$ 

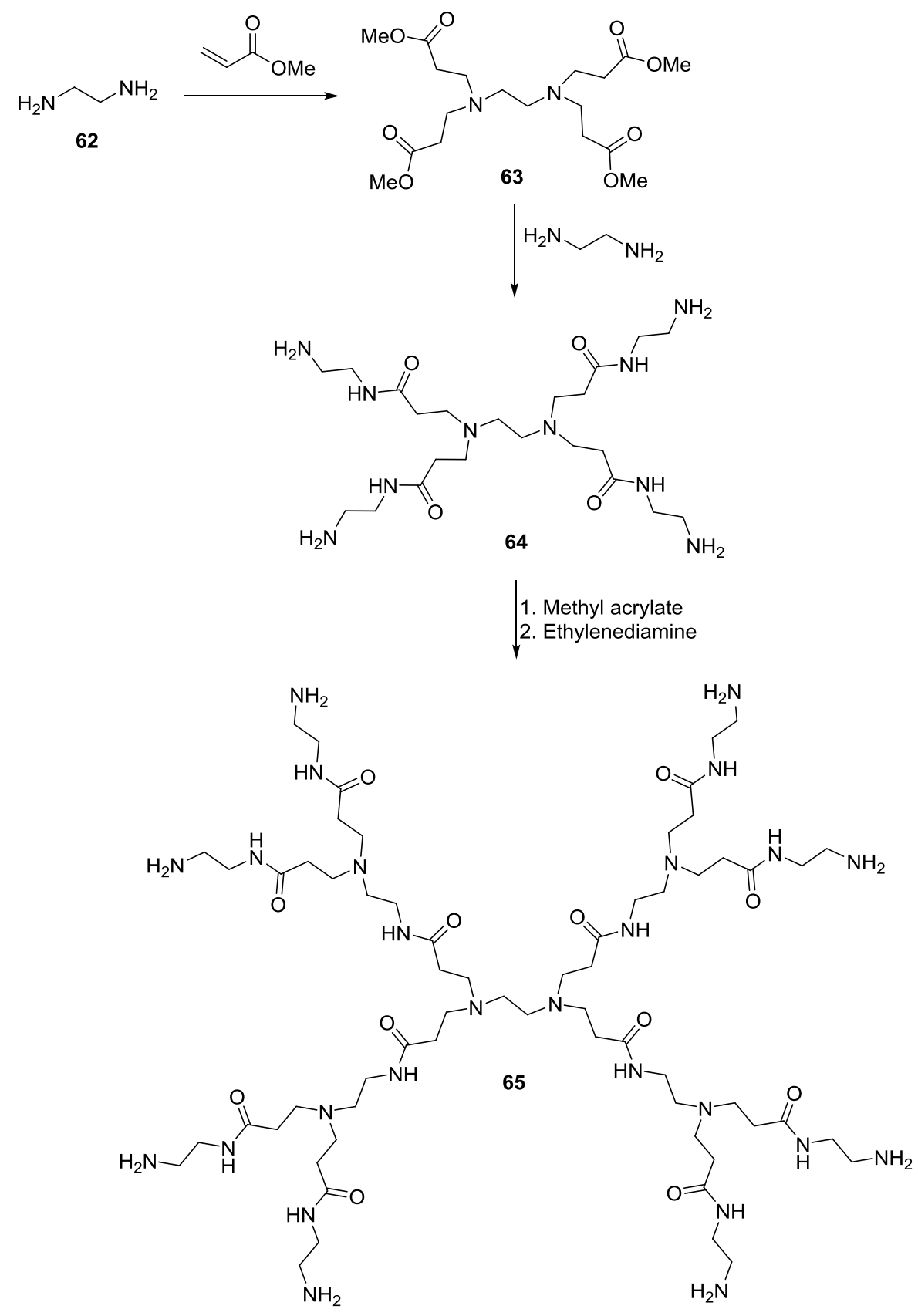

Scheme 25. The synthetic route of a first-generation PAMAM dendron $(65)^{143}$

Although the divergent method is well established, the method requires difficult purification through chromatography as well as excessive monomer loadings. Furthermore, any incomplete reaction will greatly affect the subsequent generations, leading to imperfections and discontinued sequences in the dendrimer as a whole. ${ }^{89}$ An alternative method is the convergent method, where the assembly of the dendrimer begins at the periphery, or the surface, of the dendrimer, building 
instead towards the dendrimer core. ${ }^{89,142,144}$ Here, only a small number of reactive sites are available at each step, which limits the amount of possible side reactions as well as avoids the requirement of excessive monomer loading. The purification, however, is still a problem with this strategy as the products become increasingly more similar to the reactants as the dendrimer grows larger. ${ }^{89}$ Nonetheless, Fréchet et al. demonstrated the potential of this synthetic strategy in the successful preparation of polyether dendritic structures (Scheme 26). ${ }^{144}$ Here, bromide 66 bears the benzyl groups which will ultimately form the surface of the resulting dendrimer while the bromide is the reactive centre. Two equivalents of the bromide (66) then react with triol 67, which act as the core of the resulting first generation dendron 68 . The process is then repeated as the dendron grows towards the core by converting the alcohol functionality of 68 into a bromide (69) for subsequent coupling.

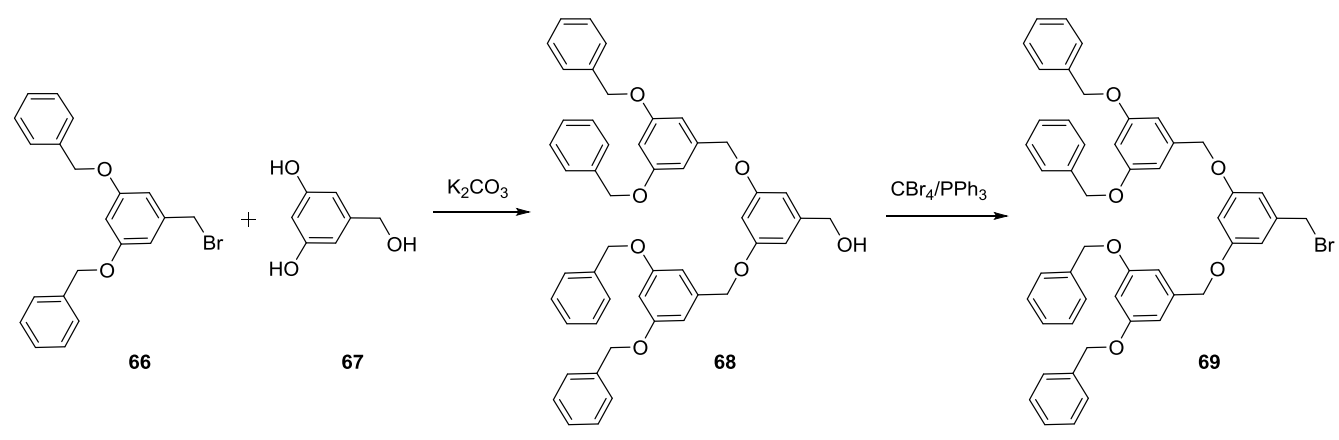

Scheme 26. Synthesis of a polyether dendritic structure 69 via a convergent method ${ }^{144}$

For the purpose of this project, I followed a synthetic strategy developed by a $\mathrm{PhD}$ student in our research lab, Stefan Munneke. ${ }^{145}$ The strategy of the glycodendron involves both the divergent and convergent methods, in a strategy known as the double exponential method. ${ }^{89}$ Here, a second generation dendron was prepared by the addition of one first generation dendron to another in a synthetic strategy. First, the commercially available bromoacetic acid (23) undergoes a substitution reaction with sodium azide in water to give azidoacetic acid (70) (Scheme 27). ${ }^{146} \mathrm{~A}$ dicyclohexyl carbodiimide (DCC)-mediated esterification reaction with $\mathrm{N}$-hydroxy succinimide (NHS) then converted the acid $\mathbf{7 0}$ into the NHS ester $\mathbf{7 1}$. Being an excellent leaving group, the NHS functional group could then be substituted for TRIS under basic conditions to give the triol 72 in $63 \%$ yield over the three steps. Successful instalment of TRIS was confirmed by the two resonances in the ${ }^{1} \mathrm{H}$ - 
NMR spectrum with integral ratios of 2:6 for the $\mathrm{CH}_{2}-\mathrm{N}_{3}$ and $\mathrm{CH}_{2}$-TRIS protons. The presence of the azide group was evident in the IR spectrum with a peak at $2104 \mathrm{~cm}^{-1}$ characteristic of asymmetric azide stretches. ${ }^{138}$

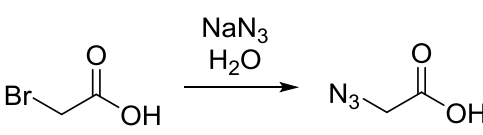

23
70<smiles>CC(C)(C)OC(=O)COCC(COCC(=O)OC(C)(C)C)(COCC(=O)OC(C)(C)C)NC(=O)CN</smiles><smiles>CC(C)(C)OC(=O)CBr</smiles>

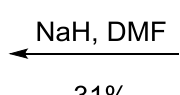<smiles>[NH]CC(=O)ON1C(=O)CCC1=O</smiles>

71

TRIS, $\mathrm{NEt}_{3}$

DMF

$63 \%, 3$ steps

22

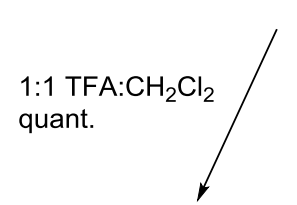

$\left\{\begin{array}{l}\mathrm{PPh}_{3} \\ \text { 3:1:1 MeOH: } \mathrm{H}_{2} \mathrm{O}: \mathrm{CH}_{2} \mathrm{Cl}_{2} \\ \text { quant. }\end{array}\right.$<smiles>[N]CC(=O)NC(COCC(=O)O)(COCC(=O)O)COCC(=O)O</smiles>

20<smiles>CC(C)(C)OC(=O)COCC(COCC(=O)OC(C)(C)C)(NC(=O)CN)OCC(=O)OC(C)(C)C</smiles>

21

Scheme 27. Synthesis of first generation dendrons $\mathbf{2 0}$ and $\mathbf{2 1}$

Subsequent deprotonation of the hydroxyl groups on amide $\mathbf{7 2}$ by $\mathrm{NaH}$ allows for alkylation with tert-butyl bromoacetic acid to give the ester and common intermediate 22 . The reaction was monitored by mass spectrometry $(\mathrm{m} / \mathrm{z}$ calcd. for $\left[\mathrm{C}_{24} \mathrm{H}_{42} \mathrm{~N}_{4} \mathrm{O}_{10}+\mathrm{H}\right]^{+}:$547.2974; obsd.: 547.2984) to ensure that full alkylation had taken place before quenching the reaction. In this case, TLC analysis was not used as the product did not stain well with any of the stains and due to streaking of the 
product on TLC. Purification by silica gel flash column chromatography (5:1, petroleum ether : ethyl acetate, $\mathrm{v}: \mathrm{v})$, followed by $\mathrm{C}_{18}$ reverse phase chromatography then resulted in the protected intermediate 22 , albeit in a modest $31 \%$ yield. However, sufficient material was obtained and in the interests of time, the next steps of the synthetic sequence were explored.

Having made the common intermediate 22, it was then either hydrolysed or reduced to give $\mathbf{2 0}$ and $\mathbf{2 1}$, respectively. The tert-butyl deprotection of $\mathbf{2 2}$ proceeded smoothly by dissolving it in a 1:1 mixture of freshly distilled trifluoroacetic acid (TFA) and $\mathrm{CH}_{2} \mathrm{Cl}_{2}$ and leaving the reaction to stir for $16 \mathrm{~h}$ at room temperature, forming the triacid $\mathbf{2 0}$ quantitatively. Again, the reaction progress could be readily monitored by mass spectrometry rather than TLC analysis due to poor staining. Triacid 20 was purified using $\mathrm{C}_{18}$ reverse phase chromatography $(1: 10, \mathrm{MeOH}$ : $\mathrm{H}_{2} \mathrm{O}$, v:v), with HRMS (m/z calcd. for $\left[\mathrm{C}_{12} \mathrm{H}_{18} \mathrm{~N}_{4} \mathrm{O}_{10}+\mathrm{H}\right]^{+}:$379.1096; obsd.: 379.1076) as well as ${ }^{1} \mathrm{H}-\mathrm{NMR}$ analysis confirming the formation of the desired product, showing a 6:2:6 ratio of $\mathrm{CH}_{2}$ protons 5,1 , and 4 , respectively (Figure 20).

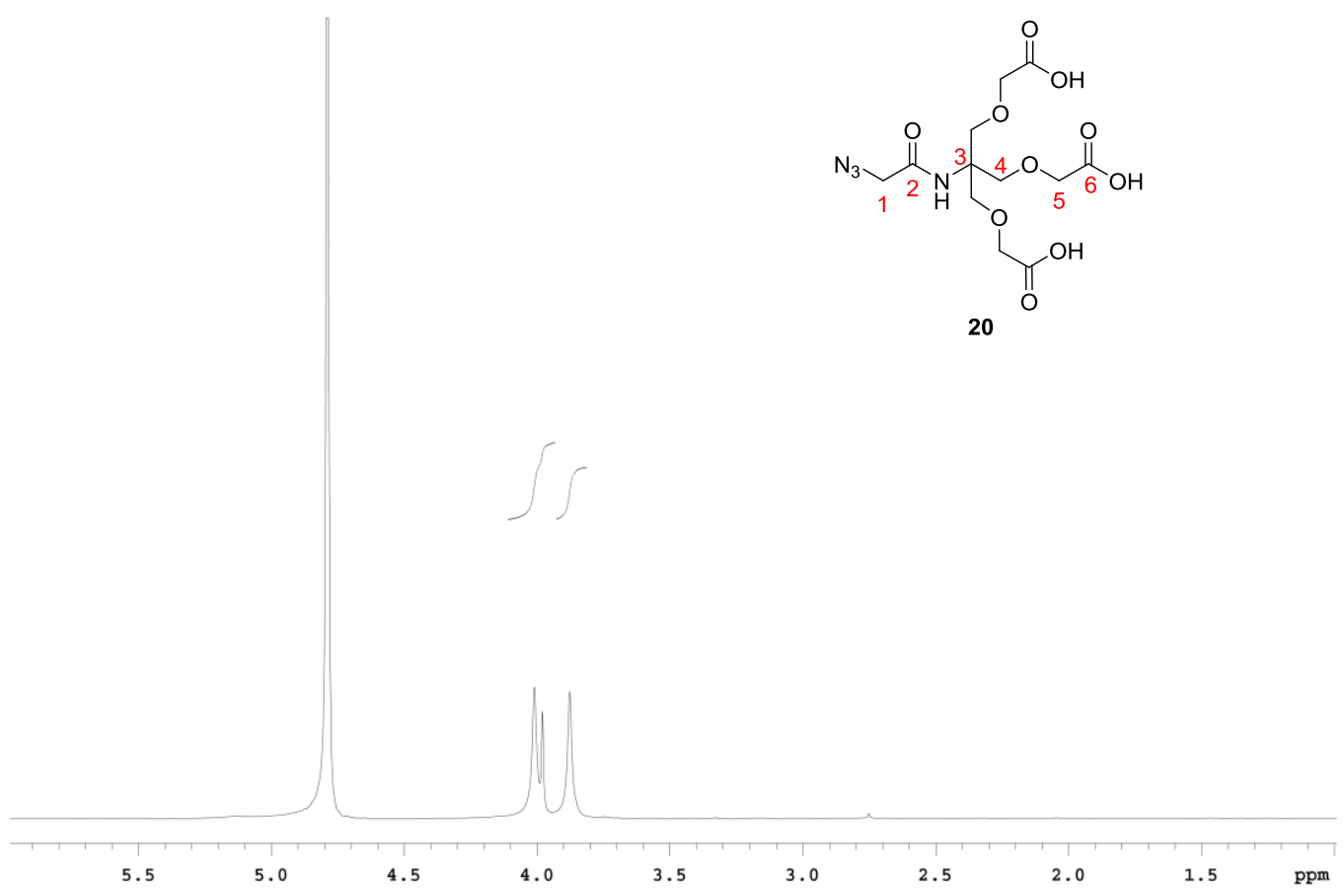

Figure 20. ${ }^{1} \mathrm{H}-\mathrm{NMR}\left(500 \mathrm{MHz}, \mathrm{D}_{2} \mathrm{O}\right)$ spectrum of 20 showing protons $\mathrm{H}-5, \mathrm{H}-1$, and $\mathrm{H}-4$ in a 6:2:6 ratio 
The conversion of the azide group into an amino group on the dendron core $\mathbf{2 1}$ was carried out under Staudinger reduction conditions. ${ }^{147}$ Here, $\mathrm{PPh}_{3}$ reduces the azide group via the formation of a four-membered intermediate XVI (via XV) that subsequently breaks down with concomitant ejection of $\mathrm{N}_{2}$ (Scheme 28). The resulting phosphazene (XVII) is then hydrolysed, forming triphenylphosphine oxide and the target amine. ${ }^{148}$ Again, the formation of the amine was confirmed by mass spectrometry (m/ ₹ calcd. for $\left[\mathrm{C}_{24} \mathrm{H}_{44} \mathrm{~N}_{2} \mathrm{O}_{10}+\mathrm{H}^{+}\right]$: 521.3069, obsd.: 521.3071 .

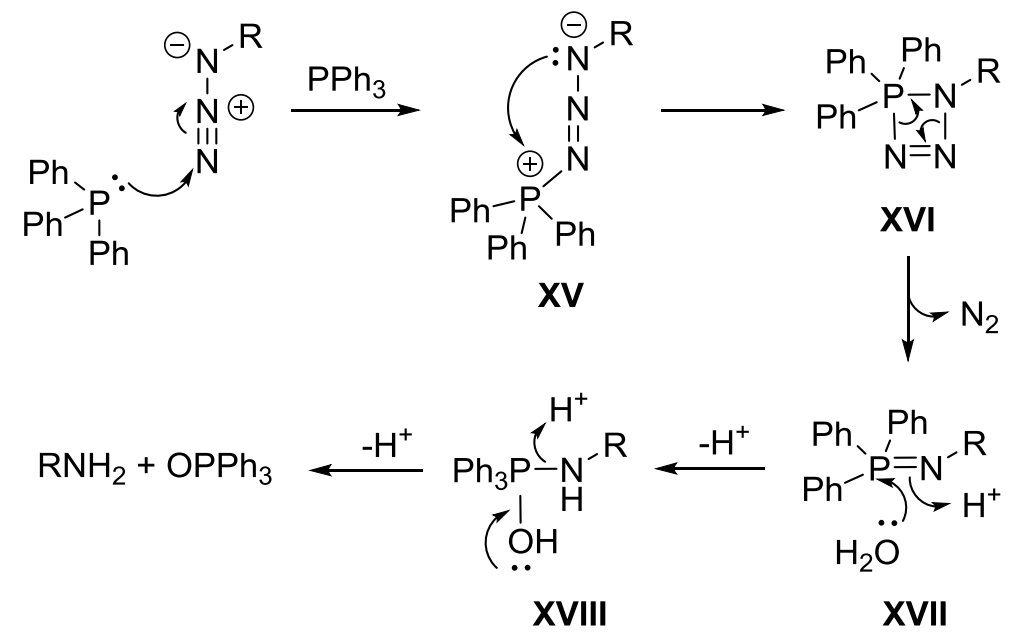

Scheme 28. Mechanism of the Staudinger reduction of azides ${ }^{148}$

With the two first generation dendrons (20 and 21) in hand, the formation of second generation dendron 18 was undertaken (Scheme 29). Again, HBTU was used as the coupling reagent to form the amide bond between the carboxylic acid functionalities in $\mathbf{2 0}$ with the amine moiety in $\mathbf{2 1}$. Successful coupling was seen by mass spectrometry $\left(m / z\right.$ calcd. for $\left[\mathrm{C}_{84} \mathrm{H}_{144} \mathrm{~N}_{10} \mathrm{O}_{37}+\mathrm{H}^{+}\right]$: 1885.9767, obsd.: 1885.9772), and the product (18) was purified using $C_{18}$ reverse phase chromatography. 
<smiles>CC(C)(C)OC(=O)COCC(COCC(=O)OC(C)(C)C)(COCC(=O)OC(C)(C)C)NC(=O)CN</smiles>

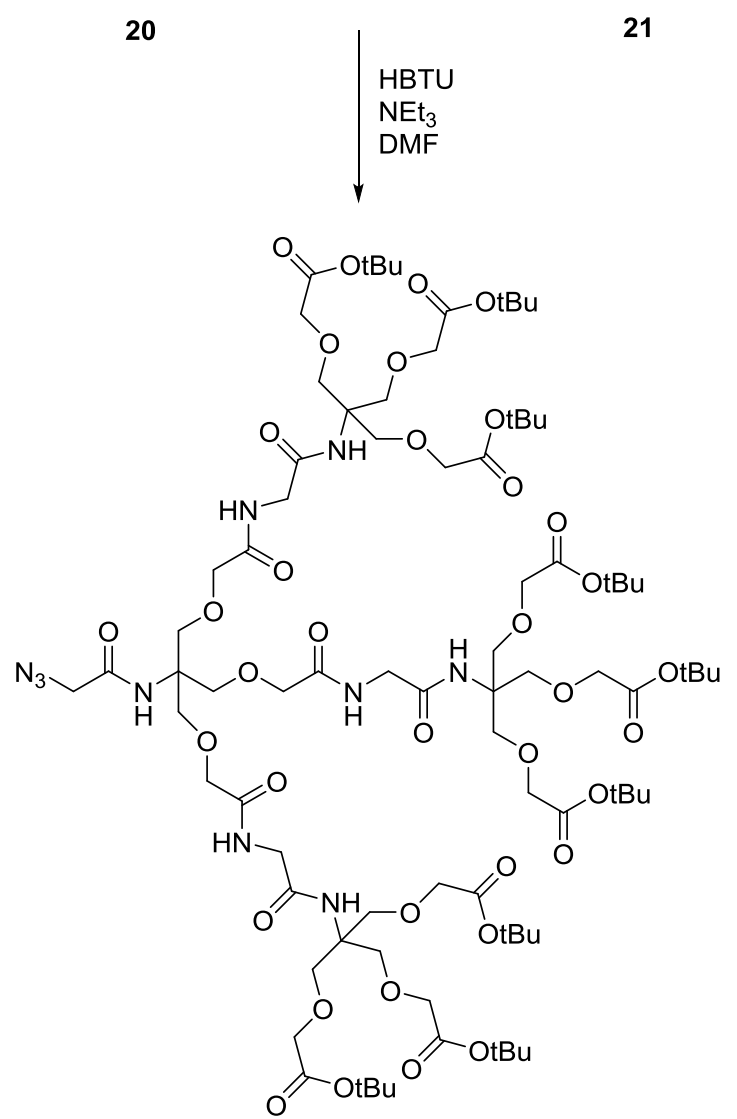

18

Scheme 29. The formation of second generation dendron 18 via a coupling reaction between triacid $\mathbf{2 0}$ and amine $\mathbf{2 1}$

The azide moiety of dendron 18 was subsequently reduced under Staudinger reduction conditions into an amine, which was coupled to D-Biotin (15) without further purification (Scheme 30), giving the biotinylated dendron 73. The success of the reaction was confirmed by mass spectrometry $(\mathrm{m} / \mathrm{z}$ calcd. for $\left[\mathrm{C}_{94} \mathrm{H}_{160} \mathrm{~N}_{10} \mathrm{O}_{39} \mathrm{~S}+2 \mathrm{H}^{2+}\right]$ : 1043.5355 , obsd.: 1043.5360), though optimisation in the purification of the dendron $\mathbf{7 3}$ is required. Due to time constraints, the second generation dendron 73 was not conjugated to glycans 19a and 19b, though it is 
important to note that dendron $\mathbf{7 3}$ has been previously used for the conjugation of other glycans, and thus the synthesis of glycodendrons 11a and 11b is not envisioned to be problematic. ${ }^{145}$
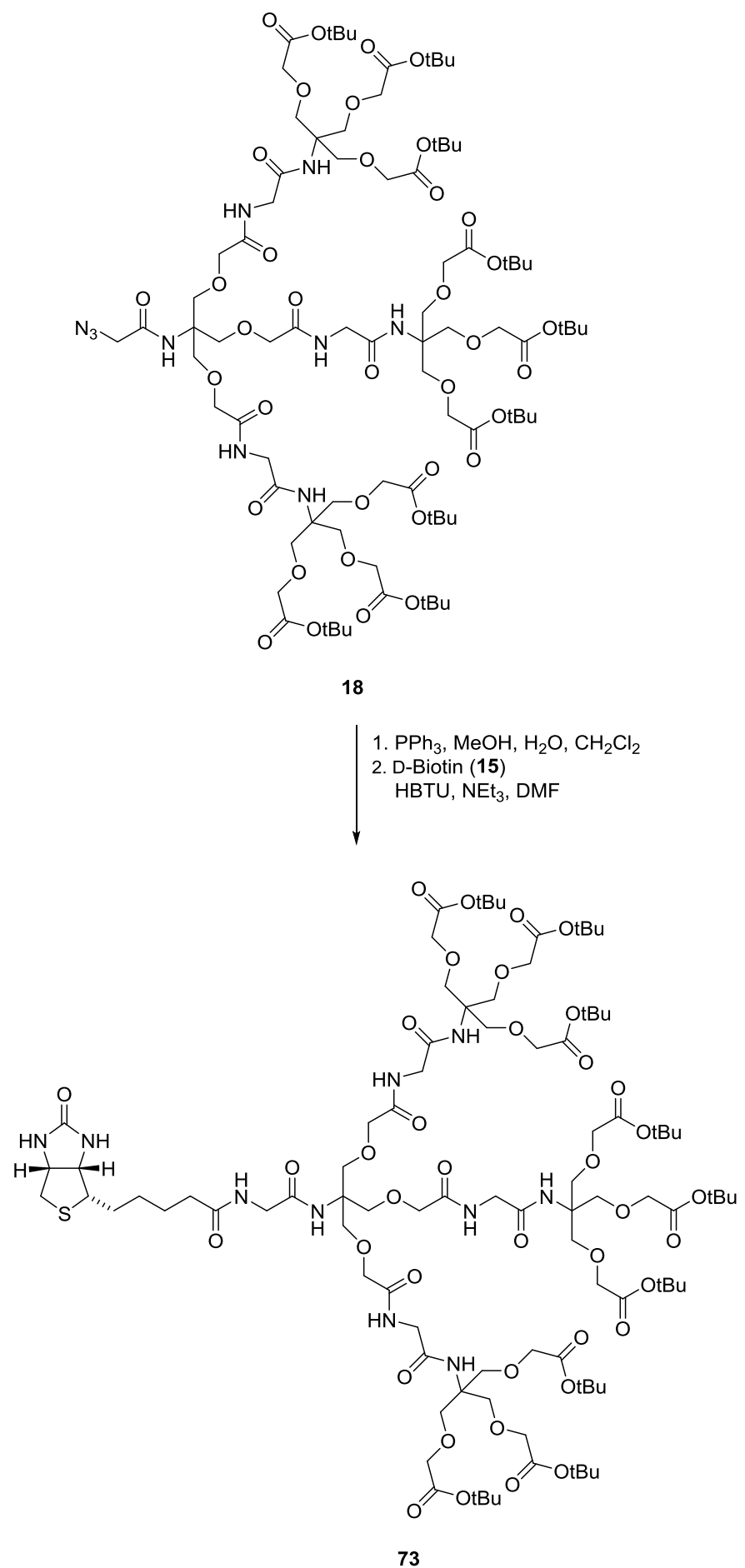

Scheme 30. The HBTU-mediated coupling reaction of second generation dendron $\mathbf{7 3}$ with D-Biotin (15) 


\subsection{ELISA Results}

\subsubsection{Coating ELISA Plates with Streptavidin}

To establish a protocol for the ELISA of MS patient plasma for the presence of anti-carbohydrate antibodies, initial assays were performed in order to determine the amount of streptavidin needed to coat ELISA plates. Subsequently, the required amount of biotinylated antigens to bind the plate-bound streptavidin also needed to be determined. Accordingly, the first ELISA was carried out in a 96-well plate, using decreasing concentrations of streptavidin across the $\mathrm{x}$-axis of the plate. Starting with $4000 \mathrm{ng}$ in $100 \mu \mathrm{L}$ of phosphate buffer saline (PBS), streptavidin (ProSpec, Israel) was added in a two-fold serial dilution, with the lowest dilution containing $3.91 \mathrm{ng}$ of streptavidin $(100 \mu \mathrm{L})$ and the negative control containing PBS only $(100 \mu \mathrm{L})$. Each amount of streptavidin was done in triplicates and was incubated for $12 \mathrm{~h}$ at $4{ }^{\circ} \mathrm{C}$ before the plate was washed four times with $0.05 \%$ Tween-20 (Sigma, USA) in PBS. To minimise non-specific binding of the antibodies onto the bottoms of the wells, the plate was blocked using $200 \mu \mathrm{L} \mathrm{1 \%}$ bovine serum albumin (BSA). The BSA will coat any exposed parts of the wells without being recognised by the antibodies to be tested.

To check successful streptavidin-coating, biotin-conjugated rat anti-mouse antibodies (CD206, Serotec, UK) were added to the plates at 1:200 dilution in 100 $\mu \mathrm{L}$ of PBS. Due to the high affinity of biotin to streptavidin, the antibodies will be bound to the bottom of the plate. Any unbound antibodies will hence be removed during the following washing step (Tween-20/PBS), which was followed by the addition of HRP-conjugated goat anti-rat secondary antibodies (Jackson, USA) and subsequent addition of 3,3',5,5'-tetramethylbenzidine (TMB) and $\mathrm{H}_{2} \mathrm{O}_{2}$. HRP catalyses the redox reaction between TMB and $\mathrm{H}_{2} \mathrm{O}_{2}$ whereby TMB is oxidised into the fluorescent 3,3,5,5'-tetramethylbenzidine diimine. The absorbance of this compound is measured and is indicative of the relative concentration of bound antibodies in the wells. After sufficient colouring along the plate, the redox reaction is quenched by the addition of $0.18 \mathrm{M} \mathrm{H}_{2} \mathrm{SO}_{4}$. From the studies, it was determined that the saturation point of streptavidin began at $250 \mathrm{ng}$ per plate, where it reached a maximum read-out before decreasing slightly and remaining 
constant (Figure 21). From this analysis, it was decided that $500 \mathrm{ng}$ of streptavidin was sufficient to coat each well so as to ensure maximum plate-coating.

The Amount of Streptavidin Required to Coat an ELISA Plate

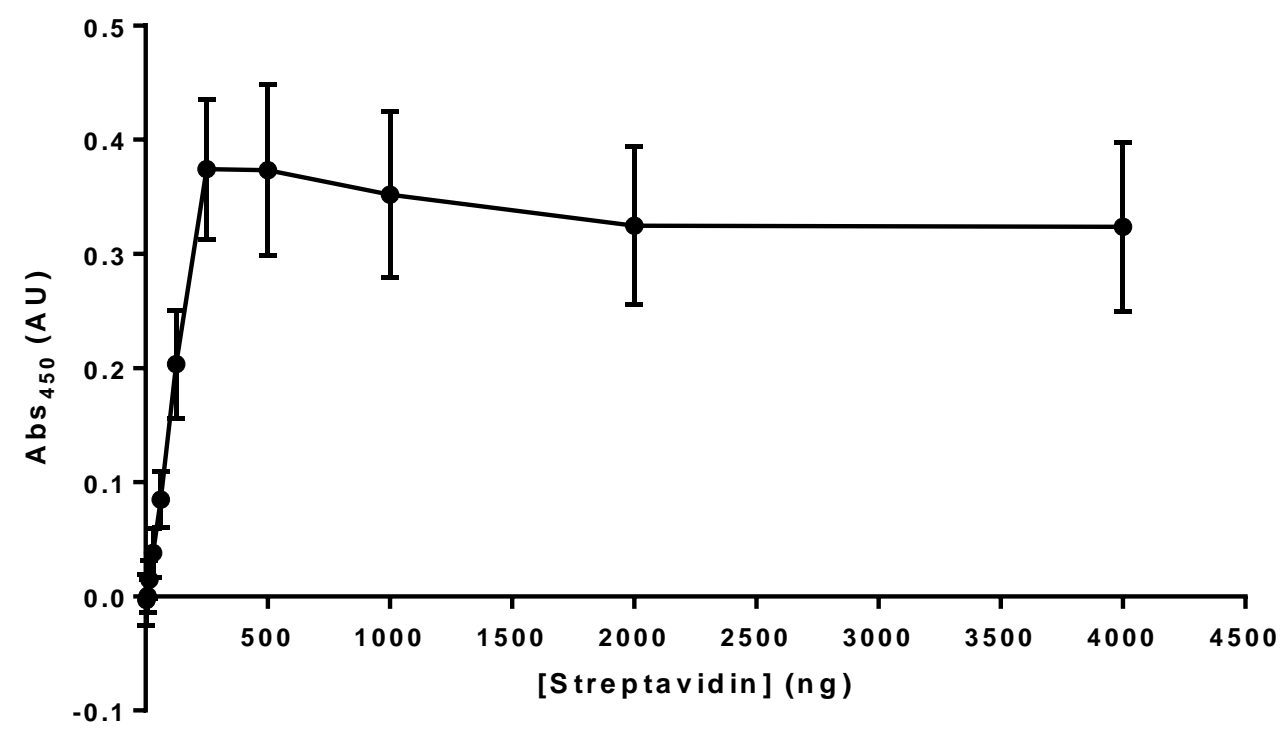

Figure 21. The amount of streptavidin required to coat an ELISA plate. Shown are means and standard errors of the mean (SEM) of a representative experiment of two conducted in triplicates

\subsubsection{Establishing a Positive Control and Plasma Concentration}

Having successfully coated the 96-well plates with streptavidin, the next step was to establish a suitable positive control for the subsequent ELISAs using patient plasma. Ideally, such a positive control would encompass the use of specific antiglycan antibodies, namely anti- $\alpha$-glucose-antibodies and anti- $\alpha$-maltose antibodies for the appropriate glycan antigens, however, these antibodies are not readily available and would have to be generated using expensive monoclonal antibody generation techniques. Accordingly, $\beta$-GlcNAc (75) was used as a positive control, which was based on the findings by Huflejt, et al..$^{61}$ whereby it was reported that 102 out of 106 healthy individual control sera contain antibodies against $\beta$-GlcNAc. The $\beta$-linked biotinylated GlcNAc used was synthesised by a $\mathrm{PhD}$ student in our research group, Stefan Munneke, and is N-linked and bears an oxyamine linker similar to aminopropanol (Figure 22). ${ }^{145}$ Having identified a suitable positive control, the optimal concentration of plasma for the experiments then 
needed to be determined. Accordingly, an ELISA was carried out where the plasma of a healthy individual was two-fold serially diluted along the $\mathrm{x}$-axis of the plate, and the carbohydrate concentration was also serially diluted down the y-axis of the plate. As expected, with decreasing plasma concentration, a lower read-out was observed (Figure 23). Simultaneously, as the concentration of biotinylated $\beta$ GlcNAc (75) was increased, the absorbance values increased until reaching a maxima with $50 \mathrm{ng}$ of the antigen before decreasing slightly when a higher concentration of $100 \mathrm{ng}$ was used. From these studies, it was determined that maximum binding was achieved using $50 \mathrm{ng}$ of $\mathbf{7 5}$.

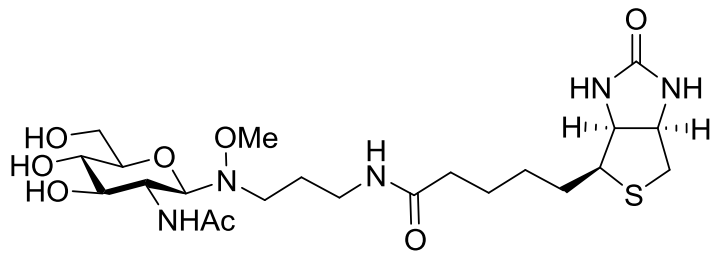

74

Figure 22. Biotinylated $\beta$-GIcNAc (74), glycan antigen chosen as the positive control for ELISA

\section{The Effect of Different [Antigen] and [Plasma] on ELISA}

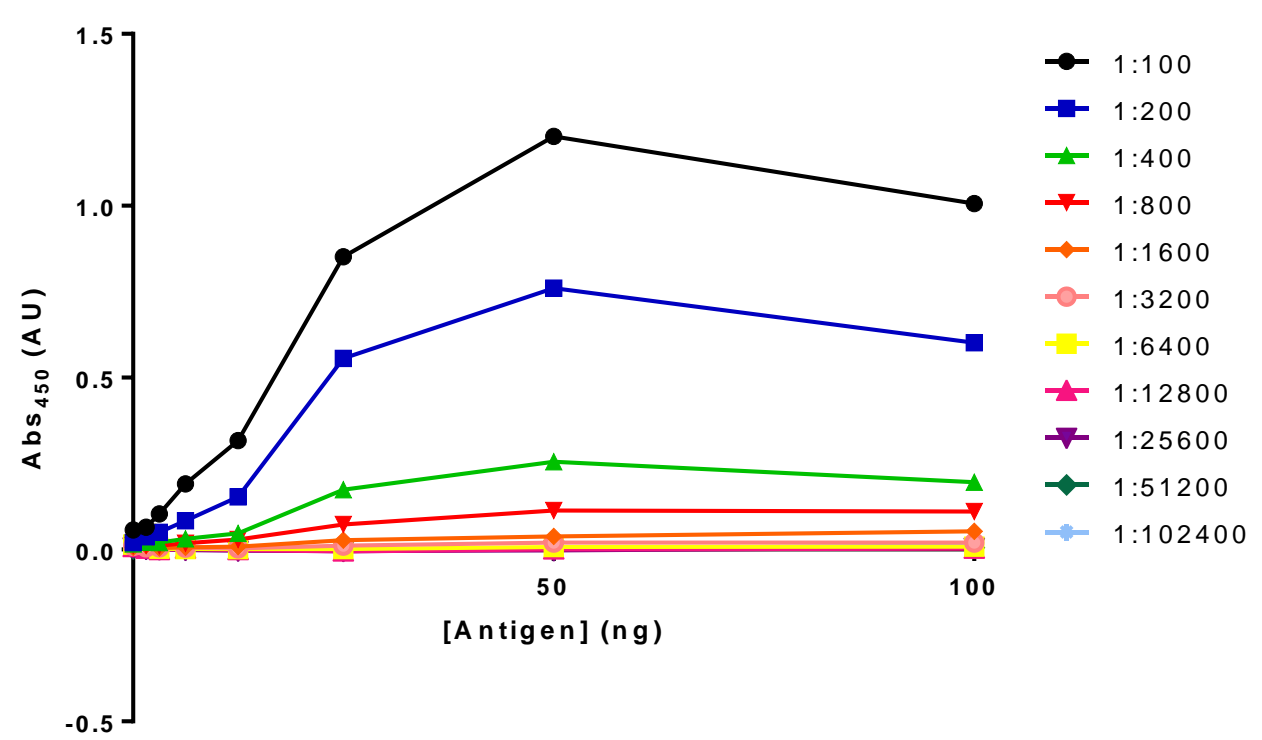

Figure 23. Different concentrations of biotinylated $\beta$-GIcNAc (74) at different plasma dilutions. Each data point did not have a replicate

Although the high absorbance values achieved by using high plasma concentrations is desired, a relatively high read-out was also evident in these 
concentrated plasma samples in the negative controls, e.g. when the biotinylated antigen $\mathbf{7 4}$ was not included (Figure 24). A high background absorbance is indicative of undesired non-specific interactions that could be occurring within the wells. From the results shown, the highest signal-to-noise ratio was attained by the 1:200 plasma dilution.

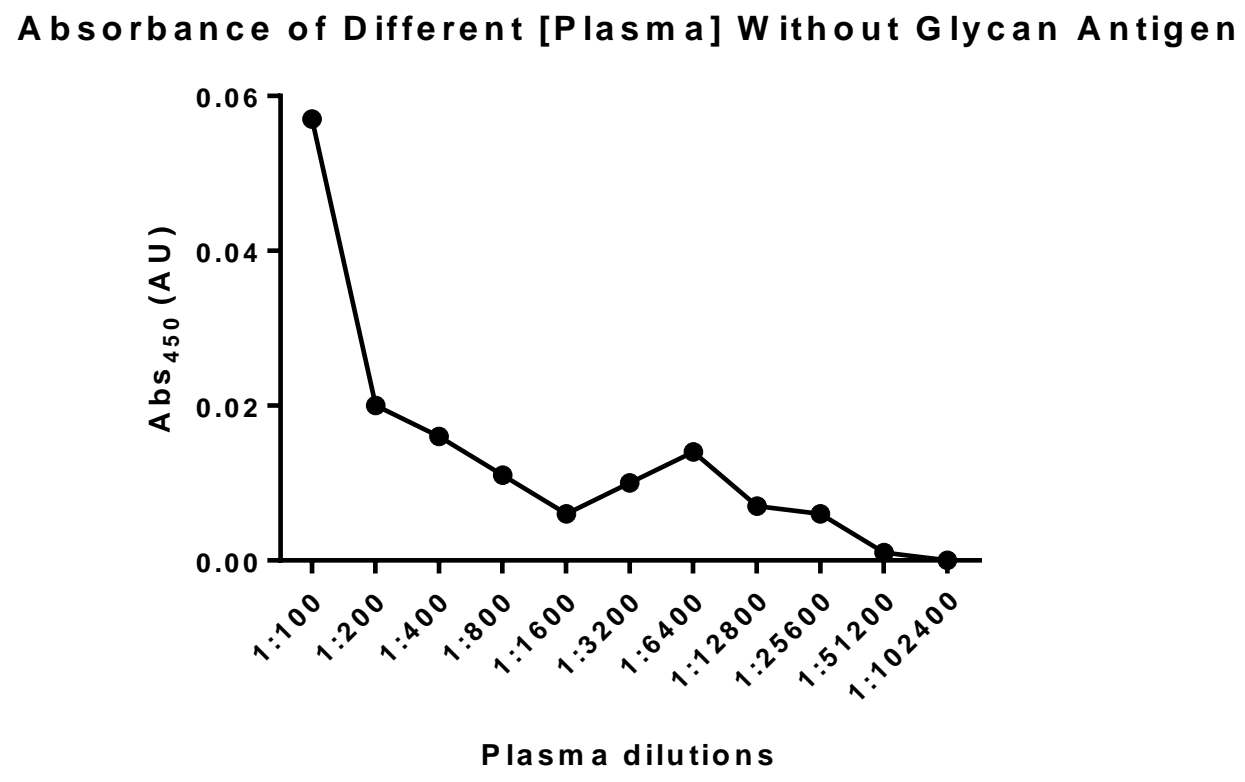

Figure 24. The background absorbance of wells without $\beta$-GIcNAc $\mathbf{7 4}$ at different plasma dilutions indicates non-specific binding at high plasma concentrations

Using this preliminary data as a guide, the experiment was then repeated in duplicates, using the plasma of the same healthy individual to verify the previous results. Using the same plasma dilutions as in the previous experiment, and with two-fold serial dilutions of $\mathbf{7 4}$ starting at $50 \mathrm{ng}$, similar results were achieved as expected. This time, however, $25 \mathrm{ng}$ of $\mathbf{7 4}$ was shown to also be sufficient to give a maximum read-out in the higher plasma concentrations (1:100 and 1:200 dilutions) but not in the more dilute samples (Figure 25). Again, this experiment showed that the 1:200 plasma dilution was sufficient to achieve maximum absorption while also giving low background absorbance (Figure 26). 
The Effect of Different [Antigen] on Different [Plasma]

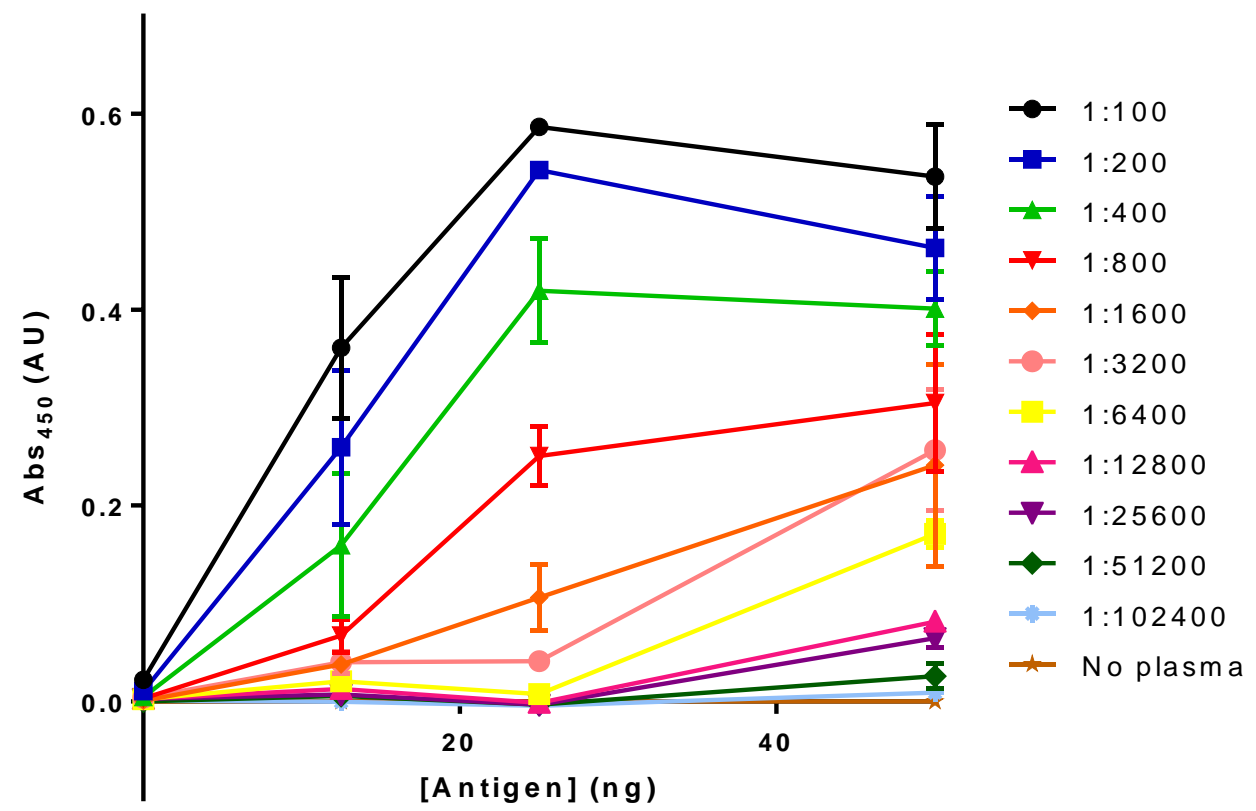

Figure 25. Different antigen concentrations at different plasma dilutions. Shown are means and SEM of a representative experiment of two performed in duplicates

\section{Background Absorbance at Different [Plasma]}

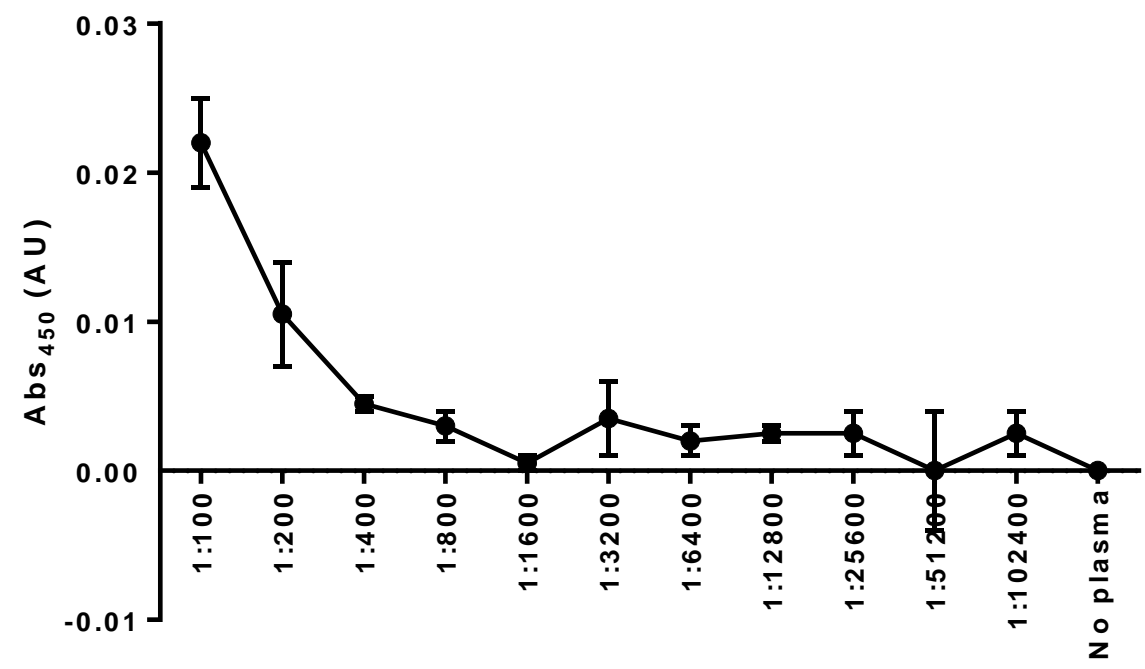

Plasma dilutions

Figure 26. Absorbance values from wells without antigen $\mathbf{7 4}$ indicates non-specific binding at high plasma concentrations (1:100 to 1:400) 
Through the analysis of both experiments, it was decided that the optimal read-out signal was given where $50 \mathrm{ng}$ of biotinylated $\beta$-GlcNAc (74) was used in a 1:200 plasma dilution. Although $25 \mathrm{ng}$ of the antigen 74 was shown to be sufficient, it was hypothesised that saturating the plate with twice the concentration of GlcNAc required (50 ng) might reduce patient-to-patient variability for positive control.

\subsubsection{Prevention of Non-Specific Interactions}

A commonly encountered problem with conducting ELISA for the detection of proteins in plasma is the potentially high non-specific interactions between blood proteins and the plastic plates. ${ }^{149-152}$ In the previous assays, relatively high absorbance values were produced by wells that lacked the biotinylated antigen $\mathbf{7 4}$. Using plasma concentration 1:200 in 1\% BSA-PBS, different plasma samples were used to examine whether the signal-to-noise ratio was consistent across all patients (Figure 27). This was done by having alternating columns of positive (50 ng of 74) and negative (PBS only) controls for each sample to allow for the quantification of non-specific interactions. Indeed, in some patients ( $\# 4$, MS \#6), the difference in absorbance values between wells with $50 \mathrm{ng}$ of $\beta$-GlcNAc 74 compared to wells without is negligible. In any case, in the samples where a difference in absorbance values was evident, the signal-to-noise ratio is lower than expected when compared to the previous assays (Figures 23 and 24). As these wells represent the positive and negative controls of the assays respectively, ideally the difference in absorbance values will consistently be significant for all samples. To prevent these undesirable interactions, many factors can be explored, such as reagent dilutions, ${ }^{153}$ or blocking methods. ${ }^{154,155}$ 


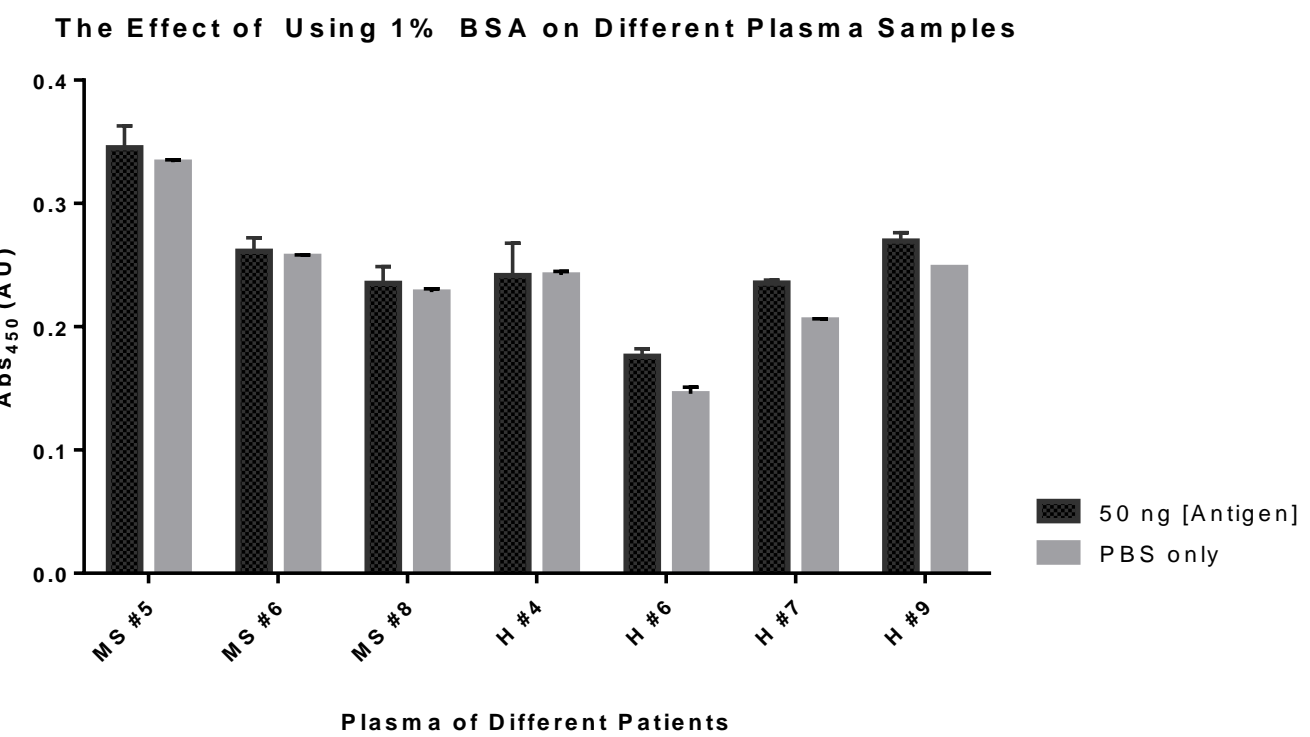

Figure 27. Different extents of blockage are achieved using 1\% BSA with plasma of different patients diluted 1:200 in 1\% BSA-PBS: three MS patients (MS \#5, MS \#6, MS \#8) and four healthy patients $(\mathrm{H} \# 4, \mathrm{H} \# 6, \mathrm{H} \# 7, \mathrm{H} \# 9$ ). $\beta$-GIcNAc antigen 74 was used to bind anti-glycan antibodies in the plasma, but due to non-specific interactions within the wells, the difference between 50 ng [antigen] and PBS only is at times negligible

\subsubsection{Reagent Dilutions}

The concentrations of reagents used in ELISA could play a part in the high background absorbance observed. Non-specific interactions could occur between proteins found in plasma, the streptavidin, the different antibody subtypes (IgM, $\operatorname{IgG}, \operatorname{IgA}, \operatorname{Ig} \mathrm{E}, \operatorname{Ig} \mathrm{D})$, or the plastic wells. To ensure these interactions occur at the lowest level possible, the concentration of each reagent needed to be optimised. Having established the plasma, antigen, and streptavidin concentrations to give a maximum read-out while giving minimal background absorption, the dilution of the HRP-conjugated secondary antibodies was to be determined. Too high a concentration of these antibodies could result in false positive readings if they are able to bind onto the plastic of the wells, even at such a late stage in the assay. To this end, a titration of the secondary antibodies was performed, starting with the recommended 1:2000 dilution (in 1\% BSA-PBS), decreasing in two-fold dilutions across the $\mathrm{x}$-axis of the plate (Figure 28). Again, the plasma was diluted in a 1:200 dilution in 1\% BSA-PBS, while the concentration of the antigen alternated between positive (50 ng) and negative ( $0 \mathrm{ng}$ ). As expected, as the secondary antibodies 
increased in dilution, the absorbance values decreased. Interestingly, however, only the 1:2000 dilution of antibodies was able to effectively distinguish the samples that contain $50 \mathrm{ng}$ of $\mathbf{7 4}$ from those without.

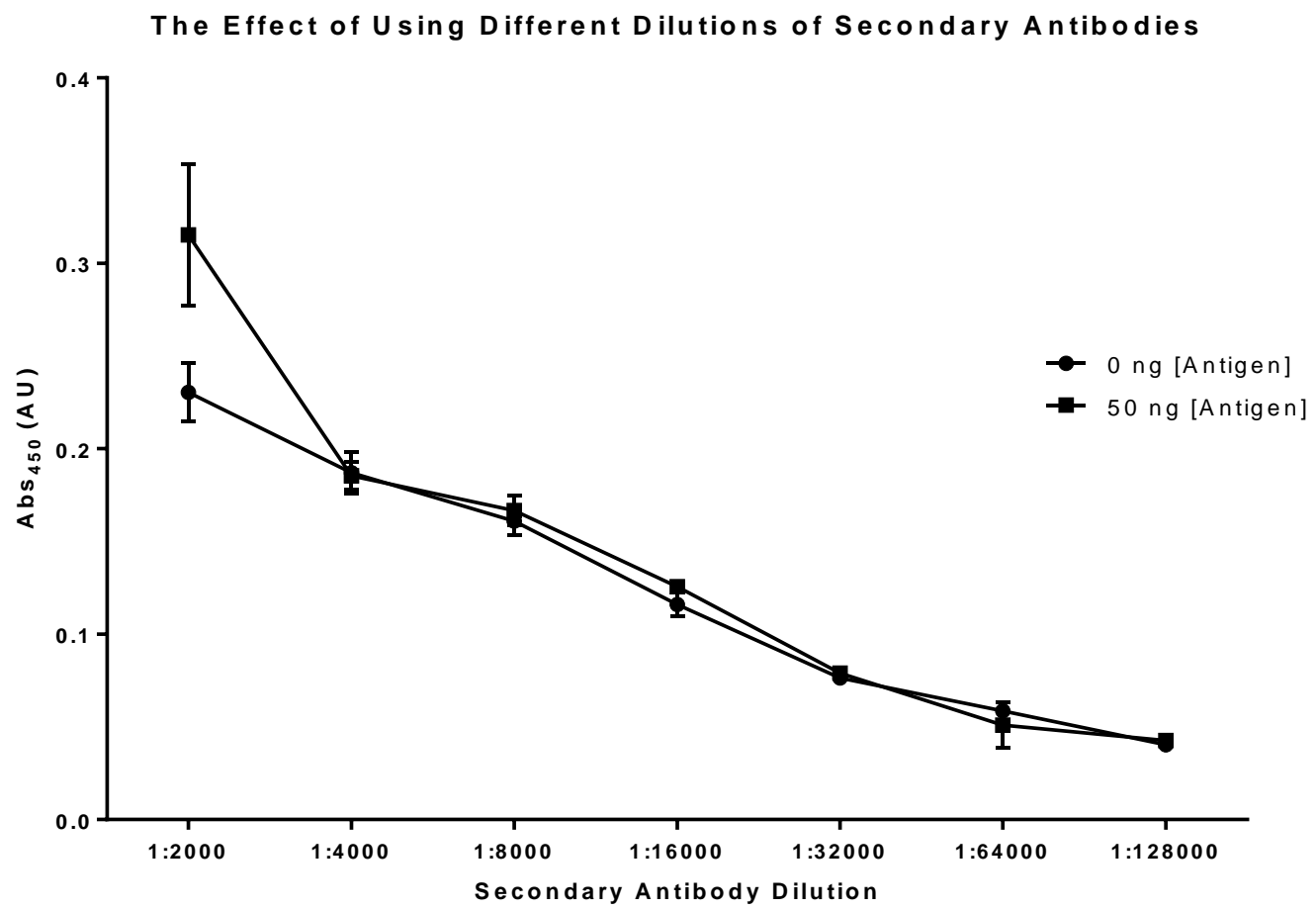

Figure 28. The effect of different dilutions of HRP-conjugated secondary antibodies on the absorbance values of wells containing either $50 \mathrm{ng}$ or no antigen

\subsubsection{Different Blocking Methods}

Another parameter to analyse in the prevention of non-specific binding is the blocking agents. Insufficient blocking could allow high amounts of non-specific interactions in the wells to take place, resulting in inconsistent absorbance values within replicates and false positive readings. Accordingly, a wide variety of blocking solutions were examined, including BSA $(1 \%$ or $5 \%),{ }^{150} 5 \%$ BSA with $3 \%$ sucrose and $0.01 \% \mathrm{NaN}_{3},{ }^{156} 5 \% \mathrm{BSA}$ with $3 \%$ sucrose, $0.01 \% \mathrm{NaN}_{3}$ and $0.1 \%$ Tween$20,{ }^{152,157}$ foetal calf serum (FCS) $(5 \%$ or $10 \%),{ }^{158} 20 \%$ goat serum, ${ }^{152}$ casein, or PBS only. ${ }^{152}$ Shown are representative examples of some of these blocking agents, each dissolved in PBS, using one plasma sample to find a blocking method that could give the highest signal-to-noise ratio (Figure 29). Either a 1:200 or 1:400 dilution of plasma in respective blocks were used, with only one triplicate containing the 
biotinylated antigen $\mathbf{7 4}$ (the black bars). This was the positive control and was expected to show the highest absorbance values, while the remaining data points lacked the antigen, which should give no or low read-outs. Interestingly, the positive control gave a low read-out in the more dilute plasma sample (1:400 dilution), making it indistinguishable from the negative controls. This could be due to the low concentration of anti- $\beta$-GlcNAc antibodies in the plasma compared to that of the blood proteins that cause a high background absorbance. In either case, casein seems to elicit additional non-specific interactions and is not a suitable blocking agent.

\section{The Effect of Using Different Blocking Methods}

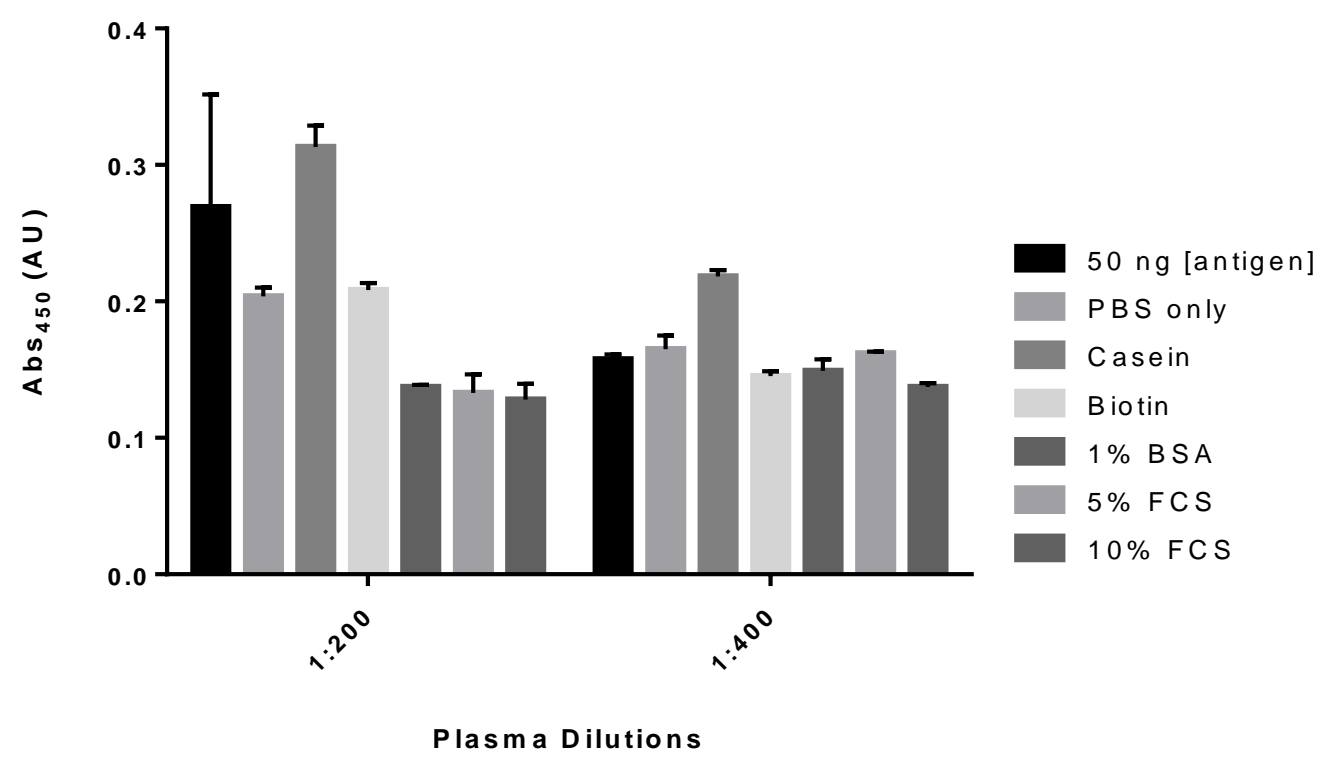

Figure 29. Different blocks used for one healthy plasma sample, $\mathrm{H} \# 5$. Comparison was made between samples treated with $50 \mathrm{ng}$ [antigens] as the positive control (black bars), and those containing only block to explore the effectiveness of different blocks for the establishment of a reliable negative control

Given the relatively high absorbance values $(>0.1)$ of the negative controls in comparison with the positive controls $(0.27$ and 0.16 for 1:200 and 1:400 plasma dilutions, respectively), it is clear that none of the blocking agents completely suppressed the non-specific interactions. In saying this, however, the difference in absorbance values between the positive control and negative controls with $1 \%$ BSA-PBS, 5\% FCS-PBS, and 10\% FCS-PBS in 1:200 plasma dilution could be 
sufficiently significant to be used as a negative control, provided that this is the case for all plasma samples.

To this end, the experiment was repeated using 1\% BSA-PBS, 5\% BSA-PBS, 5\% FCS-PBS, and 10\% FCS-PBS as blocking agents on different plasma samples that had been diluted 1:200 in the appropriate blocking solutions. Shown in figure 30 is the difference in absorbance values between the positive and negative controls. From this experiment, 10\% FCS-PBS consistently gave the largest signalto-noise ratio between the positive and negative controls, while 1\% BSA-PBS was the least effective blocking agent.

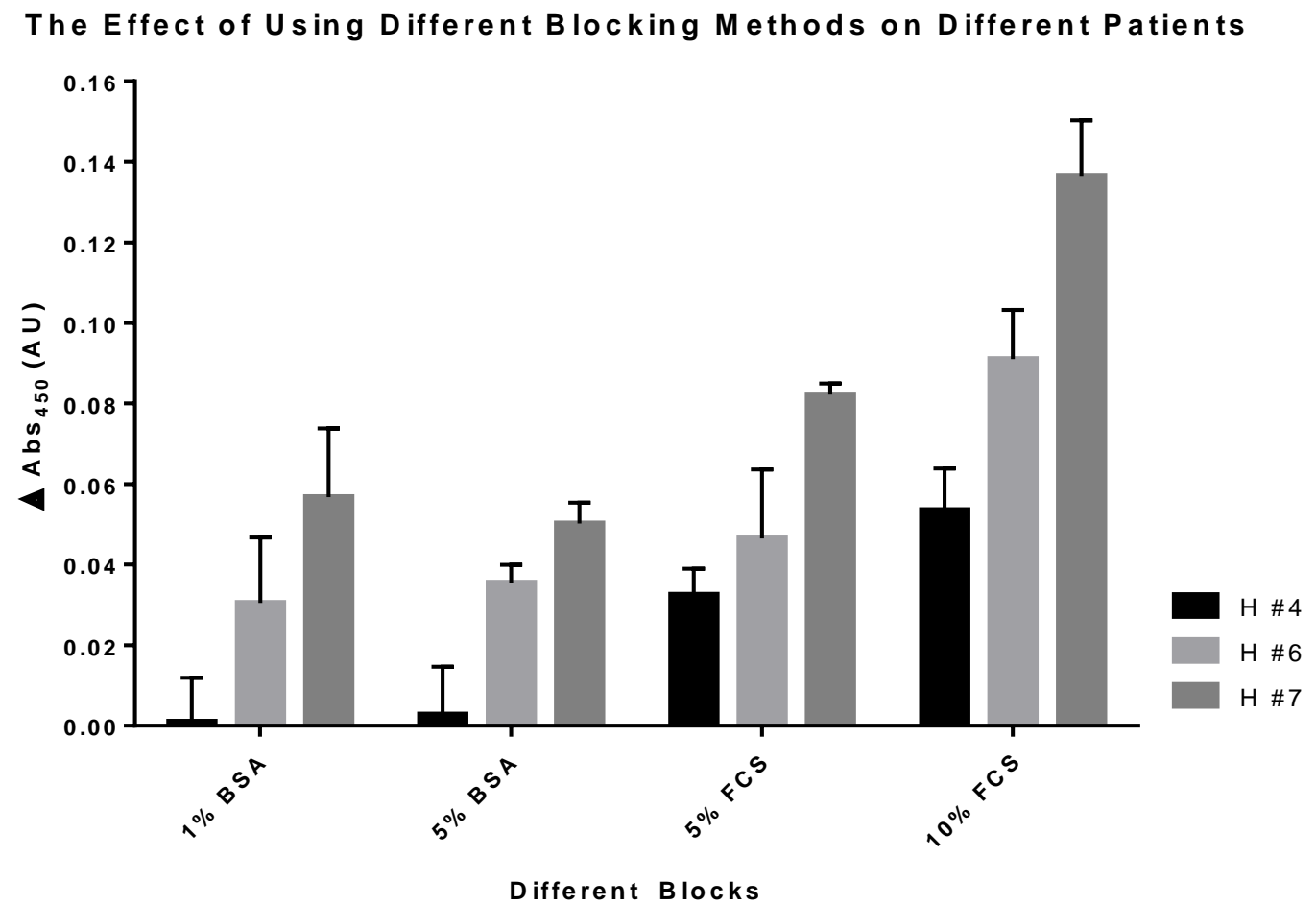

Figure 30. The difference in absorbance values between positive and negative controls using different blocks in different plasma samples. The positive control was prepared by the addition of $50 \mathrm{ng}$ of biotinylated $\beta$-GICNAc (74) and the negative control contains only the blocking agent tested. The difference was calculated by subtracting the absorbance values of the negative control from those of the positive control

To establish the stability of $10 \%$ FCS-PBS to consistently prevent non-specific interactions, the experiment was repeated using the same healthy patient samples 
( $\mathrm{H} \# 4, \mathrm{H} \# 6, \mathrm{H} \mathrm{\# 7)}$ as well as three MS patient samples (MS \#3, MS \#4, MS \#5) at a 1:200 dilution in 10\% FCS-PBS (Figure 31). Again, the comparison was made of the absorbance values between the positive and negative controls in each case. From the results shown, it is clear that patient-to-patient variability is still an issue, where blocking seems to be more effective in one patient than in others. Interestingly, the only reproducible result was that of $\mathrm{H} \mathrm{\# 6}$, as the signal-to-noise ratio is comparable to the previous assay. On the other hand, $\mathrm{H} \mathrm{\# 4}$ and $\mathrm{H} \mathrm{\# 7}$ showed very little difference between the positive and negative control. This was mirrored in the MS plasma samples, with MS \#4 having a relatively large signal-tonoise ratio and MS \#3 and \#5 having very little difference between positive and negative controls. This experiment was repeated to give very similar results, which enforces the unreliability of the blocking agent to suppress non-specific interactions within the wells. Unfortunately, through these experiments, no suitable blocking agent and therefore ELISA protocol could be established.

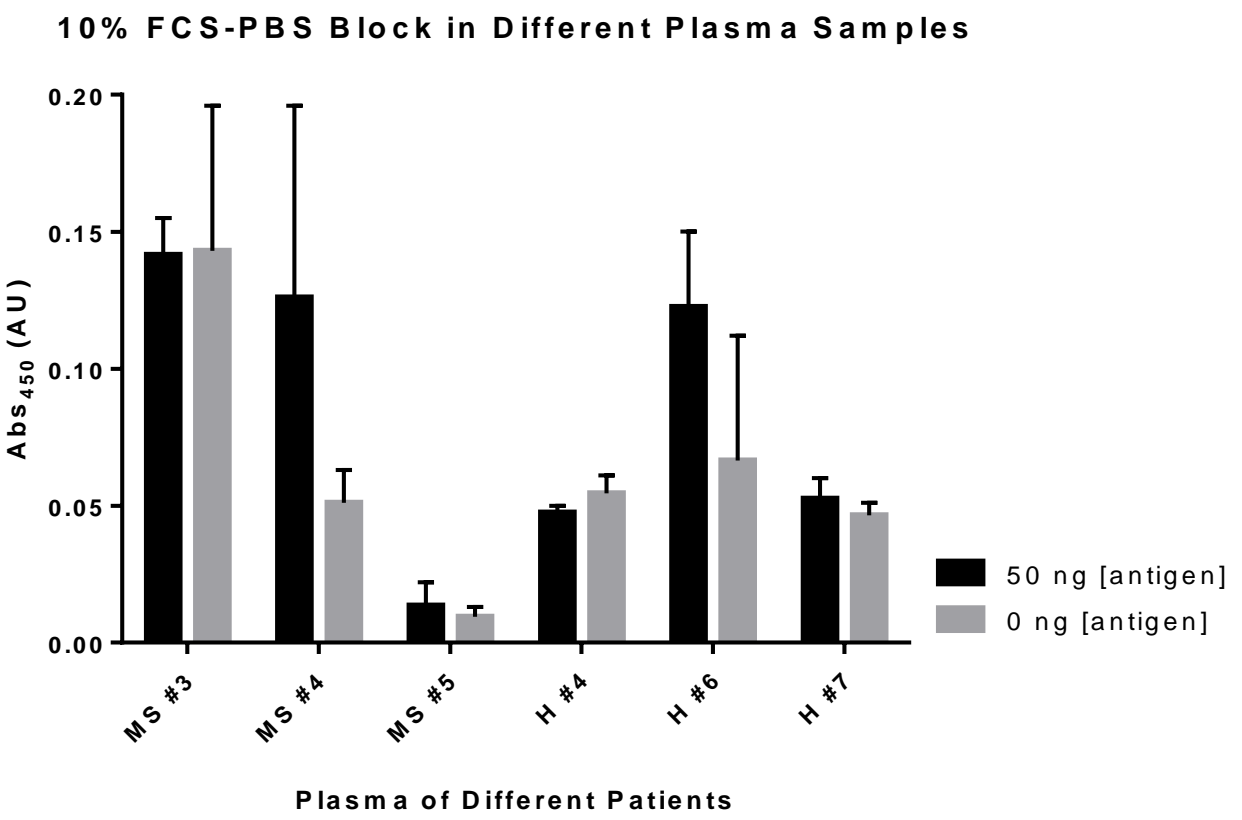

Figure 31. The effect of $10 \%$ FCS-PBS as a blocking agent in different plasma samples. Plasma were treated either with 50 ng of biotinylated antigen $\mathbf{7 4}$ (black bars) or PBS only (grey bars) to establish the signal-to-noise ratio. Shown are the means and SEM of representative experiment of two in duplicates 


\subsection{Future Work}

The main objective of this thesis was to synthesise biotin-conjugated $\alpha$-Glc (10a) and $\alpha$-Glc $(\alpha-1,4)$ Glc $(\mathbf{1 0 b})$ glycans for use in a diagnostic test for the detection of MS. The synthesis of these two glycans was achieved, however, it would also be valuable to prepare the $\alpha$-Glc $(\alpha-1,4) \operatorname{Glc}(\alpha-1,4)$ Glc trisaccharide $(\mathbf{1 0 c})$ to determine if a larger carbohydrate epitope was a better diagnostic predictor of MS. Herein, it should be noted that the trisaccharide donor (75) has been prepared from maltotriose (16c) in a manner similar to that previously described (see Chapter 5.1 for experimental details) and it is envisioned that functionalization with the azidopropanol (30) linker will then allow for the synthesis of glycan $14 \mathrm{c}$, which can be further functionalized via conjugation to biotin or the dendron (Scheme 31).
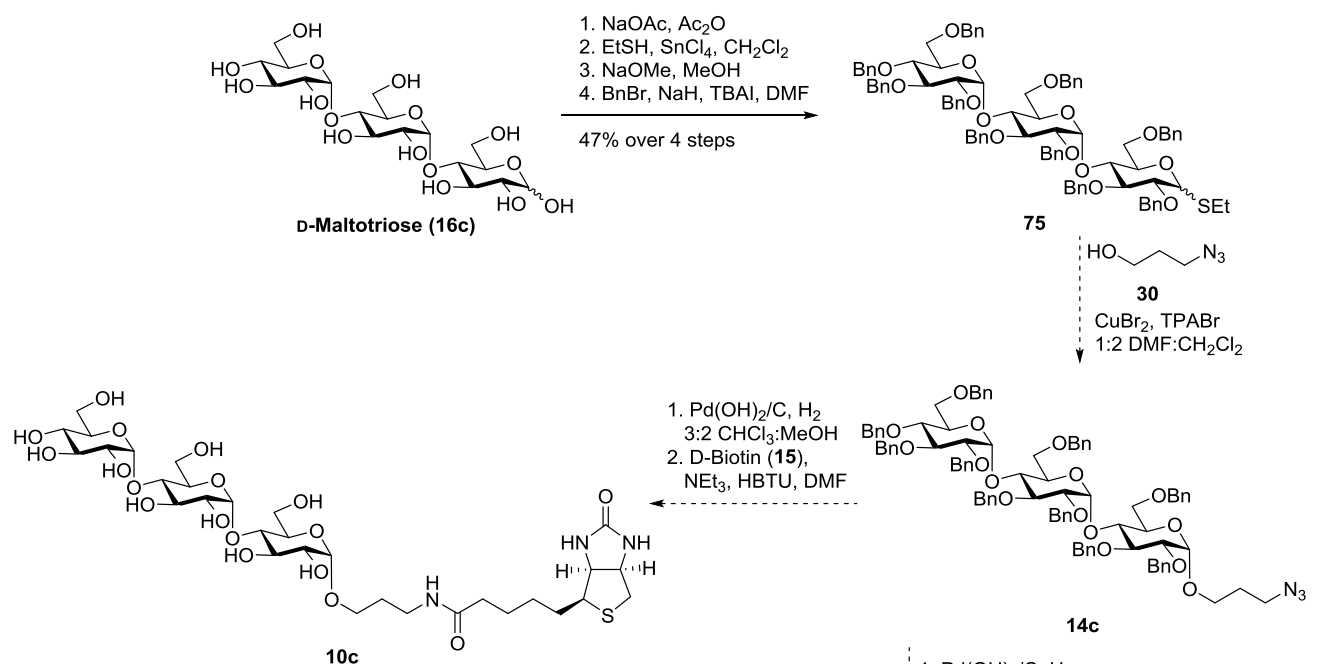

$10 c$

1. $\mathrm{Pd}(\mathrm{OH})_{2} / \mathrm{C}, \mathrm{H}_{2}$ 3:2 $\mathrm{CHCl}_{3}: \mathrm{MeOH}$ 2. $74, \mathrm{NEt}_{3}, \mathrm{HBTU}, \mathrm{DMF}$

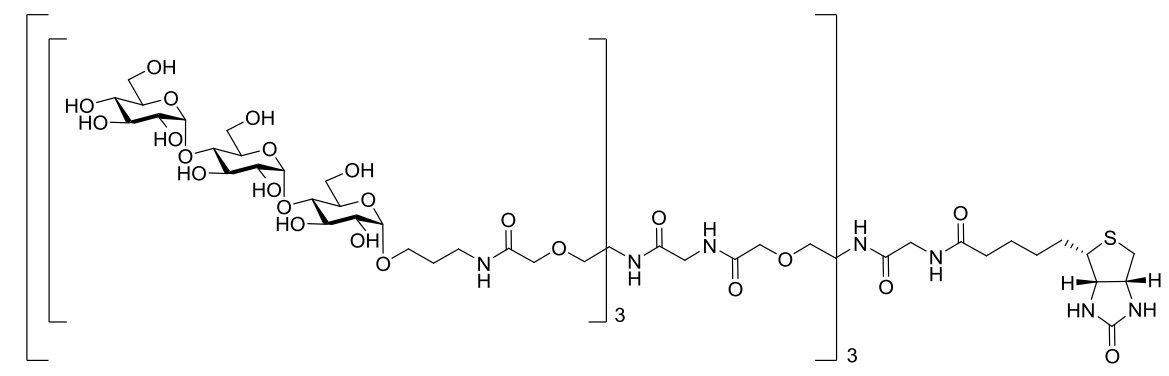

$11 \mathrm{c}$

Scheme 31. Partial synthesis of target trisaccharide glycoside 10c or glycodendron 11c

In light of the difficulties in establishing the ELISA for the detection of MSspecific glycans, it is even more imperative to develop a second method of 
detecting glycans in the serum of patients. Accordingly, future work will include the conjugation of the second generation dendron $\mathbf{7 3}$ to the synthesised carbohydrate antigens $19 \mathrm{a}$ and $19 \mathrm{~b}$, and also trisaccharide 19c, so as to provide glycodendrons 11a-c (Scheme 32). The glycodendrons will provide multivalency and allow for other biological assays, such as the Ouchterlony immunodiffusion assay to be performed. It is anticipated that the Ouchterlony assay may circumvent the problems encountered with the non-specific antibody binding observed during the development of the ELISA assay, as only antibodies that strongly bind to the glycodendron should precipitate. The Ouchterlony assay, however, will undoubtedly require optimisation.

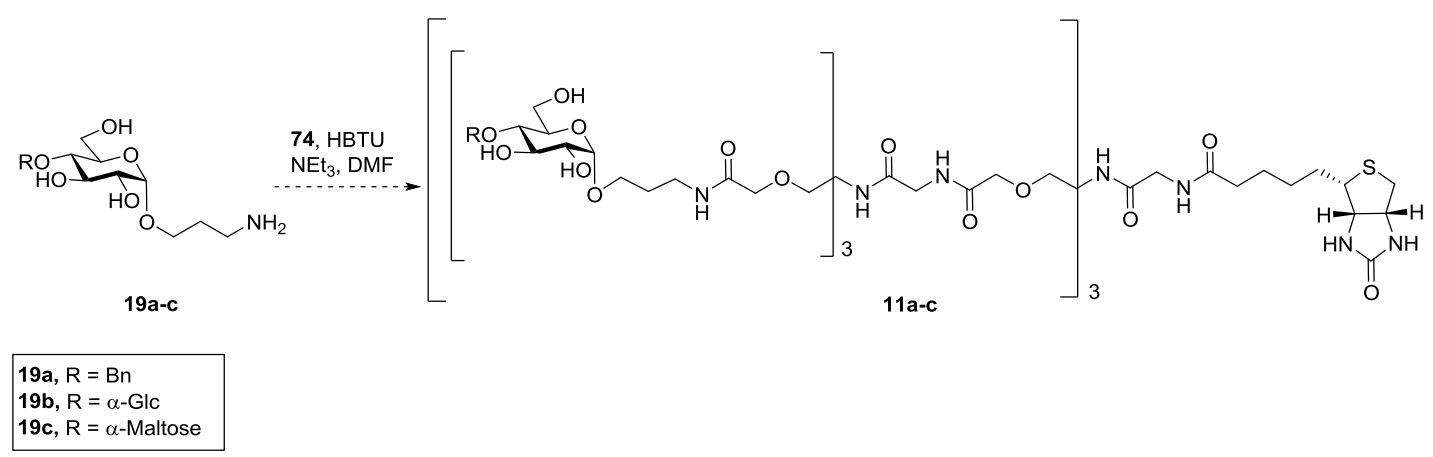

Scheme 32. The tentative synthesis of glycodendrons 11a-c

With regard to the development of an ELISA for the detection of MS-specific antibodies, the main problem with this assay was the lack of a suitable negative control due to non-specific binding of antibodies. The use of the 10\% FCS-PBS as a blocking buffer has shown promise in reducing the effect of non-specific antibody binding, however, further experiments will be needed to confirm the reproducibility of this method across a larger sample of patient plasmas. If this blocking methodology reliably leads to significant differences between the positive and negative controls, the methodology can then be used for the detection of glycan-specific MS antibodies using the biotin-functionalised glycans $10 \mathbf{a}$ and $\mathbf{1 0 b}$, and also the corresponding trisaccharide $10 \mathrm{c}$, once synthesised. If the use of the 10\% FCS-PBS blocking technique, however, still leads to false positives, then an alternative ELISA protocol needs to be developed. 
The problem of non-specific antibody binding is commonly encountered when the antibody is present in low concentrations in the serum, which is typical when the antibodies bind to highly specific antigens. ${ }^{152}$ It is likely that this is the cause for high background absorption in our case because our target antibodies bind specifically to $\beta$-GlcNAc. Furthermore, as IgM antibodies were reported to be the antibody subtype binding to the $\alpha$-glucose-based antigens, ${ }^{52,67,68}$ it may prove useful to firstly purify IgM antibodies from the plasma as there is typically a much higher concentration of IgG and IgA antibodies in the healthy plasma (800-1600 $\mathrm{mg} / 100 \mathrm{~mL}$ and $140-420 \mathrm{mg} / 100 \mathrm{~mL}$, respectively) compared to IgM antibodies (50-190 mg/100 mL). ${ }^{159}$ Another solution would be to use a more specific HRPconjugated secondary antibody, namely the anti-human-IgM antibodies, instead of the anti-human-IgA, $\operatorname{IgM}, \operatorname{IgE}$ antibodies that were used in the project. In this way, only bound anti-glycan IgM antibodies will be detected from ELISA. 


\section{CONCLUSION}

In this Masters project, target biotin-conjugated glycosides $10 \mathrm{a}$ and $10 \mathrm{~b}$ were successfully synthesised with high yields (43\% and $12 \%$ over 7 steps, respectively) and $\alpha$-selectivities. En route to this synthesis, a new method of obtaining $\alpha$ glycosylation products was established, allowing for successful separation from the $\beta$-anomer. To this end, many aspects of $\alpha$-selective glucosylation reactions were explored which included the influence of protecting groups, the anomeric leaving group of the donor, and the activating agents on the $\alpha$-selectivity of the reaction. It was determined that both electron-withdrawing benzoyl protecting groups and the electron-donating benzyl protecting groups gave similar $\alpha: \beta$ selectivities, though the per-benzylated donor was preferred as it leads to higher glucosylation yields. It was also determined that the thioethyl leaving group was much more readily activated than the thiophenyl group due to the thioethyl group being more electron-donating.

Mild activating agents $\left(\mathrm{CuBr}_{2} / \mathrm{TPABr}\right)$ over long glucosylation periods were required to obtain the desired high $\alpha$-selectivity. This was due to the in situ anomerisation, which takes place between the $\alpha$ - and $\beta$-glycosyl bromide intermediates. The $\beta$-bromide is less stable than the $\alpha$-bromide, thus the $\beta$-anomer more readily undergoes nucleophilic attack by azidopropanol (30) in an $\mathrm{S}_{\mathrm{N}} 2$ fashion to give the $\alpha$-glucosylated product. This in turn leads to the fast consumption of the $\beta$-anomer, which shifts the equilibrium to the formation of the $\beta$-product, ultimately providing the $\alpha$-glycosylation product as the major anomer formed. This phenomenon was investigated by the comparison between a glycosylation reaction starting with only $\alpha$-donor and another with a racemic mixture of the donor, which gave the same $\alpha: \beta$ selectivity. Accordingly, an improved method for the $\alpha$-selective glucosylation was developed, whereby an anomeric mixture of thioglucosides could be used as starting materials. This greatly aids in obtaining higher overall yields as the isolation of the $\alpha$-thioglucoside is not a requirement in the synthetic route.

The second generation bi-functional dendron $\mathbf{7 3}$ was successfully prepared in ten steps form bromoacetic acid (23), using the double exponential growth strategy 
For coupling to glycans $19 \mathrm{a}$ and $\mathbf{1 9 b}$, which unfortunately could not be undertaken due to time constraints, a peptide coupling reaction with HBTU as the peptide coupling reagent was to be performed glycodendrons 11a and 11b.

Biological assays (ELISA) were also conducted in order to establish a robust method to detect anti-glycan antibodies in the sera samples of both MS and healthy patients. To establish an ELISA protocol, the concentration of the streptavidin required to bind the ELISA plates was determined, as well as the optimal dilution of the plasma samples and the concentration of the biotinylated antigens required to elicit an optimal absorbance value. The final factor to be determined is a reliable negative control, which still requires optimisation as currently the non-specific antibody binding is too high to provide a clear distinction between the positive and negative controls. Once this is established, the test could be used to quantify potentially MS-specific antibodies for diagnostic purposes. 


\section{EXPERIMENTAL}

\subsection{Chemistry Synthesis}

Unless otherwise stated, the following conditions apply. Reactions were conducted in flame-dried or oven-dried glassware, under an inert atmosphere, using dry solvents. $\mathrm{CH}_{2} \mathrm{Cl}_{2}$ was freshly distilled from phosphorus pentoxide and toluene was stored over sodium. $\mathrm{Ac}_{2} \mathrm{O}$ (Acros Organics), $\mathrm{BnBr}$ (Fluka), $\mathrm{BF}_{3}$. OEt 2 (Janssen Chimica), bromopropanol (Sigma Aldrich), BzCl (Riedel-de-Haën), $\mathrm{CuBr}_{2}$ (ChemPur), D-biotin (Acros), D-glucose (Panreac), EtSH (Sigma Aldrich), HBTU (Novabiochem), NaH (Sigma Aldrich), $\mathrm{NaN}_{3}$ (Ajax Chemicals), NIS (Sigma Aldrich), $\mathrm{Pd}(\mathrm{OH})_{2} / \mathrm{C}$ (Sigma Aldrich), $\mathrm{PhSH}$ (Koch-Light Labs), $\mathrm{PPh}_{3}$ (Merck), pTsOH (Sigma Aldrich), TBAI (Riedel-deHaën), TPABr (Acros) were used as received. AcCN (Panreac) was freshly distilled from calcium hydride, $\mathrm{CH}_{2} \mathrm{Cl}_{2}$ (Fischer) was freshly distilled over phosphorus pentoxide, and DMF (Acros) was freshly distilled from barium oxide. Methanol, ethanol, ethyl acetate, and petroleum ether (Fischer), and toluene (Panreac) used for column chromatography were of technical grade and distilled prior to use. Concentrations of solutions in vacuo was achieved using a rotary evaporator fitted to a vacuum pump, with a bath temperature of $48^{\circ} \mathrm{C}$. Residual solvents were removed using an Edwards E2M1.5 oil pump. Reaction progress was monitored using TLC-analysis on Macherey-Nagel silica gel coated plastic sheets $\left(0.20 \mathrm{~mm}\right.$, with fluorescent indicator $\left.\mathrm{UV}_{254}\right)$ with detection by UV-absorption (short wave UV -254 nm; long wave UV -366 nm), by dipping in 10\% $\mathrm{H}_{2} \mathrm{SO}_{4}$ in EtOH with subsequent heating to visualise the compounds, by dipping in $I_{2}$ in silica, or by dipping into a solution of ninhydrin in $\mathrm{EtOH}$ followed by subsequent heating to visualise the compounds. Purification by column chromatography was conducted using glass columns packed with silica gel (Pure Science Silica Gel 60, 40-63 microns) as the stationary phase and the solvent system as indicated. Purification by reverse phase column chromatography was conducted using either $\mathrm{C}_{8}$ or $\mathrm{C}_{18}$ (Accu BOND II ODS-C18 cartridges, $500 \mathrm{mg}$, $3 \mathrm{~mL}$ ) pre-packed cartridges from Agilent Technologies as stated and the solvent system as indicated. Purification by size exclusion chromatography was conducted using a glass column (180 cm height and $1.9 \mathrm{~cm}$ wide) packed with lipophilic Sephadex (Sigma Aldrich Sephadex ${ }^{\circledR}$ LH-20,25-100 microns). Infrared spectra were recorded as thin films using a Bruker Tensor 27 FTIR spectrometer equipped with an Attenuated Total Reflectance (ATR) sampling accessory and are reported in wave numbers $\left(\mathrm{cm}^{-1}\right)$. Nuclear magnetic resonance spectra were recorded at $20{ }^{\circ} \mathrm{C}$ in $\mathrm{CD}_{3} \mathrm{OD}, \mathrm{CDCl}_{3}$, or $\mathrm{D}_{2} \mathrm{O}$ using a Varian INOVA operating at $500 \mathrm{MHz}$. Chemical shifts are given in ppm ( $\delta$ ) relative to TMS. NMR peak assignments were made using COSY, HSQC and HMBC 2D experiments. 


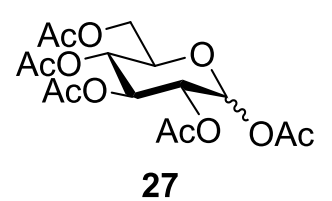

1,2,3,4,6-penta- $O$-acetyl- $\alpha / \beta$-D-glucopyranose (27). DGlucose (16a) (10 g, $55.5 \mathrm{mmol}$ ) was dissolved in pyridine $(100 \mathrm{~mL})$. After cooling the solution to $0{ }^{\circ} \mathrm{C}$, acetic anhydride (34.1 mL, $361 \mathrm{mmol}, 6.5$ equiv.) was slowly

added to the solution. The reaction mixture was allowed to stir at $\mathrm{rt}$ for $16 \mathrm{~h}$, after which TLC-analysis showed the complete disappearance of starting material. The mixture was concentrated in vacuo to remove excess pyridine before it was diluted with ethyl acetate and washed with $0.1 \mathrm{M} \mathrm{HCl}$, sat. aq. $\mathrm{NaHCO}_{3}$, water, and brine (100 mL each). The combined extracts was then dried with anhydrous $\mathrm{MgSO}_{4}$, which was filtered off and the filtrate concentrated in vacuo to yield the pentaacetate 25 as white crystals $(21.7 \mathrm{~g}$, quant., $1: 6 \alpha: \beta) . R_{f}=0.82$ (1:1, petroleum ether : ethyl acetate, v:v); Mp = $111.2{ }^{\circ} \mathrm{C}$; IR (thin film): 1737, 1363, 1220, 1033, $938 \mathrm{~cm}^{-1} ;{ }^{1} \mathrm{H}-$ $\operatorname{NMR}\left(500 \mathrm{MHz}, \mathrm{CDCl}_{3}\right): \delta 6.33\left(\mathrm{~d}, 1 \mathrm{H}, J_{1,2}=3.6 \mathrm{~Hz}, \alpha-\mathrm{H}-1\right), 5.72\left(\mathrm{~d}, 1 \mathrm{H}, J_{1,2}=8.3\right.$ $\mathrm{Hz}, \beta-\mathrm{H}-1), 5.47$ (t, 1H, $\left.J_{2,3}=J_{3,4}=10.0 \mathrm{~Hz}, \alpha-\mathrm{H}-3\right), 5.25$ (t, 1H, , $J_{2,3}=J_{3,4}=9.5$ $\mathrm{Hz}, \beta-\mathrm{H}-3), 5.14\left(\mathrm{t}, 1 \mathrm{H}, J_{3,4}=J_{4,5}=10.0 \mathrm{~Hz}, \mathrm{H}-4\right), 5.10\left(\mathrm{dd}, 1 \mathrm{H}, J_{1,2}=3.5 \mathrm{H}, J_{2,3}=\right.$ $10.3 \mathrm{~Hz}, \mathrm{H}-2$ ), 4.27 (dd, $J_{4,5}=12.5 \mathrm{~Hz}, J_{5,6}=4 \mathrm{~Hz}, \mathrm{H}-6 \mathrm{a}$ ), 4.14-4.08 (m, 2H, H-5, H-6b), 2.18 (s, 3H, $\mathrm{CH}_{3} \mathrm{O}-\mathrm{Ac}$ ), 2.10 (s, 3H, $\mathrm{CH}_{3} \mathrm{O}-\mathrm{Ac}$ ), 2.04 (s, 3H, $\mathrm{CH}_{3} \mathrm{O}-\mathrm{Ac}$ ), 2.03 (s, 3H, $\mathrm{CH}_{3} \mathrm{O}-\mathrm{Ac}$ ), 2.02 (s, 3H, $\mathrm{CH}_{3} \mathrm{O}-\mathrm{Ac}$ ); ${ }^{13} \mathrm{C}-\mathrm{NMR}\left(125 \mathrm{MHz}, \mathrm{CDCl}_{3}\right.$ ):

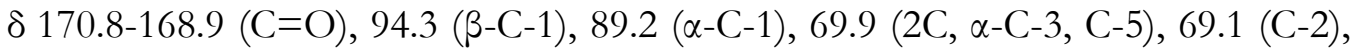
68.0 (C-4), 61.6 (C-6), 20.8-20.6 ( $\mathrm{CH}_{3}$ O-Ac); HRMS(ESI) $\mathrm{m} / \mathrm{z}$ calcd. for $\left[\mathrm{C}_{16} \mathrm{H}_{22} \mathrm{O}_{11}+\mathrm{NH}_{4}{ }^{+}\right]:$408.1500, obsd.: 408.1507.

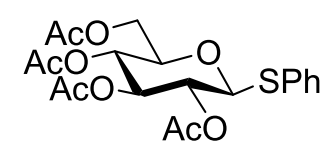

28

\section{Phenyl} glucopyranoside (28). Glucose pentaacetate (27) was coevaporated with dry toluene and dissolved in freshly distilled $\mathrm{CH}_{2} \mathrm{Cl}_{2}(50 \mathrm{~mL})$ under an argon atmosphere.

Thiophenol (2.8 mL, $27.8 \mathrm{mmol}, 1$ equiv.) was added to the solution, followed by freshly distilled $\mathrm{BF}_{3} . \mathrm{OEt}_{2}(7.9 \mathrm{~mL}, 63.8 \mathrm{mmol}, 2.3$ equiv.). The reaction mixture was allowed to stir for $16 \mathrm{~h}$ at $\mathrm{rt}$, after which TLC-analysis showed complete conversion of the starting material into a lower running spot. The solution was neutralised with sat. aq. $\mathrm{NaHCO}_{3}(150 \mathrm{~mL})$, followed by extraction with $\mathrm{CH}_{2} \mathrm{Cl}_{2}$ $(150 \mathrm{~mL})$. The organic layer was then washed with water $(100 \mathrm{~mL})$, and brine $(50$ $\mathrm{mL}$ ) before it was dried using anhydrous $\mathrm{MgSO}_{4}$, which was filtered and the filtrate concentrated in vacuo. Purification by column chromatography (20:1 $\rightarrow$ 10:1, 
petroleum ether : ethyl acetate, v:v) yielded the thioglucoside 28 as a white solid $(10.0 \mathrm{~g}, 86 \%) . R_{f}=0.22(2: 1$, petroleum ether : ethyl acetate, $\mathrm{v}: \mathrm{v}) ;[\alpha]_{\mathrm{D}}{ }^{20}=+51^{\circ}(\mathrm{c}$ $=1.0, \mathrm{CH}_{2} \mathrm{Cl}_{2}$ ); IR (thin film): 3475, 2959, 1751, 1373, 1256, 1226, 1089, 1043, 913, 743, $688 \mathrm{~cm}^{-1} ; \mathrm{Mp}=105.6{ }^{\circ} \mathrm{C} ;{ }^{1} \mathrm{H}-\mathrm{NMR}\left(500 \mathrm{MHz}, \mathrm{CDCl}_{3}\right): \delta 7.51-7.49(\mathrm{~m}, 2 \mathrm{H}$, $\mathrm{CH}$ arom.), 7.33-7.31 (m, 3H, CH arom.), 5.23 (t, $\left.J_{2,3}=J_{3,4}=9.2 \mathrm{~Hz}, 1 \mathrm{H}, \mathrm{H}-3\right), 5.05$ $\left(\mathrm{t}, J_{3,4}=J_{4,5}=9.8 \mathrm{~Hz}, 1 \mathrm{H}, \mathrm{H}-4\right), 4.98\left(\mathrm{t}, J_{1,2}=J_{2,3}=9.9 \mathrm{~Hz}, 1 \mathrm{H}, \mathrm{H}-2\right), 4.71$ (d, $J_{1,2}=$ $10.0 \mathrm{~Hz}, 1 \mathrm{H}, \mathrm{H}-1$ ), 4.25-4.17 (m, 2H, H-6a, H-6b), 3.75-3.71 (m, 1H, H-5), 2.10 (s, $3 \mathrm{H}, \mathrm{CH}_{3}$ 6-O-Ac), 2.09 (s, 3H, $\mathrm{CH}_{3} 2-\mathrm{O}-\mathrm{Ac}$ ), 2.02 (s, 3H, $\mathrm{CH}_{3} 4-\mathrm{O}-\mathrm{Ac}$ ), 2.00 (s, 3H, $\mathrm{CH}_{3} 3-\mathrm{O}-\mathrm{Ac}$ ); ${ }^{13} \mathrm{C}-\mathrm{NMR}\left(125 \mathrm{MHz}, \mathrm{CDCl}_{3}\right): \delta 170.8$ (C=O 6-O-Ac), 170.4 (C=O 3-O-Ac), 169.6 (C=O 4-O-Ac), 169.5 (C=O 2-O-Ac), 133.3 (CH arom.), $129.1(\mathrm{CH}$ arom.), 128.6 (CH arom.), 85.9 (C-1), 76.0 C-5), 74.1 (C-3), 70.1 (C-2), 68.4 (C-4), 62.3 (C-6), 20.9 ( $\mathrm{CH}_{3}$ 6-O-Ac, 2-O-Ac), 20.8 ( $\mathrm{CH}_{3}$ 3-O-Ac, 4-O-Ac); HRMS(ESI) $m /$ z calcld. for $\left[\mathrm{C}_{20} \mathrm{H}_{24} \mathrm{O}_{9} \mathrm{~S}+\mathrm{NH}_{4}\right]^{+}:$458.1479, obsd.: 458.1574 .

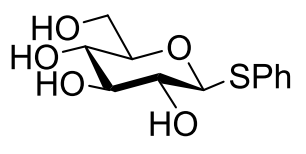

29

Phenyl 1-thio- $\beta$-D-glucopyranoside (29). Thioglycoside 28 (10 g, $22.7 \mathrm{mmol})$ was dissolved in $\mathrm{MeOH}(300 \mathrm{~mL})$ before $\mathrm{NaOMe}(0.061 \mathrm{~g}, 1.14 \mathrm{mmol}, 0.05$ equiv.) was added to the solution. The reaction mixture was allowed to stir overnight at room temperature, after which TLC-analysis showed complete conversion of starting material into a lower running spot. Neutralisation using Dowex $\mathrm{H}^{+}$was carried out, followed by filtration of the Dowex $\mathrm{H}^{+}$beads and coevaporation of the filtrate with $\mathrm{MeOH}$. Purification by column chromatography $(0: 1 \rightarrow 1: 10$, methanol : ethyl acetate, v:v) yielded 29 as a white solid (6.2 g, quant.). $R_{f}=0.48(1: 20$, methanol : ethyl acetate, $\mathrm{v}: \mathrm{v}) ;[\alpha]_{\mathrm{D}}{ }^{19}=-19^{\circ}\left(\mathrm{c}=1.0, \mathrm{CH}_{3} \mathrm{OH}\right) ; \mathrm{IR}$ (thin film): 3409, 3371, 3246, 2900, 1482, 1439, 1406, 1117, 1087, 1070, 1051, 1032, 738, $688 \mathrm{~cm}^{-1}$; Mp $126.1{ }^{\circ} \mathrm{C} ;{ }^{1} \mathrm{H}-\mathrm{NMR}\left(500 \mathrm{MHz}, \mathrm{D}_{2} \mathrm{O}\right): \delta 7.55\left(\mathrm{~d}, J_{\mathrm{o}, \mathrm{m}}=\right.$ 6.10 Hz, 2H, ortho- $\mathrm{CH}$ arom.), 7.30-7.24 (m, 3H, meta- and para-CH arom.), 4.58 (d, $\left.J_{1,2}=10 \mathrm{~Hz}, 1 \mathrm{H}, \mathrm{H}-1\right), 3.85$ (d, $\left.J_{6 \mathrm{a}, 6 \mathrm{~b}}=11.5 \mathrm{~Hz}, 1 \mathrm{H}, \mathrm{H}-6 \mathrm{a}\right), 3.65$ (dd, $J_{5,6}=4.18 \mathrm{~Hz}$, $\left.J_{6 \mathrm{a}, 6 \mathrm{~b}}=11.7 \mathrm{~Hz}, 1 \mathrm{H}, \mathrm{H}-6 \mathrm{~b}\right), 3.37-3.29$ (m, 3H, H-3, H-4, H-5), 3.20 (t, $J_{1,2}=J_{2,3}=$ $9.1 \mathrm{~Hz}, 1 \mathrm{H}, \mathrm{H}-2) ;{ }^{13} \mathrm{C}-\mathrm{NMR}\left(125 \mathrm{MHz}, \mathrm{D}_{2} \mathrm{O}\right): \delta 132.7$ (ortho- $\mathrm{CH}$ arom.), 129.8 (meta-CH arom.), 128.3 (para-CH arom.), 89.4 (C-1), 82.0 (C-5), 79.6 (C-3), 73.7 (C2), 71.3 (C-4), 62.8 (C-6); HRMS(ESI) $m / z$ calcld. for $\left[\mathrm{C}_{12} \mathrm{H}_{16} \mathrm{O}_{9} \mathrm{~S}+\mathrm{NH}_{4}\right]^{2+}$ : 290.1057, obsd.: 290.1055 . 


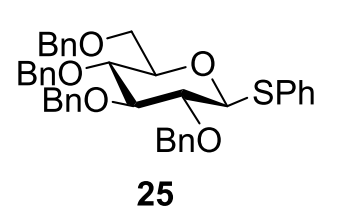

Phenyl

2,3,4,6-tetra- $O$-benzyl-1-thio- $\beta$-D-

glucopyranoside (25). Thioglycoside 29 (0.3 g, $1.4 \mathrm{mmol})$ was co-evaporated three times with DMF $(15 \mathrm{~mL})$, where the solution was partially concentrated to leave $7 \mathrm{~mL}$ of

DMF during the final co-evaporation. After placing the solution under an argon atmosphere, $\mathrm{BnBr}(0.6 \mathrm{~mL}, 5 \mathrm{mmol}, 3.6$ equiv.) and TBAI (0.05 g, $0.14 \mathrm{mmol}, 0.1$ equiv.) were added into the reaction vessel. The reaction was then cooled to $0{ }^{\circ} \mathrm{C}$ before $\mathrm{NaH}$ (0.24 g, 5.4 mmol, 3.9 equiv.) was added slowly. The reaction mixture was then allowed to warm to $\mathrm{rt}$ and left to stir for $16 \mathrm{~h}$, after which TLC-analysis deemed the reaction complete, with the appearance of a single higher running spot. The solution was quenched using $\mathrm{H}_{2} \mathrm{O}(10 \mathrm{~mL})$, followed by extraction using $\mathrm{Et}_{2} \mathrm{O}$ ( $3 \times 20 \mathrm{~mL})$. The combined ether layers were then washed with $\mathrm{H}_{2} \mathrm{O},(20 \mathrm{~mL})$, brine $(20 \mathrm{~mL})$, dried with anhydrous $\mathrm{MgSO}_{4}$, which was filtered off, and the filtrate concentrated in vacuo. Purification using column chromatography (10:1 $\rightarrow$ 1:1, petroleum ether: ethyl acetate, v:v) yielded 25 as white crystals $(0.35 \mathrm{~g}, 40 \%)$. $R_{f}=0.53(4: 1$, petroleum ether : ethyl acetate, $\mathrm{v}: \mathrm{v}) ;[\alpha]_{\mathrm{D}}{ }^{28}=-36^{\circ}\left(\mathrm{c}=0.1, \mathrm{CHCl}_{3}\right)$; $\mathrm{Mp}=81.6{ }^{\circ} \mathrm{C}$; IR (thin film): 2903, 1453, 1357, 1054, 1027, 751, $692 \mathrm{~cm}^{-1} ;{ }^{1} \mathrm{H}-$ NMR (500 MHz, $\mathrm{CDCl}_{3}$ ): $\delta$ 7.59-7.57 (m, 1H, CH arom.), 7.40-7.19 (m, 24H, CH arom.), 4.89 (d, $\left.J_{\mathrm{a}, \mathrm{b}}=11 \mathrm{~Hz}, 1 \mathrm{H}, \mathrm{CH}_{2} 2-\mathrm{O}-\mathrm{Bn}-\mathrm{a}\right), 4.88$ (d, $J_{\mathrm{a}, \mathrm{b}}=10 \mathrm{~Hz}, 1 \mathrm{H}, \mathrm{CH}_{2} 3-\mathrm{O}-$ Bn-a), 4.84 (d, Ja,b $\left.=11 \mathrm{~Hz}, 1 \mathrm{H}, \mathrm{CH}_{2} 3-\mathrm{O}-\mathrm{Bn}-\mathrm{b}\right), 4.82\left(\mathrm{~d}, \mathrm{~J}_{\mathrm{a}, \mathrm{b}}=11 \mathrm{~Hz}, 1 \mathrm{H} \mathrm{CH}_{2}, 4-\mathrm{O}-\right.$ $\mathrm{Bn}-\mathrm{a}), 4.72$ (d, $\left.J_{\mathrm{a}, \mathrm{b}}=10.5 \mathrm{~Hz}, 1 \mathrm{H}, \mathrm{CH}_{2} 2-\mathrm{O}-\mathrm{Bn}-\mathrm{b}\right), 4.66$ (d, $J_{1,2}=9.5 \mathrm{~Hz}, 1 \mathrm{H}, \mathrm{H}-1$ ), 4.60 (d, $J_{\mathrm{a}, \mathrm{b}}=12 \mathrm{~Hz}, 1 \mathrm{H}, \mathrm{CH}_{2}$ 6-O-Bn-a), 4.59 (d, Ja,b $\left.=10.3 \mathrm{~Hz}, 1 \mathrm{H}, \mathrm{CH}_{2} 4-\mathrm{O}-\mathrm{Bn}-\mathrm{b}\right)$, 4.54 (d, $J_{\mathrm{a}, \mathrm{b}}=12 \mathrm{~Hz}, 1 \mathrm{H}, \mathrm{CH}_{2}$ 6-O-Bn-b), 3.79 (d, $\left.J_{6 \mathrm{a}, 6 \mathrm{~b}}=11.2 \mathrm{~Hz}, 1 \mathrm{H}, \mathrm{H}-6 \mathrm{a}\right), 3.74-$ 3.69 (m, 2H, H-6b, H-3), 3.65 (t, $\left.J_{3,4}=J_{4,5}=9.8 \mathrm{~Hz}, 1 \mathrm{H}, \mathrm{H}-4\right), 3.53-3.49$ (m, 2H, H-5, $\mathrm{H}-2) ;{ }^{13} \mathrm{C}-\mathrm{NMR}$ (125 MHz, $\mathrm{CDCl}_{3}$ ): $\delta 132.1$ (CH arom.), 129.0 (CH arom.), 128.6 (CH arom.), 128.5 (CH arom.), 128.4 (CH arom.), 128.1 (CH arom.), 128.0 (CH arom.), 127.9 (CH arom.), 127.8 (CH arom.), 127.7 (CH arom.), 127.6 (CH arom.), 87.6 (C-1), 86.9 (C-3), 81.0 (C-5), 79.2 (C-2), 77.9 (C-4), $76.0\left(\mathrm{CH}_{2}\right.$ 3-O-Bn), 75.6 $\left(\mathrm{CH}_{2}\right.$ arom. 2-O-Bn), $75.2\left(\mathrm{CH}_{2}\right.$ 4-O-Bn), $73.6\left(\mathrm{CH}_{2}\right.$ 6-O-Bn), 69.2 (C-6); HRMS(ESI) $m / z$ calcd. for $\left[\mathrm{C}_{40} \mathrm{H}_{40} \mathrm{O}_{5} \mathrm{~S}+\mathrm{NH}_{4}{ }^{+}\right]:$650.2935, obsd.: 650.2931.<smiles>[N]CCCO</smiles>

30
3-Azidopropanol (30). $\mathrm{NaN}_{3}(7.0 \mathrm{~g}, 108 \mathrm{mmol}, 5$ equiv.) was added to a solution of bromopropanol (17) $(1.95 \mathrm{~mL}, 21.6$ $\mathrm{mmol})$ in $\mathrm{H}_{2} \mathrm{O}(50 \mathrm{~mL})$. The reaction mixture was stirred at 
$90{ }^{\circ} \mathrm{C}$ under reflux for $16 \mathrm{~h}$, after which TLC-analysis showed complete disappearance of the starting material. Purification by column chromatography $(6: 1 \rightarrow 3: 1$, petroleum ether : ethyl acetate, $\mathrm{v}: \mathrm{v})$ yielded $\mathbf{3 0}$ as a colourless liquid (1.7 g, $79 \%) . R_{f}=0.19$ (1:1, petroleum ether : ethyl acetate, v:v); IR (thin film): 3330, 2946, 2881, 2088, 1258, $1045 \mathrm{~cm}^{-1}$; ${ }^{1} \mathrm{H}-\mathrm{NMR}\left(500 \mathrm{MHz}, \mathrm{CDCl}_{3}\right.$ ): $\delta 3.77$ (t, 2H, $\mathrm{CH}_{2} \mathrm{OH}$ ), 3.46 (t, 2H, $\mathrm{CH}_{2} \mathrm{~N}_{3}$ ), 1.84 (quint, $2 \mathrm{H}, \mathrm{CH}_{2}$ ); ${ }^{13} \mathrm{C}-\mathrm{NMR}$ (125 MHz, $\left.\mathrm{CDCl}_{3}\right): 60.1\left(\mathrm{CH}_{2} \mathrm{OH}\right), 48.6\left(\mathrm{CH}_{2} \mathrm{~N}_{3}\right), 31.6\left(\mathrm{CH}_{2}\right), 48.6,31.6 ; \mathrm{HRMS}(\mathrm{ESI}) \mathrm{m} / \mathrm{z}$ calcd. for $\left[\mathrm{C}_{3} \mathrm{H}_{7} \mathrm{~N}_{3} \mathrm{O}+\mathrm{H}\right]^{+}$: 102.0662 , obsd.: 102.0632 .

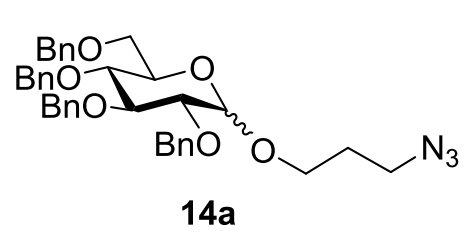

3-Azidopropyl 2,3,4,6-tetra- $O$-benzyl- $\alpha, \beta$-Dglucopyranoside (14a). Method A: Thioglycoside 25 ( $0.26 \mathrm{~g}, 0.41 \mathrm{mmol})$ along with azidopropanol (30) (0.14 g, $1.4 \mathrm{mmol}, 3.5$ equiv.) were coevaporated in dry toluene three times. $\mathrm{CH}_{2} \mathrm{Cl}_{2}(2.0 \mathrm{~mL})$ was added and the solution was stirred for $1 \mathrm{~h}$ in the presence of $4 \AA$ molecular sieves under an argon atmosphere. After NIS (0.12 g, 0.53 mmol, 1.3 equiv.) was added, the light red solution was cooled to $0{ }^{\circ} \mathrm{C}$ before the addition of freshly distilled $\mathrm{TfOH}(0.04 \mathrm{~mL}$, $0.41 \mathrm{mmol}, 1$ equiv.). The reaction mixture was allowed to stir for half an hour before TLC-analysis showed complete disappearance of the starting materials and the reaction was quenched with $\mathrm{NEt}_{3}(0.041 \mathrm{~mL}, 0.41 \mathrm{mmol}, 1$ equiv.). Purification by column chromatography $(10: 1 \rightarrow 4: 1$, petroleum ether : ethyl acetate, v:v) yielded 14a as a colourless oil $(0.14 \mathrm{~g}, 57 \%, 1: 3 \alpha: \beta)$. Method B: Thioethyl glucose 25 (100 mg, $0.17 \mathrm{mmol})$ and azidopropanol 30 (172 mg, $1.7 \mathrm{mmol}, 10$ equiv.) were co-evaporated three times with DMF, where the solvent was partially concentrated upon the final co-evaporation, leaving $1.4 \mathrm{~mL}$ of DMF in the flask. Freshly activated $4 \AA$ molecular sieves were added to the reaction flask before the solution was dissolved in $2.8 \mathrm{~mL}$ of $\mathrm{CH}_{2} \mathrm{Cl}_{2}$ and left to stir under an argon atmosphere for 15 minutes. $\mathrm{CuBr}_{2}(115 \mathrm{mg}, 0.52 \mathrm{mmol}, 3$ equiv.) and $\mathrm{TPABr}(0.140 \mathrm{mg}, 0.52$ mmol, 3 equiv.) were added to the solution, which was left to stir at rt for $10 \mathrm{~d}$ days before it was quenched by the addition of sat. aq. $\mathrm{NaHCO}_{3}(2 \mathrm{~mL})$. The product was then extracted using $\mathrm{CH}_{2} \mathrm{Cl}_{2}$ and the combined organic layers washed with brine and $\mathrm{Na}_{2} \mathrm{~S}_{2} \mathrm{O}_{3}$ (2 $\mathrm{mL}$ each). Purification by silica gel flash chromatography $(0: 1 \rightarrow 1: 200$, ethyl acetate : toluene, v:v) yielded $14 \mathrm{a}$ as a colourless oil (88.2 mg, 82\%, 5:1 $\alpha: \beta) . R_{f}=0.55$ (1:10, ethyl acetate : toluene, v:v); 
$[\alpha]_{\mathrm{D}}^{21}=-49^{\circ}\left(\mathrm{c}=0.1, \mathrm{CHCl}_{3}\right)$; IR (thin film): 2920, 2868, 2094, 1453, 1359, 1066, 1027, 734, $696 \mathrm{~cm}^{-1} ;{ }^{1} \mathrm{H}-\mathrm{NMR}\left(500 \mathrm{MHz}, \mathrm{CDCl}_{3}\right): \delta$ 7.35-7.14 (m, $20 \mathrm{H}, \mathrm{CH}$ arom.), 4.99 (d, 1H, Ja, $=11 \mathrm{~Hz}, \mathrm{CH}-\mathrm{a}$ 3'-O-Bn), 4.85-4.82 (m, 2H, CH-b 3'-O-Bn, CH-a 4'-O-Bn), 4.79 (d, 1H, Ja,b $=12 \mathrm{~Hz}, \mathrm{CH}-\mathrm{a}$ 2'-O-Bn), 4.75 (d, 1H, $J_{1,2}=2 \mathrm{~Hz}$, H-1'), 4.66-4.603 (m, 2H, CH-b 2'-O-Bn, CH-a 6-O-Bn), 4.49 (d, 1H, Ja,b $=11 \mathrm{~Hz}$, CH-b 6'-O-Bn), 3.97 (t, J = 9 Hz, H-3'), 3.76-3.73 (m, 3H, H-1a, H-5', H-6'a), 3.66 - 3.63 (m, 2H, H-6’b, H-4'), 3.59-3.56 (m, 1H, H-2'), 3.49-3.40 (m, 3H, H-1b, H3a, H-3b), 1.92-1.88 (m, 2H, H-2a, H-2b); ${ }^{13} \mathrm{C}-\mathrm{NMR}\left(125 \mathrm{MHz}, \mathrm{CDCl}_{3}\right.$ ): $\delta 139.0$ ( $\mathrm{C}_{\mathrm{i}}$ arom. 3'-O-Bn), 138.4 ( $\mathrm{C}_{\mathrm{i}}$ arom. 4'-O-Bn), 138.3 ( $\mathrm{C}_{\mathrm{i}}$ arom. 2'-O-Bn), $138.1\left(\mathrm{C}_{\mathrm{i}}\right.$ arom. 6'-O-Bn), 128.1 (CH arom.), 128.0 (CH arom.), 127.9 (CH arom.), 127.8 (CH arom.), 97.4 (C-1'), 82.2 (C-3’), 80.2 (C-2'), 77.8 (C-4'), 75.8 ( $\mathrm{CH}_{2} 3^{\prime}$-O-Bn), 75.3 ( $\mathrm{CH}_{2}$ 4'-O-Bn), 73.6 ( $\mathrm{CH}_{2}$ 6'-O-Bn), $73.4\left(\mathrm{CH}_{2} 2^{\prime}-\mathrm{O}-\mathrm{Bn}\right), 70.5$ (C-5'), $68.6\left(\mathrm{C}-6^{\prime}\right)$, 64.9 (C-1), 48.5 (C-3), 29.0 (C-2); HRMS(ESI) m/ ₹ calcd. for $\left[\mathrm{C}_{37} \mathrm{H}_{41} \mathrm{~N}_{3} \mathrm{O}_{6}+\mathrm{NH}_{4}\right]^{+}$: 641.3334, obsd.: 641.3311.

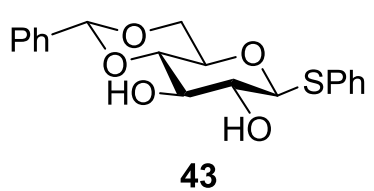

Phenyl

4,6-O-benzylidine-1-thio- $\beta$-D-

glucopyranoside (43). To a solution of thioglycoside

$29(1.02 \mathrm{~g}, 4.9 \mathrm{mmol})$ in acetonitrile $(24.5 \mathrm{~mL})$, camphor

sulfonic acid (0.051 g, $0.22 \mathrm{mmol}, 0.05$ equiv.) and benzaldehyde dimethyl acetal ( $0.88 \mathrm{~mL}, 5.89 \mathrm{mmol}, 1.2$ equiv.) were added. The solution was allowed to stir at $40{ }^{\circ} \mathrm{C}$ for $1.5 \mathrm{~h}$, upon which TLC-analysis showed the formation of a higher running product. The reaction was neutralised using sat. aq. $\mathrm{NaHCO}_{3}$, extracted with $\mathrm{Et}_{2} \mathrm{O}$, then washed with water and brine before drying with anhydrous $\mathrm{MgSO}_{4}$, which was filtered off, while the filtrate was concentrated in vacuo. Purification by column chromatography $(5: 1 \rightarrow 0: 1$, petroleum ether : ethyl acetate, $\mathrm{v}: \mathrm{v})$, followed by recrystallisation from $\mathrm{Et}_{2} \mathrm{O}$ and $\mathrm{CH}_{2} \mathrm{Cl}_{2}$ yielded 43 as white fluffy crystals $(1.03 \mathrm{~g}, 71 \%) . \mathrm{R}_{f}=0.23(2: 1$, petroleum ether : ethyl acetate, $\mathrm{v}: \mathrm{v}) ;[\alpha]_{\mathrm{D}}{ }^{21}=$ $+17^{\circ}\left(\mathrm{c}=0.1, \mathrm{CHCl}_{3}\right) ; \mathrm{Mp}=171.3^{\circ} \mathrm{C}$; IR (thin film): 3383, 1451, 1440, 1369, 1169, 1114, 1087, 1066, 1037, 1023, 1006, 970, 744, $696 \mathrm{~cm}^{-1} ;{ }^{1} \mathrm{H}-\mathrm{NMR}(500 \mathrm{MHz}$, $\left.\mathrm{CDCl}_{3}\right): \delta$ 7.55-7.54 (m, 2H, CH arom.), 7.49-7.47 (m, 2H, CH arom.), 7.37-7.34 (m, 6H, CH arom.), 5.53 (s, 1H, PhCH), 4.64 (d, $\left.J_{1,2}=9.7 \mathrm{~Hz}, 1 \mathrm{H}, \mathrm{H}-1\right), 4.39$ (dd, $\left.J_{6 \mathrm{a}, 6 \mathrm{~b}}=10.5 \mathrm{~Hz}, J_{6 \mathrm{a}, 5}=3.03 \mathrm{~Hz}, 1 \mathrm{H}, \mathrm{H}-6 \mathrm{a}\right), 3.85$ (t, $\left.J_{2,3}=J_{3,4}=8.2 \mathrm{~Hz}, 1 \mathrm{H}, \mathrm{H}-3\right)$, 3.80-3.77 (m, 1H, H-6b), 3.53-3.52 (m, 2H, H-4, H-5), 3.47 (t, $J_{1,2}=J_{2,3}=9.2 \mathrm{~Hz}$, $1 \mathrm{H}, \mathrm{H}-2), 2.83$ (s, 1H, 3-OH), 2.69 (s, $1 \mathrm{H}, 2-\mathrm{OH}) ;{ }^{13} \mathrm{C}-\mathrm{NMR}\left(125 \mathrm{MHz}, \mathrm{CDCl}_{3}\right): \delta$ 
137.0 (CH arom.), 133.2 (CH arom.), 131.4 (CH arom.), 129.5 (CH arom.), 129.3 (CH arom.), 128.7 (CH arom.), 128.5 (CH arom.), 126.4 (CH arom.), 102.1 ( $\mathrm{Ph}-$ CH), 88.8 (C-1), 80.3 (C-3), 74.7 (C-4), 72.7 (C-2), 70.7 (C-5), 68.7 (C-6); HRMS(ESI) m/z calcd. for $\left[\mathrm{C}_{19} \mathrm{H}_{20} \mathrm{O}_{5} \mathrm{~S}+\mathrm{H}\right]^{+}: 361.1104$, obsd.: 361.1121.

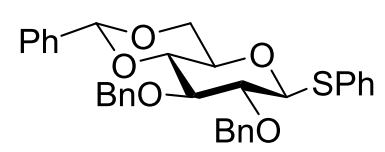

36

\section{Phenyl 2,3- $O$-benzyl-4,6- $O$-benzylidine-1-thio- $\beta$-D-} glucopyranoside (36). Thioglycoside 43 (1.61 g, 4.46 mmol) was co-evaporated three times with DMF, where the solution was concentrated to partial volume to leave $22 \mathrm{~mL}$ of DMF on the final co-evaporation. $\mathrm{BnBr}(1.91 \mathrm{~mL}, 16.1 \mathrm{mmol}$, 3.6 equiv.) and TBAI $(5 \mathrm{mg})$ were added to the reaction, which was then cooled to $0{ }^{\circ} \mathrm{C}$ before $\mathrm{NaH}$ (0.76 g, $17.4 \mathrm{mmol}, 3.9$ equiv.) was slowly added. The reaction was allowed to stir for $6 \mathrm{~h}$ at $\mathrm{rt}$, after which TLC-analysis showed complete formation of a higher running product. The solution was diluted using $\mathrm{Et}_{2} \mathrm{O}$, then washed with $\mathrm{H}_{2} \mathrm{O}$ and brine $(50 \mathrm{~mL}$ each) before the combined layers were dried with anhydrous $\mathrm{MgSO}_{4}$, which was filtered off before the filtrate was concentrated in vacuo. Purification by column chromatography $(20: 1 \rightarrow 10: 1$, petroleum ether : ethyl acetate, v:v) followed by recrystallisation from ethyl acetate and petroleum ether yielded 36 as white fluffy crystals $(1.21 \mathrm{~g}, 50 \%) . \mathrm{R}_{f}=0.52$ (4:1, petroleum ether : ethyl acetate, v:v); $[\alpha]_{\mathrm{D}}{ }^{22}=+129\left(\mathrm{c}=0.1, \mathrm{CHCl}_{3}\right) ; \mathrm{Mp}=141.5^{\circ} \mathrm{C}$; IR (thin film): 3063, 2901, 1440, 1369, 1088, 1069, 1002, $693 \mathrm{~cm}^{-1} ;{ }^{1} \mathrm{H}-\mathrm{NMR}(500 \mathrm{MHz}$, $\left.\mathrm{CDCl}_{3}\right): \delta$ 7.54-7.28 (m, $16 \mathrm{H}, \mathrm{CH}$ arom.), 5.59 (s, 1H, PhCH), $4.94\left(\mathrm{~d}, J_{\mathrm{a}, \mathrm{b}}=11.3\right.$ $\mathrm{Hz}, 1 \mathrm{H}, \mathrm{CH}-\mathrm{a}$ 3-O-Bn), 4.86 (d, $\left.J_{\mathrm{a}, \mathrm{b}}=10.4 \mathrm{~Hz}, 1 \mathrm{H}, \mathrm{CH}-\mathrm{a}, 2-\mathrm{O}-\mathrm{Bn}\right), 4.82$ (d, $J_{\mathrm{a}, \mathrm{b}}=$ $10.4 \mathrm{~Hz}, 1 \mathrm{H}, \mathrm{CH}-\mathrm{b}, 2-\mathrm{O}-\mathrm{Bn}), 4.78$ (d, $\left.J_{\mathrm{a}, \mathrm{b}}=11.3 \mathrm{~Hz}, 1 \mathrm{H}, \mathrm{CH}-\mathrm{b}, 3-\mathrm{O}-\mathrm{Bn}\right), 4.76$ (d, $J_{1,2}=10.0 \mathrm{~Hz}, 1 \mathrm{H}, \mathrm{H}-1$ ), 4.40-4.37 (m, 1H, H-6a), 3.86-3.79 (m, 2H, H-3, H-6b), $3.71\left(\mathrm{t}, J_{3,4}=J_{4,5}=9.1 \mathrm{~Hz}, 1 \mathrm{H}, \mathrm{H}-4\right), 3.53-3.45(\mathrm{~m}, 2 \mathrm{H}, \mathrm{H}-2, \mathrm{H}-5) ;{ }^{13} \mathrm{C}-\mathrm{NMR}(125$ $\mathrm{MHz}, \mathrm{CDCl}_{3}$ ): $\delta 132.5$ (CH arom.), 129.2 (CH arom.), 128.5 (CH arom.), 128.4 (CH arom.), 128.3 (CH arom.), 128.0 (CH arom.), 127.9 (CH arom.), 126.1 (CH arom.), $101.3(\mathrm{PhCH}), 88.4$ (C-1), 83.2 (C-3), 81.6 (C-4), 80.6 (C-2), $76.0\left(\mathrm{CH}_{2} 2-\mathrm{O}-\right.$ $\mathrm{Bn}), 75.5$ ( $\mathrm{CH}_{2}$ 3-O-Bn), 70.4 (C-5), 68.9 (C-6); HRMS(ESI) m/ $\%$ calcd. for $\left[\mathrm{C}_{33} \mathrm{H}_{32} \mathrm{O}_{5} \mathrm{~S}+\mathrm{H}\right]^{+}:$541.2043, obsd.: 541.2083 . 


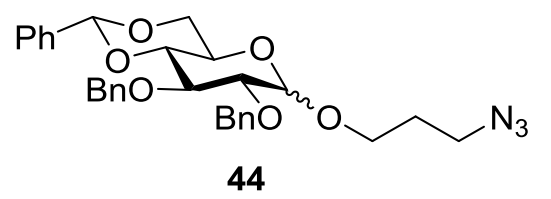

3-Azidopropyl-2,3-di-O-benzyl-4,6-Obenzylidene- $\alpha / \beta$-D-glucopyranoside (44).

Method A: Thiophenyl glycoside $36(160 \mathrm{mg}$, $0.30 \mathrm{mmol})$ and alcohol 30 (0.105 $\mathrm{mg}, 1.03$

mmol, 3.5 equiv.) were co-evaporated three times in toluene to remove traces of water before freshly distilled $\mathrm{CH}_{2} \mathrm{Cl}_{2}(1.48 \mathrm{~mL})$ and activated $4 \AA$ molecular sieves were added. The reaction mixture was then allowed to stir under an argon atmosphere for $1 \mathrm{~h}$ before cooling it to $-30{ }^{\circ} \mathrm{C}$. NIS (0.090 g, $0.39 \mathrm{mmol}, 1.3$ equiv.) was then added to the reaction flask, and the solution was cooled further to $-60^{\circ} \mathrm{C}$ before distilled TfOH ( $0.030 \mathrm{~mL}, 0.30 \mathrm{mmol}, 1$ equiv.) was added. After 1.5 $\mathrm{h}$, the reaction was allowed to warm to $0{ }^{\circ} \mathrm{C}$ for a further $1 \mathrm{~h}$ before TLC analysis showed complete disappearance of the donor. The reaction was quenched with $\mathrm{NEt}_{3}$ (0.040 mL, $0.30 \mathrm{mmol}, 1$ equiv.), followed by addition of sat. aq. $\mathrm{NaHCO}_{2}$ (5 $\mathrm{mL})$. The product was extracted using $\mathrm{CH}_{2} \mathrm{Cl}_{2}(3 \times 5 \mathrm{~mL})$, and the combined organic layers washed with brine and sat. aq. $\mathrm{Na}_{2} \mathrm{~S}_{2} \mathrm{O}_{3}(5 \mathrm{~mL}$ each) and dried using anhydrous $\mathrm{MgSO}_{4}$, which was filtered off and the filtrate concentrated in vacuo. The product was then isolated using silica gel flash column chromatography $(10: 1 \rightarrow$ 4:1, petroleum ether : ethyl acetate, v:v) to yield 44 as a colourless oil $(60 \mathrm{mg}, 36 \%$, 1:1 $\alpha: \beta)$. Method B: Thiophenol $36(30 \mathrm{mg}, 0.050 \mathrm{mmol})$ and acceptor $30(20 \mathrm{mg}$, $0.19 \mathrm{mmol}, 3.5$ equiv.) were co-evaporated in toluene three times to remove traces of water. Freshly distilled $\mathrm{CH}_{2} \mathrm{Cl}_{2}(0.27 \mathrm{~mL})$ and $4 \AA$ molecular sieves were then added before the reaction was left to stir at $40{ }^{\circ} \mathrm{C}$ under an argon atmosphere. After $20 \mathrm{~min}$, DMTST (40 mg, $0.15 \mathrm{mmol}, 3$ equiv.) was added to the reaction flask and the reaction was left to stir for a further $5 \mathrm{~h}$, when TLC analysis showed the complete disappearance of starting materials. The reaction was then quenched by the addition of sat. aq. $\mathrm{NaHCO}_{3}$, followed by $\mathrm{H}_{2} \mathrm{O}$ and brine $(5 \mathrm{~mL}$ each) and the product extracted with $\mathrm{CH}_{2} \mathrm{Cl}_{2}(3 \times 5 \mathrm{~mL})$. The combined organic layers were then dried using anhydrous $\mathrm{MgSO}_{4}$, which is filtered off and the filtrate concentrated in vacuo. Purification by silica gel chromatography (10:1 $\rightarrow$ 4:1, petroleum ether : ethyl acetate, v:v) gave 46 as a colourless oil $(5.1 \mathrm{mg}, 18 \%, 2: 1$ $\alpha: \beta)$. Method C: Thioglycoside $36(64 \mathrm{mg}, 0.12 \mathrm{mmol}$ ) and acceptor 30 (42 mg, $0.42 \mathrm{mmol}, 3.5$ equiv.) were co-evaporated in $\mathrm{CH}_{2} \mathrm{Cl}_{2}$ before dry $\mathrm{CH}_{2} \mathrm{Cl}_{2}(0.65 \mathrm{~mL})$ and freshly activated $4 \AA$ molecular sieves were added. TPABr $(16 \mathrm{mg}, 0.60 \mathrm{mmol}$, 5 equiv.) and $\mathrm{Br}_{2}$ (24 mg, $0.30 \mathrm{mmol}, 2.5$ equiv.) were then added, and the reaction 
was allowed to stir at $\mathrm{rt}$ under argon atmosphere for 3 days, after which TLC analysis showed the complete disappearance of starting materials. The reaction was then quenched by the addition of sat. aq. $\mathrm{NaHCO}_{3}$, followed by brine and $\mathrm{H}_{2} \mathrm{O}(5$ $\mathrm{mL}$ each), and the product extracted using $\mathrm{CH}_{2} \mathrm{Cl}_{2}(3 \times 5 \mathrm{~mL})$. The combined organic layers were then dried using anhydrous $\mathrm{MgSO}_{4}$, which was filtered off and the filtrate concentrated in vacuo. Purification by silica gel flash column chromatography $(10: 1 \rightarrow 4: 1$, petroleum ether : ethyl acetate, v:v) gave 44 as a colourless oil (8.3 mg, 18\%, 3:1 $\alpha: \beta) ; R_{f}=0.28$ (4:1, petroleum ether : ethyl acetate, v:v); IR (thin film): 2925, 2096, 1454, 1089, 749, $698 \mathrm{~cm}^{-1} ;{ }^{1} \mathrm{H}-\mathrm{NMR}(500 \mathrm{MHz}$, $\left.\mathrm{CDCl}_{3}\right) \delta$ 7.56-7.13 (CH arom.), 5.61 (s, $\left.1 \mathrm{H}, \mathrm{PhCH}\right), 4.97-4.95$ (m, 2H, $\beta-\mathrm{CH}_{2}$-a 3'$\mathrm{O}-\mathrm{Bn}, \alpha-\mathrm{CH}_{2}$-a 3'-O-Bn), 4.88-4.82 (m, 5H, $\beta-\mathrm{CH}_{2}-\mathrm{b}$ 3'-O-Bn, $\beta-\mathrm{CH}_{2}-\mathrm{b}$ 3'-O-Bn, $\beta$ $\mathrm{CH}_{2}$-a 2'-O-Bn, $\beta-\mathrm{CH}_{2}-\mathrm{b} 2^{\prime}-\mathrm{O}-\mathrm{Bn}, \alpha-\mathrm{CH}_{2}-\mathrm{a} 2^{\prime}-\mathrm{O}-\mathrm{Bn}$ ), 4.76 (d, $J_{1^{\prime}, 2^{2}}=3.7 \mathrm{~Hz}, 1 \mathrm{H}, \alpha-$ H-1'), 4.71 (d, $\left.J_{a, b}=12 \mathrm{~Hz}, 1 \mathrm{H}, \alpha-\mathrm{CH}_{2}-\mathrm{b} 2^{\prime}-\mathrm{O}-\mathrm{Bn}\right), 4.52$ (d, $J_{1,2}=8.1 \mathrm{~Hz}, 1 \mathrm{H}, \beta-\mathrm{H}-1^{\prime}$ ), 4.39 (m, 1H, $\left.\beta-\mathrm{H}-6^{\prime} \mathrm{a}\right), 4.31$ (m, 1H, $\left.\alpha-\mathrm{H}-6^{\prime} \mathrm{a}\right), 4.08$ (t, $J_{\alpha-2^{\prime}, \alpha-3^{\prime}}=J_{\alpha-3^{\prime}, \alpha-4^{\prime}}=9.5 \mathrm{~Hz}, 1 \mathrm{H}, \alpha-$ H-3'), 4.02 (m, 1H, $\beta-\mathrm{H}-1 \mathrm{a}), 3.88$ (m, 1H, $\left.\alpha-\mathrm{H}-4^{\prime}\right)$, 3.86-3.43 (m, 8H, $\beta-\mathrm{H}-6$ 'b, $\alpha-\mathrm{H}-$ 1a, $\beta-H-3$ ', $\alpha-H-6$ 'b, $\beta-\mathrm{H}_{-5}$ ', $\beta-\mathrm{H}-1 \mathrm{~b}, \alpha-\mathrm{H}-5$ ', $\alpha-\mathrm{H}-2$ '), 3.50-3.43 (m, 5H, $\alpha-\mathrm{H}-1 \mathrm{~b}, \beta-$ H-2', H-3, $\left.\beta-\mathrm{H}^{\prime}{ }^{\prime}\right)$; ${ }^{13} \mathrm{C}-\mathrm{NMR}\left(125 \mathrm{MHz}, \mathrm{CDCl}_{3}\right)$ : $\delta 138.6\left(\mathrm{C}_{\mathrm{i}} 3^{\prime}-\mathrm{O}-\mathrm{Bn}\right), 138.4\left(\mathrm{C}_{\mathrm{i}} \beta-\right.$ 2'-O-Bn), 138.3 (C $\mathrm{C}_{\mathrm{i}} \alpha-2$ '-O-Bn), $137.5\left(\mathrm{C}_{\mathrm{i}} \alpha-\mathrm{PhCH}\right), 137.4\left(\mathrm{C}_{\mathrm{i}} \beta-\mathrm{PhSH}\right), 129.0(\mathrm{CH}$ arom.), 128.6 (CH arom.), 128.5 (CH arom.), 128.4 (CH arom.), 128.3 (CH arom.), 128.1 (CH arom.), 128.1 (CH arom.), 128.0 (CH arom.), 127.9 (CH arom.), 127.7 (CH arom.), 127.7(CH arom.), 104.0 ( $\left.\beta-\mathrm{C}-1^{\prime}\right), 101.3(\alpha-\mathrm{PhCH}), 101.2(\beta-\mathrm{PhCH})$, $98.3\left(\alpha-\mathrm{C}-1^{\prime}\right), 82.2\left(\alpha-\mathrm{C}-2^{\prime}\right), 82.1\left(\alpha-\mathrm{C}-5^{\prime}\right), 81.5\left(\beta-\mathrm{C}-5^{\prime}\right), 81.0\left(\beta-\mathrm{C}-3^{\prime}\right), 79.4\left(\alpha-\mathrm{C}-2^{\prime}\right)$, $78.6\left(\alpha-\mathrm{C}-3^{\prime}\right), 75.5\left(\beta-\mathrm{CH}_{2} 3^{\prime}-\mathrm{O}-\mathrm{Bn}\right), 75.3\left(\alpha-\mathrm{CH}_{2} 3^{\prime}-\mathrm{O}-\mathrm{Bn}\right), 75.1\left(\beta-\mathrm{CH}_{2}{ }^{\prime}-\mathrm{O}-\mathrm{Bn}\right)$, $73.7\left(\alpha-\mathrm{CH}_{2} 2^{\prime}-\mathrm{O}-\mathrm{Bn}\right), 69.1$ ( $\left.\alpha-\mathrm{C}-6^{\prime}\right), 68.8$ ( $\left.\beta-\mathrm{C}-6^{\prime}\right), 66.9$ ( $\left.\beta-\mathrm{C}-4^{\prime}\right), 66.1(\beta-\mathrm{C}-1), 65.0$ $(\alpha-\mathrm{C}-1), \quad 62.6\left(\alpha-\mathrm{C}^{\prime}\right), 48.2$ (C-3), 29.3 (C-2); HRMS(ESI) $\mathrm{m} / \mathrm{z}$ calcd. for $\left[\mathrm{C}_{30} \mathrm{H}_{33} \mathrm{~N}_{3} \mathrm{O}_{6}+\mathrm{H}^{+}\right]:$532.2442, obsd.: 532.2447.

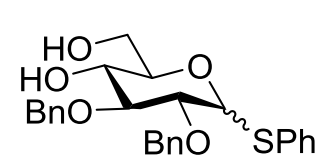

50

\section{Phenyl 2,3-di- $O$-benzyl-1- $\alpha / \beta$-thio-D-glucopyranoside}

(50). Thioglucoside 44 (238 $\mathrm{mg}, 0.44 \mathrm{mmol})$ was dissolved in $10 \mathrm{~mL}$ of $\mathrm{CH}_{2} \mathrm{Cl}_{2}$ and $\mathrm{MeOH}(1: 1, \mathrm{v}: \mathrm{v})$ before paratoluenesulfonic acid (pTsOH) (7.58 mg, $0.044 \mathrm{mmol}, 0.1$ equiv.) was added. The reaction was left to stir for $16 \mathrm{~h}$ at $\mathrm{rt}$, after which TLC analysis showed complete conversion of starting materials into a lower running product. The solution was quenched with $\mathrm{NEt}_{3}(1 \mathrm{~mL})$ and concentrated in vacuo to yield crude thioglucoside 
50 (114 mg, 57\%) which was used without further purification. $\mathrm{R}_{f}=0.02(1: 1$, petroleum ether : ethyl acetate, v:v); HRMS(ESI) $m /$ r calcd. for $\left[\mathrm{C}_{26} \mathrm{H}_{28} \mathrm{O}_{5} \mathrm{~S}+\mathrm{H}^{+}\right]$: 453.1730, obsd.: 453.1728 .

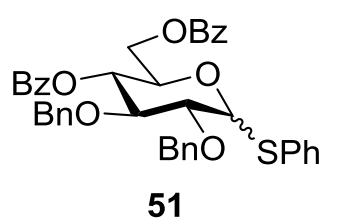

Phenyl 2,3-di- $O$-benzyl-4,6-di- $O$-benzoyl-1-thio- $\alpha / \beta$ D-glucopyranoside (51). Diol 50 (114 mg, $0.25 \mathrm{mmol}$ ) was dissolved in pyridine $(10 \mathrm{~mL})$ before the dropwise addition of $\mathrm{BzCl}(0.070 \mathrm{~mL}, 0.58 \mathrm{mmol}, 2.3$ equiv.). The yellow solution was left to stir for $16 \mathrm{~h}$, after which TLC analysis showed the complete conversion of a lower running product. The reaction was then neutralized with $0.1 \mathrm{M} \mathrm{HCl}(5 \mathrm{~mL})$ and the product was extracted using $\mathrm{CH}_{2} \mathrm{Cl}_{2}$ (3 x $10 \mathrm{~mL})$ and washed with brine and $\mathrm{H}_{2} \mathrm{O}(10 \mathrm{~mL}$ each). The combined organic layers were dried using anhydrous $\mathrm{MgSO}_{4}$, which was filtered off and the filtrate concentrated in vacuo. Purification using silica gel flash column chromatography $(10: 1 \rightarrow 5: 1$, petroleum ether : ethyl acetate, v:v) gave $\mathbf{5 1}$ as a colourless oil ( $0.13 \mathrm{~g}$, $96 \%) . \mathrm{R}_{f}=0.64$ (1:1, petroleum ether : ethyl acetate, v:v); IR (thin film): 3062, 2924, 1787, 1720, 1691, 1452, 1318, 1277, 1212, 1039, 1016, $707 \mathrm{~cm}^{-1} .{ }^{1} \mathrm{H}-\mathrm{NMR}$ (500 MHz, $\left.\mathrm{CDCl}_{3}\right): \delta 8.02(\mathrm{~m}, 2 \mathrm{H}, \mathrm{CH}$ arom. 6-O-Bz), 7.97 (m, 2H, CH arom. 4O-Bz), 7.56-7.05 (m, $25 \mathrm{H}, \mathrm{CH}$ arom.), 5.42 (t, $\left.J_{\mathrm{e}, \mathrm{r}}=9.5 \mathrm{~Hz}, 1 \mathrm{H}, \mathrm{H}-4\right), 4.92$ (d, $\left.J_{\mathrm{a}, \mathrm{b}}=10 \mathrm{~Hz}, 1 \mathrm{H}, \mathrm{CH}_{2}-\mathrm{a} 2-\mathrm{O}-\mathrm{Bn}\right), 4.78-4.74\left(\mathrm{~m}, 3 \mathrm{H}, \mathrm{CH}_{2}-\mathrm{b} 2-\mathrm{O}-\mathrm{Bn}, \mathrm{CH}_{2}-\mathrm{a} 3-\mathrm{O}-\mathrm{Bn}\right.$, H-1), 4.64-4.59 (m, 2H, $\mathrm{CH}_{2}$-b 3-O-Bn, H-6a), 4.37-4.34 (m, 1H, H-6b), 3.93 (t, $\left.J_{4,5}=J_{5,6}=7.5 \mathrm{~Hz}, 1 \mathrm{H}, \mathrm{H}-5\right), 3.86\left(\mathrm{t}, J_{2,3}=J_{3,4}=9 \mathrm{~Hz}, 1 \mathrm{H}, \mathrm{H}-3\right), 3.64\left(\mathrm{t}, J_{1,2}=J_{2,3}=9.5 \mathrm{~Hz}\right.$, 1H, H-2); ${ }^{13} \mathrm{C}-\mathrm{NMR}\left(125 \mathrm{MHz}, \mathrm{CDCl}_{3}\right): \delta 166.3$ (C=O 6-O-Bz), $165.4(\mathrm{C}=\mathrm{O} 4-\mathrm{O}-$ $\mathrm{Bz}), 138.0$ (CH arom.), 137.6 ( $\mathrm{CH}$ arom.), 133.5 (CH arom.), 133.2 (CH arom.), 132.4 (CH arom.), 130.0 (CH arom.), 129.9 (CH aom.), 129.4 (CH arom.), 129.0 (CH arom.), 128.6 (CH arom.), 128.5 (CH arom.), 128.4 (CH arom.), 128.2 (CH arom.), 128.1 (CH arom.), 127.9 (CH arom.), 87.7 (C-1), 83.8 (C-3), 80.7 (C-2), 76.1 (C-5), 75.8 ( $\mathrm{CH}_{2}$ 2-O-Bn), 75.7 ( $\mathrm{CH}_{2}$ 3-O-Bn), 70.9 (C-4), 63.6 (C-6); HRMS(ESI) $m /$ z. calcd. for $\left[\mathrm{C}_{40} \mathrm{H}_{36} \mathrm{O}_{7} \mathrm{~S}+\mathrm{NH}_{4}{ }^{+}\right]$: 678.2520, obsd.: 678.2512 .

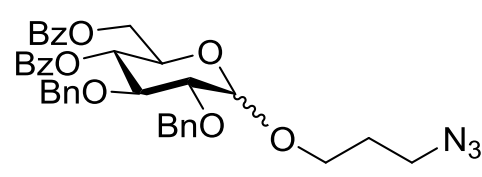

52
3-Azidopropyl-2,3-di- $O$-benzyl-4,6-di- $O$ benzoyl- $\alpha / \beta$-D-glucopyranoside (52). Thioglycoside 51 (19.7 $\mathrm{mg}, 0.036 \mathrm{mmol})$ and azidopropanol (30) were co-evaporated with dry

$\mathrm{CH}_{2} \mathrm{Cl}_{2}$ before freshly activated $4 \AA$ molecular sieves and dry $\mathrm{CH}_{2} \mathrm{Cl}_{2}(0.20 \mathrm{~mL})$ 
were added. The reaction was allowed to stir for 30 minutes in an argon atmosphere at rt before $\mathrm{Br}_{2}(3.0 \mu \mathrm{L}, 0.126 \mathrm{mmol}, 3.5$ equiv.) and $\mathrm{TPABr}(57.5 \mathrm{mg}$, 0.216 mmol, 5 equiv.) were added. The reaction was stirred for a further 30 minutes in an argon atmosphere at rt before TLC analysis showed the complete disappearance of starting materials. The reaction was then quenched by the addition of sat. aq. $\mathrm{NaHCO}_{3}$, washed with brine and $\mathrm{H}_{2} \mathrm{O}(5 \mathrm{~mL}$ each), and the product extracted using $\mathrm{CH}_{2} \mathrm{Cl}_{2}(3 \times 5 \mathrm{~mL})$. Purification by silica gel flash column chromatography $(10: 1 \rightarrow 5: 1$, petroleum ether : ethyl acetate, v:v) gave $\mathbf{5 2}(6.6 \mathrm{mg}$, $25 \%, 4.5: 1 \alpha: \beta) ; R_{f}=0.55$ (2:1, petroleum ether : ethyl acetate, v:v); IR (thin film): 2921, 2099, 1726, 1452, 1272, 1097, 1028, $711 \mathrm{~cm}^{-1}$; ${ }^{1} \mathrm{H}-\mathrm{NMR}$ (500 MHz, CD 3 OD):

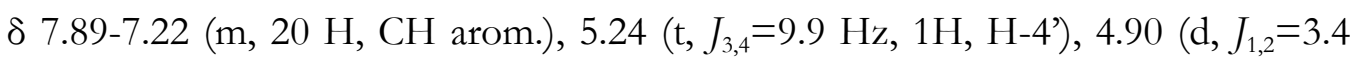
$\left.\mathrm{Hz}, 1 \mathrm{H}, \mathrm{H}-1^{\prime}\right), 4.72$ (d, $J_{\mathrm{a}, \mathrm{b}}=11.2 \mathrm{~Hz}, 1 \mathrm{H}, \mathrm{CH}_{2}$-a 3'-O-Bn), 4.68-4.62 (m, 2H, $\mathrm{CH}_{2}$-a 2'-O-Bn, $\mathrm{CH}_{2}-\mathrm{b}$ 2'-O-Bn), 4.53 (d, Ja,b $=11.2 \mathrm{~Hz}, 1 \mathrm{H}, \mathrm{CH}_{2}-\mathrm{b}$ 3'-O-Bn), 4.38 (d, $\left.J_{6 \mathrm{a}, 6 \mathrm{~b}}=12.3 \mathrm{~Hz}, 1 \mathrm{H}, \mathrm{H}-6 \mathrm{a}\right), 4.26$ (dd, $\left.J_{6 \mathrm{a}, 6 \mathrm{~b}}=12.3 \mathrm{~Hz}, 1 \mathrm{H}, \mathrm{H}-6 \mathrm{~b}\right), 4.14$ (m, 1H, H-5'), $4.04\left(\mathrm{t}, J_{2,3}=J_{3,4}=9.0 \mathrm{~Hz}, 1 \mathrm{H}, \mathrm{H}-3^{\prime}\right), 3.77$ (m, 2H, H-1), 3.64 (dd, $J_{1,2}=3.1 \mathrm{~Hz}, J_{2,3}=9.0$ $\left.\mathrm{Hz}, 1 \mathrm{H}, \mathrm{H}-2^{\prime}\right), 3.39$ (m, 2H, H-3), 1.83 (m, 2H, H-2); ${ }^{13} \mathrm{C}-\mathrm{NMR}$ (125 MHz, $\left.\mathrm{CD}_{3} \mathrm{OD}\right): \delta 165.6(\mathrm{C}=\mathrm{O}), 138.2\left(\mathrm{C}_{\mathrm{i}}{ }^{\prime}\right.$ '-O-Bn), 138.0 (C $\mathrm{C}_{\mathrm{i}}$ '-O-Bn), 133.2 (CH arom.), 132.9 (CH arom.), 129.4 (CH arom.), 129.2 (CH arom.), 128.2 ( $\mathrm{CH}$ arom.), 128.1 (CH arom.), 127.8 (CH arom.), 127.8 (CH arom.), 96.8 (C-1'), 80.1 (C-2’), 78.7 (C3'), 75.0 ( $\mathrm{CH}_{2}$ 3'-O-Bn), 72.7 ( $\mathrm{CH}_{2}$ 2'-O-Bn), 71.2 (C-4'), 67.6 (C-5'), 64.7 (C-1), 63.2 (C-6'), 47.8 (C-3), 28.4 (C-2); HRMS(ESI) m/ z calcd. for $\left[\mathrm{C}_{37} \mathrm{H}_{38} \mathrm{~N}_{3} \mathrm{O}_{8}+\mathrm{NH}_{4}\right]^{+}$: 669.2919, obsd.: 669.2906.

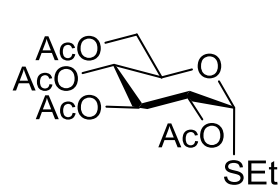

\section{Ethyl 2,3,4,6-tetra- $O$-acetyl-1-thio- $\alpha$-D-glucopyranoside}

(53). Peracetylated glucose 27 (3.8 g, $9.7 \mathrm{mmol})$ was co53

SEt evaporated three times with toluene before it was dissolved in dry $\mathrm{CH}_{2} \mathrm{Cl}_{2}(35 \mathrm{~mL})$. EtSH (0.86 mL, $11.6 \mathrm{mmol}, 1.2$ equiv.) was then added, followed by the dropwise addition of $\mathrm{SnCl}_{4}(0.56 \mathrm{~mL}, 4.9 \mathrm{mmol}$, 0.5 equiv.). The solution was allowed to stir for $16 \mathrm{~h}$, after which TLC-analysis showed complete disappearance of starting materials. The mixture was then diluted with $\mathrm{CH}_{2} \mathrm{Cl}_{2}$, and washed with sat. aq. $\mathrm{NaHCO}_{3}$ and brine (40 $\mathrm{mL}$ each), dried over anhydrous $\mathrm{MgSO}_{4}$, which was filtered off and the filtrate concentrated in vacuo to give crude $\mathbf{5 3}$ as a yellow oil. Purification using flash column chromatography $(5: 1 \rightarrow 1: 1$, petroleum ether : ethyl acetate, v:v) yielded a colourless oil, which was 
then recrystallised in boiling 3:1 petroleum ether : EtOH (v:v), forming white crystals upon cooling $(2.6 \mathrm{~g}, 70 \%) . R_{f}=0.47$ (1:1, petroleum ether : ethyl acetate, $\mathrm{v}: \mathrm{v}) ; \mathrm{Mp}=101.1^{\circ} \mathrm{C} ;[\alpha]_{\mathrm{D}}{ }^{20}=+1.78^{\circ}\left(\mathrm{c}=1.0, \mathrm{CH}_{2} \mathrm{Cl}_{2}\right)$; IR (film): $1735,1361,1325$, 1227, 1031, $641 \mathrm{~cm}^{-1} ;{ }^{1} \mathrm{H}-\mathrm{NMR}\left(500 \mathrm{MHz}, \mathrm{CDCl}_{3}\right): \delta 5.68$ (d, 1H, $J_{1,2}=5.6 \mathrm{~Hz}, \mathrm{H}-$ 1), $5.36\left(\mathrm{t}, 1 \mathrm{H}, J_{3,2}=J_{3,4}=9.3 \mathrm{~Hz}, \mathrm{H}-3\right), 5.04(\mathrm{~m}, 2 \mathrm{H}, \mathrm{H}-2$ and $\mathrm{H}-4), 4.44(\mathrm{~m}, 1 \mathrm{H}$, H-5), $4.30\left(\mathrm{dd}, 1 \mathrm{H}, J_{6 \mathrm{a}, 6 \mathrm{~b}}=12.2 \mathrm{~Hz}, J_{6 \mathrm{a}, 5}=3.6 \mathrm{~Hz}, \mathrm{H}-6 \mathrm{a}\right), 4.08\left(\mathrm{~d}, 1 \mathrm{H}, J_{6 \mathrm{~b}, 6 \mathrm{a}}=12.2\right.$ $\mathrm{Hz}, \mathrm{H}-6 \mathrm{~b}$ ), 2.56 (m, 2H, $\mathrm{CH}_{2} \mathrm{EtSH}$ ), 2.09 (s, 3H, $\mathrm{CH}_{3}, \mathrm{O}-\mathrm{Ac}$ ), 2.06 (s, 3H, $\mathrm{CH}_{3}, \mathrm{O}-$ Ac), 2.03 (s, 3H, $\mathrm{CH}_{3}, \mathrm{O}-\mathrm{Ac}$ ), 2.01 (s, 3H, $\mathrm{CH}_{3}, \mathrm{O}-\mathrm{Ac}$ ), 1.27 (t, 3H, $J_{\mathrm{CH} 3, \mathrm{CH} 2}=7.3$ $\left.\mathrm{Hz}, \mathrm{CH}_{3} \mathrm{EtSH}\right) ;{ }^{13} \mathrm{C}-\mathrm{NMR}\left(125 \mathrm{MHz}, \mathrm{CDCl}_{3}\right.$ ): $\delta 170.6$ (O-Ac), 170.0 (O-Ac), 169.9 (O-Ac), 169.6 (O-Ac), 81.7 (C-1), 70.7 (C-2), 70.5 (C-3), 68.6 (C-4), 67.5 (C-5), 61.9 (C-6), 24.2 ( $\mathrm{CH}_{2}$ EtSH), 20.7-20.6 ( $\left.\mathrm{CH}_{3}-\mathrm{OAc}\right), 14.7\left(\mathrm{CH}_{3} \mathrm{EtSH}\right) ; \mathrm{HRMS}(\mathrm{ESI}) \mathrm{m} / \mathrm{z}$ calcld. for $\left[\mathrm{C}_{10} \mathrm{H}_{24} \mathrm{O}_{9} \mathrm{~S}+\mathrm{NH}_{4}\right]^{2+}$ : 410.1479, obsd.: 410.1470 .

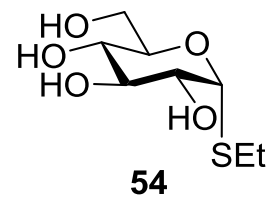

Ethyl 1-thio- $\alpha$-D-glucopyranoside (54). To a solution of $\mathbf{5 3}$ (2.6 g, $6.8 \mathrm{mmol})$ in dry $\mathrm{MeOH}(65 \mathrm{~mL}), \mathrm{NaOMe}(18 \mathrm{mg}, 0.34$ $\mathrm{mmol}$ ) was added. The reaction was left to stir at $\mathrm{rt}$ for $5 \mathrm{~h}$, after which the reaction was deemed complete by TLC-analysis (MeOH : ethyl acetate, 1:20, v:v) showing the formation of a low running spot. The reaction was neutralised by the addition of Dowex $-\mathrm{H}^{+}$, which was filtered off, and the solution concentrated in vacuo to yield $\mathbf{5 4}$ as a colourless oil (1.5 g, 99\%), which was used without further purification. $R_{f}=0.12(1: 20, \mathrm{MeOH}$ : ethyl acetate, v:v); ${ }^{1} \mathrm{H}-\mathrm{NMR}\left(500 \mathrm{MHz}, \mathrm{D}_{2} \mathrm{O}\right): \delta 5.42\left(\mathrm{~d}, 1 \mathrm{H}, J_{1,2}=5.4 \mathrm{~Hz}, \mathrm{H}-1\right), 4.04-4.01(\mathrm{~m}$, 1H, H-5), 3.86-3.75 (m, 3H, H-6a, H-2, H-6b), 3.56 (t, 1H, $J_{3,2}=J_{3,4}=9.5 \mathrm{~Hz}, \mathrm{H}-$ 3), $3.39\left(\mathrm{t}, 1 \mathrm{H}, J_{4,3}=J_{4,5}=9.8 \mathrm{~Hz}, \mathrm{H}-4\right), 2.67-2.59$ (m, $\left.2 \mathrm{H}, \mathrm{CH}_{2} \mathrm{EtSH}\right), 1.26(\mathrm{t}, 3 \mathrm{H}$, $\left.J_{\mathrm{CH} 2 \mathrm{CH} 3}=7.4 \mathrm{~Hz}, \mathrm{CH}_{3} \mathrm{EtSH}\right) \cdot{ }^{13} \mathrm{C}-\mathrm{NMR}\left(125 \mathrm{MHz}, \mathrm{D}_{2} \mathrm{O}\right): 84.9(\mathrm{C}-1), 73.6$ (C-3), 72.1 (C-5), 70.9 (C-2), 69.6 (C-4), 60.5 (C-6), 24.0 ( $\left.\mathrm{CH}_{2} \mathrm{EtSH}\right), 14.0\left(\mathrm{CH}_{3} \mathrm{EtSH}\right)$.

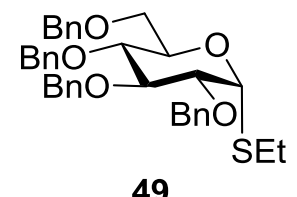

Ethyl 2,3,4,6-tetra- $O$-benzyl-1-thio- $\alpha$-D-glucopyranoside (49). Thioglucoside 54 (1.64 g, $7.3 \mathrm{mmol}$ ) was co-evaporated three times with DMF, whereby the solution was concentrated to partial volume to leave $36 \mathrm{~mL}$ of $\mathrm{DMF}$ on the final coevaporation. $\mathrm{BnBr}(7.0 \mathrm{~mL}, 58 \mathrm{mmol}, 8$ equiv.) and TBAI (0.27 g, $0.73 \mathrm{mmol}, 0.1$ equiv.) were added under an argon atmosphere, and the reaction was cooled to 0 ${ }^{\circ} \mathrm{C}$ before $\mathrm{NaH}$ (4.0 g, 55 mmol, 7.5 equiv.) was slowly added. The white solution 
was then left to stir under argon for $16 \mathrm{~h}$, upon which TLC analysis showed complete conversion of starting material into a higher running product. To quench the excess $\mathrm{BnBr}, \mathrm{MeOH}(10 \mathrm{~mL})$ was added before the solution was diluted with ethyl acetate $(20 \mathrm{~mL})$. The organic layer was washed with sat. aq. $\mathrm{NaHCO}_{3}$ and brine $\left(20 \mathrm{~mL}\right.$ each) and dried using anhydrous $\mathrm{MgSO}_{4}$, which was filtered off before the filtrate was concentrated in vacuo. Silica gel flash column chromatography $(20: 1 \rightarrow 10: 1$, petroleum ether : ethyl acetate, v:v) was used to isolate 49 as white crystals $(4.0 \mathrm{~g}, 94 \%) . \mathrm{R}_{f}=0.45$ (5:1, petroleum ether : ethyl acetate, v:v); $[\alpha]_{\mathrm{D}}{ }^{23}=-20^{\circ}\left(\mathrm{c}=0.1, \mathrm{CHCl}_{3}\right)$; IR (thin film): 3063, 2910, 2868, 1496, 1366, 1121, 1065, 733, 696; ${ }^{1} \mathrm{H}-\mathrm{NMR}\left(500 \mathrm{MHz} \mathrm{CDCl}_{3}\right): \delta 7.40-7.14(\mathrm{~m}, 20 \mathrm{H}, \mathrm{CH}$ arom.), 5.41 (d, $\left.J_{1,2}=4 \mathrm{~Hz}, \mathrm{H}-1\right), 4.95$ (d, $\left.J_{\mathrm{a}, \mathrm{b}}=11 \mathrm{~Hz}, 1 \mathrm{H}, \mathrm{CH}-\mathrm{a} 4-\mathrm{O}-\mathrm{Bn}\right), 4.83$ (d, $\left.J_{\mathrm{a}, \mathrm{b}}=11 \mathrm{~Hz}, 1 \mathrm{H}, \mathrm{CH}-\mathrm{a} 3-\mathrm{O}-\mathrm{Bn}\right), 4.77\left(\mathrm{~d}, J_{\mathrm{a}, \mathrm{b}}=11 \mathrm{~Hz}, 1 \mathrm{H}, \mathrm{CH}-\mathrm{b} 4-\mathrm{O}-\mathrm{Bn}\right), 4.73$ (d, $\left.J_{\mathrm{a}, \mathrm{b}}=12 \mathrm{~Hz}, 1 \mathrm{H}, \mathrm{CH}-\mathrm{a} 2-\mathrm{O}-\mathrm{Bn}\right), 4.67$ (d, $\left.J_{\mathrm{a}, \mathrm{b}}=12 \mathrm{~Hz}, 1 \mathrm{H}, \mathrm{CH}-\mathrm{b} 2-\mathrm{O}-\mathrm{Bn}\right), 4.61$ (d, $J_{\mathrm{a}, \mathrm{b}}=12 \mathrm{~Hz}, 1 \mathrm{H}, \mathrm{CH}-\mathrm{a}$ 6-O-Bn), 4.49-4.45 (m, 2H, CH-b 3-O-Bn, CH-b 6-O-Bn), $4.19\left(\mathrm{~d}, J_{5,6 \mathrm{a}}=10 \mathrm{~Hz}, \mathrm{H}-5\right), 3.87-3.84$ (m, 2H, H-4, H-2), 3.77 (dd, $J_{5,6 \mathrm{a}}=11 \mathrm{~Hz}$, $\left.J_{6 \mathrm{a}, 6 \mathrm{~b}}=2 \mathrm{~Hz}, 1 \mathrm{H}, \mathrm{H}-6 \mathrm{a}\right), 3.66-3.63$ (m, 2H, H-3, H-6b), 2.60-2.51 (m, 2H, $\mathrm{CH}_{2}$ $\mathrm{EtSH}), 1.27$ (t, $\left.J_{\mathrm{CH} 2, \mathrm{CH} 3}=7.3 \mathrm{~Hz}, 3 \mathrm{H}, \mathrm{CH}_{3} \mathrm{EtSH}\right) ;{ }^{13} \mathrm{C}-\mathrm{NMR}\left(125 \mathrm{MHz}, \mathrm{CDCl}_{3}\right): \delta$ 138.9 ( $\mathrm{C}_{\mathrm{i}}$ arom. O-Bn), 138.5 ( $\mathrm{C}_{\mathrm{i}}$ arom. O-Bn), 138.1 ( $\mathrm{C}_{\mathrm{i}}$ arom. O-Bn), $138.0\left(\mathrm{C}_{\mathrm{i}}\right.$ arom. O-Bn), 128.6 (CH arom.), 128.5 (CH arom.), 128.5 (CH arom.), $128.2(\mathrm{CH}$ arom.), 128.2 (CH arom.), 128.0 (CH arom.), 128.0 (CH arom.), 128.0 (CH arom.), 127.8 (CH arom.), 127.8 (CH arom.), 127.7 (CH arom.), 83.2 (C-1), 82.7 (C-4), 79.7 (C-2), 77.6 (C-3), 75.9 ( $\mathrm{CH}_{2}$ 4-O-Bn), 75.1 ( $\mathrm{CH}_{2}$ 3-O-Bn), 73.6 ( $\mathrm{CH}_{2}$ 6-O-Bn), 72.5 $\left(\mathrm{CH}_{2}\right.$ 2-O-Bn), 70.6 (C-5), 68.7 (C-6); HRMS(ESI) $\mathrm{m} / \mathrm{z}$ calcld. for $\left[\mathrm{C}_{36} \mathrm{H}_{40} \mathrm{O}_{5} \mathrm{~S}+\mathrm{NH}_{4}\right]^{+}$: 602.2935, obsd.: 602.2961

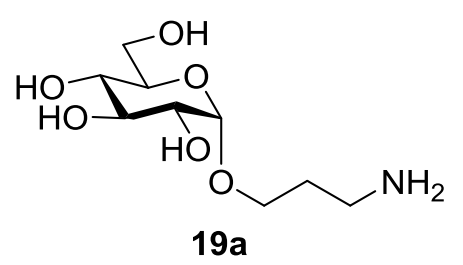

3-Azidopropyl-D-glucoside (19a). To a solution of per-benzylated glucoside 14a $(20 \mathrm{mg}, 0.032$ $\mathrm{mmol})$ in $\mathrm{CHCl}_{3}: \mathrm{MeOH}(10 \mathrm{~mL}, 3: 2, \mathrm{v}: \mathrm{v})$ was added $\mathrm{Pd}(\mathrm{OH})_{2} / \mathrm{C}(5 \mathrm{mg}, 20 \%$ catalyst, 0.0064 mmol, 0.2 equiv.). The reaction mixture was placed under $\mathrm{H}_{2}$ atmosphere and left to stir overnight. After TLC analysis showed complete conversion of starting materials into a lower running spot, the reaction mixture was filtered over celite, washed with $\mathrm{H}_{2} \mathrm{O}$, and concentrated in vacuo. Purification by flash column chromatography $\left(\mathrm{CH}_{2} \mathrm{Cl}_{2} \rightarrow\right.$ 5:2:2:1 $\mathrm{CH}_{2} \mathrm{Cl}_{2}: \mathrm{MeOH}: \mathrm{EtOH}: \mathrm{NH}_{3}(35 \%)$, v:v:v:v) 
yielded the fully deprotected glucoside 19a as a white amorphous solid (7.6 mg, quant.) $\mathrm{R}_{f}=0.20$ (5:2:2:2:1 $\mathrm{CH}_{2} \mathrm{Cl}_{2}: \mathrm{MeOH}: \mathrm{EtOH}: \mathrm{H}_{2} \mathrm{O}: \mathrm{NH}_{3}(35 \%)$, v:v:v:v:v); $[\alpha]_{\mathrm{D}}^{22}=+20^{\circ}(\mathrm{c}=2.0, \mathrm{MeOH})$; IR (thin film): 3124, 3046, 1403, $1016 \mathrm{~cm}^{-1} ;{ }^{1} \mathrm{H}-$ NMR (500 MHz, D $2 \mathrm{O}$ ): $\delta 4.93$ (d, $\left.J_{1,2}=3.7 \mathrm{~Hz}, 1 \mathrm{H}, \mathrm{H}-1^{\prime}\right)$, 3.92-3.8 (m, 1H, H-1a), $3.84\left(\mathrm{~d}, J_{6 \mathrm{a}, 6 \mathrm{~b}}=12.8 \mathrm{~Hz}, 1 \mathrm{H}, \mathrm{H}-6 \mathrm{\prime}\right.$ ) $), 3.73$ (dd, $J_{6 \mathrm{a}, 6 \mathrm{~b}}=12.8 \mathrm{~Hz}, J_{5,6 \mathrm{~b}}=5.5 \mathrm{~Hz}, 1 \mathrm{H}, \mathrm{H}-$ 6’b), 3.69-3.56 (m, 4H, H-5', H-4', H-1b, H-2'), 3.40 (t, $J_{2,3}=J_{3,4}=9.5 \mathrm{~Hz}, 1 \mathrm{H}$, H-3'), 3.21-3.11 (m, 2H, H-3), 2.012.02-1.97 (m, 2H, H-2); ${ }^{13} \mathrm{C}-\mathrm{NMR}$ (125 MHz, $\left.\mathrm{D}_{2} \mathrm{O}\right): \delta 98.2$ (C-1'), 72.9 (C-5’), 71.8 (C-4'), 71.0 (C-2’), 69.4 (C-3’), 65.7 (C-1), 60.5 (C-6'), 37.8 (C-3), 26.5(C-2); HRMS(ESI) $m / z$ calcld. for $\left[\mathrm{C}_{9} \mathrm{H}_{19} \mathrm{NO}_{6}+\mathrm{H}\right]^{+}$: 238.1285, obsd.: 238.1284 .

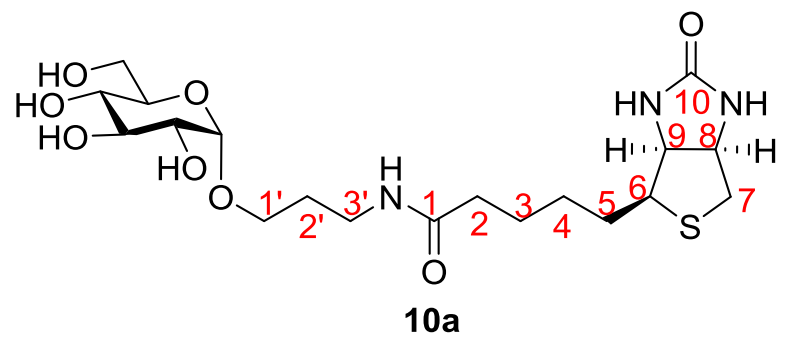

O-( $\alpha-\mathrm{D}-$ Glucopyranosyl)-3biotinylamido-propanol (10a). Deprotected glucoside 19a (8.7 $\mathrm{mg}, \quad 0.037 \mathrm{mmol})$ was coevaporated three times with DMF, where the solvent was concentrated to partial volume on the final co-evaporation, leaving $0.2 \mathrm{~mL}$ of DMF. D-Biotin (15) (11 mg, $0.041 \mathrm{mmol}, 1.1$ equiv.), HBTU $(28 \mathrm{mg}, 0.074 \mathrm{mmol}$, 2 equiv.), and $\mathrm{NEt}_{3}(0.011 \mathrm{~mL}, 0.081 \mathrm{mmol}, 2.2$ equiv.) were then added to the reaction, which was left to stir under an argon atmosphere. After $16 \mathrm{~h}$, TLC analysis showed complete conversion of starting materials to a higher running spot, the reaction was concentrated in vacuo. Purification using silica gel flash column chromatography $\left(\mathrm{CH}_{2} \mathrm{Cl}_{2} \rightarrow\right.$ 5:2:2:1, $\mathrm{CH}_{2} \mathrm{Cl}_{2}: \mathrm{MeOH}: \mathrm{EtOH}: \mathrm{NH}_{3}(35 \%)$, v:v:v:v) and further isolation using a size exclusion column (1:1, $\left.\mathrm{MeOH}: \mathrm{CH}_{2} \mathrm{Cl}_{2}, \mathrm{v}: \mathrm{v}\right)$ yielded 10a as a white amorphous solid (14 mg, 81\%). $\mathrm{R}_{f}=0.59$ (5:2:2:1, $\mathrm{CH}_{2} \mathrm{Cl}_{2}$ : $\mathrm{MeOH}: \mathrm{EtOH}: \mathrm{NH}_{3}(35 \%)$, v:v:v:v); $[\alpha]_{\mathrm{D}}{ }^{19}=12^{\circ}\left(\mathrm{c}=0.1, \mathrm{H}_{2} \mathrm{O}\right)$; IR (thin film): $3290,1677,1452,1428,1075,1032 \mathrm{~cm}^{-1} ;{ }^{1} \mathrm{H}-\mathrm{NMR}\left(500 \mathrm{MHz}, \mathrm{D}_{2} \mathrm{O}\right): \delta 4.88$ (d, $J_{1,2}, 2$ = 3.6 Hz, 1H, H-1"), 4.59-4.57 (m, 1H, H-8), 4.43-4.41 (m, 1H, H-9), 3.81 (d,

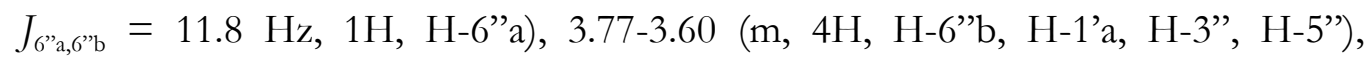
3.53-3.48 (m, 2H, H-1'b, H-2”), 3.37 (t, $J_{3^{\prime \prime}, 4^{\prime \prime}}=J_{4^{\prime \prime}, 5^{\prime}}=9.6 \mathrm{~Hz}, 1 \mathrm{H}, \mathrm{H}-4$ ”), 3.33-3.26 (m, 3H, H-6, H-3'a, H-3’b), 2.97 (dd, $J_{7 \mathrm{a}, 7 \mathrm{~b}}=13.0 \mathrm{~Hz}, J_{7 \mathrm{a}, 8}=5.2 \mathrm{~Hz}, 1 \mathrm{H}, \mathrm{H}-7 \mathrm{a}$ ), $2.75\left(\mathrm{~d}, J_{7 \mathrm{a}, 7 \mathrm{~b}}=13.2 \mathrm{~Hz}, 1 \mathrm{H}, \mathrm{H}-7 \mathrm{~b}\right), 2.23\left(\mathrm{t}, J_{2,3 \mathrm{a}}=J_{2,3 \mathrm{~b}}=8.1 \mathrm{~Hz}, 2 \mathrm{H}, \mathrm{H}-2\right), 1.86-$ 1.79 (m, 2H, H-2'), 1.73-1.52 (m, 3H, H-5a, H-3, H-5b), 1.41-1.35 (m, 2H, H-4); 
${ }^{13} \mathrm{C}-\mathrm{NMR}$ (125 MHz, D $2 \mathrm{O}$ ): $\delta 177.1$ (C=O C-10), 161.1 (C-1), 98.2 (C-1”), 73.1 (C3”), 71.8 (C-5”), 71.2 (C-2”), 69.7 (C-4”), 65.4 (C-1'), 62.0 (C-9), 60.2 (C-8), 55.4 (C-6), 39.7 (C-7), 36.2 (C-3’), 35.4 (C-2), 28.2 (C-2’), 27.9 (C-4), 27.5 (C-5), 25.1 (C3); HRMS(ESI) $m / z$ calcld. for $\left[\mathrm{C}_{19} \mathrm{H}_{33} \mathrm{~N}_{3} \mathrm{O}_{8} \mathrm{~S}+\mathrm{H}\right]^{+}$: 464.2061, obsd.: 464.2053.

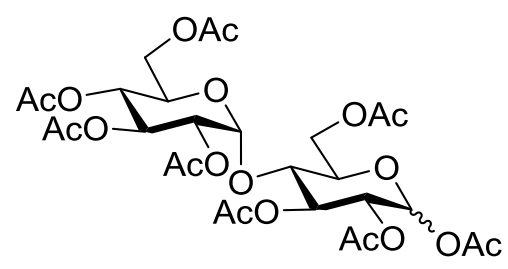

55
4-O-(2,3,4,6-tetra- $O$-acetyl- $\alpha-\mathrm{D}-$ glucopyranosyl)-1,2,3,6-tetra- $O$-acetyl-Dglucopyranoside (55). D-Maltose (16b) (5.0 g, $13.9 \mathrm{mmol})$ and $\mathrm{NaOAc}(3.0 \mathrm{~g}, 36 \mathrm{mmol})$ were dissolved in $\mathrm{Ac}_{2} \mathrm{O}(20 \mathrm{~mL})$ and left to stir at

$80{ }^{\circ} \mathrm{C}$ for $4 \mathrm{~h}$, upon which TLC analysis showed complete disappearance of the starting materials. The solution was neutralised by the addition of $1.2 \mathrm{M} \mathrm{HCl}$, followed by the extraction of the product with $\mathrm{Et}_{2} \mathrm{O}$ and subsequent washing of the organic layer with sat. aq. $\mathrm{NaHCO}_{3}, \mathrm{H}_{2} \mathrm{O}$, and brine (50 mL each). The organic solutions were dried using anhydrous $\mathrm{MgSO}_{4}$, which was filtered off, and the filtrate concentrated in vacuo to yield $\mathbf{5 5}$ white crystals $(9.35 \mathrm{~g}, 99 \%) . \mathbf{R}_{f}=0.40$ (1:1, petroleum ether : ethyl acetate, v:v); $\mathrm{Mp}=96.5^{\circ} \mathrm{C}$; IR (thin film): 1743, 1367, 1212, $1030 \mathrm{~cm}^{-1} .{ }^{1} \mathrm{H}-\mathrm{NMR}\left(500 \mathrm{MHz}, \mathrm{CDCl}_{3}\right): \delta 6.24$ (d, 1H, $\left.J_{1,2}=3.4 \mathrm{~Hz}, \alpha-\mathrm{H}-1 "\right)$, $5.74\left(\mathrm{~d}, 1 \mathrm{H}, J_{1,2}=8 \mathrm{~Hz}, \beta-\mathrm{H}-1^{\prime \prime}\right), 5.40\left(\mathrm{~d}, 1 \mathrm{H}, J_{1,2}=3.6 \mathrm{~Hz}, \alpha-\mathrm{H}-1^{\prime}\right), 5.35(\mathrm{t}, 1 \mathrm{H}, J=$ $\left.10 \mathrm{~Hz}, \mathrm{H}-3^{\prime}\right), 5.29$ (t, 1H, J = 8.9 Hz, H-3), 5.06 (t, 1H, J = $9.9 \mathrm{~Hz}, \mathrm{H}-4$ '), 4.97 (t, $1 \mathrm{H}, J=8.6 \mathrm{~Hz}, \mathrm{H}-2), 4.86(\mathrm{dd}, 1 \mathrm{H}, J=10.5 \mathrm{~Hz}, J=3.9 \mathrm{~Hz}, \mathrm{H}-2$ '), 4.45 (d, 1H, J= 11.7 Hz, H-6'a), 4.22 (m, 2H, H-6a, H-6b), 4.04 (m, 2H, H-6'b, H-4), 3.93 (d, 1H, J $=10 \mathrm{~Hz}, \mathrm{H}-5$ '), 3.83 (d, $1 \mathrm{H}, J=8 \mathrm{~Hz}, \mathrm{H}-5), 2.22-2.00\left(\mathrm{~m}, 24 \mathrm{H}, \mathrm{CH}_{3}-\mathrm{O}-\mathrm{Ac}\right) ;{ }^{13} \mathrm{C}-$ NMR (125 MHz, $\mathrm{CDCl}_{3}$ ): 170.7 (C=O 2'-O-Ac), 170.7 (C=O 6-O-Ac), 170.6 (C=O 6'-O-Ac), 170.2 (C=O 3-O-Ac), 170.1 (C=O 3'-O-Ac), $170.0(\mathrm{C}=\mathrm{O}$ 2-O-Ac), 169.6 (C=O 4'-O-Ac), 169.0 (C=O 1-O-Ac), 95.9 (C-1'), 91.4 (C-1), 75.4 (C-3), 73.1 (C-5), 72.5 (C-4), 71.1 (C-2), 70.1 (C-2’), 69.4 (C-3’), 68.7 (C-5’), 68.1 (C-4'), 62.7 (C-6), 61.6 (C-6'), 21.0 ( $\left.\mathrm{CH}_{3} \mathrm{O}-\mathrm{Ac}\right), 20.9$ ( $\left.\mathrm{CH}_{3} \mathrm{O}-\mathrm{Ac}\right), 20.8\left(\mathrm{CH}_{3} \mathrm{O}-\mathrm{Ac}\right), 20.7$ $\left(\mathrm{CH}_{3} \mathrm{O}-\mathrm{Ac}\right)$; HRMS(ESI) $\mathrm{m} / \mathrm{z}$ calcd. for $\left[\mathrm{C}_{28} \mathrm{H}_{38} \mathrm{O}_{19}+\mathrm{NH}_{4}\right]^{+}$: 696.2346, obsd.: 696.2367 . 


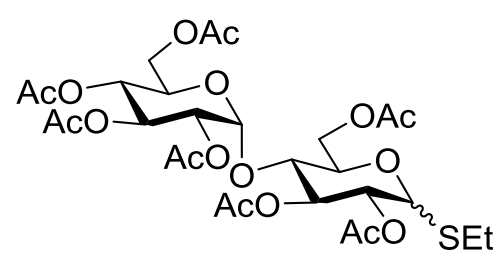

56
Ethyl 4- $O$ - $(2,3,4,6$-tetra- $O$-acetyl- $\alpha / \beta$ glucopyranosyl)-(1’ $\rightarrow 4)-2,3,6$-tri- $O$-acetyl-1thio- $\beta$-D-glucopyranoside (56). Maltose octaacetate 55 (0.98 g, $1.45 \mathrm{mmol})$ was coevaporated with toluene three times to remove

traces of water before being dissolved in freshly distilled $\mathrm{CH}_{2} \mathrm{Cl}_{2}(15 \mathrm{~mL})$. Activated $4 \AA$ molecular sieves were then added, followed by EtSH $(0.20 \mathrm{~mL}, 2.9$ mmol, 2 equiv.). The reaction was then left to stir under an argon atmosphere for $45 \mathrm{~min}$ at $-30{ }^{\circ} \mathrm{C}$. Following the slow addition of $\mathrm{SnCl}_{4}(0.20 \mathrm{~mL}, 1.67 \mathrm{mmol}, 1.15$ equiv.), the reaction mixture was slowly warmed to $-17{ }^{\circ} \mathrm{C}$ (over $1.5 \mathrm{~h}$ ) before it was quenched by the addition of sat. aq. $\mathrm{NaHCO}_{3}$ and the product extracted with $\mathrm{CH}_{2} \mathrm{Cl}_{2}\left(20 \mathrm{~mL}\right.$ each). The organic layer was washed with $\mathrm{H}_{2} \mathrm{O}$ and brine $(20 \mathrm{~mL}$ each) before it was dried with anhydrous $\mathrm{MgSO}_{4}$, which was filtered off and the filtrate concentrated in vacuo. The colourless oil was then subjected to flash column chromatography ( $8: 1 \rightarrow 5: 1$, petroleum ether : ethyl acetate, v:v) to yield $\mathbf{5 6}$ as white crystals $(0.50 \mathrm{~g}, 51 \%) . \mathrm{R}_{f}=0.53(1: 1$, petroleum ether : ethyl acetate, $\mathrm{v}: \mathrm{v})$; IR (thin film): 1740, 1367, 1211, 1027, $601 \mathrm{~cm}^{-1} ;{ }^{1} \mathrm{H}-\mathrm{NMR}\left(500 \mathrm{MHz}, \mathrm{CDCl}_{3}\right): \delta 5.41$ (d, $\left.J_{1^{\prime}, 2^{\prime}}=4.05 \mathrm{~Hz}, 1 \mathrm{H}, \mathrm{H}-1^{\prime}\right), 5.35$ (t, $\left.J_{2^{\prime}, 3^{\prime}}=J_{3^{\prime}, 4^{\prime}}=9.9 \mathrm{~Hz}, 1 \mathrm{H}, \mathrm{H}-3^{\prime}\right), 5.28$ (t, $J_{2,3}=$ $\left.J_{3,4}=9.2 \mathrm{~Hz}, 1 \mathrm{H}, \mathrm{H}-3\right), 5.05\left(\mathrm{t}, J_{3^{\prime}, 4^{\prime}}=J_{4^{\prime}, 5^{\prime}}=9.9 \mathrm{~Hz}, 1 \mathrm{H}, \mathrm{H}-4^{\prime}\right), 4.88-4.84(\mathrm{~m}, 2 \mathrm{H}$, H-2, H-2'), 4.54 (d, $\left.J_{1,2}=10.4 \mathrm{~Hz}, 1 \mathrm{H}, \mathrm{H}-1\right), 4.46\left(\mathrm{dd}, J_{5,6 \mathrm{a}}=2.1 \mathrm{~Hz}, J_{6 \mathrm{a}, 6 \mathrm{~b}}=12.0\right.$ Hz, 1H, H-6a), 4.26-4.20 (m, 2H, H-6b, H-6'a), 4.05-3.93 (m, 3H, H-6'b, H-4, H5'), 3.70-3.68 (m, 1H, H-5), 2.73-2.63 (m, 2H, CH $\mathrm{CtSH}_{2}, 2.13-2.00$ (m, 21H, OAc), 1.27 (t, $\left.J_{\mathrm{CH} 2, \mathrm{CH} 3}=7.59 \mathrm{~Hz}, 3 \mathrm{H}, \mathrm{CH}_{3} \mathrm{EtSH}\right) ;{ }^{13} \mathrm{C}-\mathrm{NMR}\left(125 \mathrm{MHz}, \mathrm{CDCl}_{3}\right): \delta$ 170.5 (C=O 2'-O-Ac), 170.5 (C=O 6'-O-Ac), 170.4 (C=O 6-O-Ac), 170.1 (C=O 3O-Ac), 169.9 (C=O 3'-O-Ac), 169.6 (C=O 2-O-Ac), 169.4 (C=O 4-O-Ac), 95.6 (C1'), 83.1 (C-1), 76.4 (C-3), 76.1 (C-5), 72.7 (C-4), 70.8 (C-2), 70.0 (C-2’), 69.3 (C-3’), 68.5 (C-5’), 68.0 (C-4'), 63.1 (C-6), 61.5 (C-6’), 24.3 (CH $\left.\mathrm{CH}_{2} \mathrm{EtSH}\right), 20.9\left(\mathrm{CH}_{3} \mathrm{O}-\mathrm{Ac}\right)$, 20.8 ( $\left.\mathrm{CH}_{3} \mathrm{O}-\mathrm{Ac}\right), 20.7$ ( $\left.\mathrm{CH}_{3} \mathrm{O}-\mathrm{Ac}\right), 20.6\left(\mathrm{CH}_{3} \mathrm{O}-\mathrm{Ac}\right), 15.0\left(\mathrm{CH}_{3} \mathrm{EtSH}\right)$; HRMS(ESI) $m /$ z calcld. for $\left[\mathrm{C}_{28} \mathrm{H}_{40} \mathrm{O}_{17} \mathrm{~S}+\mathrm{NH}_{4}\right]^{+}$: 698.2324, obsd.: 698.2310 .

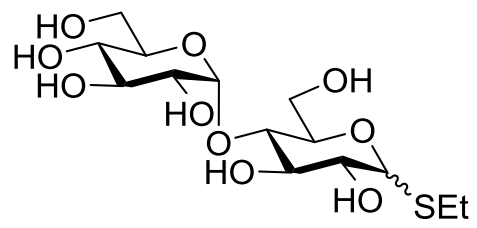

57
Ethyl 4- $O$-( $\alpha$-D-glucopyranosyl)-1-thio- $\alpha / \beta-D-$ glucopyranoside (57). To a solution of 56 $(0.35 \mathrm{~g}, 0.51 \mathrm{mmol})$ in dry $\mathrm{MeOH}(5 \mathrm{~mL})$, $\mathrm{NaOMe}(1.4 \mathrm{mg}, 0.026 \mathrm{mmol}, 0.05$ equiv.) were 
added. The reaction was left to stir under an argon for $16 \mathrm{~h}$ at $\mathrm{rt}$, after which TLC analysis showed the formation of a lower running product. The reaction was neutralised by the addition Dowex $\mathrm{H}^{+}$, which was filtered off and the filtrate concentrated in vacuo to produce $\mathbf{5 7}$ as a colourless oil ( $0.20 \mathrm{~g}$, quant.). $\mathbf{R}_{f}=0.35$ (1:5, MeOH : ethyl acetate, v:v); ${ }^{1} \mathrm{H}-\mathrm{NMR}\left(500 \mathrm{MHz}, \mathrm{D}_{2} \mathrm{O}\right): \delta 5.28\left(\mathrm{~d}, J_{1,2},=3.5\right.$ $\mathrm{Hz}, 1 \mathrm{H}, \mathrm{H}-1^{\prime}$ ), 4.44 (d, $\left.J_{1,2}=9.9 \mathrm{~Hz}, 1 \mathrm{H}, \mathrm{H}-1\right), 3.71$ (d, $\left.J_{6 \mathrm{a}, 6 \mathrm{~b}}=12.5 \mathrm{~Hz}, 1 \mathrm{H}, \mathrm{H}-6 \mathrm{a}\right)$, 3.61 (d, $J_{6^{\prime} \mathrm{a}, 6^{\prime} \mathrm{b}}=12 \mathrm{~Hz}, 1 \mathrm{H}, \mathrm{H}-6$ 'a), 3.58-3.40 (m, 6H, H-6b, H-6'b, H-3, H-3', H-4, H-4'), 3.37-3.34 (m, 2H, H-2', H-5), 3.21-3.11 (m, 2H, H-5', H-2), 2.58-2.54 (m, $\left.2 \mathrm{H}, \mathrm{CH}_{2} \mathrm{EtSH}\right), 1.09$ (t, $\left.J_{\mathrm{CH} 2 \mathrm{CH} 3}=7 \mathrm{~Hz}, 3 \mathrm{H}, \mathrm{CH}_{3} \mathrm{EtSH}\right) ;{ }^{13} \mathrm{C}-\mathrm{NMR}(125 \mathrm{MHz}$, $\left.\mathrm{D}_{2} \mathrm{O}\right): \delta 99.8$ (C-1'), 84.9 (C-1), 78.4 (C-2'), 77.6 (C-3), 77.2 (C-4), 72.9 (C-3'), 72.7 (C-4'), 72.0 (C-2), 71.8 (C-5), 69.3 (C-5'), 60.8 (C-6), 60.5 (C-6'), $24.0\left(\mathrm{CH}_{2} \mathrm{EtSH}\right)$, $14.4\left(\mathrm{CH}_{3} \mathrm{EtSH}\right)$; HRMS(ESI) $\mathrm{m} / \mathrm{z}$ calcd. for $\left[\mathrm{C}_{14} \mathrm{H}_{26} \mathrm{O}_{10} \mathrm{~S}+\mathrm{NH}_{4}{ }^{+}\right]$: 404.1585, obsd.: 404.1585 .

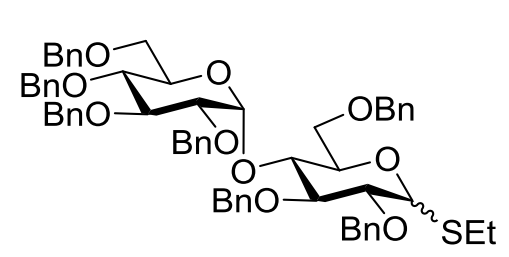

58

Ethyl 4-O-(2,3,4,6-tetra- $O$-benzyl- $\alpha-$ glucopyranosyl)-2,3,6-tri- $O$-benzyl-1-thio- $\alpha / \beta$ D-glucopyranoside (58). Thioglycoside $\quad 57$ (0.20 g, $0.51 \mathrm{mmol})$ was co-evaporated with DMF three times, where the solvent was concentrated to partial volume, leaving $2.55 \mathrm{~mL}$ of DMF on the final co-evaporation. The reaction was placed under an argon atmosphere before $\mathrm{BnBr}(0.9 \mathrm{~mL}, 7.7 \mathrm{mmol}$, 15 equiv.) and TBAI (28 mg, $0.077 \mathrm{mmol}, 0.15$ equiv.) were added. The solution was then cooled to $0^{\circ} \mathrm{C}$, followed by the slow addition of $\mathrm{NaH}(0.52 \mathrm{~g}, 7.1 \mathrm{mmol}$, 14 equiv.). Upon reaching $\mathrm{rt}$, the white solution was then warmed to $80^{\circ} \mathrm{C}$ and left to stir under an argon atmosphere for $16 \mathrm{~h}$, after which TLC-analysis showed the complete formation of a higher running product. $\mathrm{MeOH}(5 \mathrm{~mL})$ was then added to quench the excess $\mathrm{BnBr}$ before sat. aq. $\mathrm{NaHCO}_{3}$ was added, followed with brine (20 mL each) and extracted using $20 \mathrm{~mL}$ of ethyl acetate. The solution was then dried using anhydrous $\mathrm{MgSO}_{4}$, which was then filtered off and the filtrate was concentrated in vacuo. The product was then isolated using silica gel flash column chromatography $(10: 1$, petroleum ether : ethyl acetate, v:v) to obtain $\mathbf{5 8}$ as a colourless oil (0.46 g, 90\%). $\mathrm{R}_{f}=0.49$ (5:2, petroleum ether : ethyl acetate, v:v); IR (thin film): 3030, 2924, 2866, 1496, 1453, 1363, 1071, 1051, 1027, 734, $696 \mathrm{~cm}^{-1}$; ${ }^{1} \mathrm{H}-\mathrm{NMR}\left(500 \mathrm{MHz}, \mathrm{CDCl}_{3}\right): \delta 7.31-7.11$ (m, 35H, CH arom.), 5.65 (d, $J_{1,2},=3.6$ 
Hz, 1H, H-1'), 4.94 (d, Ja,b $=11.7$ Hz, 1H, CH-a 3-O-Bn), 4.89-4.85 (m, 3H, CH-a 2O-Bn, CH-b 3-O-Bn, CH-a 3'-O-Bn, 4.79 (d, Ja, = 10.7 Hz, 1H, CH-a 4'-O-Bn), $4.78\left(\mathrm{~d}, J_{\mathrm{a}, \mathrm{b}}=10.8 \mathrm{~Hz}, 1 \mathrm{H}, \mathrm{CH}-\mathrm{b} 3-\mathrm{O}-\mathrm{Bn}\right.$ ), 4.62-4.54 (m, 5H, CH-b 2-O-Bn, CH-a 2'-O-Bn, CH-a 6'-O-Bn, CH-a 6-O-Bn, CH-b 6-O-Bn), 4.51 (d, $J_{\mathrm{a}, \mathrm{b}}=11.8 \mathrm{~Hz}, 1 \mathrm{H}$, CH-b 2'-O-Bn), 4.50 (d, $J_{1,2}=9.6 \mathrm{~Hz}, 1 \mathrm{H}, \mathrm{H}-1$ ), 4.45 (d, $J_{\mathrm{a}, \mathrm{b}}=10.9 \mathrm{~Hz}, 1 \mathrm{H}, \mathrm{CH}-\mathrm{b}$ 4'-O-Bn), 4.08 (t, $\left.J_{3,4}=J_{4,5}=9.07 \mathrm{~Hz}, 1 \mathrm{H}, \mathrm{H}-4\right), 3.91$ (t, $J_{2^{\prime}, 3^{3}}=J_{3^{\prime}, 4^{\prime}}=9.5 \mathrm{~Hz}, 1 \mathrm{H}, \mathrm{H}-$ 3'), 3.82-3.76 (m, 3H, H-6a, H-6b, H-5'), 3.65 (t, $J_{3^{\prime}, 4^{\prime}}=J_{4^{\prime}, 5^{\prime}}=9.6 \mathrm{~Hz}, 1 \mathrm{H}, \mathrm{H}-4^{\prime}$ ), 3.59-3.49 (m, 4H, H-6'a, H-5, H-2, H-2'), 3.45 (d, J6a,6b $=10.3$ Hz, 1H, H-6’b), 2.78 $\left(\mathrm{m}, 2 \mathrm{H}, \mathrm{CH}_{2} \mathrm{EtSH}\right), 1.34\left(\mathrm{t}, \mathrm{J}_{\mathrm{CH} 2, \mathrm{CH} 3}=7.4 \mathrm{~Hz}, 3 \mathrm{H}, \mathrm{CH}_{3} \mathrm{EtSH}\right) ;{ }^{13} \mathrm{C}-\mathrm{NMR}$ (125 MHz, $\left.\mathrm{CDCl}_{3}\right): \delta 138.8\left(\mathrm{C}_{\mathrm{i}}\right.$ arom. O-Bn), $138.5\left(\mathrm{C}_{\mathrm{i}}\right.$ arom. O-Bn), $138.1\left(\mathrm{C}_{\mathrm{i}}\right.$ arom. O-Bn), 137.9 ( $\mathrm{C}_{\mathrm{i}}$ arom. O-Bn), 97.2 (C-1'), 86.7 (C-3), 84.9 (C-1), 82.2 (C-3’), 82.0 (C-2), 79.4 (C-2’), 78.9 (C-5), 77.9 (C-4'), 75.6 ( $\mathrm{CH}_{2}$ 3'-O-Bn), $75.4\left(\mathrm{CH}_{2} 2-\mathrm{O}\right.$ $\mathrm{Bn}), 75.1$ ( $\mathrm{CH}_{2}$ 4'-O-Bn), 74.3 ( $\left.\mathrm{CH}_{2} 3-\mathrm{O}-\mathrm{Bn}\right), 73.6\left(\mathrm{CH}_{2}\right.$ 6'-O-Bn), $73.5\left(\mathrm{CH}_{2} 2-\mathrm{O}-\right.$ Bn), 73.4 ( $\mathrm{CH}_{2}$ 6-O-Bn), 73.0 (C-4), 71.2 (C-5’), 69.4 (C-6), 68.3 (C-6’), $24.9\left(\mathrm{CH}_{2}\right.$ EtSH), $15.3\left(\mathrm{CH}_{3}\right.$ EtSH); HRMS(ESI) $m / z$ calcld. for $\left[\mathrm{C}_{63} \mathrm{H}_{68} \mathrm{O}_{10} \mathrm{~S}+\mathrm{NH}_{4}\right]^{2+}$ : 1034.4871, obsd.: 1034.4913.

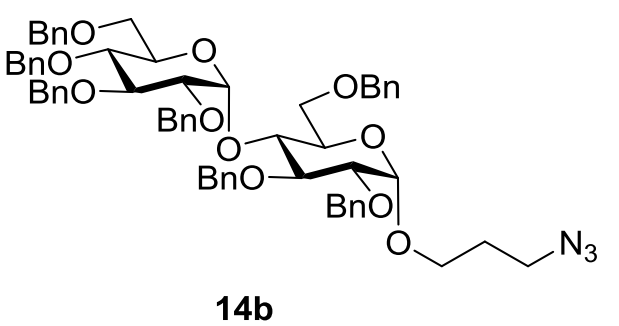
3-Azidopropyl 4- $O-(2,3,4,6$-tetra- $O$ - benzyl- $\alpha$-glucopyranosyl)-2,3,6-tri- $O$ - benzyl- $\alpha$-D-glucopyranoside (14b).
Thioglycoside donor $\mathbf{5 8}$ (50 $\mathrm{mg}, 0.05$ mmol) and acceptor 30 (75 mg, 0.75

mmol, 15 equiv.) was co-evaporated in DMF three times, upon where the solvent was concentrated to partial volume on the final co-evaporation, leaving $0.2 \mathrm{~mL}$ of DMF. Activated $4 \AA$ molecular sieves were then added followed by freshly distilled $\mathrm{CH}_{2} \mathrm{Cl}_{2}(0.4 \mathrm{~mL})$. The reaction was allowed to stir under an argon atmosphere for $30 \mathrm{~min}$ before $\mathrm{CuBr}_{2}$ (38 mg, $0.15 \mathrm{mmol}, 3$ equiv.) and TPABr (45 mg, $0.15 \mathrm{mmol}$, 3 equiv.) were added. The reaction was left to stir under an argon for $10 \mathrm{~d}$, after which the reaction was quenched using sat. aq. $\mathrm{NaHCO}_{3}$, followed by extraction with $\mathrm{CH}_{2} \mathrm{Cl}_{2}$ and further washing of the organic layer with $\mathrm{Na}_{2} \mathrm{~S}_{2} \mathrm{O}_{3}$ and brine (5 $\mathrm{mL}$ each). The resulting solution was then dried using anhydrous $\mathrm{MgSO}_{4}$, which was filtered off and the filtrate concentrated in vacuo. Flash column chromatography was performed to isolate $\mathbf{1 4 b}$ as a colourless oil $(27 \mathrm{mg}, 51 \%) . \mathbf{R}_{f}$ $=0.40\left(1: 20\right.$, ethyl acetate : toluene, v:v); $[\alpha]_{\mathrm{D}}{ }^{21}=-3.9\left(\mathrm{c}=0.1, \mathrm{CHCl}_{3}\right) ; \mathrm{IR}$ (thin 
film): 3467, 3063, 3029, 2924, 2108, 1724, 1491, 1445, 1153, 1001, 755, $696 \mathrm{~cm}^{-1}$; ${ }^{1} \mathrm{H}-\mathrm{NMR}\left(500 \mathrm{MHz}, \mathrm{CDCl}_{3}\right.$ ): $\delta$ 7.29-7.10 (m, 35H, CH arom.), 5.70 (d, $J_{1 ", 2}{ }^{,}=3.3$ $\mathrm{Hz}, 1 \mathrm{H}, \mathrm{H}-1$ "), 5.05 (d, $J_{\mathrm{a}, \mathrm{b}}=11.5 \mathrm{~Hz}, 1 \mathrm{H}, \mathrm{CH}_{2}$-a 3"-O-Bn), 4.90 (d, $J_{\mathrm{a}, \mathrm{b}}=10.8 \mathrm{~Hz}$, $1 \mathrm{H}, \mathrm{CH}_{2}$-b 3'-O-Bn), 4.84-4.78 (m, 3H, $\mathrm{CH}_{2}$-b 3"-O-Bn, $\mathrm{CH}_{2}$-b 3'-O-Bn, $\mathrm{CH}_{2}$-a 4"'O-Bn), 4.75 (d, $\left.J_{1^{\prime}, 2}=3.3 \mathrm{~Hz}, 1 \mathrm{H}, \mathrm{H}-1^{\prime}\right), 4.69$ (d, $J_{\mathrm{a}, \mathrm{b}}=12.0 \mathrm{~Hz}, 1 \mathrm{H}, \mathrm{CH}_{2^{-a}}$ 2'-O-

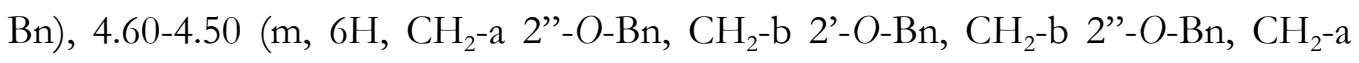
6"'-O-Bn, $\mathrm{CH}_{2}$-a 6'-O-Bn, $\mathrm{CH}_{2}$-b 6'-O-Bn), 4.43 (d, Ja,b $=10.8 \mathrm{~Hz}, 1 \mathrm{H}, \mathrm{CH}_{2}$-b 4"'-O$\mathrm{Bn}$ ), 4.29 (d, $J_{\mathrm{a}, \mathrm{b}}=12.3 \mathrm{~Hz}, 1 \mathrm{H}, \mathrm{CH}_{2}$ 6"'-O-Bn), 4.09-4.04 (m, 2H, H-3', H-4'), 3.92 (t, $\left.J_{2^{\prime \prime}, 3^{\prime \prime}}=J_{3^{\prime \prime}, 4}=9.3 \mathrm{~Hz}, 1 \mathrm{H}, \mathrm{H}-3^{\prime \prime}\right)$ ) 3.87-3.82 (m, 2H, H-5', H-6'), 3.77-3.72 (m, 2H, H-1a, H-5”), 3.68-3.61 (m, 3H, H-6', H-4", H-2'), 3.52-3.39 (m, 6H, H-2”, H-6”a, H-1b, H-3a, H-3b, H-6”b), 1.92 (quint., $\left.J_{\mathrm{CH} 2, \mathrm{CH} 2}=6.1 \mathrm{~Hz}, 2 \mathrm{H}, \mathrm{H}-2\right) ;{ }^{13} \mathrm{C}-\mathrm{NMR}(125$ $\left.\mathrm{MHz}, \mathrm{CDCl}_{3}\right) \delta 139.1$ ( $\mathrm{C}_{\mathrm{i}}$ arom. O-Bn), 138.9 (C $\mathrm{C}_{\mathrm{i}}$ arom. O-Bn), $138.6\left(\mathrm{C}_{\mathrm{i}}\right.$ arom. O$\mathrm{Bn}), 138.3$ ( $\mathrm{C}_{\mathrm{i}}$ arom. O-Bn), $138.2\left(\mathrm{C}_{\mathrm{i}}\right.$ arom. O-Bn), 138.1 ( $\mathrm{C}_{\mathrm{i}}$ arom. O-Bn), 128.6 (CH arom.), 128.5-128.4 (CH arom.), 128.2 (CH arom.), 128.2 (CH arom.), 128.1 (CH arom.), 128.0 (CH arom.), 127.9 (CH arom.), 127.8 (CH arom.), 127.7 (CH arom.), 127.6 (CH arom.), 127.5 (CH arom.), 127.4 (CH arom.), 127.2 (CH arom.), 126.9 (CH arom.), 97.0 (C-1'), 96.9 (C-1”), 82.1 (C-3’), 82.0 (C-3”), 80.5 (C-2'), 79.5 (C-2”), 77.8 (C-4'), 75.7 ( $\mathrm{CH}_{2}$ 3'-O-Bn), 75.1 ( $\mathrm{CH}_{2}$ 4'-O-Bn), $74.4\left(\mathrm{CH}_{2}\right.$ 3"'-O-Bn), 73.6 ( $\mathrm{CH}_{2}$ 6”-O-Bn), 73.4 ( $\mathrm{CH}_{2}$ 2'-O-Bn), 73.3 (C-2”, C-6'), 72.6 (C-4'), 71.1 (C-5”), 69.9 (C-5'), 69.1 (C-6'), 68.3 (C-6’), 64.9 (C-1), 48.5 (C-3), 29.0 (C-2); HRMS(ESI) $m /$ z calcd. for $\left[\mathrm{C}_{64} \mathrm{H}_{69} \mathrm{~N}_{3} \mathrm{O}_{11}+\mathrm{NH}_{4}\right]^{+}: 1073.5270$, obsd.: 1073.5273 .

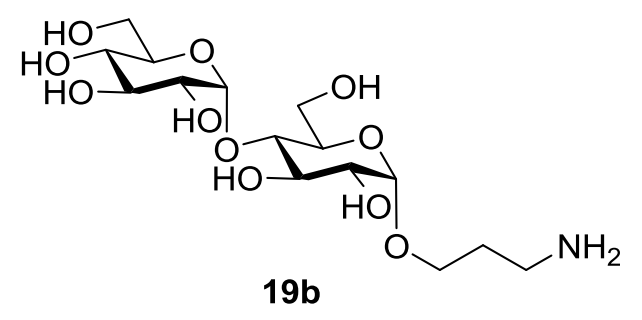

\section{3-Aminopropyl 4-O- $(\alpha-$} glucopyranosyl- $\alpha$-D-glucopyranoside (19b). Per-benzylated glycoside 14b (20 $\mathrm{mg}, 0.18 \mathrm{mmol}$ ) was dissolved in a $5 \mathrm{~mL}$ mixture of dry $\mathrm{MeOH}$ and $\mathrm{CHCl}_{3}(2: 3$, v:v) before $\mathrm{Pd}(\mathrm{OH})_{2} / \mathrm{C}\left(5 \mathrm{mg}, 20 \%\right.$ catalyst, $0.036 \mathrm{mmol}, 0.2$ equiv.) was added. $\mathrm{H}_{2}$ was then bubbled through the solution, and the reaction was left to stir for $16 \mathrm{~h}$ at room temperature, after which TLC-analysis showed the complete conversion to a low running product (5:2:2:2:1, $\mathrm{CH}_{2} \mathrm{Cl}_{2}: \mathrm{MeOH}: \mathrm{EtOH}: \mathrm{H}_{2} \mathrm{O}: \mathrm{NH}_{3}$ (35\%), $\mathrm{v}: \mathrm{v}: \mathrm{v}: \mathrm{v}: \mathrm{v})$. The reaction was then filtered through celite to remove $\mathrm{Pd}(\mathrm{OH})_{2} / \mathrm{C}$ and concentrated in vacuo before it was purified using silica gel flash column chromatography $\left(\mathrm{CH}_{2} \mathrm{Cl}_{2} \rightarrow\right.$ 5:2:2:1, $\mathrm{CH}_{2} \mathrm{Cl}_{2}: \mathrm{MeOH}: \mathrm{EtOH}: \mathrm{NH}_{3}$ (35\%), v:v:v:v) to obtain $\mathbf{1 9 b}$ as a white amorphous solid (7.5 mg, quant.). $\mathrm{R}_{f}=0.15$ (5:2:2:2:1, 
$\mathrm{CH}_{2} \mathrm{Cl}_{2}: \mathrm{MeOH}: \mathrm{EtOH}: \mathrm{H}_{2} \mathrm{O}: \mathrm{NH}_{3}(35 \%)$, v:v:v:v:v); $[\alpha]_{\mathrm{D}}^{23}=+10^{\circ}$ (c=0.1, $\mathrm{H}_{2} \mathrm{O}$ ); IR (thin film): 3378, 1634, $1022 \mathrm{~cm}^{-1} ;{ }^{1} \mathrm{H}-\mathrm{NMR}\left(500 \mathrm{MHz}, \mathrm{D}_{2} \mathrm{O}\right): \delta 5.39$ (d, $\left.J_{1^{\prime \prime}, 2^{\prime}}=3.8 \mathrm{~Hz}, 1 \mathrm{H}, \mathrm{H}-1^{\prime \prime}\right), 4.91$ (d, $\left.J_{1^{\prime}, 2^{2}}=3.7 \mathrm{~Hz}, 1 \mathrm{H}, \mathrm{H}-1^{\prime}\right), 3.94$ (t, $J_{2^{\prime}, 3^{\prime}}=J_{3^{\prime}, 4^{\prime}}=9.4 \mathrm{~Hz}$, 1H, H-3'), 3.90-3.55 (m, 12H, H-1a, H-6'a, H-6'b, H-6"a, H-6'b, H-5', H-3', H5", H-4', H-2', H-1b, H-2"), 3.40 (t, $J_{3^{\prime \prime},{ }^{\prime},}=J_{4,}, 5,=9.5$ Hz, 1H, H-4”), 3.16-3.05 (m, 2H, H-3), 1.97 (m, 2H, H-2); ${ }^{13} \mathrm{C}-\mathrm{NMR}$ (125 MHz, $\left.\mathrm{D}_{2} \mathrm{O}\right): \delta 99.6$ (C-1”), 98.0 (C-1'), 76.7 (C-4’), 73.4 (C-3’), 72.8 (C-5”), 72.6 (C-3’), 71.6 (C-2”), 70.9 (C-2'), 70.3 (C5’), 69.2 (C-4”), 65.8 (C-1), 60.5 (C-6”), 60.4 (C-6'), 37.7 (C-3), 26.8 (C-2); HRMS(ESI) $m / z$ calcd. for $\left[\mathrm{C}_{15} \mathrm{H}_{29} \mathrm{NO}_{11}+\mathrm{H}\right]^{+}: 400.1813$, obsd.: 400.1817.

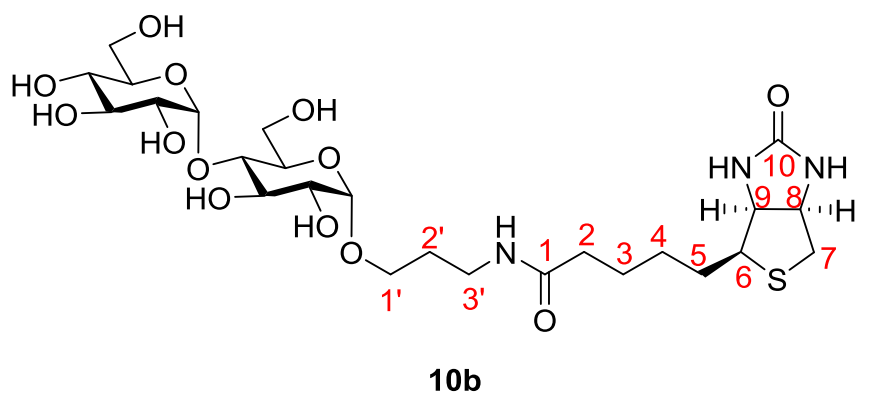

\author{
$O-4-O-1(\alpha-$ \\ glucopyranosyl- $\alpha-\mathrm{D}-$ \\ glucopyranosyl)-3- \\ biotinylamido-propanol \\ (10b). \\ Deprotected \\ disaccharide 19b (6.0 mg,
} $0.015 \mathrm{mmol}$ ) was co-evaporated three times with DMF, where upon the last coevaporation, the solvent was concentrated to partial volume, leaving $0.2 \mathrm{~mL}$ of DMF. D-Biotin (15) (4 mg, 0.017 mmol, 1.1 equiv.), HBTU (11 mg, 0.030 mmol, 2 equiv.), and $\mathrm{NEt}_{3}(4.5 \mu \mathrm{L}, 0.033 \mathrm{mmol}, 2.2$ equiv.) were then added to the reaction vessel, and the solution was left to stir for four hours at room temperature under an argon atmosphere. After TLC-analysis (5:2:2:1, $\mathrm{CH}_{2} \mathrm{Cl}_{2}: \mathrm{MeOH}: \mathrm{EtOH}: \mathrm{NH}_{3}$ (35\%), v:v:v:v) showed completion of reaction, the solution was concentrated in vacuo before purifying using silica gel flash column chromatography $\left(\mathrm{CH}_{2} \mathrm{Cl}_{2} \rightarrow\right.$ 5:2:2:1, $\mathrm{CH}_{2} \mathrm{Cl}_{2}: \mathrm{MeOH}: \mathrm{EtOH}: \mathrm{NH}_{3}(35 \%)$, v:v:v:v). Further purification was done using a Sephadex ${ }^{\circledR}$ LH-20 size-exclusion chromatography (bead size 25-100 $\mu \mathrm{m}$ ), yielding $10 \mathrm{~b}$ as a white amorphous solid (4.6 mg, 50\%). $\mathrm{R}_{f}=0.17$ (5:2:2:1, $\mathrm{CH}_{2} \mathrm{Cl}_{2}: \mathrm{MeOH}: \mathrm{EtOH}: \mathrm{NH}_{3}(35 \%)$, v:v:v:v); $[\alpha]_{\mathrm{D}}{ }^{19}=+1.1$ (c=0.1, $\left.\mathrm{MeOH}\right) ; \mathrm{IR}$ (thin film): 3291, 2930, 1675, 1558, 1453, 1430, 1335, 1150, 1031, 609, $578 \mathrm{~cm}^{-1}$; ${ }^{1} \mathrm{H}-\mathrm{NMR}\left(500 \mathrm{MHz}, \mathrm{D}_{2} \mathrm{O}\right): \delta 5.37$ (d, $J_{1,2,2^{\prime \prime}}=3.07 \mathrm{~Hz}, 1 \mathrm{H}, \mathrm{H}-1$ '”), 4.89 (d, $J_{1,2,2^{\prime}}=3.1$ Hz, 1H, H-1"), 4.59 (m, 1H, H-8), 4.41 (m, 1H, H-9), 3.96 (t, $J_{2^{\prime \prime}, 3^{\prime \prime}}=J_{3^{\prime \prime}, 4^{\prime}}=9.5 \mathrm{~Hz}$, 1H, H-3"), 3.86-3.50 (m, 10H, H-1'a, H-6", H-6”, H-5", H-5'”, H-3”", H-4", H-2”, H-2"', H-1'b), 3.40 (t, $J_{3 ", 4},{ }^{\prime \prime}=J_{4 ", 5},=9.2 \mathrm{~Hz}, 1 \mathrm{H}, \mathrm{H}-4$ "'), 3.34-3.28 (m, 2H, H-3', H- 
6), $2.98\left(\mathrm{dd}, J_{7 \mathrm{a}, 7 \mathrm{~b}}=12.8 \mathrm{~Hz}, J_{7 \mathrm{a}, 8}=4.6 \mathrm{~Hz}, 1 \mathrm{H}, \mathrm{H}-7 \mathrm{a}\right), 2.77$ (d, $J_{7 \mathrm{a}, 7 \mathrm{~b}}=13.2 \mathrm{~Hz}, 1 \mathrm{H}, \mathrm{H}-$ 7b), 2.24 (t, $\left.J_{2,3 \mathrm{a}}=J_{2,3 \mathrm{~b}}=7.3 \mathrm{~Hz}, 1 \mathrm{H}, \mathrm{H}-2\right), 1.89-1.79$ (m, 2H, H-2'), 1.75-1.54 (m, 4H, H-5, H-3), 1.46-1.37 (m, 2H, H-4); ${ }^{13} \mathrm{C}-\mathrm{NMR}$ (125 MHz, $\left.\mathrm{D}_{2} \mathrm{O}\right): \delta 167.4$ (C-10), 165.3 (C-1), 77.0 (C-4”), 73.5 (C-3”), 72.8 (C-5”'), 72.6 (C-3”’), 71.7 (C-2””), 71.1 (C-2”), 70.2 (C-5”), 69.2 (C-4"'), 65.4 (C-1'), 62.0 (C-9), 60.4 (C-6”, C-6”'), 60.2 (C8), 55.3 (C-6), 39.6 (C-7), 36.4 (C-3’), 35.5 (C-2), 28.0 (C-2’), 27.8 (C-4), 27.6 (C-5), 25.1 (C-3); HRMS(ESI) $m / z$ calcd. for $\left[\mathrm{C}_{23} \mathrm{H}_{43} \mathrm{~N}_{3} \mathrm{O}_{13} \mathrm{~S}+\mathrm{H}\right]^{+}$: 626.2589; obsd.: 626.2584 .<smiles>N#CC(=O)NC(CO)(CO)CO</smiles>

72

\section{N-(2-azidoacetyl)-1,1,1-tris(hydroxymethyl)} methylamine (72). Bromoacetic acid (23) (5.03 g, 36.2 mmol) was dissolved in of $\mathrm{H}_{2} \mathrm{O}(10 \mathrm{~mL})$ before $\mathrm{NaN}_{3}$ (9.9 g, $152 \mathrm{mmol}, 4.2$ equiv.) was added. The reaction was allowed to stir for $16 \mathrm{~h}$ at $\mathrm{rt}$, after which TLC analysis showed the complete disappearance of starting materials. The reaction mixture was diluted with $\mathrm{H}_{2} \mathrm{O}$, and the product extracted using ethyl acetate $(10 \mathrm{~mL}$ each). The resulting organic layer was dried using anhydrous $\mathrm{MgSO}_{4}$, which was filtered off and the filtrate concentrated in vacuo. The crude mixture was then dissolved in $\mathrm{CH}_{2} \mathrm{Cl}_{2}(125 \mathrm{~mL})$ and left to stir for $1 \mathrm{~h}$ at $\mathrm{rt}$ under an argon atmosphere, after which TLC analysis showed the complete conversion of the reactant into a lower running spot. The resulting white precipitate was removed by filtration, which was washed repeatedly with ethyl acetate before the filtrate was concentrated in vacuo. The crude oil was then co-evaporated three times in DMF, where upon the last co-evaporation, the solvent was concentrated to partial volume, leaving $100 \mathrm{~mL}$ of DMF. Tris (19.4 g, $181 \mathrm{mmol}, 5$ equiv.) was added to the reaction vessel, followed by $\mathrm{NEt}_{3}(0.5 \mathrm{~mL}$, $3.6 \mathrm{mmol}, 0.1$ equiv.). The reaction mixture was then stirred overnight under an argon atmosphere. After TLC-analysis (1:10, MeOH : ethyl acetate, v:v) showed completion of reaction, the thick pink solution was dissolved in water and concentrated in vacuo to remove the DMF, followed by co-evaporation with toluene and $\mathrm{MeOH}$ to remove the water. Silica gel was then added into the reaction vessel and dissolved in ethyl acetate for dry-loading. Purification by column chromatography $(0: 1 \rightarrow 1: 10, \mathrm{MeOH}$ : ethyl acetate, v:v) yielded 72 as white crystals (4.6 g, 63\%, 3 steps) $\mathrm{R}_{f}=0.58$ (1:10, MeOH : ethyl acetate, v:v); IR (thin film): 3347, 3241, 3082, 2932, 2104, 1630, 1572, 1448, 1425, 1386, 1370, 
1268, 1038, 726, 612, 583, $549 \mathrm{~cm}^{-1}$; ${ }^{1} \mathrm{H}-\mathrm{NMR}\left(500 \mathrm{MHz}, \mathrm{D}_{2} \mathrm{O}\right) \delta 4.02$ (s, 2H, $\alpha-$ $\left.\mathrm{CH}_{2}-\mathrm{N}_{3}\right), 3.78$ (s, 6H, $\left.\mathrm{CH}_{2}-\mathrm{OH}\right) ;{ }^{13} \mathrm{C}-\mathrm{NMR}\left(125 \mathrm{MHz}, \mathrm{D}_{2} \mathrm{O}\right): \delta 170.5(\mathrm{C}=\mathrm{O}), 62.2$ $\left(\mathrm{C}_{\mathrm{i}}\right.$ tris), $60.1 \quad\left(\mathrm{CH}_{2}-\mathrm{OH}\right), \quad 52.0 \quad\left(\mathrm{CH}_{2}-\mathrm{N}_{3}\right) ; \mathrm{HRMS}(\mathrm{ESI}) \mathrm{m} / \mathrm{z}$ calcd. for $\left[\mathrm{C}_{6} \mathrm{H}_{12} \mathrm{~N}_{4} \mathrm{O}_{4}+\mathrm{H}^{+}\right]$: 205.0931, obsd.: 205.0940.<smiles>CCCCOC(=O)COCC(COCC(=O)OCCC)(COCC(=O)OCCC)NC(=O)CN</smiles>

22
N-(2-azidoacetyl)-1,1,1-tris(tertbutyloxycarbonylmethyloxymethyl) methylamine (22). Triol 72 (0.71 g, $3.49 \mathrm{mmol})$ was co-evaporated three times in DMF, where upon the last co-evaporation, the solvent was evaporated to partial volume to leave $30 \mathrm{~mL}$ of DMF. The reaction was placed under an argon atmosphere before tert-butyl bromoacetate (4.04

$\mathrm{mL}, 27.3 \mathrm{mmol}, 4.5$ equiv.) was added. After cooling to $0{ }^{\circ} \mathrm{C}, \mathrm{NaH}(1.45 \mathrm{~g}, 36.5$ mmol, 6 equiv.) was slowly added to the reaction, and the cloudy white solution was allowed to warm to $\mathrm{rt}$. The reaction was left to stir for three days, upon which TLC analysis showed the complete conversion of starting materials to a higher running spot. The reaction mixture was diluted with $\mathrm{H}_{2} \mathrm{O}(50 \mathrm{~mL})$, and the product extracted using $\mathrm{CH}_{2} \mathrm{Cl}_{2}(50 \mathrm{~mL})$. The combined organic layers were dried using anhydrous $\mathrm{MgSO}_{4}$, which was filtered off and the filtrate concentrated in vacuo. Purification by $\mathrm{C}_{18}$ reverse phase column chromatography $\left(60 \% \mathrm{MeOH}\right.$ in $\left.\mathrm{H}_{2} \mathrm{O}\right)$ yielded 22 as a colourless oil $(0.37 \mathrm{~g}, 31 \%) . \mathrm{R}_{f}=0.32$ (1:1, petroleum ether : ethyl acetate, v:v); IR (thin film): 3316, 2979, 2935, 2107, 1745, 1684, 1230, 1159, 1119, $731 \mathrm{~cm}^{-1}$; ${ }^{1} \mathrm{H}-\mathrm{NMR}\left(500 \mathrm{MHz}, \mathrm{CDCl}_{3}\right.$ ): $\delta 3.95$ (s, 2H, H-6), 3.91 (s, 2H, H-5), 3.85 (s, 2H, H-1), 1.45 (s, 9H, H-O-tBu); ${ }^{13} \mathrm{C}-\mathrm{NMR}\left(125 \mathrm{MHz}, \mathrm{CDCl}_{3}\right.$ ): $\delta 170.0$ (C-7), 167.3 (C-2), 81.7 (C O-tBu), 69.9 (C-5), 68.7 (C-6), 59.9 (C-4), 52.7 (C-1), 28.0 $\left(\mathrm{CH}_{3} \mathrm{O}-\mathrm{tBu}\right)$; HRMS(ESI) $m / z$ calcd. for $\left[\mathrm{C}_{24} \mathrm{H}_{42} \mathrm{~N}_{4} \mathrm{O}_{10}+\mathrm{H}^{+}\right]$: 547.2974, obsd.: 547.2984 . 


\section{$N$-(2-azidoacetyl)-1,1,1-tris(carboxy}<smiles>N#CC(=O)NC(COCC(=O)O)(COCC(=O)O)COCC(=O)O</smiles>

20

methyloxymethyl)methylamine (20). Triester 22 (30 $\mathrm{mg}, 0.060 \mathrm{mmol}$ ) was co-evaporated three times with $\mathrm{CH}_{2} \mathrm{Cl}_{2}$ before it was dissolved in $2 \mathrm{~mL}$ mixture of $\mathrm{CH}_{2} \mathrm{Cl}_{2}$ and freshly distilled TFA (1:1, $\mathrm{v}: \mathrm{v})$. The reaction mixture was then left to stir at $\mathrm{rt}$ for $16 \mathrm{~h}$ before it was concentrated in vacuo. The resulting colourless oil was then purified using $\mathrm{C}_{18}$ reverse phase chromatography $\left(1: 10, \mathrm{MeOH}: \mathrm{H}_{2} \mathrm{O}, \mathrm{v}: \mathrm{v}\right)$ to obtain 20 as a colourless oil (21 mg, quant.). $\mathrm{R}_{f}=0.2$ (5:2:2:1, $\mathrm{CH}_{2} \mathrm{Cl}_{2}: \mathrm{MeOH}: \mathrm{EtOH}: \mathrm{NH}_{3}$ (35\%), v:v:v:v); IR (thin film): $\delta 3418,2930,2115,1727,1661,1121 \mathrm{~cm}^{-1} ;{ }^{1} \mathrm{H}-\mathrm{NMR}$ $\left(500 \mathrm{MHz}, \mathrm{D}_{2} \mathrm{O}\right): \delta 4.01$ (s, 6H, H-5), 3.98 (s, 2H, H-1), 3.88 (s, 6H, H-4); ${ }^{13} \mathrm{C}-$ NMR (125 MHz, D 2 ): $\delta 177.1$ (C-6), 170.1 (C-2), 70.0 (C-5, C-4)), 59.8 (C-3), 52.2 (C-1); HRMS(ESI) $\mathrm{m} / \mathrm{z}$ calcd. for $\left[\mathrm{C}_{12} \mathrm{H}_{18} \mathrm{~N}_{4} \mathrm{O}_{10}+\mathrm{H}^{+}\right]$: 378.1096, obsd.: 378.1076.<smiles>CCCCOC(=O)COCC(COCC(=O)OCCC)(COCC(=O)OCCC)NC(=O)CN</smiles>

21

N-(2-aminoacetyl)-1,1,1-tris(tertbutyloxycarbonylmethyloxymethyl)methyl amine (21). Triester 22 (0.16 g, $0.296 \mathrm{mmol})$ was dissolved in $10 \mathrm{~mL}$ of 3:1:1 $\mathrm{MeOH}: \mathrm{H}_{2} \mathrm{O}$ : $\mathrm{CH}_{2} \mathrm{Cl}_{2}$ (v:v:v) before $\mathrm{PPh}_{3}(0.23 \mathrm{~g}, 0.888 \mathrm{mmol}$, 3 equiv.) was added. The reaction mixture was allowed to stir for $16 \mathrm{~h}$ at $\mathrm{rt}$, after which TLC analysis showed complete disappearance of starting materials. The reaction was then diluted and washed with $\mathrm{H}_{2} \mathrm{O}(3 \times 5 \mathrm{~mL})$ to remove triphenylphosphine oxide, and the product extracted with $\mathrm{CH}_{2} \mathrm{Cl}_{2}$. The organic layers were combined and dried with anhydrous $\mathrm{MgSO}_{4}$, which was filtered off and the filtrate concentrated in vacuo to give 21 as a colourless oil (0.15 g, quant.). $\mathrm{R}_{f}=0.10$ (1:10, $\mathrm{MeOH}$ : ethyl acetate, v:v); IR (thin film): 3336, 2978, 2933, 1745, 1674, 1520, 1368, 1300, 1229, 1159, 1121, 1044, $847 \mathrm{~cm}^{-1} ;{ }^{1} \mathrm{H}-\mathrm{NMR}$ (500 MHz, $\mathrm{CDCl}_{3}$ ): $\delta 3.97$ (s, 6H, H-5), 3.94 (s, 6H, H-4), 3.33 (s, 2H, H-1), 1.46 (s, $\left.9 \mathrm{H}, \mathrm{CH}_{3} \mathrm{O}-\mathrm{tBu}\right) ;{ }^{13} \mathrm{C}-\mathrm{NMR}\left(125 \mathrm{MHz}, \mathrm{CDCl}_{3}\right): \delta 173.6(\mathrm{C}-2), 170.1(\mathrm{C}-6), 81.9\left(\mathrm{C}_{\mathrm{i}}\right.$ O-tBu), 70.4 (C-4), 69.1 (C-5), 59.6 (C-3), 45.9 (C-1), $28.3\left(\mathrm{CH}_{3} \mathrm{O}-\mathrm{tBu}\right)$; HRMS(ESI) $m /$ z calcd. for $\left[\mathrm{C}_{24} \mathrm{H}_{44} \mathrm{~N}_{2} \mathrm{O}_{10}+\mathrm{H}^{+}\right]: 521.3069$, obsd.: 521.3071 . 


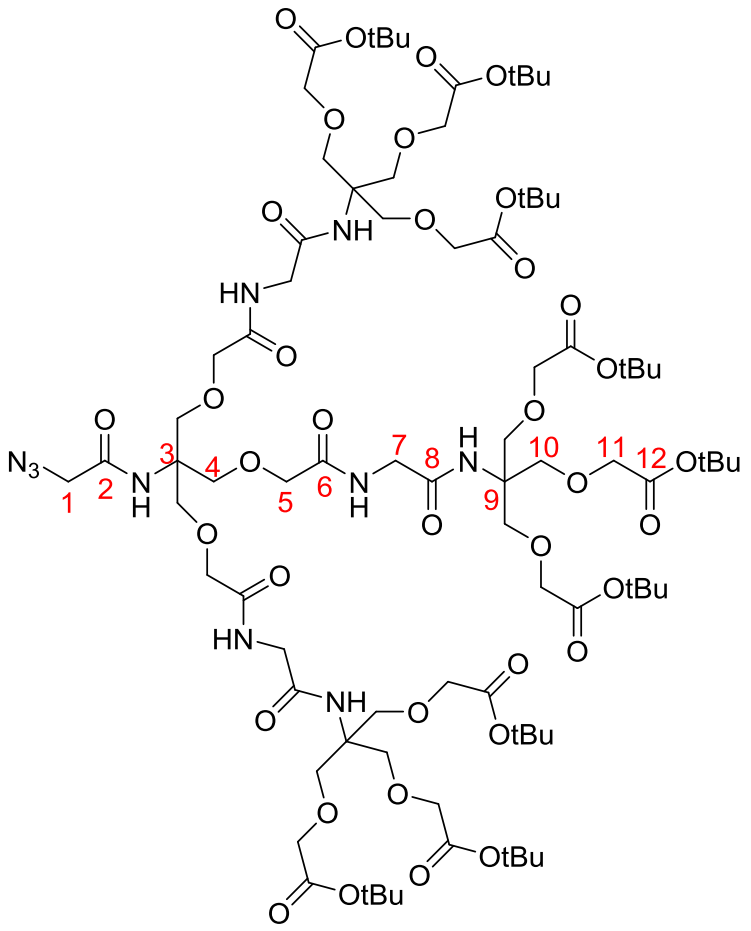

18
$N$-(2-azidoacetyl)-1,1,1-tris-

(1,1,1)-tris(tert-butyloxy carbonylmethoxymethyl) methylaminocarbonylmethyl aminocarbonylmethoxymethyl) methylamine (18). Tri-acid 20 (8.3 $\mathrm{mg}, 0.02 \mathrm{mmol}$ ) and amine 21 (53 mg, $0.10 \mathrm{mmol}$ ) were coevaporated in DMF three times, where the solvent was partially concentrated during the final coevaporation, leaving $0.3 \mathrm{~mL}$ of DMF. HBTU (41.7 mg, 0.11 mmol, 5.3 equiv.) and $\mathrm{NEt}_{3}(4 \mu \mathrm{L}$, $0.3 \mathrm{mmol}, 15$ equiv.) were then

added to the reaction and the solution left to stir for $16 \mathrm{~h}$ at $\mathrm{rt}$, after which TLC analysis showed complete conversion of starting materials to the desired product. The reaction mixture was then concentrated in vacuo before 18 was isolated using $\mathrm{C}_{18}$ reverse phase column chromatography (3:4, $\left.\mathrm{MeOH}: \mathrm{H}_{2} \mathrm{O}, \mathrm{v}: \mathrm{v}\right)$, yielding $\mathbf{1 8}$ as a colourless oil (44.5 mg, quant.). $\mathrm{R}_{f}=0.48$ (1:20, MeOH : ethyl acetate, v:v); IR (thin film): 3316, 3083, 2979, 2107, 1745, 1670, 1474, 1159, 1120, $731 \mathrm{~cm}^{-1} ;{ }^{1} \mathrm{H}-$ NMR (500 MHz, $\left.\mathrm{CDCl}_{3}\right): \delta 4.02$ (s, 6H, H-5), 3.93 (S, 18H, H-11), 3.87 (s, 12H, H4, H-7), 3.85 (s, 2H, H-1), 3.80 (s, 18H, H-10), 1.41 (s, 81H, H-O-tBu); ${ }^{13} \mathrm{C}-\mathrm{NMR}$ (125 MHz, CDCl $)_{3}$ : $\delta 171.2(\mathrm{C}-6), 170.4(\mathrm{C}-12), 169.5(\mathrm{C}-8), 169.2(\mathrm{C}-2), 81.5\left(\mathrm{C}_{\mathrm{i}}\right.$ O-tBu), 70.0 (C-5, C-7), 69.5 (C-10), 68.5 (C-11), 59.9 (C-3, C-9), 27.03 (C-O-tBu); HRMS(ESI) $m / z$ calcd. for $\left[\mathrm{C}_{84} \mathrm{H}_{144} \mathrm{~N}_{10} \mathrm{O}_{37}+\mathrm{H}^{+}\right]:$1885.9767, obsd.: 1885.9772 . 


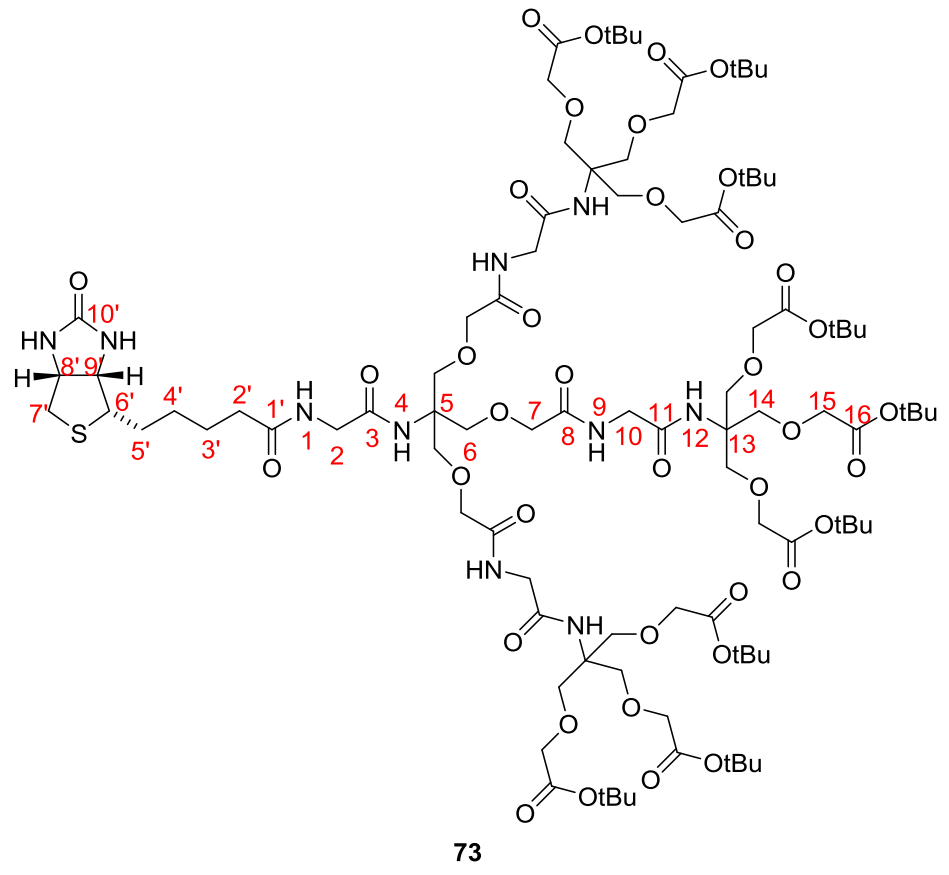

azidoacetyl)-1,1,1-

tris-(1,1,1)-tris(tert-

butyloxycarbonyl

methoxymethyl)

methylamino

carbonylmethyl

aminocarbonyl

methoxymethyl)

methylamino

biotinylamide (73).

Second generation

dendron 18 (17.3 mg,

$9.0 \mu \mathrm{mol}) \quad$ was

dissolved in 3:1:1 MeOH : $\mathrm{H}_{2} \mathrm{O}: \mathrm{CH}_{2} \mathrm{Cl}_{2}(\mathrm{v}: \mathrm{v}: \mathrm{v}, 1 \mathrm{~mL})$ before $\mathrm{PPh}_{3}(7.0 \mathrm{mg}, 27$ $\mu$ mol, 3 equiv.) was added. The reaction was left to stir for $16 \mathrm{~h}$ at rt, after which TLC analysis complete disappearance of starting materials. The reaction mixture was diluted and washed with $\mathrm{H}_{2} \mathrm{O}$, followed by extraction with $\mathrm{CH}_{2} \mathrm{Cl}_{2}$. The organic layers were then combined and dried using anhydrous $\mathrm{MgSO}_{4}$, which was filtered off and the filtrate concentrated in vacuo. The colourless oil was then co-evaporated three times in DMF, where the solvent was partially concentrated upon the last co-evaporation, leaving $0.2 \mathrm{~mL}$ of $\mathrm{DMF}$ in the reaction flask. D-Biotin (15) (2 mg, $9.9 \mu \mathrm{mol}, 1.1$ equiv.) was then added, followed by the addition of $\mathrm{NEt}_{3}(2.8 \mu \mathrm{L}, 20 \mu \mathrm{mol}, 2.2$ equiv.) and $\mathrm{HBTU}(7.0 \mathrm{mg}, 18 \mu \mathrm{mol}, 2$ equiv.). The reaction was then left to stir for $16 \mathrm{~h}$ at $\mathrm{rt}$, after which TLC analysis showed complete disappearance of the product spot. The reaction was concentrated in vacuo before it was purified using $\mathrm{C}_{18}$ reverse phase column chromatography (3:4, $\mathrm{MeOH}: \mathrm{H}_{2} \mathrm{O}$, v:v) to yield 73 as a colourless oil (18.7 mg, quant.). $\mathrm{R}_{f}=0.5$ (1:10, $\mathrm{MeOH}: \mathrm{CH}_{2} \mathrm{Cl}_{2}$, v:v); IR (thin film): 3309, 3063, 2979, 1744, 1668, 1527, 1393, 1230, 1158, 1118, $733 \mathrm{~cm}^{-1}$; ${ }^{1} \mathrm{H}-\mathrm{NMR}\left(500 \mathrm{MHz}, \mathrm{CDCl}_{3}\right.$ ): 7.74 (s, 3H, H-12), 7.70 $\left(\mathrm{t}, J_{1,1}=J_{1,2}=5.7 \mathrm{~Hz}, 1 \mathrm{H}, \mathrm{H}-1\right), 7.61(\mathrm{~s}, 1 \mathrm{H}, \mathrm{H}-4), 7.53\left(\mathrm{t}, J_{9,10 \mathrm{a}}=J_{9,10 \mathrm{~b}}=5.1 \mathrm{~Hz}\right), 4.41(\mathrm{t}$, $\left.J_{8^{\prime}, 7^{\prime} \mathrm{a}}=J_{8^{\prime}, 7^{\mathrm{b}}}=6.3 \mathrm{~Hz}, 1 \mathrm{H}, \mathrm{H}-8^{\prime}\right), 4.32\left(\mathrm{dd}, J_{9^{\prime}, 8^{\prime}}=4.6 \mathrm{~Hz}, J_{9^{\prime}, 6^{\prime}}=7.0 \mathrm{~Hz}, 1 \mathrm{H}, \mathrm{H}-9^{\prime}\right), 4.04$ (s, 6H, H-7), 4.01 (s, 2H, H-2), 3.96 (s, 18H, H-15), 3.90 (s, 18 H, H-14), 3.87 (s, 6H, H-6), 3.13 (q, $J_{6^{\prime}, 9}=7.2 \mathrm{~Hz}, J_{6,5},=12.0 \mathrm{~Hz}, 1 \mathrm{H}, \mathrm{H}-6^{\prime}$ ), 2.89 (dd, $J_{7^{\prime} \mathrm{a}, 8}=5.3 \mathrm{~Hz}$, 
$\left.J_{7^{\mathrm{a}} \mathrm{a},{ }^{\prime \mathrm{b}}}=13.0 \mathrm{~Hz}, 1 \mathrm{H}, \mathrm{H}-7^{\prime} \mathrm{a}\right), 2.75$ (d, $\left.J_{7^{\mathrm{a}} \mathrm{a}, 7^{\mathrm{b}}}=12.8 \mathrm{~Hz}, 1 \mathrm{H}, \mathrm{H}-7^{\prime} \mathrm{b}\right), 2.27$ (m, 2H, H-2'), 1.68-1.58 (m, 6H, H-2', H-3', H-4'), 1.46 (s, $81 \mathrm{H}, \mathrm{H}-\mathrm{O}-\mathrm{tBu}){ }^{13} \mathrm{C}-\mathrm{NMR}(125 \mathrm{MHz}$, $\mathrm{CDCl}_{3}$ ); $\delta 174.4\left(\mathrm{C}-10^{\prime}\right), 170.6\left(\mathrm{C}^{\prime} 1^{\prime}\right), 170.1$ (C-8), 170.0 (C-16), 169.0 (C-8), 163.9 (C-3), 82.0 (C-13), 70.6 (C-7), 70.4 (C-10), 70.0 (C-14), 68.8 (C-15), 61.8 (C-9’), 59.9 (C-5), 60.1 (C-8’), 55.5 (C-6'), 40.3 (C-7'), 35.5 (C-2'), 28.0 (C-4'), 27.9 (C-5’), 25.3 (C-3'); HRMS(ESI) $m / z$ calcd. for $\left[\mathrm{C}_{94} \mathrm{H}_{160} \mathrm{~N}_{10} \mathrm{O}_{39} \mathrm{~S}+2 \mathrm{H}^{2+}\right]: 1043.5355$, obsd.: 1043.5360 .

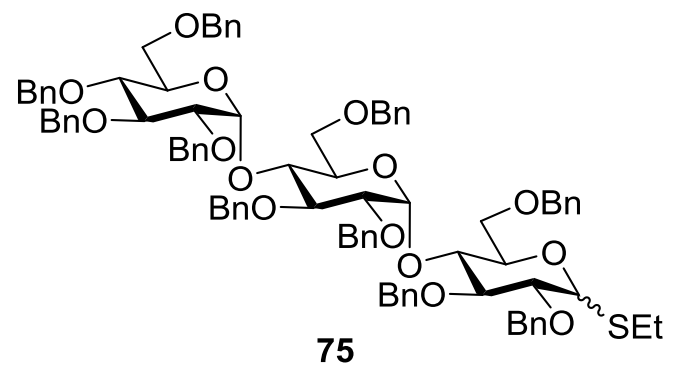

Ethyl-4- $O-(4-O-(2,3,4,6-$ tetra- $O$ benzyl-D-glucopyranosyl)-2,3,6-tri$O$-benzyl- $\alpha$-D-glucopyranosyl)2,3,6-tri- $O$-benzyl-1-thio- $\alpha-D-$ glucopyranoside (75). D-Maltotriose $(1.0 \mathrm{~g}, 2.0 \mathrm{mmol})(\mathbf{1 6 c})$ and $\mathrm{NaOAc}$ (0.81 g, 9.9 mmol, 5 equiv.) were dissolved in $\mathrm{Ac}_{2} \mathrm{O}$ (1.9 mL, $19.8 \mathrm{mmol}, 10$ equiv.) and left at $80{ }^{\circ} \mathrm{C}$ for $16 \mathrm{~h}$, after which TLC analysis showed the complete conversion to a higher running product (2:1, petroleum ether : ethyl acetate, $\mathrm{v}: \mathrm{v})$. The reaction mixture was then poured into $300 \mathrm{~mL}$ of ice-water, which gave white crystals that were filtered off and dried in a dessicator. The crystals were then coevaporated three times in dry toluene to remove traces of $\mathrm{H}_{2} \mathrm{O}$ before dissolving them in $\mathrm{CH}_{2} \mathrm{Cl}_{2}(5 \mathrm{~mL})$. EtSH $(0.14 \mathrm{~mL}, 1.86 \mathrm{mmol})$ was then added, and the reaction cooled to $0{ }^{\circ} \mathrm{C}$ before $\mathrm{SnCl}_{4}(0.009 \mathrm{~mL}, 0.775 \mathrm{mmol})$. After $16 \mathrm{~h}$ of stirring at rt, TLC analysis showed the complete formation of a lower running product (4:1, petroleum ether : ethyl acetate, v:v). The reaction was then quenched by the addition of sat. aq. $\mathrm{NaHCO}_{3}$ and brine $(20 \mathrm{~mL}$ each) and the product extracted using $\mathrm{Et}_{2} \mathrm{O}$. The combined ether layers were then dried using anhydrous $\mathrm{MgSO}_{4}$, which was filtered off and concentrated in vacuo. Purification by silica gel column chromatography then gave a yellow oil $(15: 1 \rightarrow 8: 1$, petroleum ether : ethyl acetate, v:v). The yellow oil was then dissolved in $\mathrm{MeOH}(5 \mathrm{~mL})$ before $1 \mathrm{M}$ $\mathrm{NaOMe}$ in $\mathrm{MeOH}$ solution $(0.2 \mathrm{~mL})$ was added. The reaction was allowed to stir for $1 \mathrm{~h}$, after which TLC analysis showed the complete conversion of a lower running product (6:2:2:2:1, $\mathrm{CH}_{2} \mathrm{Cl}_{2}: \mathrm{MeOH}: \mathrm{EtOH}: \mathrm{H}_{2} \mathrm{O}: \mathrm{NH}_{3}$ (35\%), v:v:v:v). The reaction was then neutralised using Dowex $-\mathrm{H}^{+}$, which was filtered off and the reaction concentrated in vacuo. The resulting colourless oil was then co-evaporated 
in DMF three times, where the solvent was partially concentrated upon the final evaporation, leaving $40 \mathrm{~mL}$ of DMF. $\mathrm{BnBr}(3.45 \mathrm{~mL}, 29.1 \mathrm{mmol})$ and TBAI $(0.57$ $\mathrm{g}, 1.55 \mathrm{mmol})$ were added before the reaction was cooled to $0{ }^{\circ} \mathrm{C}$ and $\mathrm{NaH}(1.36 \mathrm{~g}$, $31 \mathrm{mmol}$ ) was slowly introduced to the reaction, which was allowed to stir at rt. After $16 \mathrm{~h}$, TLC analysis showed the complete disappearance of the starting materials and the reaction was quenched using sat. aq. $\mathrm{NaHCO}_{3}$ and brine, followed by the extraction of product with $\mathrm{CH}_{2} \mathrm{Cl}_{2}(20 \mathrm{~mL}$ each). The combined organic layers were then dried using anhydrous $\mathrm{MgSO}_{4}$, which was filtered off and the filtrate concentrated in vacuo. The resulting yellow oil was then purified using silica gel flash column chromatography, yielding $\mathbf{7 5}$ as a colourless oil (1.34, 47\% over four steps, $2: 1 \alpha: \beta) . \mathrm{R}_{f}=0.37$ (2:1, petroleum ether : ethyl acetate, $\left.\mathrm{v}: \mathrm{v}\right)$; IR (thin film): 3030, 2865, 1496, 1453, 1071, 1026, 729, $695 \mathrm{~cm}^{-1} ;{ }^{1} \mathrm{H}-\mathrm{NMR}(500 \mathrm{MHz}$, $\left.\mathrm{CDCl}_{3}\right): \delta$ 7.51-7.16 (m, 50H, CH arom.), 5.80 (d, $J_{1,2,2}=3.1 \mathrm{~Hz}, 1 \mathrm{H}, \alpha-\mathrm{H}-1$ "), 5.76 (d, $J_{1^{\prime \prime}, 2^{\prime \prime}}=3.0 \mathrm{~Hz}, 1 \mathrm{H}, \beta-\mathrm{H}-1$ "), 5.65 (d, $\left.J_{1^{\prime \prime}, 2^{\prime \prime}}=2.9 \mathrm{~Hz}, 1 \mathrm{H}, \mathrm{H}-1^{\prime \prime \prime}\right), 5.53$ (d, $J_{1^{\prime}, 2}=5.1$ $\mathrm{Hz}, 1 \mathrm{H}, \alpha-\mathrm{H}_{-1}$ '), 5.09-4.51 (m, 20H, $\left.\mathrm{CH}_{2} \mathrm{O}-\mathrm{Bn}, \beta-\mathrm{H}-1^{\prime}\right), 4.40-4.37$ (m, 2H, $\mathrm{CH}_{2}$ O-Bn, $\beta-\mathrm{H}-2$ '), 4.18-4.13 (m, 4H, H-4', H-4”, H-3', H-3'”), 4.07-3.96 (m, 5H, H-3”,

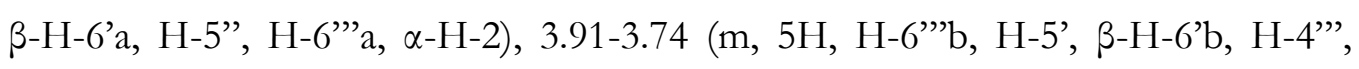

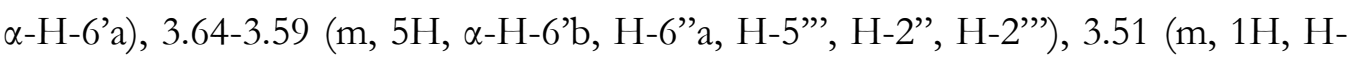
6"b), 2.87 (m, 2H, CH $\beta$-SEt), 2.65 (m, 2H, $\alpha$-SEt), 1.42 (m, 4H, $\mathrm{CH}_{2} \beta-\mathrm{SEt}, \mathrm{CH}_{2}$ $\alpha$-SEt); ${ }^{13} \mathrm{C}-\mathrm{NMR}\left(125 \mathrm{MHz}, \mathrm{CDCl}_{3}\right): \delta 139.1\left(\mathrm{C}_{\mathrm{i}}\right.$ arom. $), 139.0\left(\mathrm{C}_{\mathrm{i}}\right.$ arom. $), 138.9\left(\mathrm{C}_{\mathrm{i}}\right.$ arom.), 138.8 ( $\mathrm{C}_{\mathrm{i}}$ arom.), 138.6 ( $\mathrm{C}_{\mathrm{i}}$ arom.), 138.5 ( $\mathrm{C}_{\mathrm{i}}$ arom.), $138.4\left(\mathrm{C}_{\mathrm{i}}\right.$ arom.), 138.3 ( $\mathrm{C}_{\mathrm{i}}$ arom.), 138.2 ( $\mathrm{C}_{\mathrm{i}}$ arom.), 138.0 ( $\mathrm{C}_{\mathrm{i}}$ arom.), 137.9 ( $\mathrm{C}_{\mathrm{i}}$ arom.), 137.8 ( $\mathrm{C}_{\mathrm{i}}$ arom.), 128.4 (CH arom.), 128.3 (CH arom.), 128.2 (CH arom.), 128.1 (CH arom.), 127.9 (CH arom.), 127.8 (CH arom.), 127.7 (CH arom.), $127.6(\mathrm{CH}$ arom.), $127.5(\mathrm{CH}$ arom.), 127.4 (CH arom.), 127.3 (CH arom.), 127.2 (CH arom.), 127.1 (CH arom.), 127.0 (CH arom.), 126.9 (CH arom.), 126.8 (CH arom.), 126.7 (CH arom.), 126.6

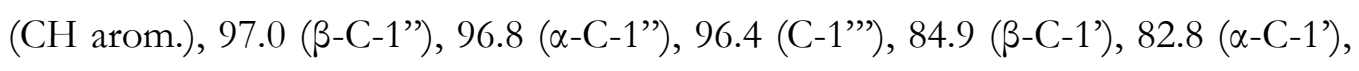

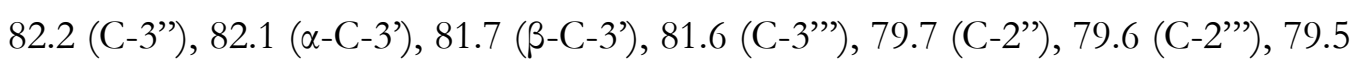

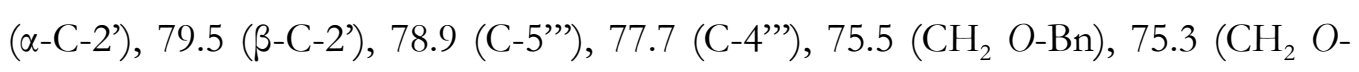
$\mathrm{Bn}), 75.0\left(\mathrm{CH}_{2} \mathrm{O}-\mathrm{Bn}\right), 74.4\left(\mathrm{CH}_{2} \mathrm{O}-\mathrm{Bn}\right), 74.1\left(\mathrm{CH}_{2} \mathrm{O}-\mathrm{Bn}\right), 74.0\left(\mathrm{CH}_{2} \mathrm{O}-\mathrm{Bn}\right), 73.8$ (C-4”), $73.6\left(\mathrm{CH}_{2} \mathrm{O}-\mathrm{Bn}\right), 73.5\left(\mathrm{CH}_{2} \mathrm{O}-\mathrm{Bn}\right), 73.3\left(\mathrm{CH}_{2} \mathrm{O}-\mathrm{Bn}\right), 73.2\left(\mathrm{CH}_{2} \mathrm{O}-\mathrm{Bn}\right)$, 73.0 ( $\left.\mathrm{CH}_{2} \mathrm{O}-\mathrm{Bn}\right), 72.9$ ( $\left.\mathrm{CH}_{2} \mathrm{O}-\mathrm{Bn}\right), 72.7$ (C-4'), 72.4 (C-5'), 71.0 (C-5'), 70.8 (C-5”),

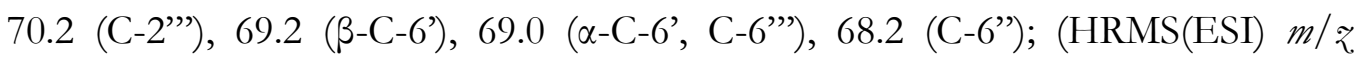
calcd. for $\left[\mathrm{C}_{90} \mathrm{H}_{96} \mathrm{O}_{15} \mathrm{~S}+\mathrm{NH}_{4}\right]^{+}: 1466.6808$, obsd.: 1466.6802 . 


\subsection{Biological Assay}

\subsubsection{Subjects}

Eight MS patients ( 7 females, 1 male) and six healthy individuals (4 females, 2 males) between 22 and 58 years of age participated in our study. Among the MS patients, there were 4 RRMS, 3 SPMS and 1 PRMS patients with diagnosis as early as 1996 and as recent as 2014. The study protocol was approved by the Human Ethics Committee at Victoria University of Wellington.

\subsubsection{Preparation of Plasma Samples}

Blood samples of up to $50 \mathrm{~mL}$ for anti-glycan antibody analyses were drawn from a forearm vein. The plasma was then separated from the blood samples and collected into CPT vacutainers containing heparin by a trained phlebotomist. These were then divided into $50 \mu \mathrm{L}$ aliquots and stored at $-20{ }^{\circ} \mathrm{C}$.

\subsubsection{General ELISA Method}

Streptavidin (ProSpec, Israel) (500 ng per well) in phosphate buffer saline (PBS) was used to coat a 96-well ELISA plate (Maxisorp, Nunc, Roskilde, Denmark). After incubation overnight at $4{ }^{\circ} \mathrm{C}$, the excess streptavidin was removed, followed by a triple washing with PBS-0.05\% Tween 20 (PBS-Tw) and blocking with 1\% bovine serum albumin (BSA) or 10\% foetal calf serum (FCS) in PBS for $2 \mathrm{~h}$ at $\mathrm{rt}$. Biotinylated $\beta$-GlcNAc (25 ng per well) in PBS were then added and the plates incubated for $2 \mathrm{~h}$ at rt. Plates were then washed 4 times with PBS-Tw, followed by the $100 \mu \mathrm{L} /$ well addition of patient plasma, diluted 1:200 in 1\% BSA-PBS or 10\% FCS-PBS. After another $2 \mathrm{~h}$ incubation period at $\mathrm{rt}$, the plates were washed 4 times with PBS-Tw and a $100 \mu \mathrm{L} /$ well of a secondary horseradish peroxidase (HRP)conjugated goat anti-human $\operatorname{IgG}, \operatorname{IgM}$ and $\operatorname{IgE}$ antibodies (ThermoFisher, NZ) diluted 1:2000 in either 1\% BSA-PBS or 10\% FCS-PBS were applied for $1 \mathrm{~h}$ at rt. The plates were washed 8 times with PBS-Tw, before the bound anti-glycan antibodies were detected through the application of $100 \mu \mathrm{L} /$ well of tetramethyl benzidine (TMB), which was stopped after sufficient colour development using 
$0.18 \mathrm{M} \mathrm{H}_{2} \mathrm{SO}_{4}(100 \mu \mathrm{L} /$ well $)$. The absorbance values were read at $450 \mathrm{nM}$ using a multi-well plate reader. 


\section{REFERENCES}

1. Ziemann U, Wahl M, Hattingen E, Tumani H: Development of biomarkers for multiple sclerosis as a neurodegenerative disorder. Prog Neurobiol 2011, 95:670-685.

2. Hafler DA, Slavik JM, Anderson DE, O'Connor KC, De Jager P, Baecher-Allan C: Multiple sclerosis. Immunol Rev 2005, 204:208-231.

3. Rosati G: Descriptive epidemiology of multiple sclerosis in Europe in the 1980s: A critical overview. Ann Neurol 1994, 36:S164-S174.

4. Rosati G: The prevalence of multiple sclerosis in the world: An update. J Neurol Sci 2001, 22:117-139.

5. Wade BJ: Spatial analysis of global prevalence of multiple sclerosis suggests need for an updated prevalence scale. Mult Scler Int 2014:1-7.

6. (WHO) WHO: Atlas: Multiple sclerosis resources in the world. Switzerland: WHO Press, World Health Organization; 2008.

7. Simpson Jr S, Blizzard L, Otahal P, Van der Mei I, Taylor B: Latitude is significantly associated with the prevalence of multiple sclerosis: A meta-analysis. J Neurol Neurosurg Psych 2011, 82:1132-1141.

8. Koch-Henriksen N, Sørensen PS: The changing demographic pattern of multiple sclerosis epidemiology. Lancet Neurol 2010, 9:520-532.

9. Koch-Henriksen N, Sorensen PS: Why does the north-south gradient of incidence of multiple sclerosis seem to have disappeared on the Northern hemisphere? $J$ Neurol Sci 2011, 311:58-63.

10. Taylor B, Richardson A, Mason D, Willoughby E, Abernethy D, Clarke G, Sabel C: Prevalence of multiple sclerosis in New Zealand. In. New Zealand: University of Otago; 2006.

11. Taylor BV, Pearson JF, Clarke G, Mason DF, Abernethy DA, Willoughby E, Sabel C: MS prevalence in New Zealand, an ethnically and latitudinally diverse country. Mult Scler 2010, 16:1422-1431.

12. Ascherio A, Munger KL, Simon KC: Vitamin D and multiple sclerosis. Lancet Neurol 2010, 9:599-612.

13. Gourraud P-A, Harbo HF, Hauser SL, Baranzini SE: The genetics of multiple sclerosis: An up-to-date review. Immunol Rev 2012, 248:87-103.

14. Sener A, Afsar I: Infection and autoimmune disease. Rheumatol Int 2012, 32:3331-3338.

15. Serafini B, Rosicarelli B, Franciotta D, Magliozzi R, Reynolds R, Cinque P, Andreoni L, Trivedi P, Salvetti M, Faggioni A et al: Dysregulated Epstein-Barr virus infection in the multiple sclerosis brain. J Exp Med 2007, 204:2899-2912.

16. Franciotta D, Salvetti M, Lolli F, Serafini B, Aloisi F: B cells and multiple sclerosis. Lancet Neurol 2008, 7:852-858.

17. Trapp BD, Klaus-Armin N: Multiple sclerosis: An immune or neurodegenerative disorder? Annu Rev Neurosci 2008, 31:247-269.

18. Ebers GC, Sadovnick AD, Risch NJ: A genetic basis for familial aggregation in multiple sclerosis. Nature 1995, 377:150-151.

19. Dean G, Elian M: Age at immigration to England of Asian and Caribbean immigrants and the risk of developing multiple sclerosis. J Neurol Neurosurg Psychiatry 1997, 63:565568.

20. DeLuca GC, Alterman R, Martin JL, Mittal A, Blundell S, Bird S, Beale H, Hong LS, Esiri MM: Casting light on multiple sclerosis heterogeneity: The role of HLA-DRB1 on spinal cord pathology. Brain 2013, 136:1025-1034.

21. Black JG: Microbiology: Principles and explorations. New York, USA: Wiley and Sons; 2002.

22. Lassmann H, van Horssen J, Mahad D: Progressive multiple sclerosis: Pathology and pathogenesis. Nat Rev Neurol 2012, 8:647-656.

23. Lappe-Siefke C, Goebbels S, Gravel M, Nicksch E, Lee J, Braun PE, Griffiths IR, Nave K-A: Disruption of Cnp1 uncouples oligodendroglial functions in axonal support and myelination. Nat Genet 2003, 33:366-374.

24. Popko B: Myelin: Not just a conduit for conduction. Nat Genet 2003, 33:327-328. 
25. Griffiths I, Klugmann M, Anderson T, Yool D, Thomson C, Schwab MH, Schneider A, Zimmermann F, McCulloch, Nadon $\mathrm{N}$ et al: Axonal swellings and degeneration in mice lacking the major proteolipid of myelin. Science 1998, 280:1610-1613.

26. Bö L, Dawson TM, Möurk S, Choi S, Kong PA, Hanley D, Trapp BD: Induction of nitric oxide synthase in demyelinating regions of multiple sclerosis brains. Ann Neurol 1994, 36:778-786.

27. Liu JS-H, Zhao M-L, Brosnan CF, Lee SC: Expression of inducible nitric oxide synthase and nitrotyrosine in multiple sclerosis lesions. Am J Pathol 2001, 158:2057-2066.

28. Smith KJ, Lassmann H: The role of nitric oxide in multiple sclerosis. Lancet Neurol 2002, 1:232-241.

29. McDonald LJ, Moss J: Stimulation by nitric oxide of an NAD linkage to glyceraldehyde3-phosphate dehydrogenase. Proc Natl Acad Sci U S A 1993, 90:6238-6241.

30. Muriel P, Castañeda G, Ortega M, Noël F: Insights into the mechanism of erythrocyte $\mathrm{Na}+\mathrm{K}+-A T P a s e$ inhibition by nitric oxide and peroxynitrite anion. J Appl Toxicol 2003, 23:275-278.

31. Renganathan M, Cummins TR, Waxman SG: Nitric oxide blocks fast, slow, and perisistent $\mathrm{Na}+$ channels in C-type DRG neurons by S-nitrosylation. J Neurophysiol 2002, 87:761-775.

32. Brown GC, Borutaite V: Nitric oxide inhibition of mitochondrial respiration and its role in cell death. Free Radical Biol Med 2002, 33:1440-1450.

33. Piani D, Frei K, Do KQ, Cuénod M, Fontana A: Murine brain macrophages induce NMDA receptor mediated neurotoxicity in vitro by secreting glutamatez. Neurosci Lett 1991, 133:159-162.

34. Garg SK, Banerjee R, Kipnis J: Neuroprotective immunity: T cell-derived glutamate endows astrocytes with a neuroprotective phenotype. J Immunol 2008, 180:3866-3873.

35. McDonald JW, Althomsons SP, Hyrc KL, Choi DW, Goldberg MP: Oligodendrocytes from forebrain are highly vulnerable to AMPA/kainate receptor-mediated excitotoxicity. Nat Med 1998, 4:291-297.

36. Srinivasan R, Sailasuta N, Hurd R, Nelson S, Pelletier D: Evidence of elevated glutamate in multiple sclerosis using magnetic resonance spectroscopy at 3 T. Brain 2005, 128:10161025.

37. Lipton SA, Rosenberg PA: Excitatory amino acids as a final common pathway for neurologic disorders. N Engl J Med 1994, 330:613-622.

38. Janeway Jr. C, A., Travers P, Walport M, Shlomchik MJ: Immunobiology: The immune system in health and disease. New York: Garland Science Publishing; 2005.

39. Morelli L, Poletti L, Lay L: Carbohydrates and immunology: Synthetic oligosaccharide antigens for vaccine formulation. Eur J Org Chem 2011:5723-5777.

40. Meinl E, Krumbholz M, Hohlfeld R: B lineage cells in the inflammatory central nervous system environment: Migration, maintenance, local antibody production, and therapeutic modulation. Ann Neurol 2006, 59:880-892.

41. Rioux JD, Abbas AK: Paths to understanding the genetic basis of autoimmune disease. Nature 2005, 435:584-589.

42. Klein L, Klugmann M, Nave K-A, Tuohy VK, Kyewski B: Shaping of the autoreactive Tcell repertoire by a splice variant of self protein expressed in thymic epithelial cells. Nat Med 2000, 6:56-61.

43. Waldner H, Whitters MJ, Sobel RA, Collins M, Kuchroo VK: Fulminant spontaneous autoimmunity of the central nervous system in mice transgenic for the myelin proteolipid protein-specific T cell receptor. Proc Nat Acad Sci 2000, 97:3412-3417.

44. Andersson M, Yu M, Söderström M, Weerth S, Baig S, Linington C, Solders G, Link H: Multiple MAG peptides are recognized by circulating $T$ and $B$ lymphocytes in polyneuropathy and multiple sclerosis. Eur J Neurol 2002, 9:243-251.

45. Weissert R, Kuhle J, de Graaf KL, Wienhold W, Herrmann MM, Müller C, Forsthuber TG, Wiesmüller K-H, Melms A: High immunogenicity of intracellular myelin oligodendrocyte glycoprotein epitopes. J Immunol 2002, 169:548-556.

46. Arbour N, Holz A, Sipe JC, Naniche D, Romine JS, Zyroff J, Oldstone MBA: A new approach for evaluating antigen-specific $T$ cell responses to myelin antigens during the course of multiple sclerosis. J Neuroimmunol 2003, 137:197-209.

47. Vu T, Myers LW, Ellison GW, Mendoza F, Bronstein JM: T-cell responses to oligodendrocyte-specific protein in multiple sclerosis. J Neurosci Res 2001, 66:506-509.

48. Sospedra M, Martin R: Immunology of multiple sclerosis. Ann Rev Immunol 2005, 23:683-747. 
49. Lassmann H: Hypoxia-like tissue injury as a component of multiple sclerosis lesions. $J$ Neurol Sci 2003, 206:187-191.

50. Mattson DH, Roos RP, Arnason BGW: Isoelectric focusing of IgG eluted from multiple sclerosis and subacute sclerosing panencephalitis brains. Nature 1980, 287:335-337.

51. Genain CP, Cannella B, Hauser SL, Raine CS: Identification of autoantibodies associated with myelin damage in multiple sclerosis. Nat Med 1999, 5:170-175.

52. Brettschneider J, Jaskowski TD, Tumani H, Abdul S, Husebye D, Seraj H, Hill HR, Fire E, Spector L, Yarden J et al: Serum anti-GAGA4 IgM antibodies differentiate relapsing remitting and secondary progressive multiple sclerosis from primary progressive multiple sclerosis and other neurological diseases. J Neuroimmunol 2009, 217:95-101.

53. Schwarz M, Spector L, Gortler M, Weisshaus O, Glass-Marmor L, Karni A, Dotan N, Miller A: Serum anti-Glc $(\alpha 1,4) \mathrm{Glc}(\alpha)$ antibodies as a biomarker for relapsing-remitting multiple sclerosis. J Neurol Sci 2006, 244:59-68.

54. Goldenberg MM: Multiple sclerosis review. Pharmacol Ther 2012, 37:175-184.

55. Steinman L: Multiple sclerosis: A two-stage disease. Nat Immunol 2001, 2:762-764.

56. O'Sullivan D, Green L, Stone S, Zareie P, Kharkrang M, Fong D, Connor B, La Flamme AC: Treatment with the antipsychotic agent, risperidone, reduces disease severity in experimental autoimmune encephalomyelitis. PLoS ONE 2014, 9:e104430.

57. Beck RW, Cleary PA, Trobe JD, Kaufman DI, Kupersmith MJ, Paty DW, Brown H: The effect of corticosteroids for acute optic neuritis on the subsequent development of multiple sclerosis. N Engl J Med 1993, 329:1764-1769.

58. Kleinschmidt-DeMasters BK, Tyler KL: Progressive multifocal leukoencephalopathy complicating treatment with natalizumab and interferon beta-1a for multiple sclerosis. $N$ Engl J Med 2005, 353:369-374.

59. McFarland HF, Martin R: Multiple sclerosis: A complicated picture of autoimmunity. Nat Immunol 2007, 8:913-919.

60. Boes M: Role of natural and immune IgM antibodies in immune responses. Mol Immunol 2000, 37:1141-1149.

61. Huflejt ME, Vuskovic M, Vasiliu D, Xu H, Obukhova P, Shilova N, Tuzikov A, Galanina $\mathrm{O}$, Arun B, Lu K et al: Anti-carbohydrate antibodies of normal sera: Findings, surprises and challenges. Mol Immunol 2009, 46:3037-3049.

62. Grönwall C, Silverman G: Natural IgM: Beneficial Autoantibodies for the Control of Inflammatory and Autoimmune Disease. J Clin Immunol 2014, 34:12-21.

63. Zouali M: Natural antibodies. Encyclopedia of Life Sciences 2009:1-9.

64. Mazzucco S, Matà S, Vergelli M, Fioresi R, Nardi E, Mazzanti B, Chelli M, Lolli F, Ginanneschi M, Pinto F et al: A synthetic glycopeptide of human myelin oligodendrocyte glycoprotein to detect antibody responses in multiple sclerosis and other neurological diseases. Bioorg Med Chem Lett 1999, 9:167-172.

65. Carotenuto A, D'Ursi AM, Nardi E, Papini AM, Rovero P: Conformational analysis of a glycosylated human myelin oligodendrocyte glycoprotein peptide epitope able to detect antibody response in multiple sclerosis. $J$ Med Chem 2001, 44:2378-2381.

66. Lolli F, Mazzanti B, Pazzagli M, Peroni E, Alcaro MC, Sabatino G, Lanzillo R, Morra VB, Santoro L, Gasperini C et al: The glycopeptide CSF114(Glc) detects serum antibodies in multiple sclerosis. J Neuroimmunol 2005, 167:131-137.

67. Freedman MS, Laks J, Dotan N, Altstock RT, Dukler A, Sindic C: Anti- $\alpha$-glucose-based glycan IgM antibodies predict relapse activity in multiple sclerosis after the first neurological event. Mult Scler 2009, 15:422-430.

68. Dotan N, Altstock RT, Schwarz M, Dukler A: Anti-glycan antibodies as biomarkers for diagnosis and prognosis. Lupus 2006, 15:1-10.

69. Schwarz M, Spector L, Gargir A, Shtevi A, Gortler M, Altstock RT, Dukler AA, Dotan N: A new kind of carbohydrate array, its use for profiling antiglycan antibodies, and the discovery of a novel human cellulose-binding antibody. Glycobiology 2003, 13:749-754.

70. van Horssen J, Bö L, Dijkstra CD, de Vries HE: Extensive extracellular matrix depositions in active multiple sclerosis lesions. Neurobiol Dis 2006, 24:484-491.

71. Polman CH, Reingold SC, Edan G, Filippi M, Hartung H-P, Kappos L, Lublin FD, Metz LM, McFarland HF, O'Connor PW et al: Diagnostic criteria for multiple sclerosis: 2005 revisions to the "McDonald Criteria". Ann Neurol 2005, 58:840-846.

72. Poser CM, Paty DW, Scheinberg L, McDonald I, Davis FA, Ebers GC, Johnson KP, Sibley WA, Silberberg DH, Tourtellotte WW: New diagnostic criteria for multiple sclerosis: Guidelines for research protocols. Ann Neurol 1983, 13:227-231.

73. McDonald WI, Compston A, Edan G, Goodkin D, Hartung H-P, Lublin FD, McFarland HF, Paty DW, Polman CH, Reingold SC et al: Recommended diagnostic criteria for 
multiple sclerosis: Guidelines from the international panel on the diagnosis of multiple sclerosis. Ann Neurol 2001, 50:121-127.

74. Cohen SR, Brooks BR, Herndon RM, McKhann GM: A diagnostic index of active demyelination: Myelin basic protein in cerebrospinal fluid. Ann Neurol 1980, 8:25-31.

75. Ponomarenko NA, Durova OM, Vorobiev II, Belogurov AA, Kurkova IN, Petrenko AG, Telegin GB, Suchkov SV, Kiselev SL, Lagarkova MA et al: Autoantibodies to myelin basic protein catalyze site-specific degradation of their antigen. Proc Natl Acad Sci U S A 2006, 103:281-286.

76. Belogurov AA, Kurkova IN, Friboulet A, Thomas D, Misikov VK, Zakharova MY, Suchkov SV, Kotov SV, Alehin AI, Avalle B et al: Recognition and degradation of myelin basic protein peptides by serum autoantibodies: Novel biomarker for multiple sclerosis. $J$ Immunol 2008, 180:1258-1267.

77. Berger T, Reindl M: Emergence of antibodies as biomarkers in multiple sclerosis. Future Neurol 2006, 1:57-66.

78. Kuhle J, Pohl C, Mehling M, Edan G, Freedman MS, Hartung H-P, Polman CH, Miller $\mathrm{DH}$, Montalban X, Barkhof $\mathrm{F}$ et al: Lack of association between antimyelin antibodies and progression to multiple sclerosis. N Engl J Med 2007, 356:371-378.

79. Pelayo R, Tintoré M, Montalban X, Rovira A, Espejo C, Reindl M, Berger T: Antimyelin antibodies with no progression to multiple sclerosis. N Engl J Med 2007, 356:426-428.

80. Hornbeck P: Double-Immunodiffusion Assay for Detecting Specific Antibodies. In: Curr Protoc Immunol. John Wiley \& Sons, Inc.; 2001.

81. Wiener E, Brechbiel MW, Brothers H, Magin RL, Gansow OA, Tomalia DA, Lauterbur PC: Dendrimer-based metal chelates: A new class of magnetic resonance imaging contrast agents. Magnetic Resonance in Medicine 1994, 31:1-8.

82. Patri AK, Majoros IJ, Baker Jr JR: Dendritic polymer macromolecular carriers for drug delivery. Current Opinion in Chemical Biology 2002, 6:466-471.

83. Gajbhiye V, Kumar PV, Sharma A, Agarwal A, Asthana A, Jain NK: Dendrimeric nanoarchitectures mediated transdermal and oral delivery of bioactives. Indian Journal of Pharmaceutical Sciences 2008, 70:431-439.

84. Zeng F, Zimmerman SC: Dendrimers in supramolecular chemistry: From molecular recognition to self-assembly. Chem $\operatorname{Rev} 1997,97: 1681-1712$.

85. Cheng Y, Xu Z, Ma M, Xu T: Dendrimers as drug carriers: Applications in different routes of drug administration. J Pharm Sci 2008, 97:123-143.

86. Bastings MMC, Helms BA, van Baal I, Hackeng TM, Merkx M, Meijer EW: From phage display to dendrimer display: Insights into multivalent binding. I Am Chem Soc 2011, 133:6636-6641.

87. Weber P, Ohlendorf D, Wendoloski J, Salemme F: Structural origins of high-affinity biotin binding to streptavidin. Science 1989, 243:85-88.

88. Nickerson DA, Kaiser R, Lappin S, Stewart J, Hood L, Landegren U: Automated DNA diagnostics using an ELISA-based oligonucleotide ligation assay. Proc Nat Acad Sci 1990, 87:8923-8927.

89. Nanjwade BK, Bechra HM, Derkar GK, Manvi FV, Nanjwade VK: Dendrimers: Emerging polymers for drug-delivery systems. Eur J Pharm Sci 2009, 38:185-196.

90. Gajbhiye V, Palanirajan VK, Tekade RK, Jain NK: Dendrimers as therapeutic agents: A systematic review. J Pharm Pharmacol 2009, 61:989-1003.

91. Ladhani S, Robbie S, Garratt RC, Chapple DS, Joannou CL, Evans RW: Development and evaluation of detection systems for Staphylococcal exfoliative toxin A responsible for scalded-skin syndrome. Journal of Clinical Microbiology 2001, 39:2050-2054.

92. Guo J, Ye X-S: Protecting groups in carbohydrate chemistry: Influence on stereoselectivity of glycosylations. Molecules 2010, 15:7235-7265.

93. Zhu X, Schmidt RR: New principles for glycoside-bond formation. Angew Chem Int Ed 2009, 48:1900-1934.

94. Nicolaou KC, Mitchell HJ: Adventures in carbohydrate chemistry: New synthetic technologies, chemical synthesis, molecular design, and chemical biology. Angew Chem Int Ed 2001, 40:1576-1624.

95. Sun L, Li P, Zhao K: Stabilization of glycosyl sulfonium ions for stereoselective $O$ glycosylation. Tet Lett 1994, 35:7147-7150.

96. Waschke D, Thimm J, Thiem J: Highly efficient synthesis of ketoheptoses. Org Lett 2011, 13:3628-3631.

97. Karplus M: Vicinal proton coupling in nuclear magnetic resonance. J Am Chem Soc 1963, 85:2870-2871. 
98. Clede S, Lambert F, Sandt C, Kascakova S, Unger M, Harte E, Plamont M-A, Saint-Fort $\mathrm{R}$, Deniset-Besseau A, Gueroui Z et al: Detection of an estrogen derivative in two breast cancer cell lines using a single core multimodal probe for imaging (SCoMPI) imaged by a panel of luminescent and vibrational techniques. Analyst 2013, 138:5627-5638.

99. Májer G, Borbás A, Illyés TZ, Szilágyi L, Bényei AC, Lipták A: Synthesis of ketopyranosyl glycosides and determination of their anomeric configuration on the basis of the threebond carbon-proton couplings. Carb Res 2007, 342:1393-1404.

100. Lourenço EC, Ventura MR: The synthesis of compatible solute analogues-solvent effects on selective glycosylation. Carb Res 2011, 346:163-168.

101. Ueda T, Hayashi M, Ikeuchi Y, Nakajima T, Numagami E, Kobayashi S: Synthesis of an $\alpha$-amylase inhibitor: Highly stereoselective glycosidation and regioselective manipulations of hydroxyl groups in carbohydrate derivatives. Org Process Res Dev 2014, 18:1728-1739.

102. Guo J, Ye X-S: Protecting groups in carbohydrate chemistry: Influence on stereoselectivity of glycosylations. Molecules 2010, 15:7235-7265.

103. Kaeothip S, Akins SJ, Demchenko AV: On the stereoselectivity of glycosidation of thiocyanates, thioimidates, and thioglycosides. Carb Res 2010, 345:2146-2150.

104. Whitfield DM, Yu SH, Dicaire CJ, Sprott GD: Development of new glycosylation methodologies for the synthesis of archaeal-derived glycolipid adjuvants. Carb Res 2010, 345:214-229.

105. Satoh H, Hansen HS, Manabe S, van Gunsteren WF, Hünenberger PH: Theoretical investigation of solvent effects on glycosylation reactions: Stereoselectivity controlled by preferential conformations of the intermediate oxacarbenium-counterion complex. $J$ Chem Theory Comput 2010, 6:1783-1797.

106. Kononov LO, Malysheva NN, Orlova AV, Zinin AI, Laptinskaya TV, Kononova EG, Kolotyrkina NG: Concentration dependence of glycosylation outcome: A clue to reproducibility and understanding the reasons behind. Eur J Org Chem 2012, 2012:19261934.

107. Ishiwata A, Sakurai A, Dürr K, Ito Y: Effects of frozen conditions on stereoselectivity and velocity of O-glycosylation reactions. Bioorg Med Chem 2010, 18:3687-3695.

108. Kalikanda J, $\mathrm{Li} \mathrm{Z}$ : Study of the stereoselectivity of 2-azido-2-deoxygalactosyl donors: Remote protecting group effects and temperature dependency. J Org Chem 2011, 76:52075218.

109. Heuckendorff M, Premathilake HD, Pornsuriyasak P, Madsen AØ, Pedersen CM, Bols M, Demchenko AV: Superarming of glycosyl donors by combined neighboring and conformational effects. Org Lett 2013, 15:4904-4907.

110. Dieskau AP, Plietker B: A mild ligand-free iron-catalyzed liberation of alcohols from allylcarbonates. Org Lett 2011, 13:5544-5547.

111. Lu S-R, Lai Y-H, Chen J-H, Liu C-Y, Mong K-KT: Dimethylformamide: An unusual glycosylation modulator. Angew Chem Int Ed 2011, 50:7315-7320.

112. Crich D: Mechanism of a chemical glycosylation. Acc Chem Res 2010, 43:1144-1153.

113. Crich D, Cai W: Chemistry of 4,6-O-benzylidene-D-glycopyranosyl triflates: Contrasting behavior between the gluco and manno Series. J Org Chem 1999, 64:4926-4930.

114. Andrews CW, Rodebaugh R, Fraser-Reid B: A solvation-assisted model for estimating anomeric reactivity. Predicted versus observed trends in hydrolysis of $\mathrm{n}$-pentenyl glycosides. J Org Chem 1996, 61:5280-5289.

115. Wang Y, Li Q, Cheng S, Wu Y, Guo D, Fan Q-H, Wang X, Zhang L-H, Ye X-S: Basepromoted rearrangement of sugar epoxides to unsaturatedsugars. Org Lett 2005, 7:55775579.

116. Janczuk AJ, Zhang W, Andreana PR, Warrick J, Wang PG: The synthesis of deoxy- $\alpha-G a l$ epitope derivatives for the evaluation of an anti- $\alpha-G a l$ antibody binding. Carb Res 2002, 337:1247-1259.

117. de Jong A-R, Hagen B, van der Ark V, Overkleeft HS, Codée JDC, Van der Marel GA: Exploring and exploiting the reactivity of glucuronic acid donors. J Org Chem 2011, 77:108-125.

118. Crich D, Sun S: Are glycosyl triflates intermediates in the sulfoxide glycosylation method? A chemical and 1H, 13C, and 19F NMR spectroscopic investigation. J Am Chem Soc 1997, 119:11217-11223.

119. Lemieux RU, Hendriks KB, Stick RV, James K: Halide ion catalyzed glycosidation reactions: Syntheses of alpha-linked disaccharides. J Am Chem Soc 1975, 97:4056-4062. 
120. Evans DJ, Searles DJ, Mittag E: Fluctuation Theorem for Hamiltonian Systems - Le Chatelier's Principle. Phys Rev E 2000, 63:1-4.

121. Andersson F, Fugedi P, Garegg PJ, Nashed M: Synthesis of 1,2-cis-linked glycosides using dimethyl(methylthio)sulfonium triflate as promoter and thioglycosides as glycosyl donors. Tet Lett 1986, 27:3919-3922.

122. Kihlberg JO, Leigh DA, Bundle DR: The in situ activation of thioglycosides with bromine: An improved glycosylation method. J Org Chem 1990, 55:2860-2863.

123. Kihlberg J, Bundle DR: The synthesis of antibody binding-site probes: a hexasaccharide and two pentasaccharides related to the Brucella $A$ antigen and prepared by in situ activation of thioglycosides with bromine. Carb Res 1992, 216:67-78.

124. Kaeothip S, Yasomanee JP, Demchenko AV: Glycosidation of thioglycosides in the presence of bromine: Mechanism, reactivity, and stereoselectivity. J Org Chem 2011, 77:291-299.

125. Pekari K, Schmidt RR: A variable concept for the preparation of branched glycosyl phosphatidyl inositol anchors. J Org Chem 2003, 68:1295-1308.

126. Fujiwara R, Horito S: Solvent-induced anomeric diastereoselectivity switching using a single glycosyl donor. Carb Res 2011, 346:2098-2103.

127. Lahmann M, Oscarson S: Investigation of the reactivity difference between thioglycoside donors with variant aglycon parts. Can J Chem 2002, 80:889-893.

128. Barry CS, Cocinero EJ, Çarçabal P, Gamblin DP, Stanca-Kaposta EC, Remmert SM, Fernández-Alonso MC, Rudić S, Simons JP, Davis BG: 'Naked' and hydrated conformers of the conserved core pentasaccharide of $\mathrm{N}$-linked glycoproteins and its building blocks. J Am Chem Soc 2013, 135:16895-16903.

129. Pilgrim W, Murphy PV: SnC14- and TiC14-catalyzed anomerization of acylated O- and Sglycosides: Analysis of factors that lead to higher $\alpha: \beta$ anomer ratios and reaction rates. $J$ Org Chem 2010, 75:6747-6755.

130. Banoub J, Bundle DR: Stannic tetrachloride catalysed glycosylation of 8ethoxycarbonyloctanol by cellobiose, lactose, and maltose octaacetates; synthesis of $\alpha$ and $\beta$-glycosidic linkages. Can J Chem 1979, 57:2085-2090.

131. Ágoston K, Dobó A, Rákó J, Kerékgyártó J, Szurmai Z: Anomalous Zemplén deacylation reactions of $\alpha$ - and $\beta$-D-mannopyranoside derivatives. Carb Res 2001, 330:183-190.

132. Seo S-k, Wei A: Probing osmotic effects on invertase with 1-(-)-sucrose. Org Biomol Chem 2008, 6:3362-3365.

133. Sato S, Mori M, Ito Y, Ogawa t: An efficient approach to O-glycosides through $\mathrm{CuBr2-}$ Bu4NBr mediated activation of glycosides. Carb Res 1986, 155:C6-C10.

134. Park J, Rader LH, Thomas GB, Danoff EJ, English DS, DeShong P: Carbohydratefunctionalized catanionic surfactant vesicles: preparation and lectin-binding studies. Soft Matter 2008, 4:1916-1921.

135. Singh S, Scigelova M, Critchley P, Crout DHG: Trisaccharide synthesis by glycosyl transfer from p-nitrophenyl $\beta$-d-N-acetylgalactosaminide on to disaccharide acceptors catalysed by the $\beta$-N-acetylhexosaminidase from Aspergillus oryzae. Carb Res 1997, 305:363-370.

136. Griffin Frank K, Paterson Duncan E, Murphy Paul V, Taylor Richard JK: A New Route to exo-Glycals Using the Ramberg-Bäcklund Rearrangement. Eur J Org Chem 2002, 2002:1305-1322.

137. Yasuma A, Ichikawa T: Ninhydrin-Schiff and alloxan-Schiff staining; a new histochemical staining method for protein. J Lab Clin Med 1953, 41:296-299.

138. Lieber E, Rao CNR, Chao TS, Hoffman CWW: Infrared spectra of organic azides. Anal Chem 1957, 29:916-918.

139. Srikanth CS, Chuang SSC: Infrared Study of Strongly and Weakly Adsorbed CO2 on Fresh and Oxidatively Degraded Amine Sorbents. J Phys Chem C 2013, 117:9196-9205.

140. Dourtoglou V, Gross B, Lambropoulou V, Zioudrou C: O-Benzotriazolyl- $N, N^{\prime}, N^{\prime}, N^{\prime}-$ tetramethyluronium hexafluorophosphate as coupling reagent for the synthesis of peptides of biological interest. Synthesis 1984, 7:572-574.

141. El-Faham A, Albericio F: Peptide coupling reagents, More than a letter soup. Chem Rev 2011, 111:6557-6602.

142. Tomalia DA: Birth of a new macromolecular architecture: dendrimers as quantized building blocks for nanoscale synthetic polymer chemistry. Prog Polym Sci 2005, 30:294324.

143. Peterson J, Ebber A, Allikmaa V, Lopp M: Synthesis and the analysis of PAMAM dendrimers with an ethylenediamine core. Proc Est Acad Sci 2001, 50:156. 
144. Hawker CJ, Frechet JMJ: Preparation of polymers with controlled molecular architecture. A new convergent approach to dendritic macromolecules. J Am Chem Soc 1990, 112:76387647.

145. Munneke S: PhD Thesis. New Zealand: Victoria University of Wellington; in press.

146. Shrimp JH, Hu J, Dong M, Wang BS, MacDonald R, Jiang H, Hao Q, Yen A, Lin H: Revealing CD38 Cellular Localization Using a Cell Permeable, Mechanism-Based Fluorescent Small-Molecule Probe. J Am Chem Soc 2014, 136:5656-5663.

147. Sletten EM, Bertozzi CR: From mechanism to mouse: A tale of two bioorthogonal reactions. Acc Chem Res 2011, 44:666-676.

148. Nyffeler PT, Liang C-H, Koeller KM, Wong C-H: The chemistry of amine-azide interconversion: Catalytic diazotransfer and regioselective azide reduction. J Am Chem Soc 2002, 124:10773-10778.

149. Bobrovnik SA: [Specific and nonspecific interactions of antibodies and immunoglobulins with antigens and the methods of analysis of these interactions]. Ukr Biokhim $Z h$ 2004, 76:132-139.

150. Ben-Anat Porat Y, Zan-Bar I, Ravid A: Quantitative dot-blot assay for low titer antilipopolysaccharide antibodies in human plasma. J Immunol Methods 1995, 180:213-218.

151. Pellegrino NM, Caccavo D: Variability in anticardiolipin antibody detection: Role of nonspecific IgG binding and different microtiter plates. Clin Appl Thromb Hemost 2007, 13:404-409.

152. Klaver AC, Patrias LM, Coffey MP, Finke JM, Loeffler DA: Measurement of anti-A $\beta 1-42$ antibodies in intravenous immunoglobulin with indirect ELISA: The problem of nonspecific binding. J Neurosci Methods 2010, 187:263-269.

153. van Venrooij WJ, Charles P, Maini RN: The consensus workshops for the detection of autoantibodies to intracellular antigens in rheumatic diseases. J Immunol Methods 1991, 140:181-189.

154. Frederix F, Bonroy K, Reekmans G, Laureyn W, Campitelli A, Abramov MA, Dehaen W, Maes G: Reduced nonspecific adsorption on covalently immobilized protein surfaces using poly(ethylene oxide) containing blocking agents. J Biochem Biophys Methods 2004, 58:67-74.

155. Péterfi Z, Kocsis B: Comparison of blocking agents for an ELISA for Lps. J Immunoassay 2000, 21:341-354.

156. McCormack G, Moriarty D, O'Donoghue DP, McCormick PA, Sheahan K, Baird AW: Tissue cytokine and chemokine expression in inflammatory bowel disease. Inflamm res 2001, 50:491-495.

157. Kenny GE, Dunsmoor CL: Effectiveness of detergents in blocking nonspecific binding of IgG in the enzyme-linked immunosorbent assay (ELISA) depends upon the type of polystyrene used. Isr J Med Sci 1987, 23:732-734.

158. Lalor PA, Revell PA: The use of foetal calf serum as a blocking agent in double immunoenzyme-cytochemistry labelling with mouse monoclonal antibodies. $J$ Immunol Methods 1989, 122:149-150.

159. Martin NH: The immunoglobulins: A review. J Clin Pathol 1969, 22:117-131. 


\section{APPENDIX}

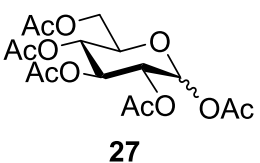

${ }^{1} \mathrm{H}-\mathrm{NMR}, 500 \mathrm{MHz}, \mathrm{CDCl}_{3}$
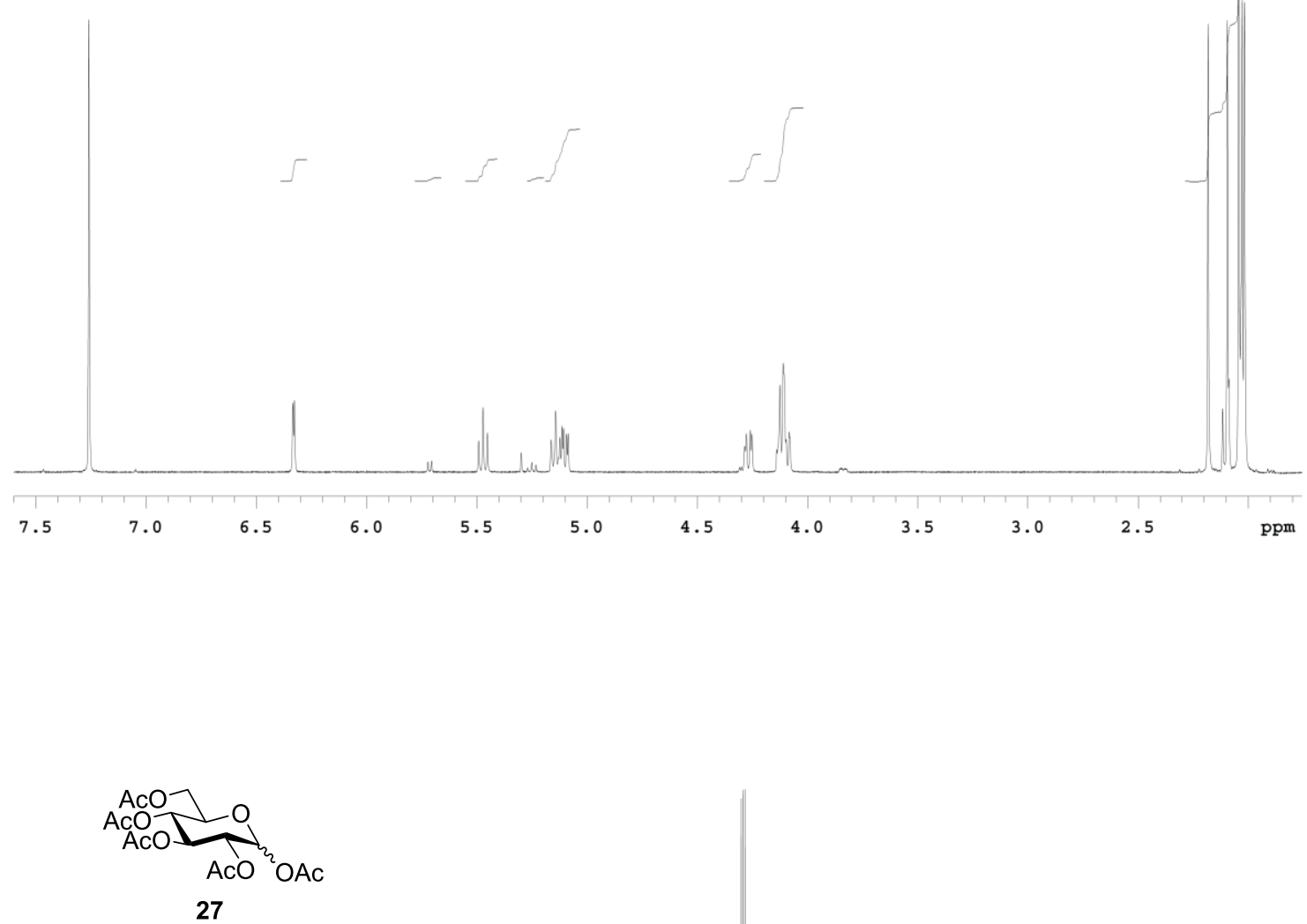

${ }^{1} \mathrm{H}-\mathrm{NMR}, 500 \mathrm{MHz}, \mathrm{CDCl}_{3}$ 


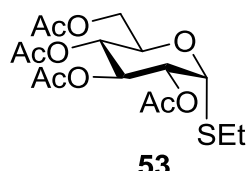

${ }^{1} \mathrm{H}-\mathrm{NMR}, 500 \mathrm{MHz}, \mathrm{CDCl}_{3}$
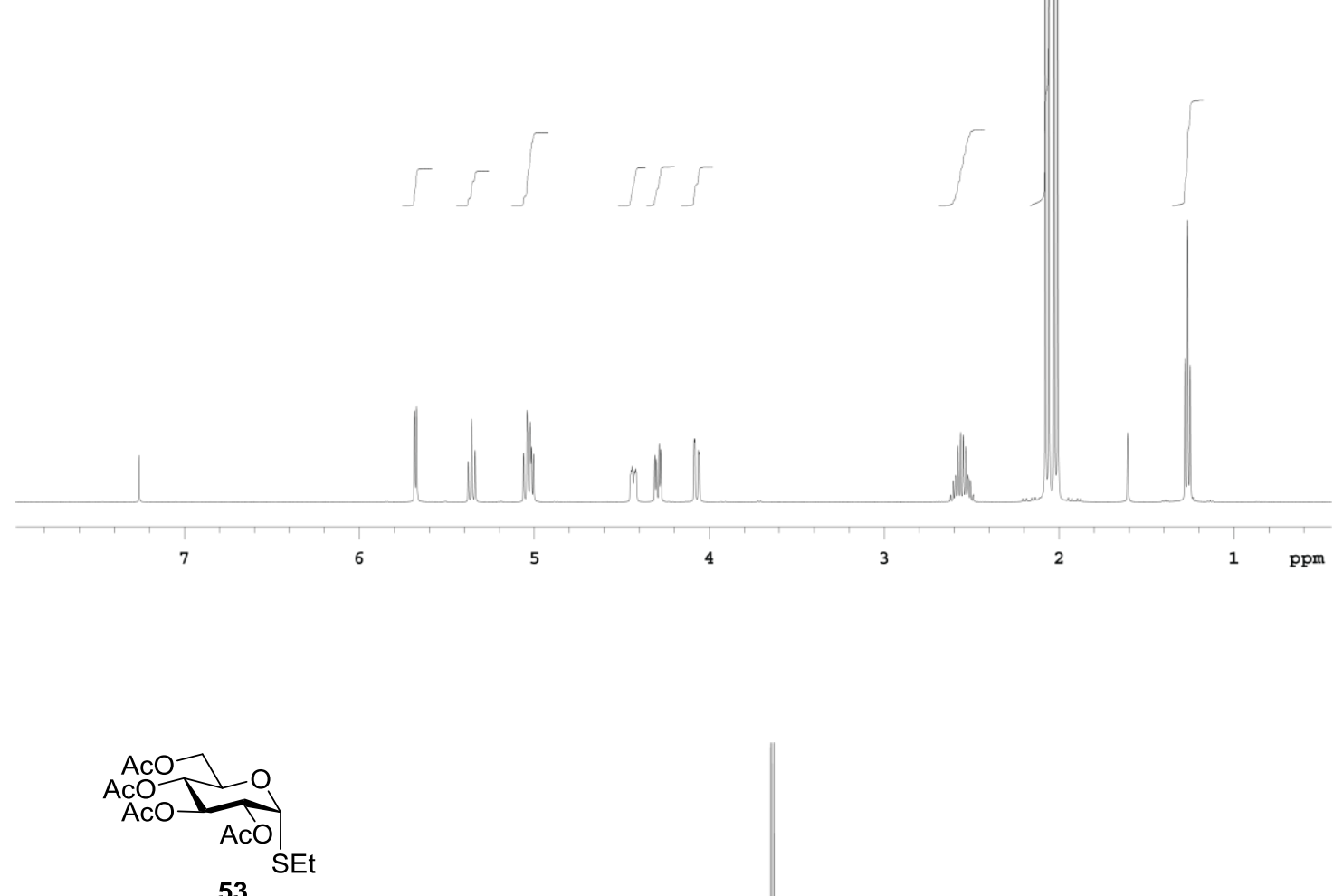

53

${ }^{13} \mathrm{C}-\mathrm{NMR}, 500 \mathrm{MHz}, \mathrm{CDCl}_{3}$ 

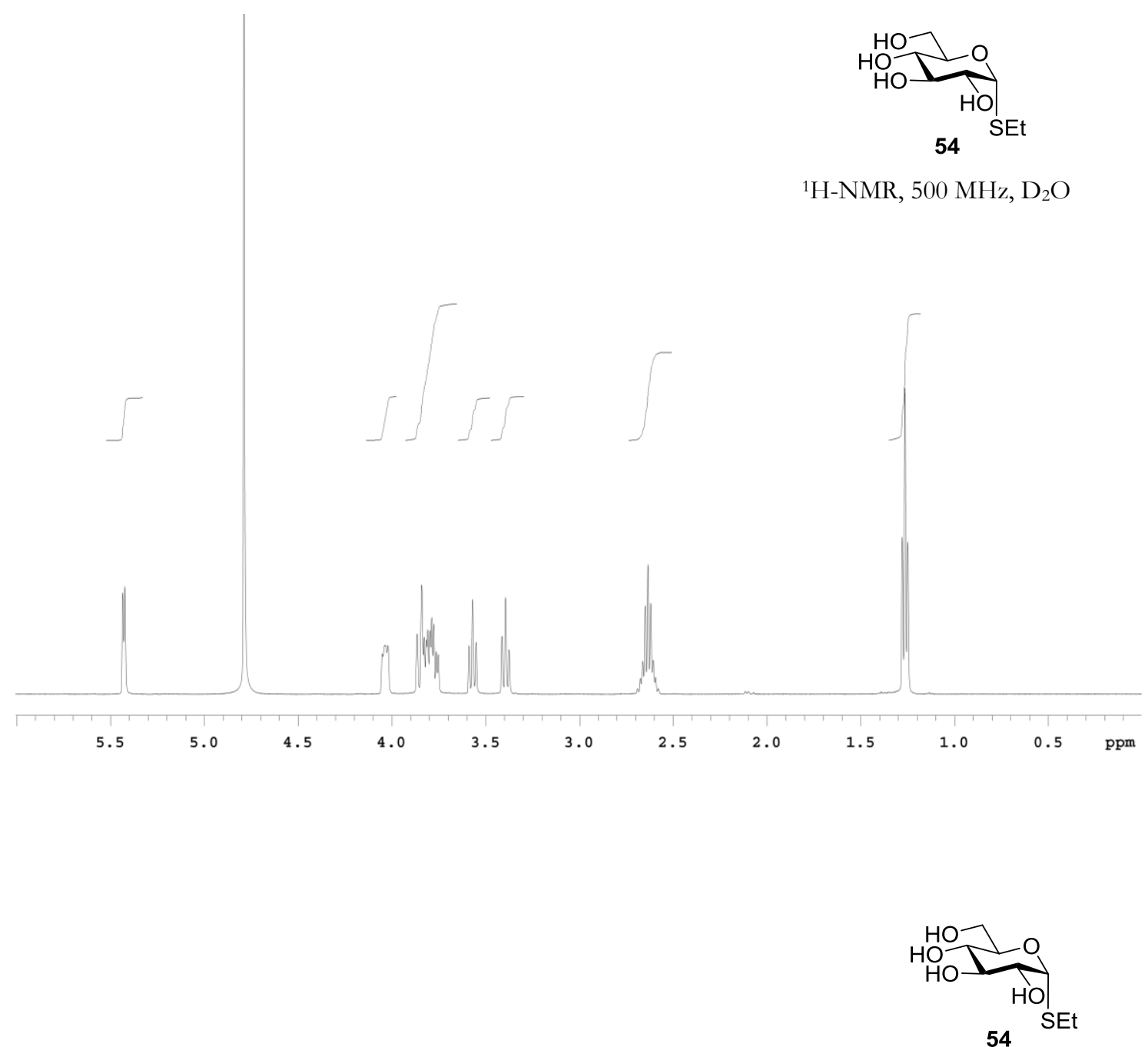

${ }^{1} \mathrm{C}-\mathrm{NMR}, 500 \mathrm{MHz}, \mathrm{D}_{2} \mathrm{O}$

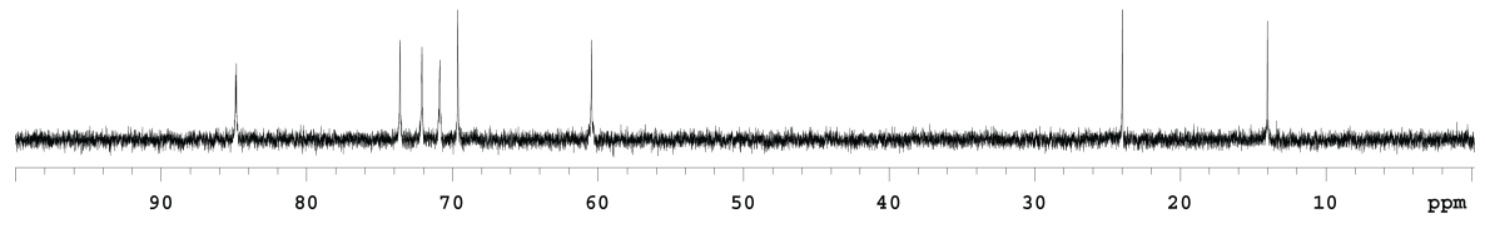




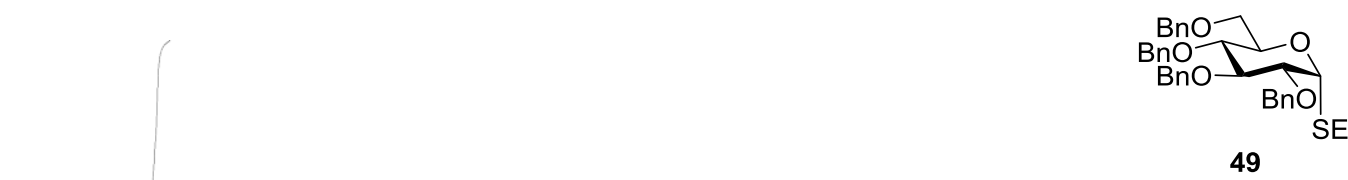

${ }^{1} \mathrm{H}-\mathrm{NMR}, 500 \mathrm{MHz}, \mathrm{CDCl}_{3}$

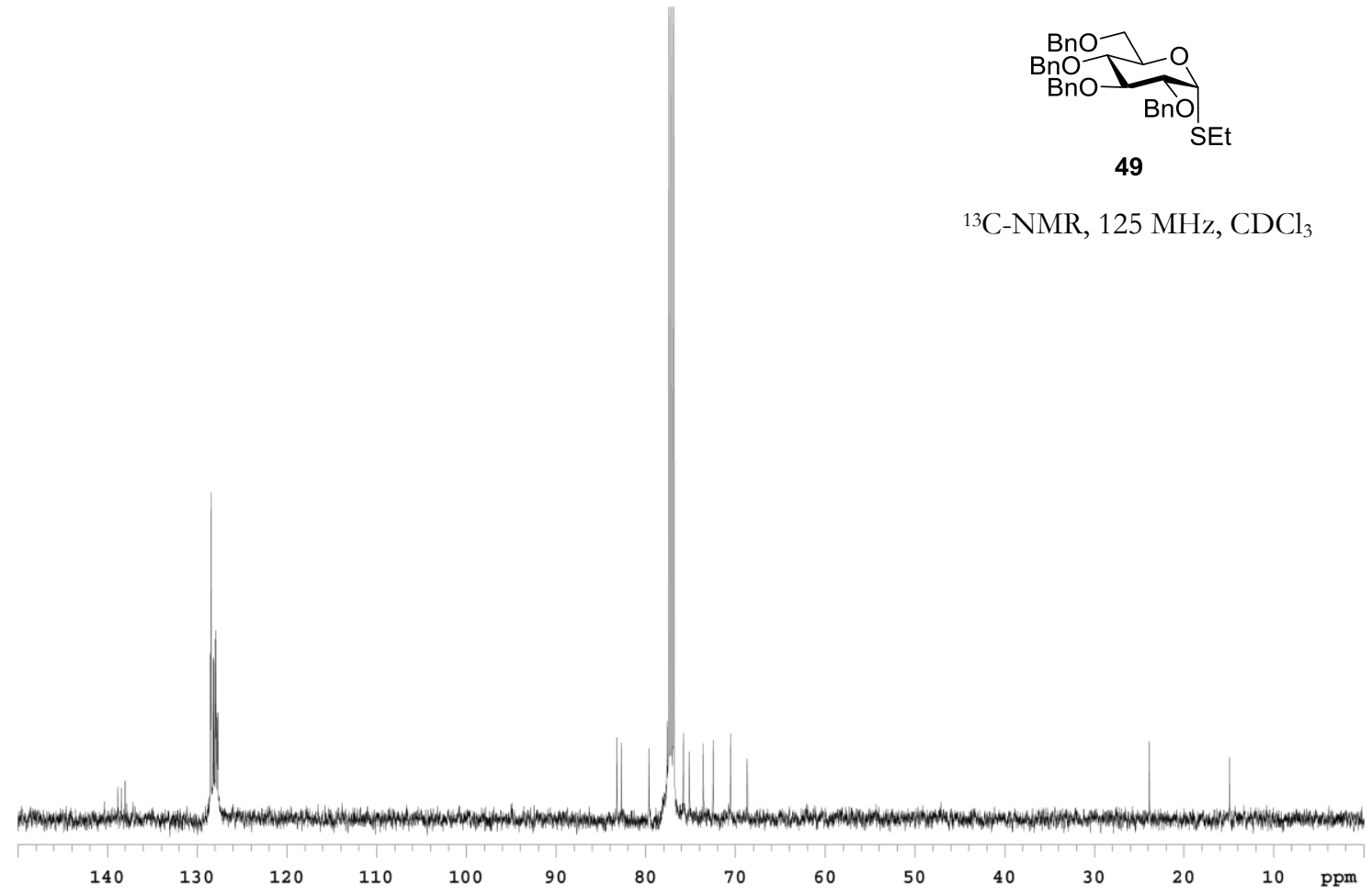




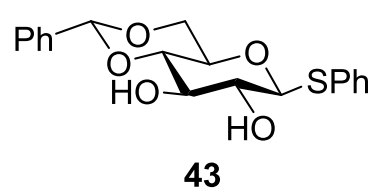

${ }^{1} \mathrm{H}-\mathrm{NMR}, 500 \mathrm{MHz}, \mathrm{CDCl}_{3}$
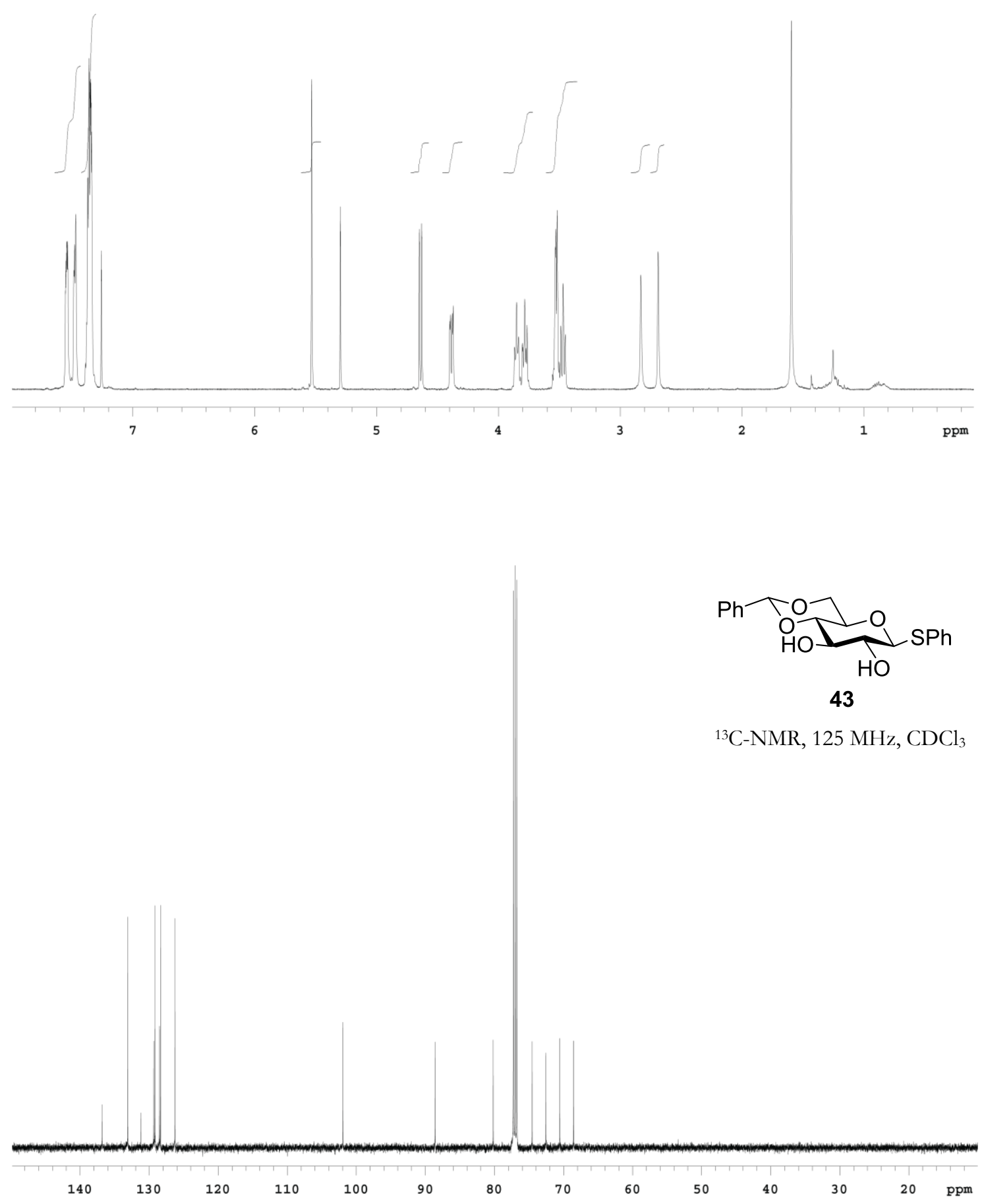

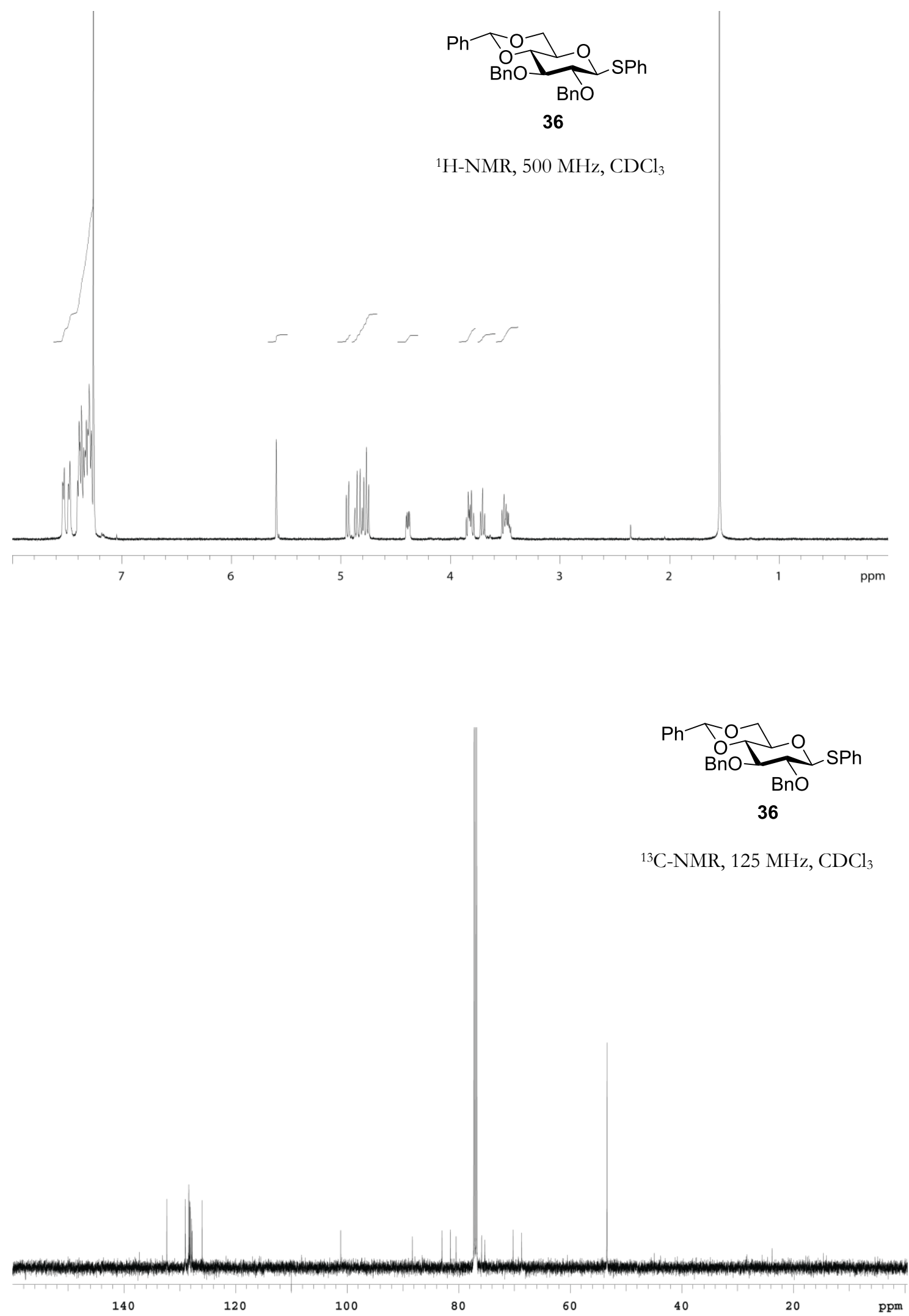


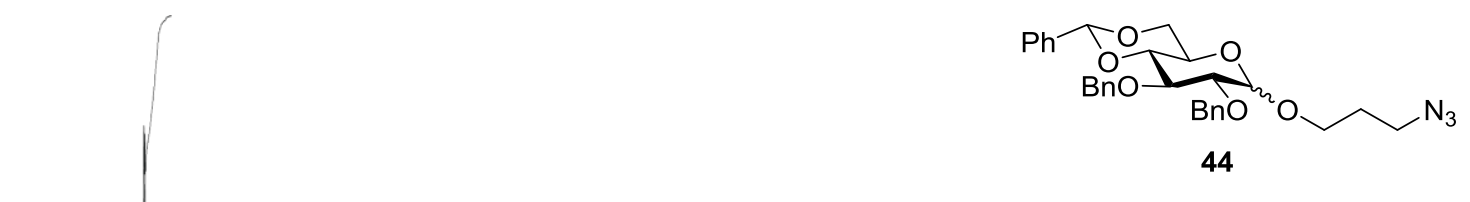

${ }^{1} \mathrm{H}-\mathrm{NMR}, 500 \mathrm{MHz}, \mathrm{CDCl}_{3}$

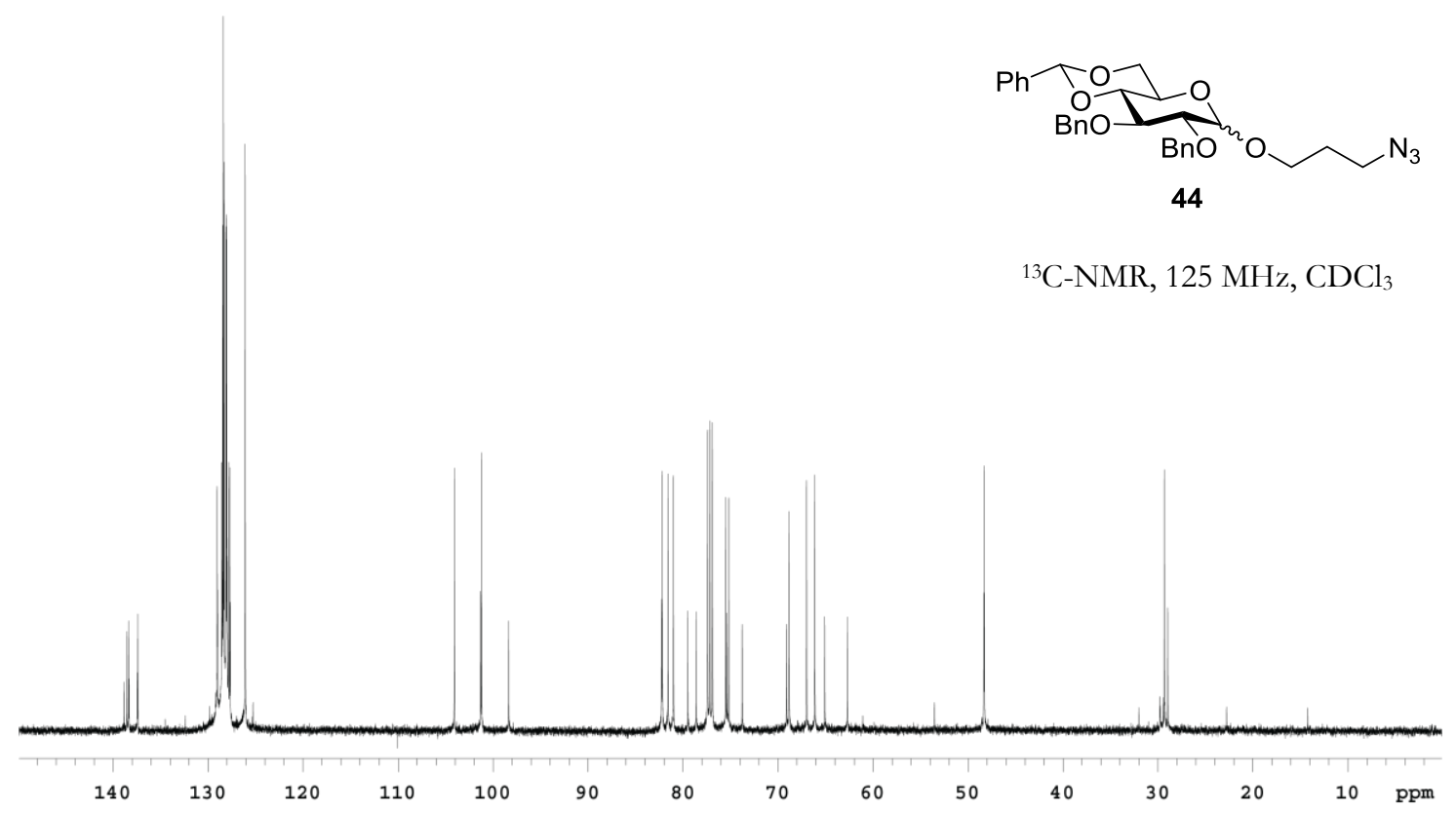




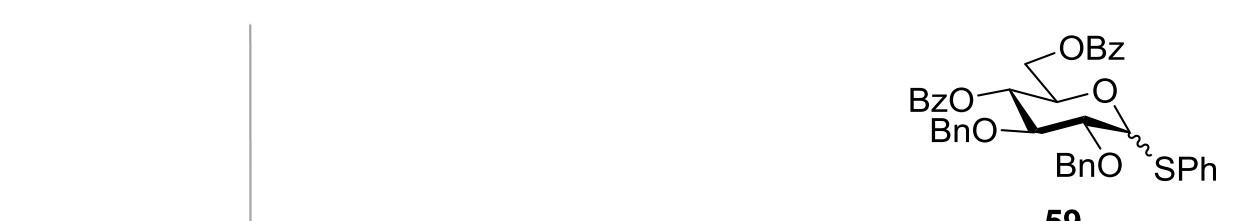

${ }^{1} \mathrm{H}-\mathrm{NMR}, 500 \mathrm{MHz}, \mathrm{CDCl}_{3}$
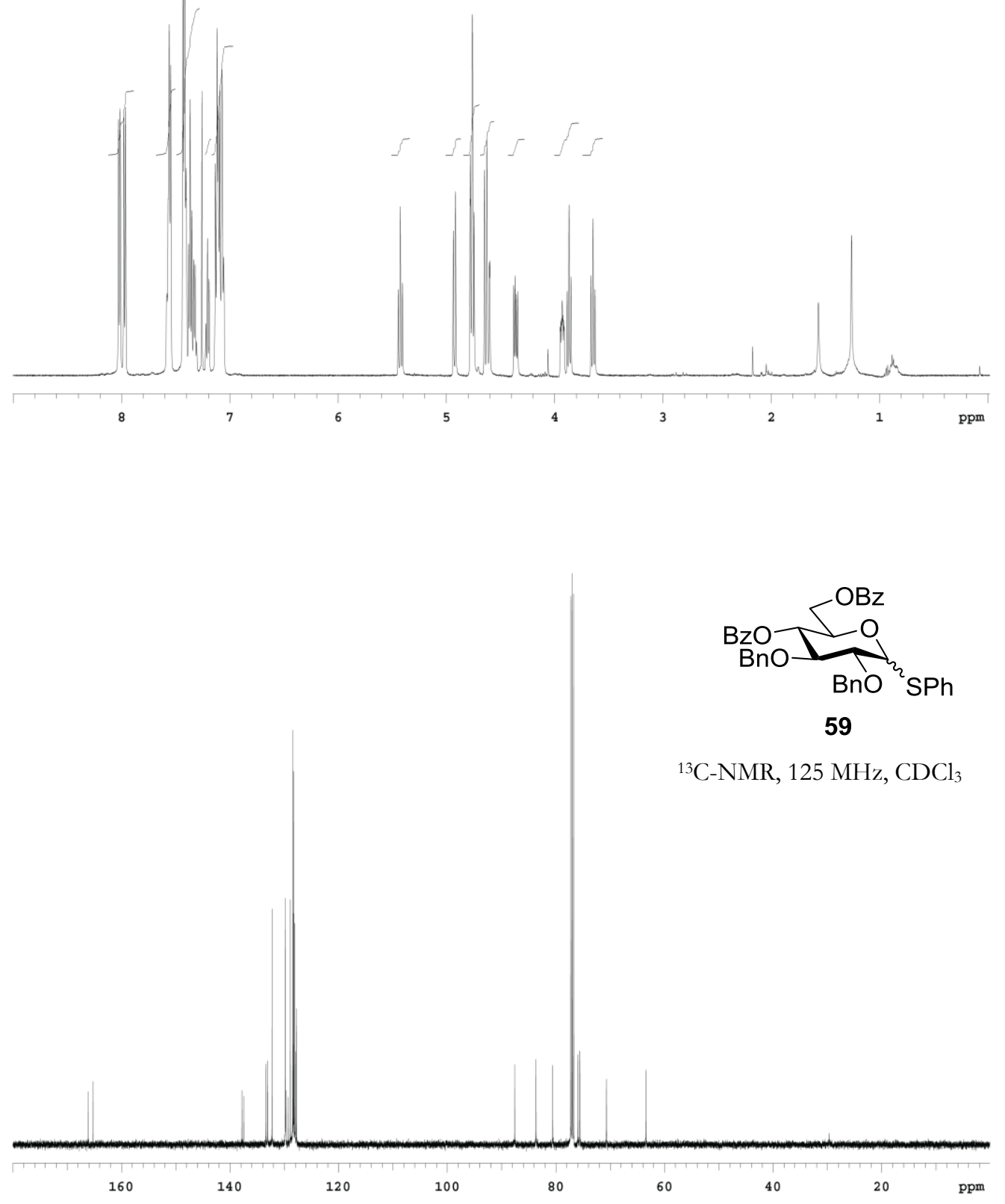

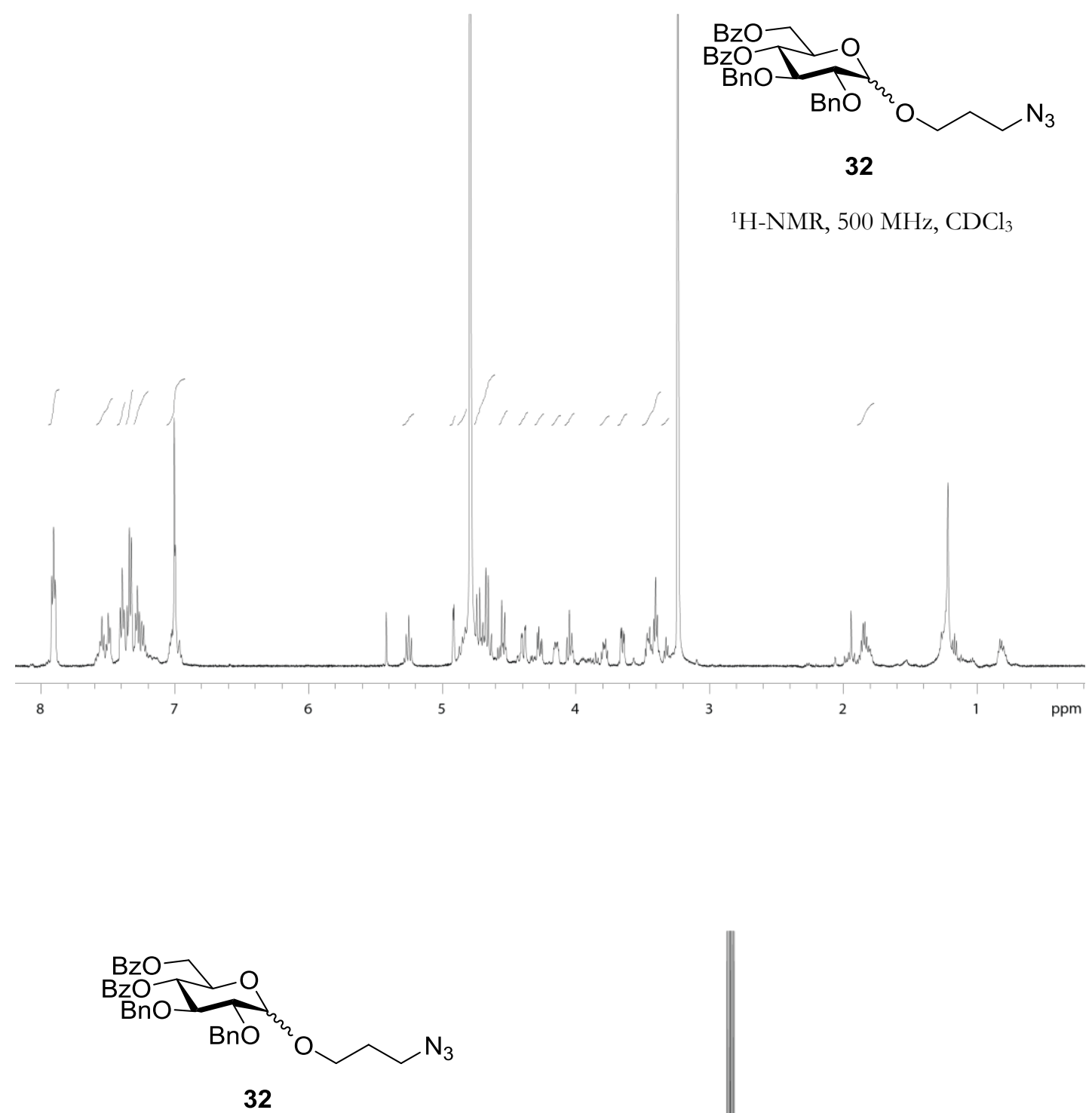

${ }^{13} \mathrm{C}-\mathrm{NMR}, 125 \mathrm{MHz}, \mathrm{CDCl}_{3}$

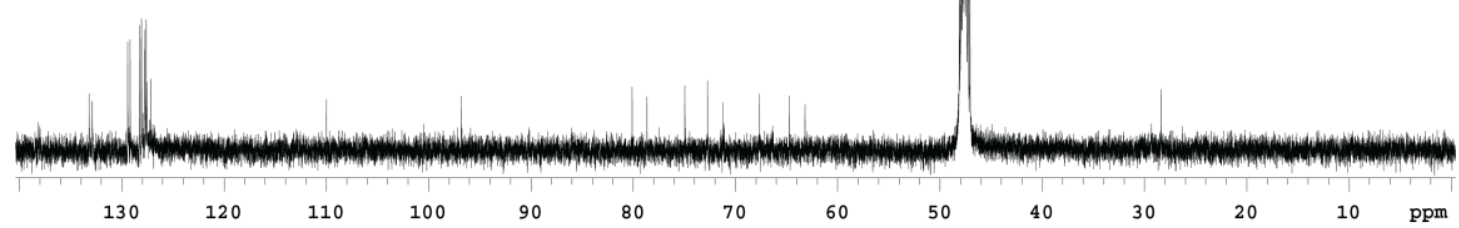


$\mathrm{HO} \sim \mathrm{N}_{3}$

30

${ }^{1} \mathrm{H}-\mathrm{NMR}, 500 \mathrm{MHz}, \mathrm{CDCl}_{3}$

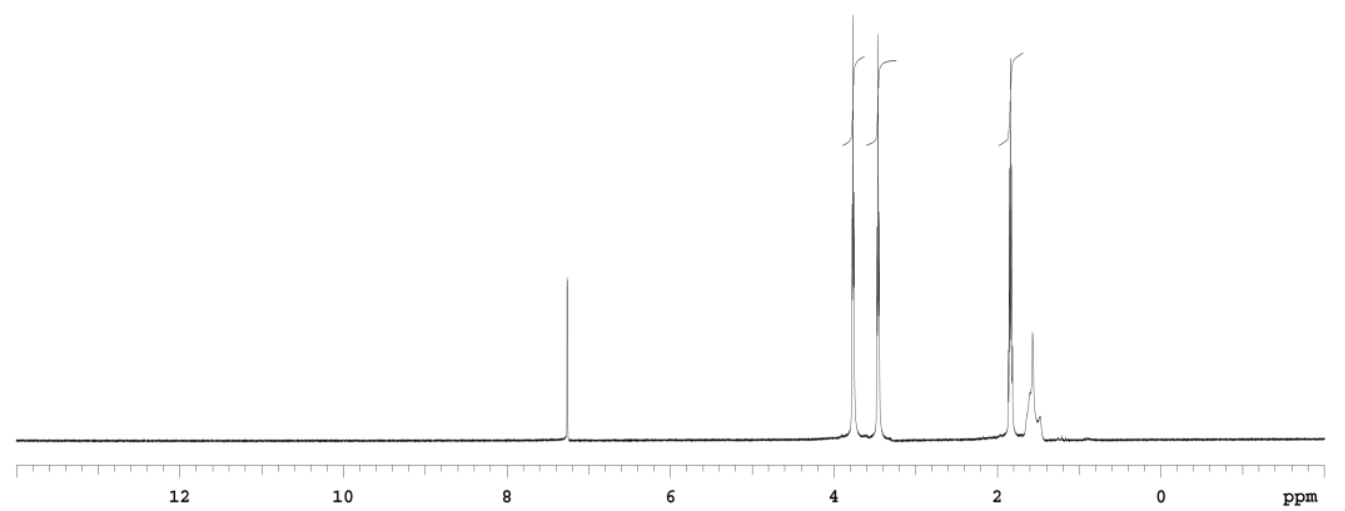

$\mathrm{HO} \sim \mathrm{N}_{3}$

30

${ }^{13} \mathrm{C}-\mathrm{NMR}, 125 \mathrm{MHz}, \mathrm{CDCl}_{3}$

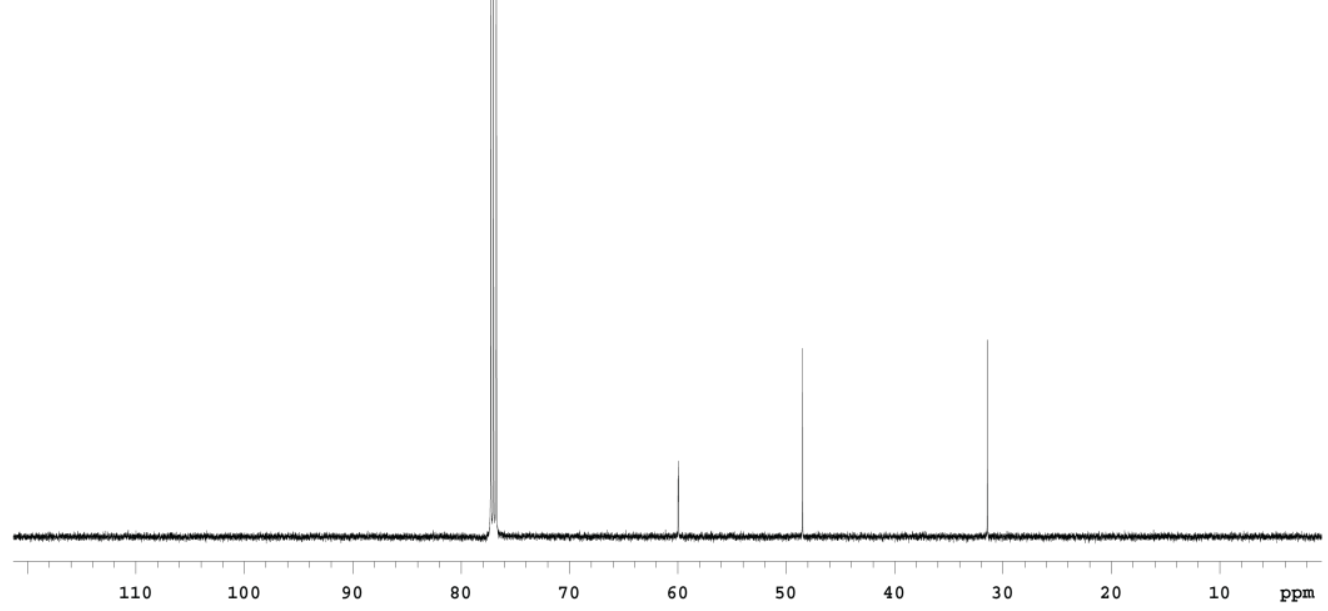



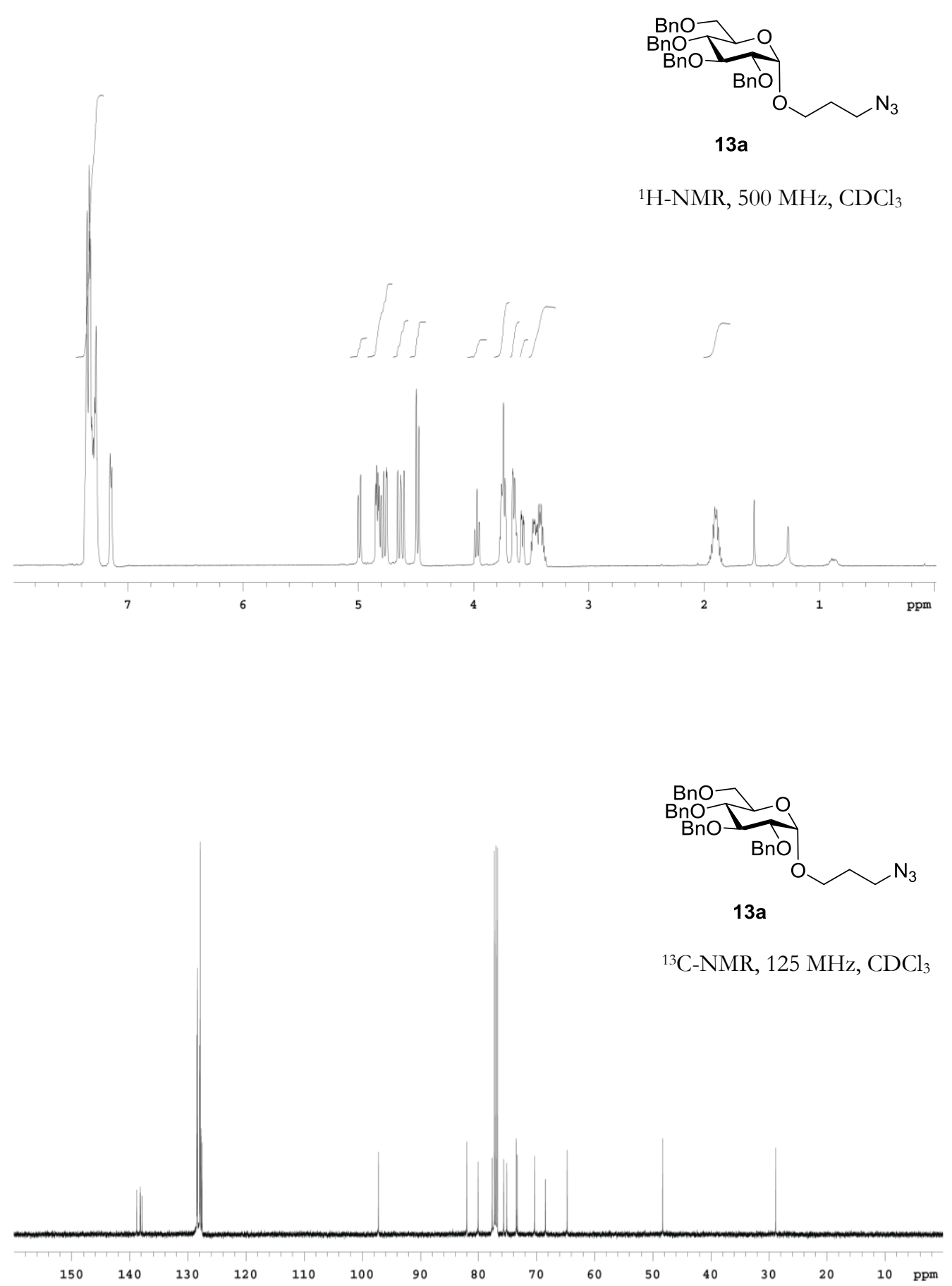

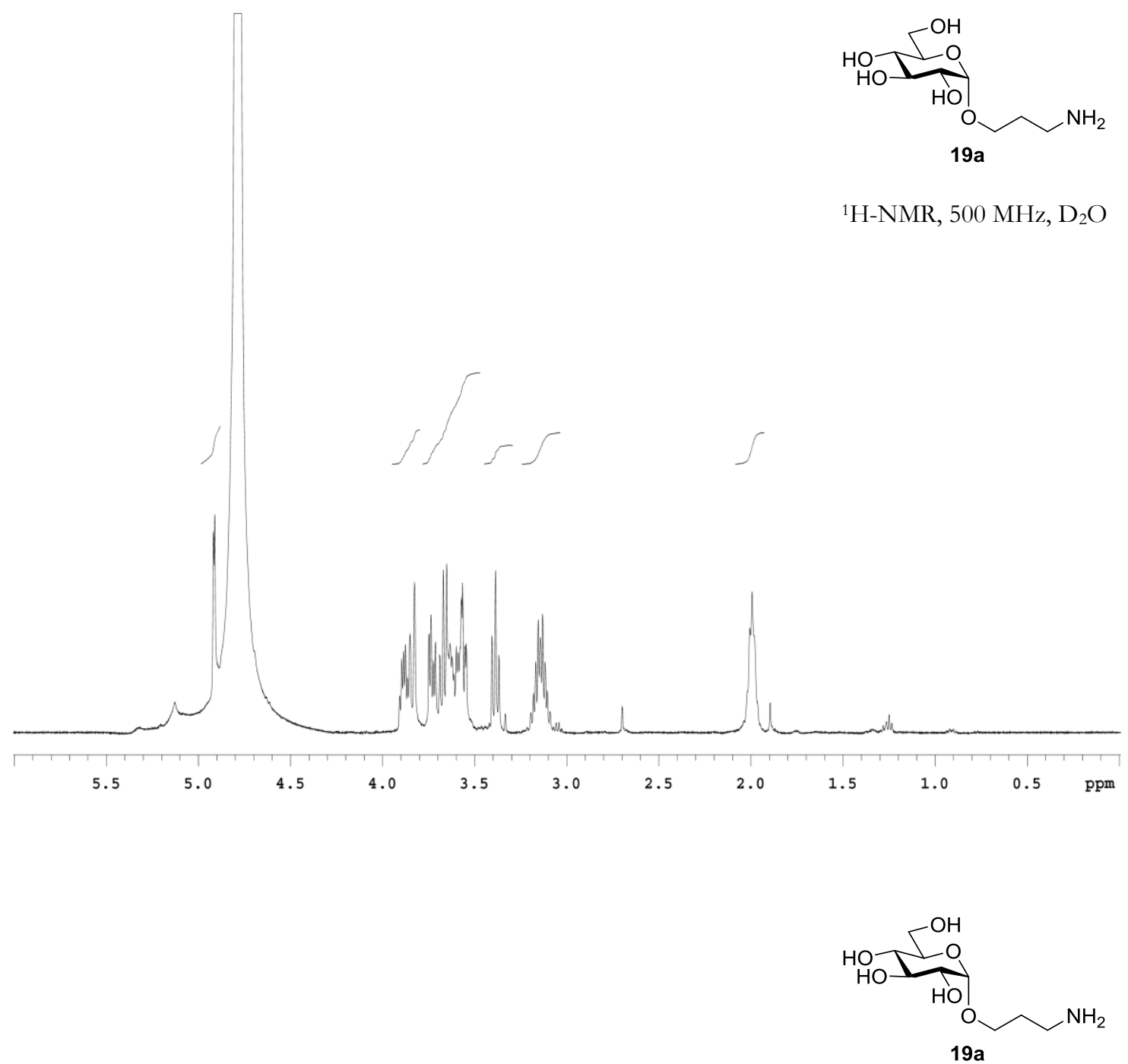

${ }^{13} \mathrm{C}-\mathrm{NMR}, 500 \mathrm{MHz}, \mathrm{D}_{2} \mathrm{O}$

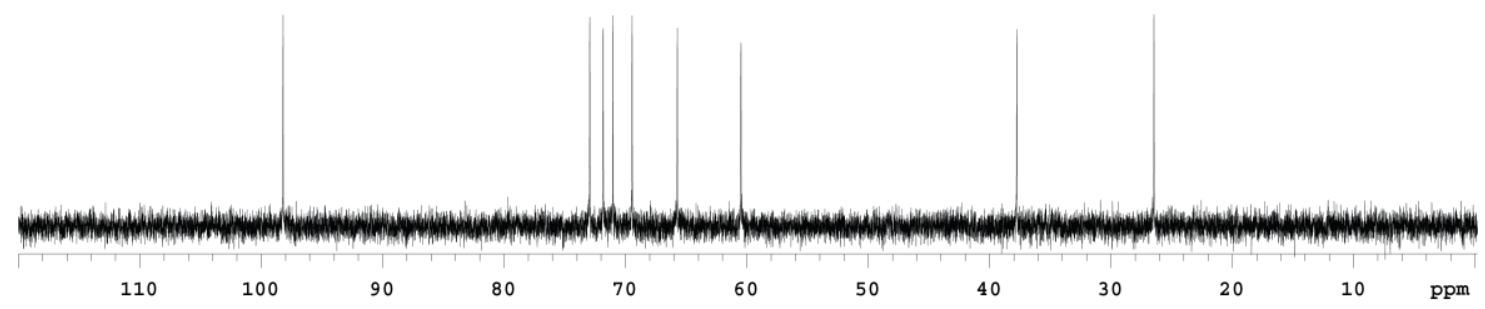



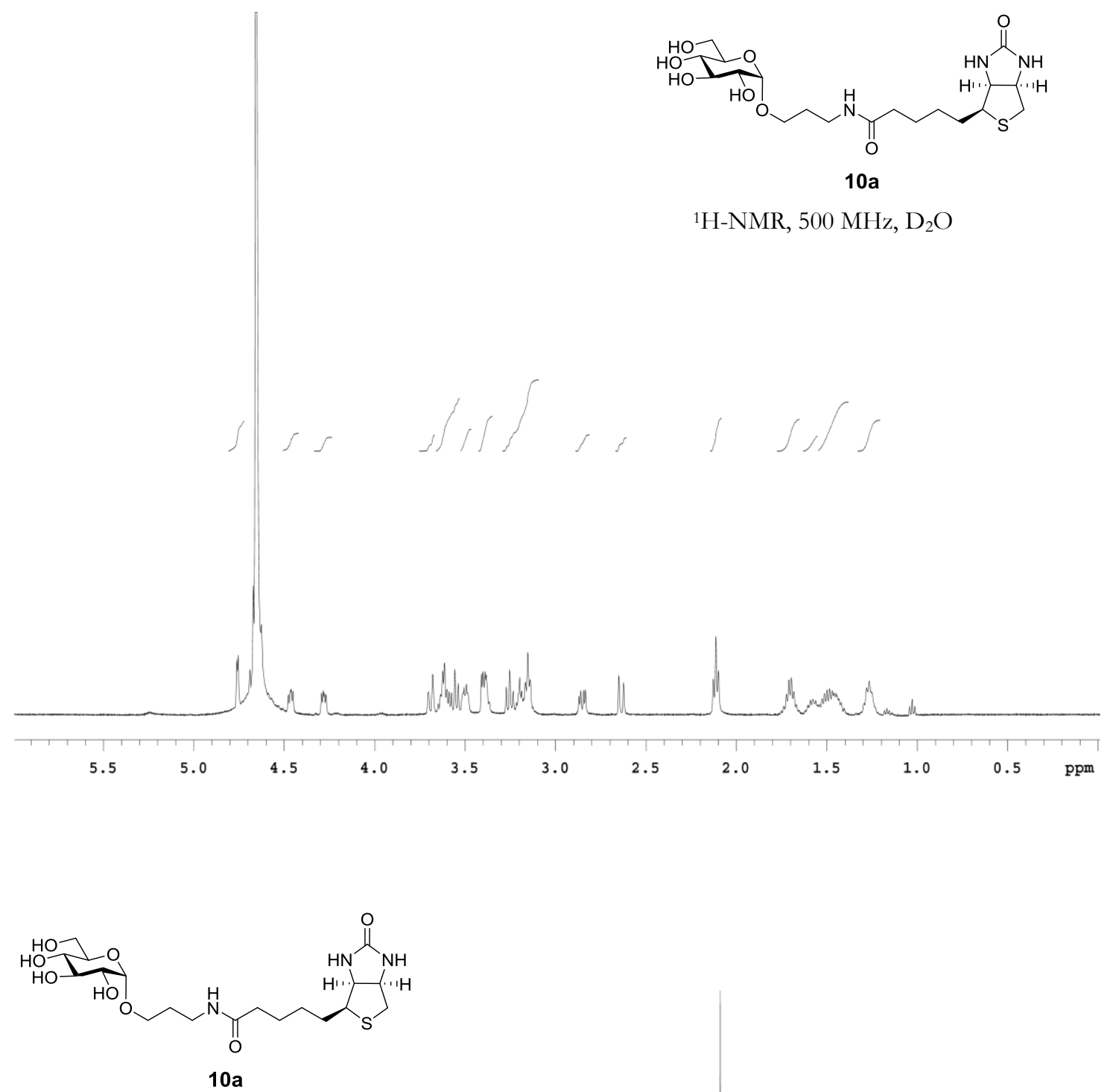

${ }^{13} \mathrm{C}-\mathrm{NMR}, 125 \mathrm{MHz}, \mathrm{D}_{2} \mathrm{O}$

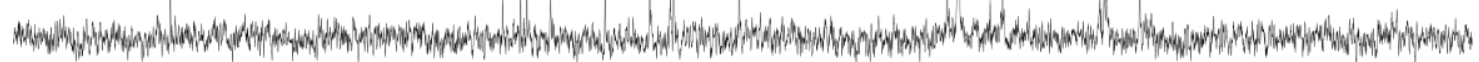




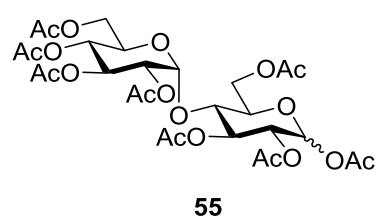

${ }^{1} \mathrm{H}-\mathrm{NMR}, 500 \mathrm{MHz}, \mathrm{CDCl}_{3}$
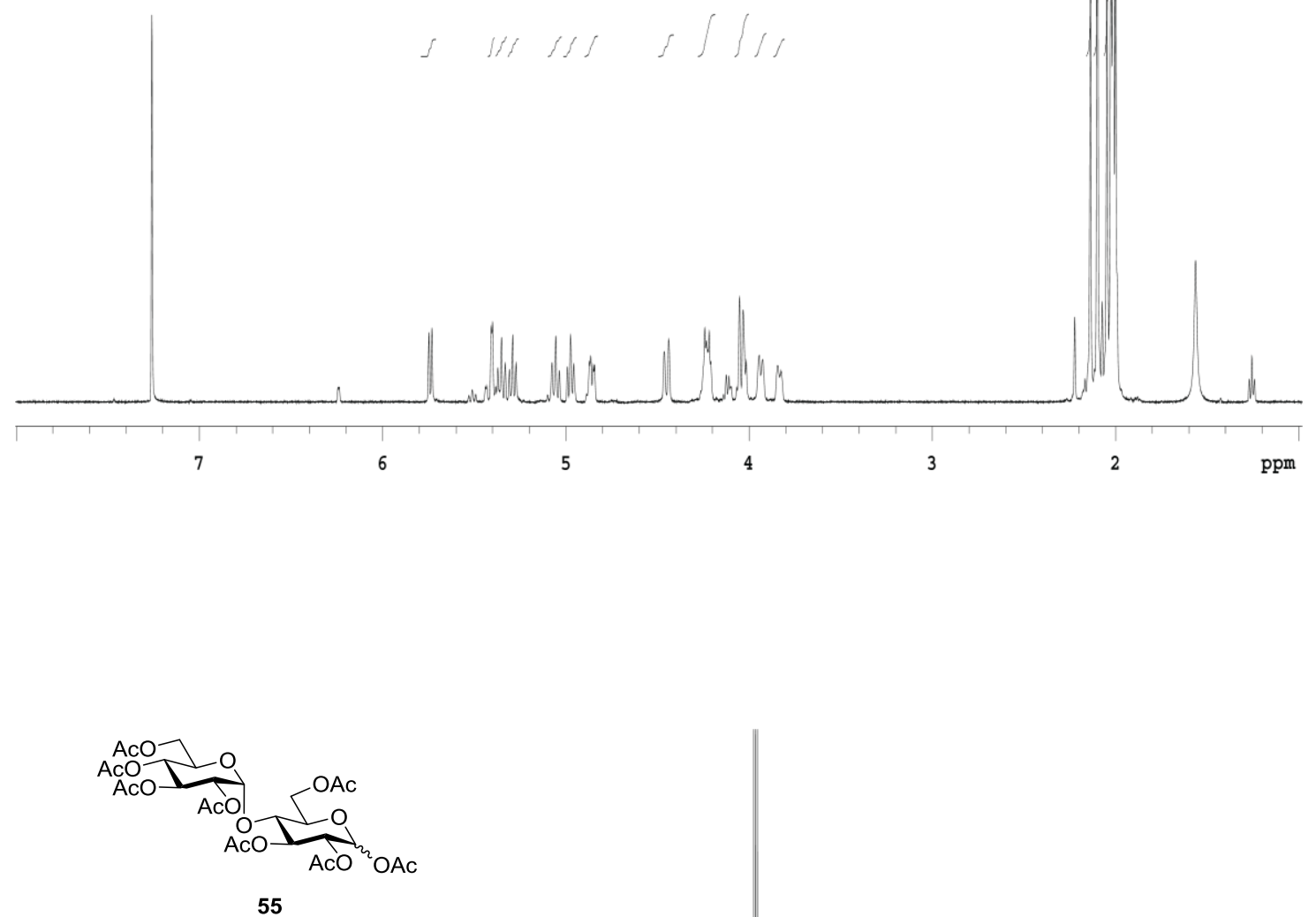

${ }^{13} \mathrm{C}-\mathrm{NMR}, 125 \mathrm{MHz}, \mathrm{CDCl}_{3}$

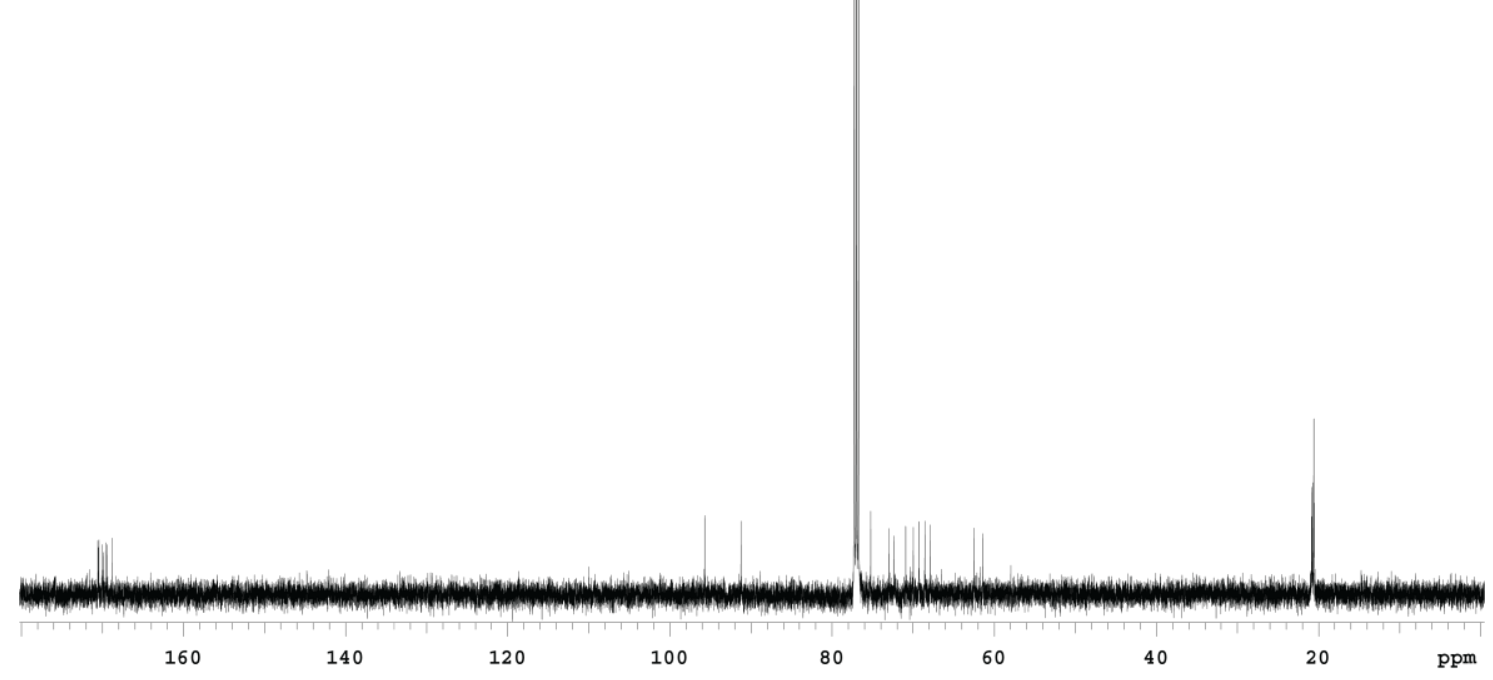




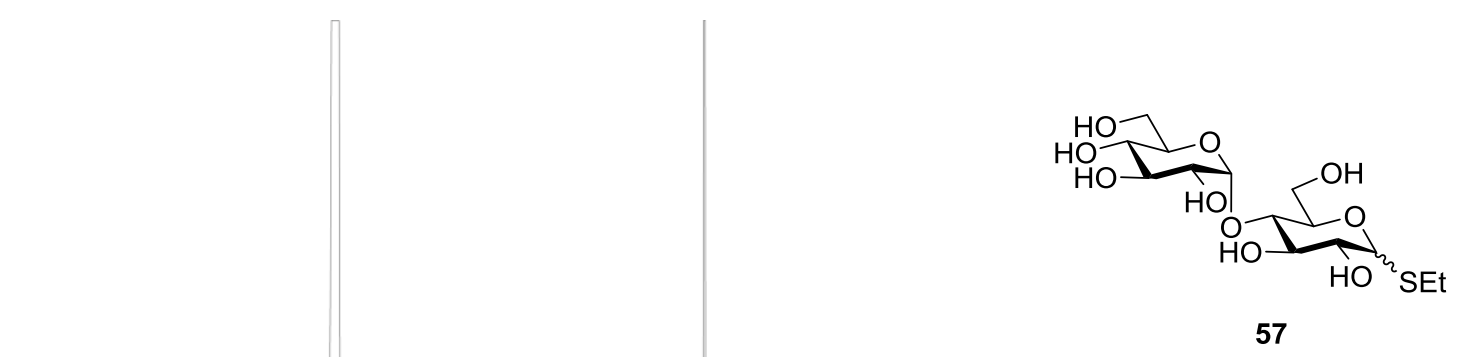

${ }^{1} \mathrm{H}-\mathrm{NMR}, 500 \mathrm{MHz}, \mathrm{D}_{2} \mathrm{O}$

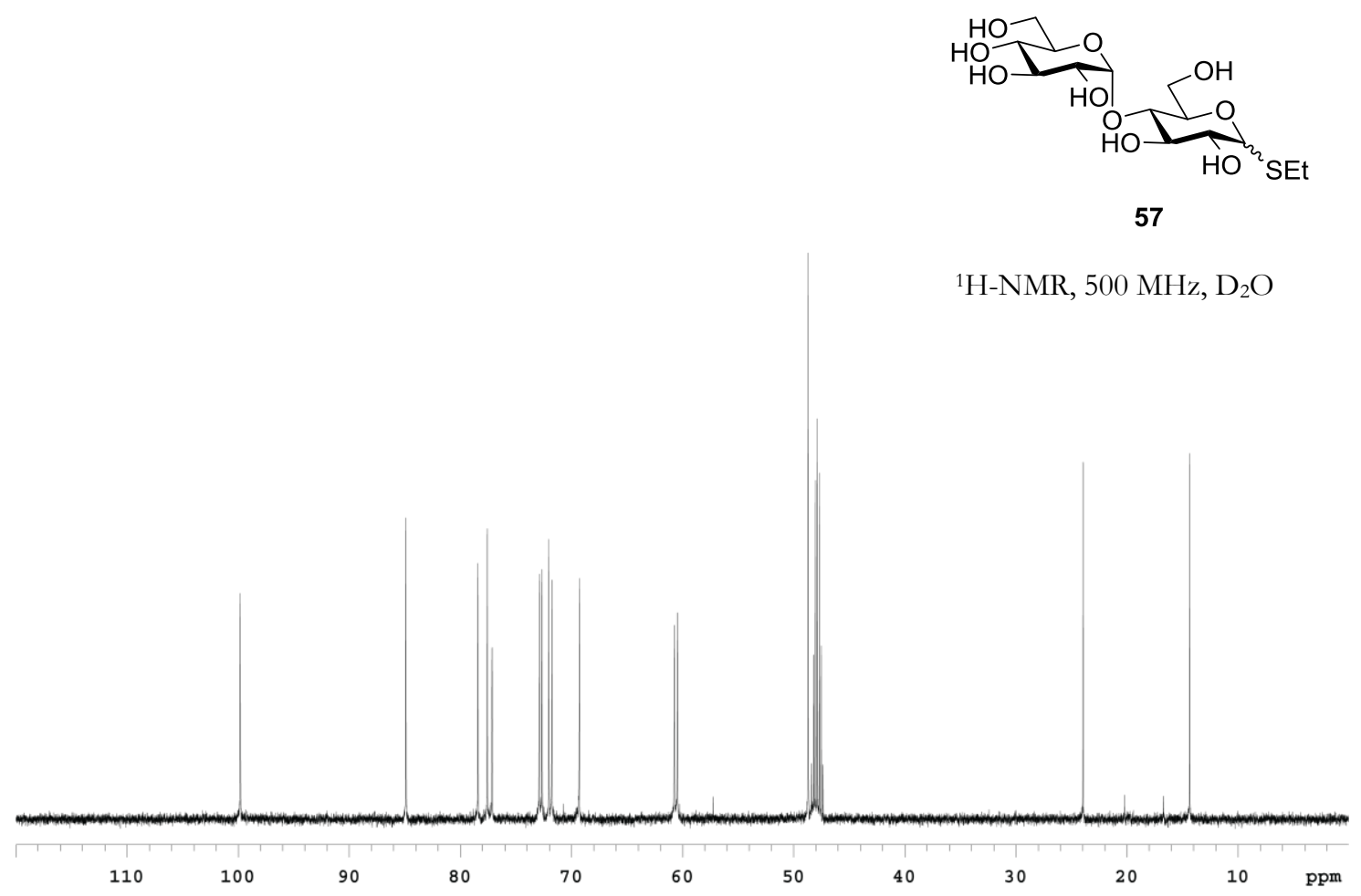



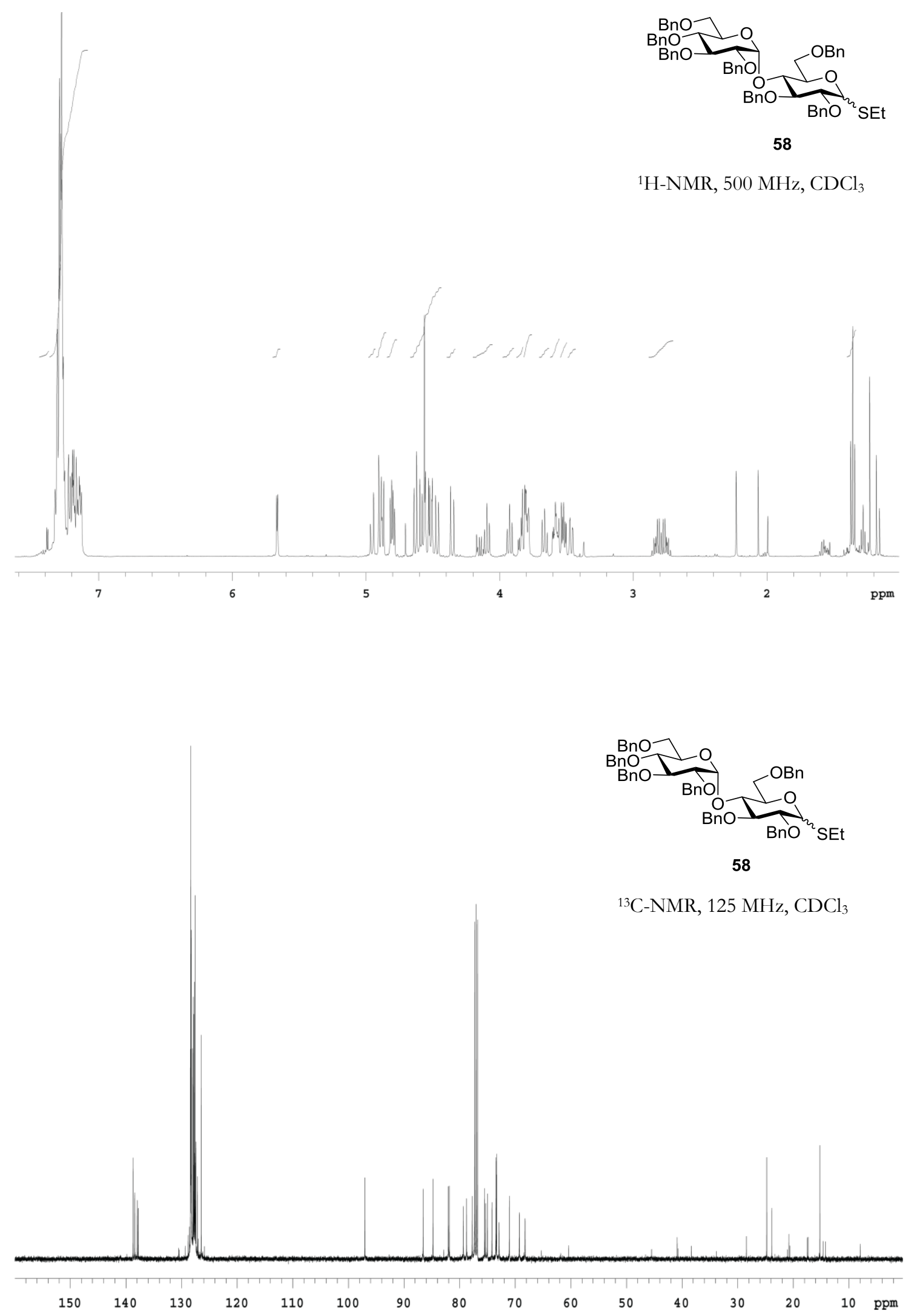


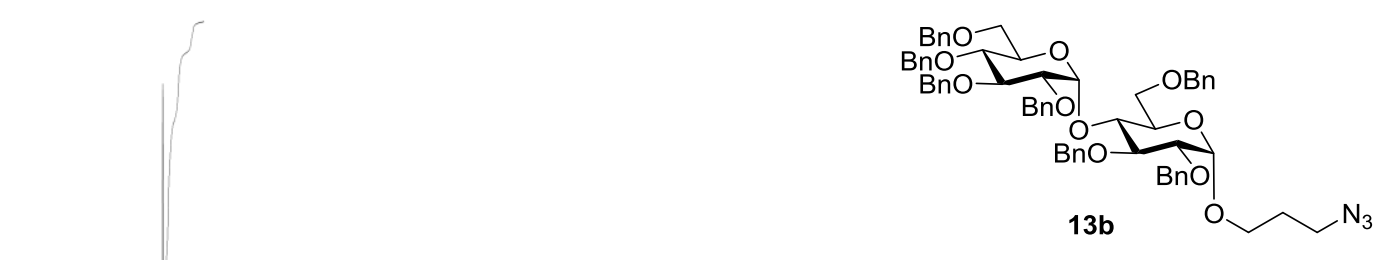

${ }^{1} \mathrm{H}-\mathrm{NMR}, 500 \mathrm{MHz}, \mathrm{CDCl}_{3}$

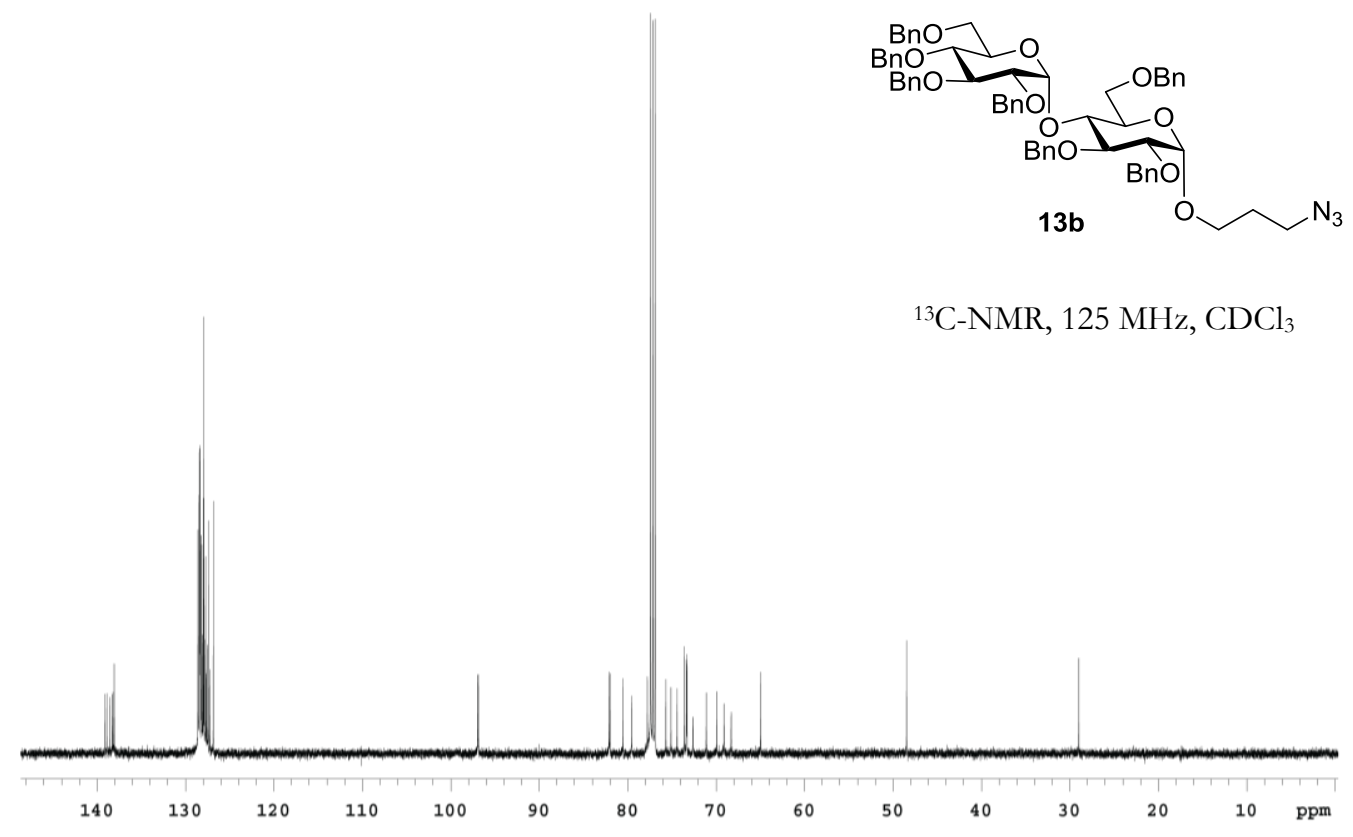




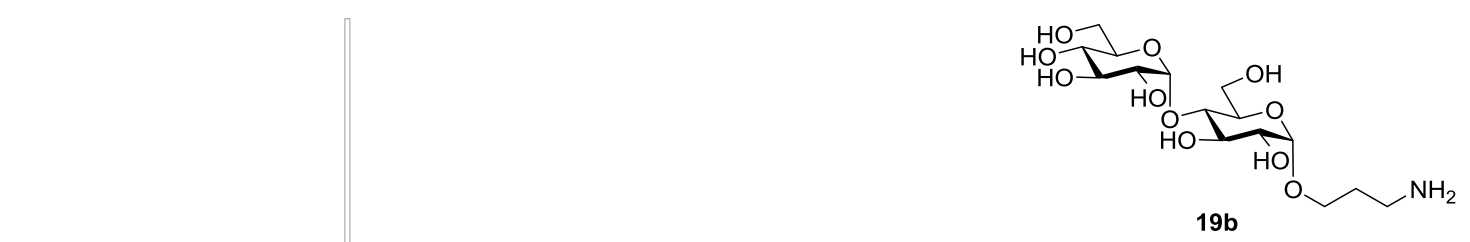

${ }^{1} \mathrm{H}-\mathrm{NMR}, 500 \mathrm{MHz}, \mathrm{D}_{2} \mathrm{O}$
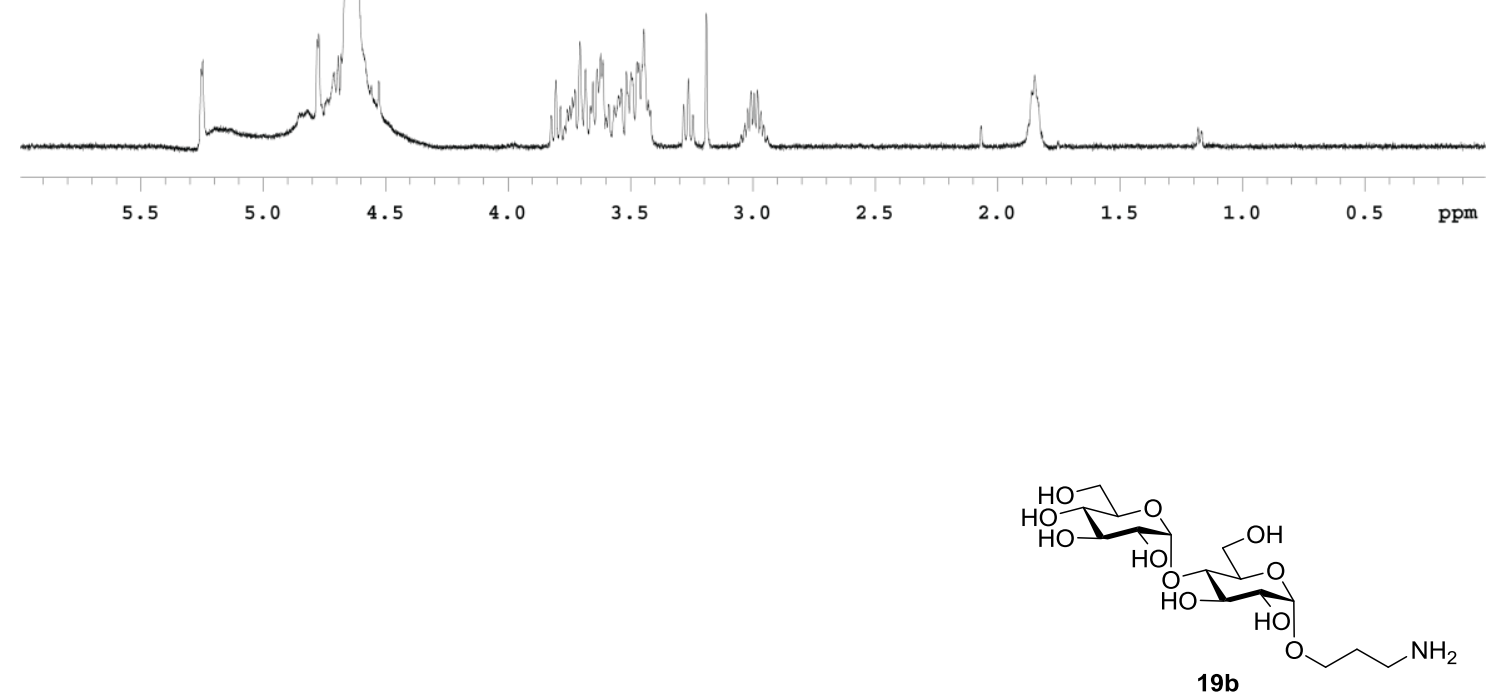

${ }^{1} \mathrm{H}-\mathrm{NMR}, 500 \mathrm{MHz}, \mathrm{D}_{2} \mathrm{O}$

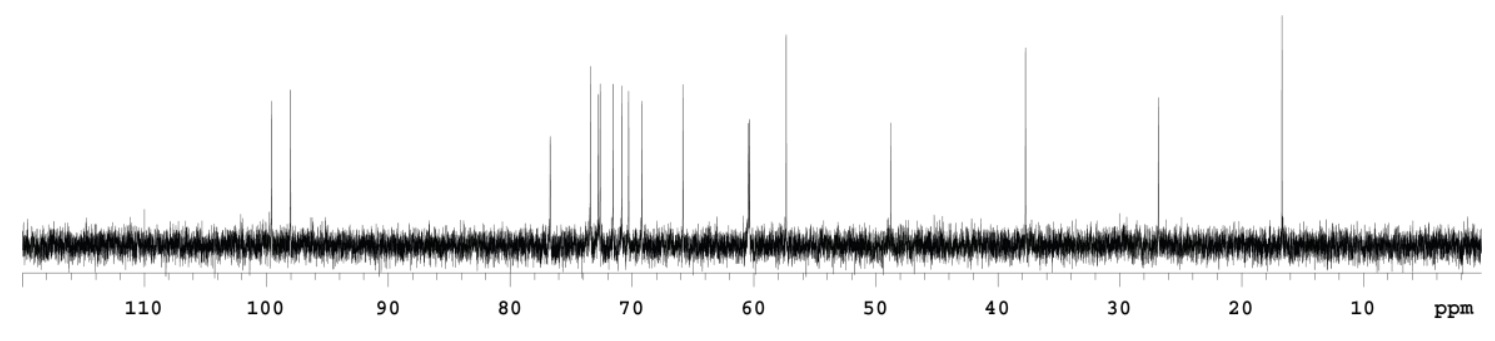




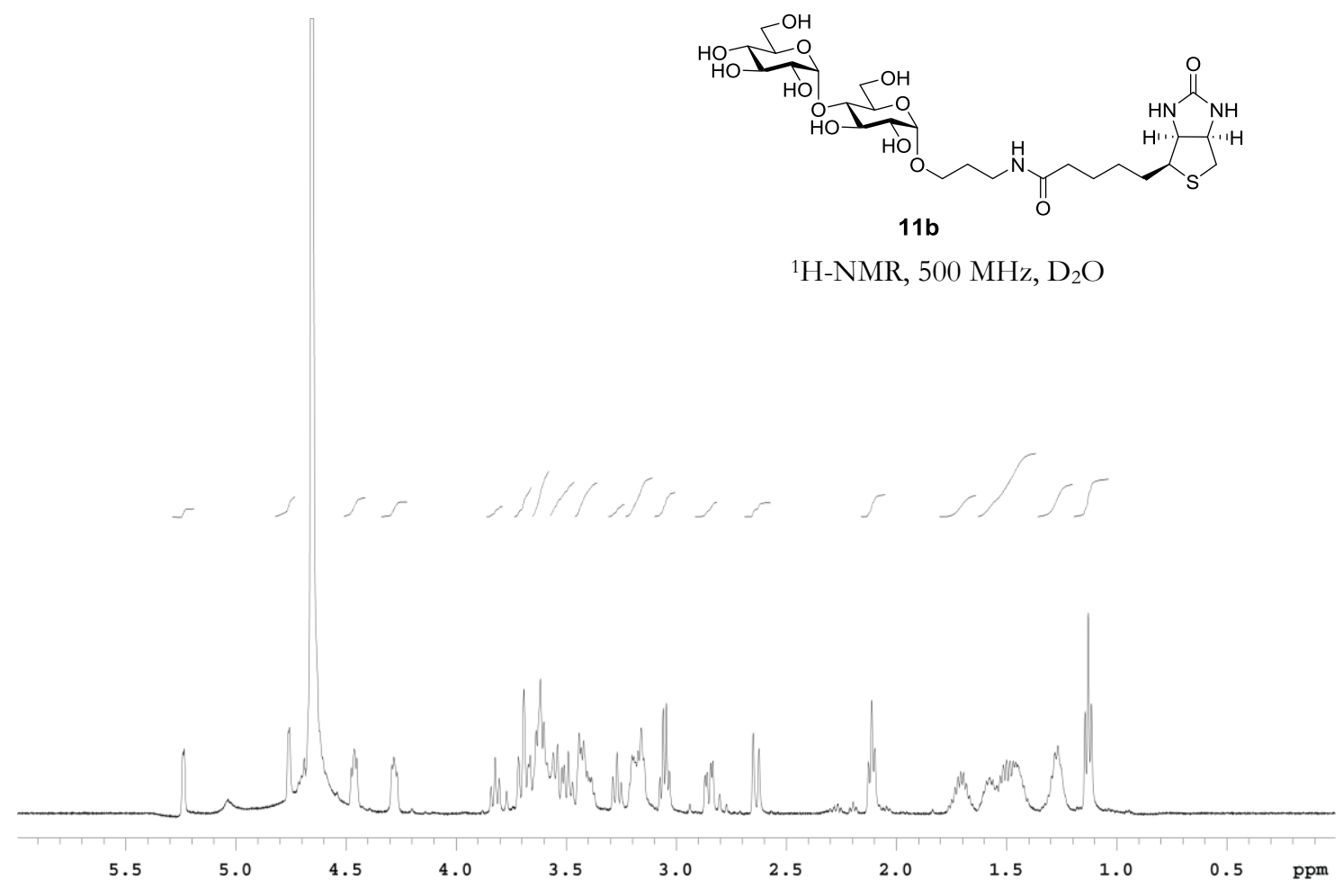




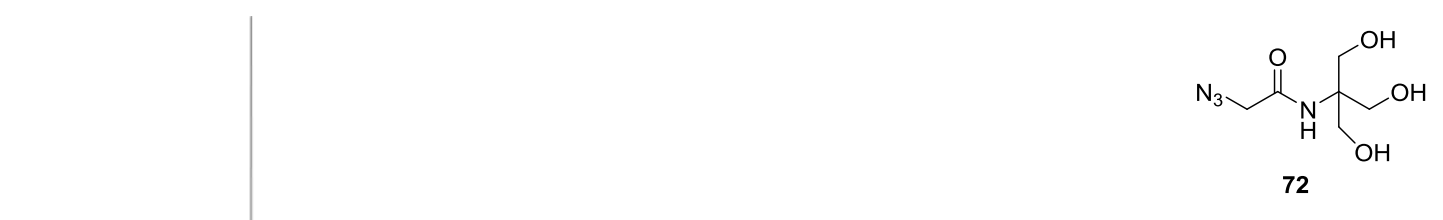

${ }^{1} \mathrm{H}-\mathrm{NMR}, 500 \mathrm{MHz}, \mathrm{D}_{2} \mathrm{O}$

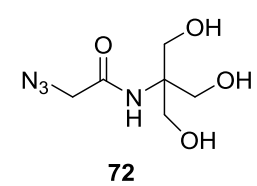

${ }^{13} \mathrm{C}-\mathrm{NMR}, 125 \mathrm{MHz}, \mathrm{D}_{2} \mathrm{O}$

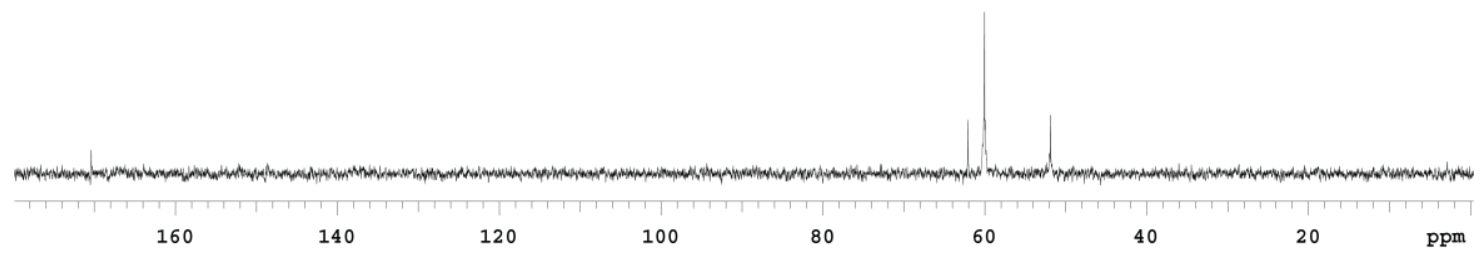




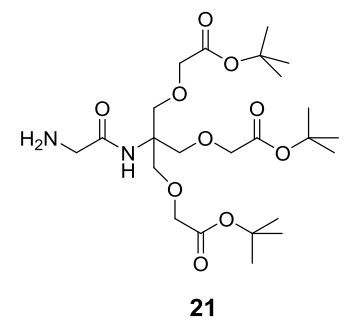

${ }^{1} \mathrm{H}-\mathrm{NMR}, 500 \mathrm{MHz}, \mathrm{CDCl}_{3}$
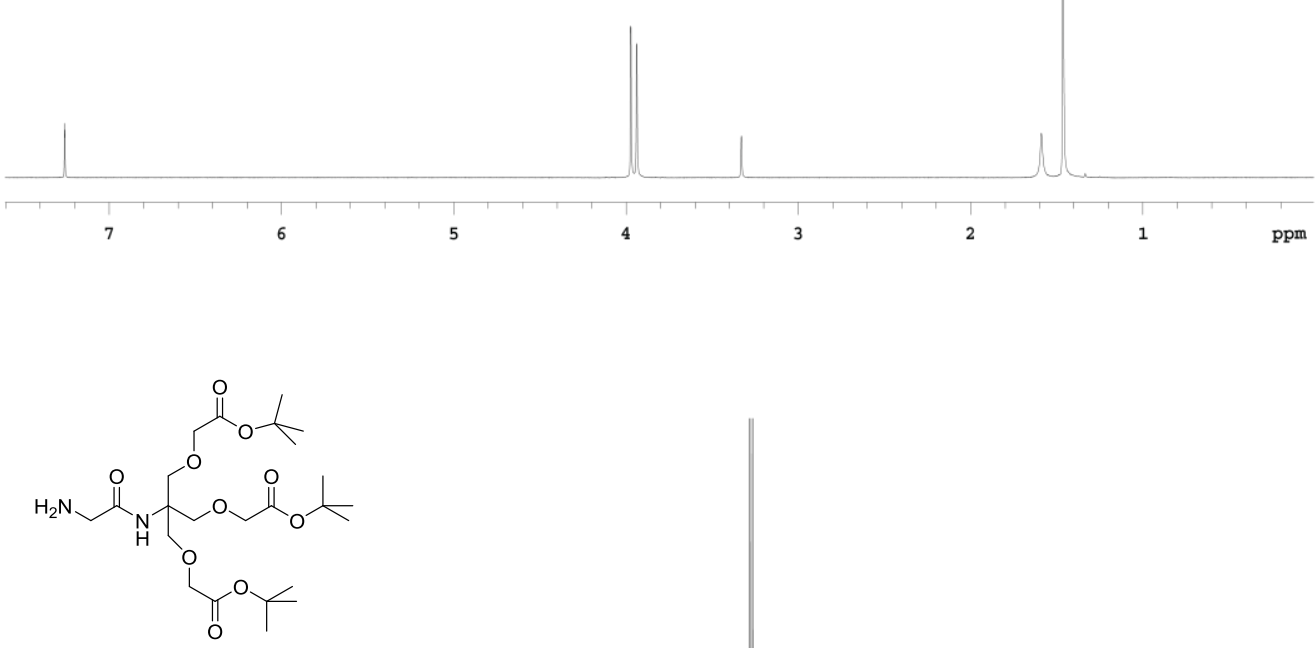

21

${ }^{13} \mathrm{C}-\mathrm{NMR}, 125 \mathrm{MHz}, \mathrm{CDCl}_{3}$ 

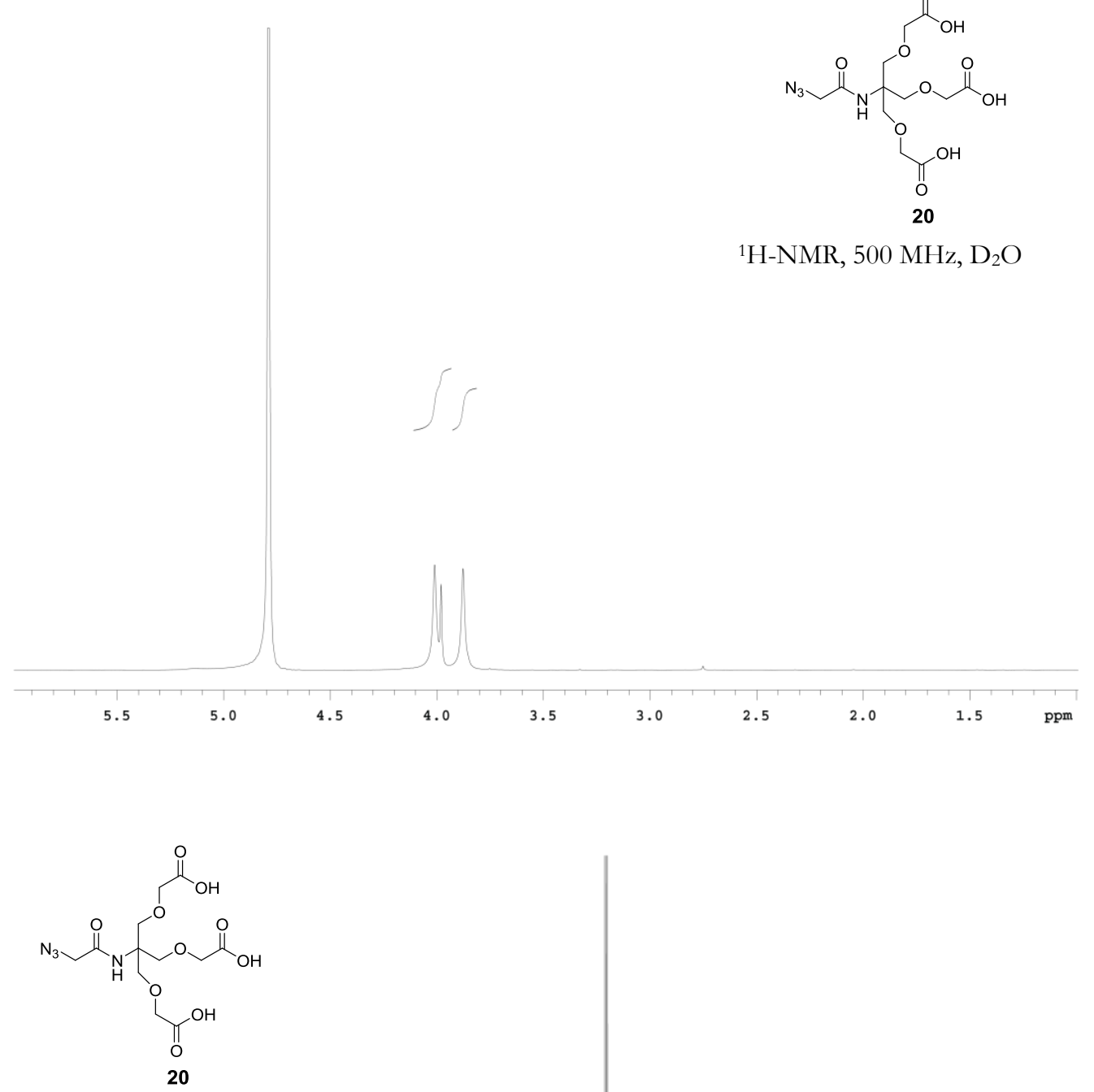

${ }^{13} \mathrm{C}-\mathrm{NMR}, 125 \mathrm{MHz}, \mathrm{D}_{2} \mathrm{O}$

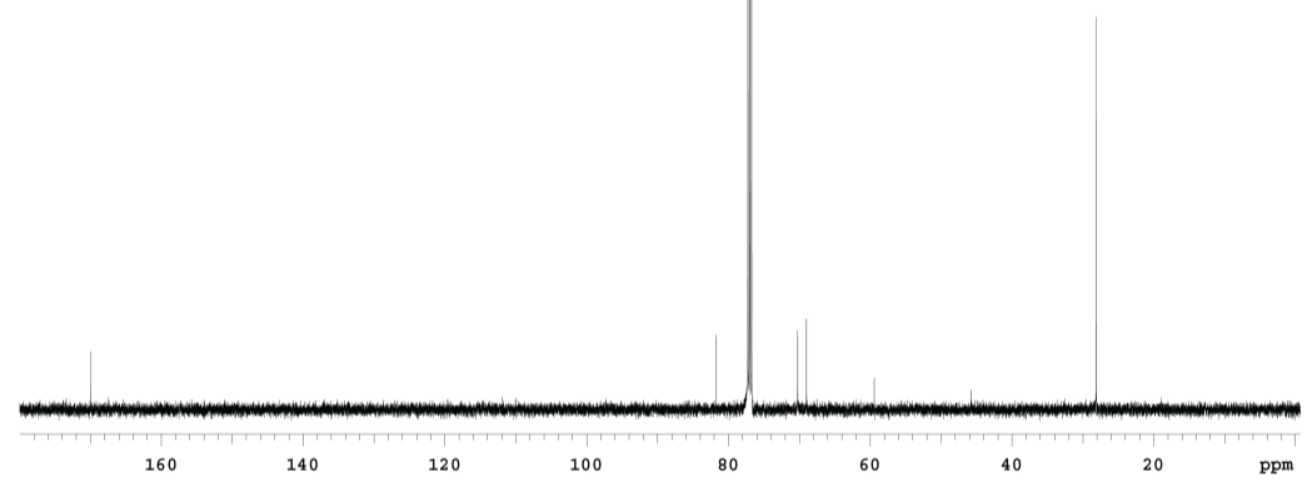




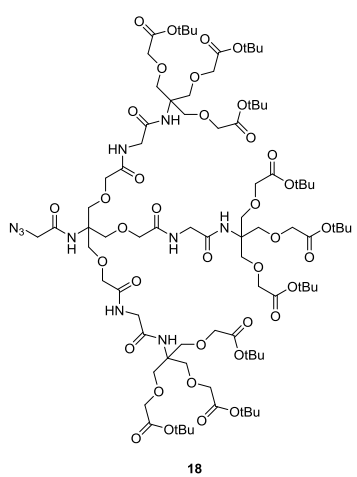

${ }^{1} \mathrm{H}-\mathrm{NMR}, 500 \mathrm{MHz}, \mathrm{CDCl}_{3}$
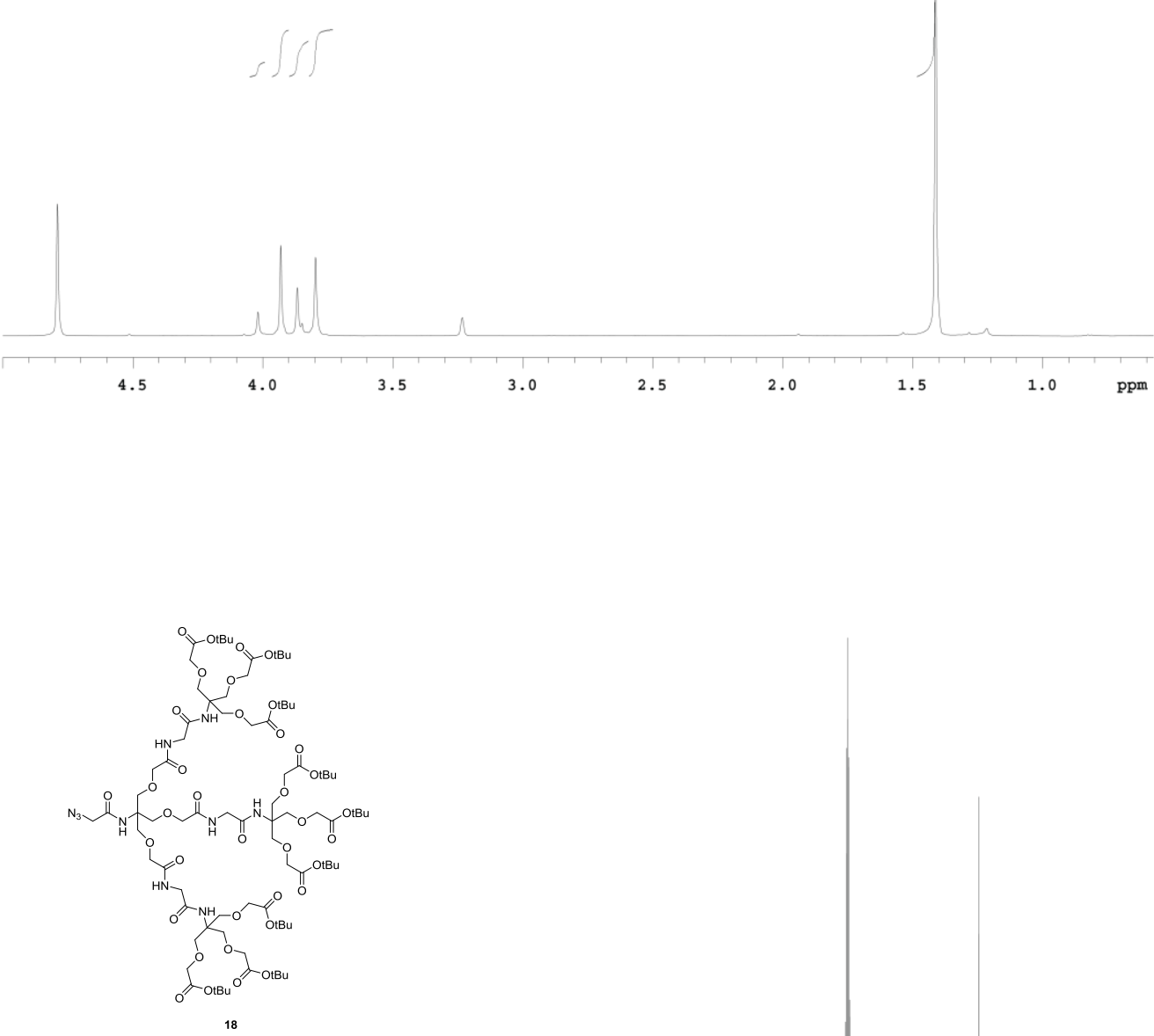

${ }^{13} \mathrm{C}-\mathrm{NMR}, 125 \mathrm{MHz}, \mathrm{CDCl}_{3}$

160

120

100

80

60

40

$20 \quad \mathrm{ppm}$ 


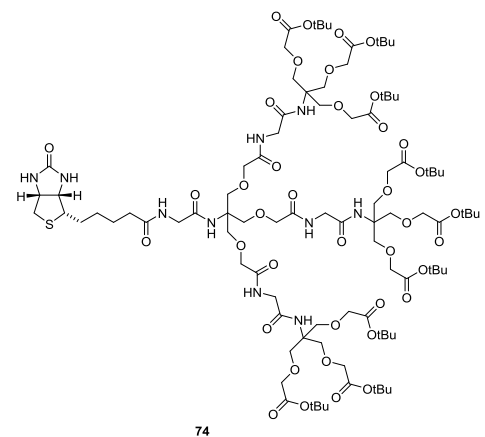

${ }^{1} \mathrm{H}-\mathrm{NMR}, 500 \mathrm{MHz}, \mathrm{CDCl}_{3}$
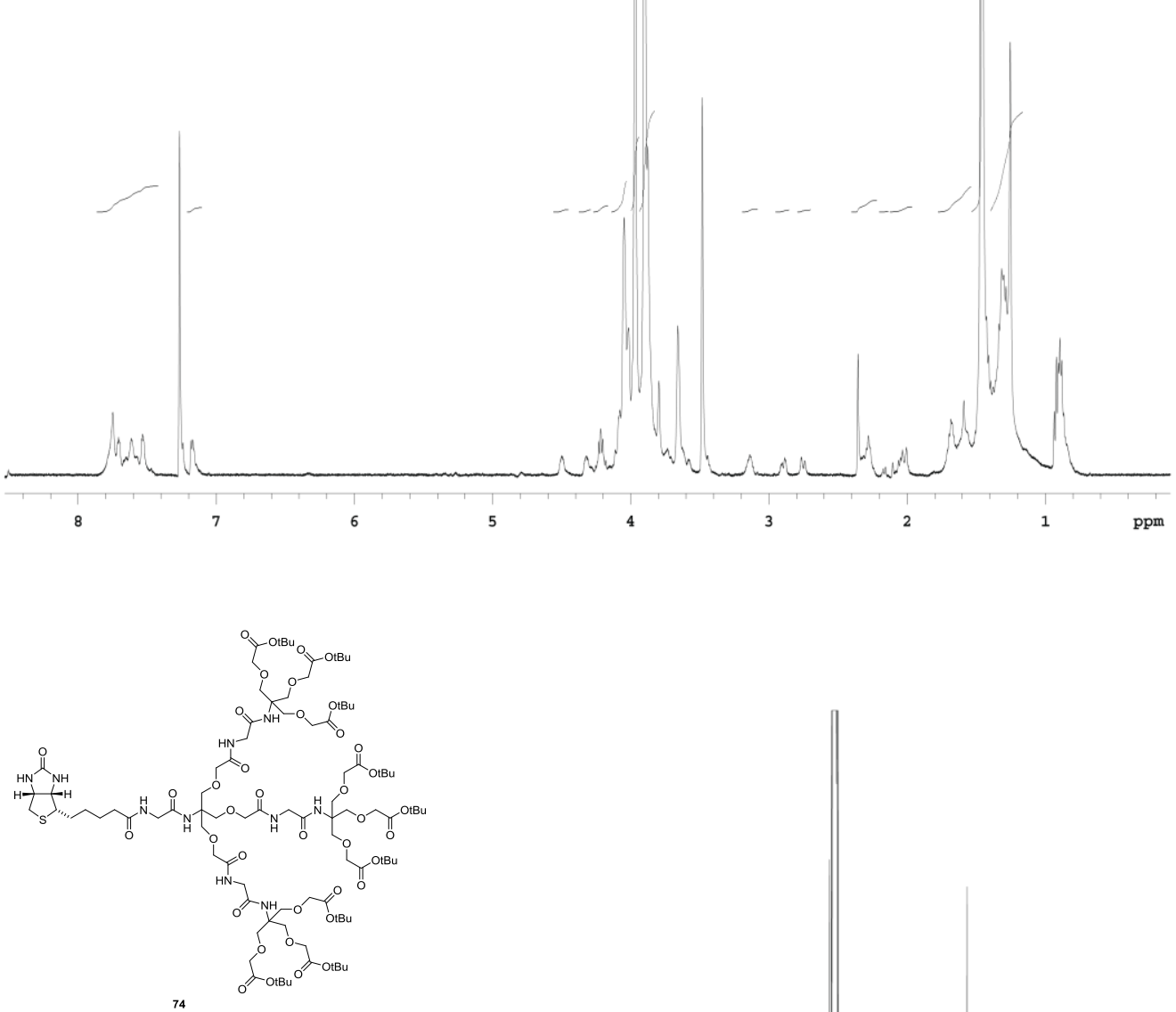

${ }^{13} \mathrm{C}-\mathrm{NMR}, 125 \mathrm{MHz}, \mathrm{CDCl}_{3}$

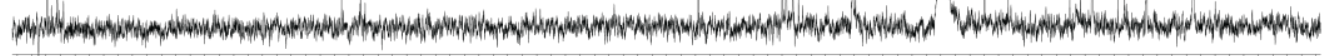
160 140 120 100 80

60 40 $20 \quad$ ppm 


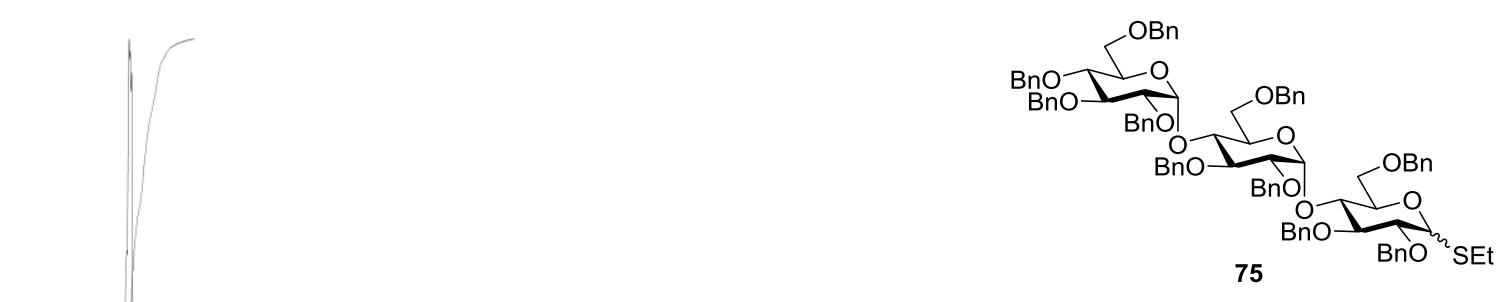

${ }^{1} \mathrm{H}-\mathrm{NMR}, 500 \mathrm{MHz}, \mathrm{CDCl}_{3}$

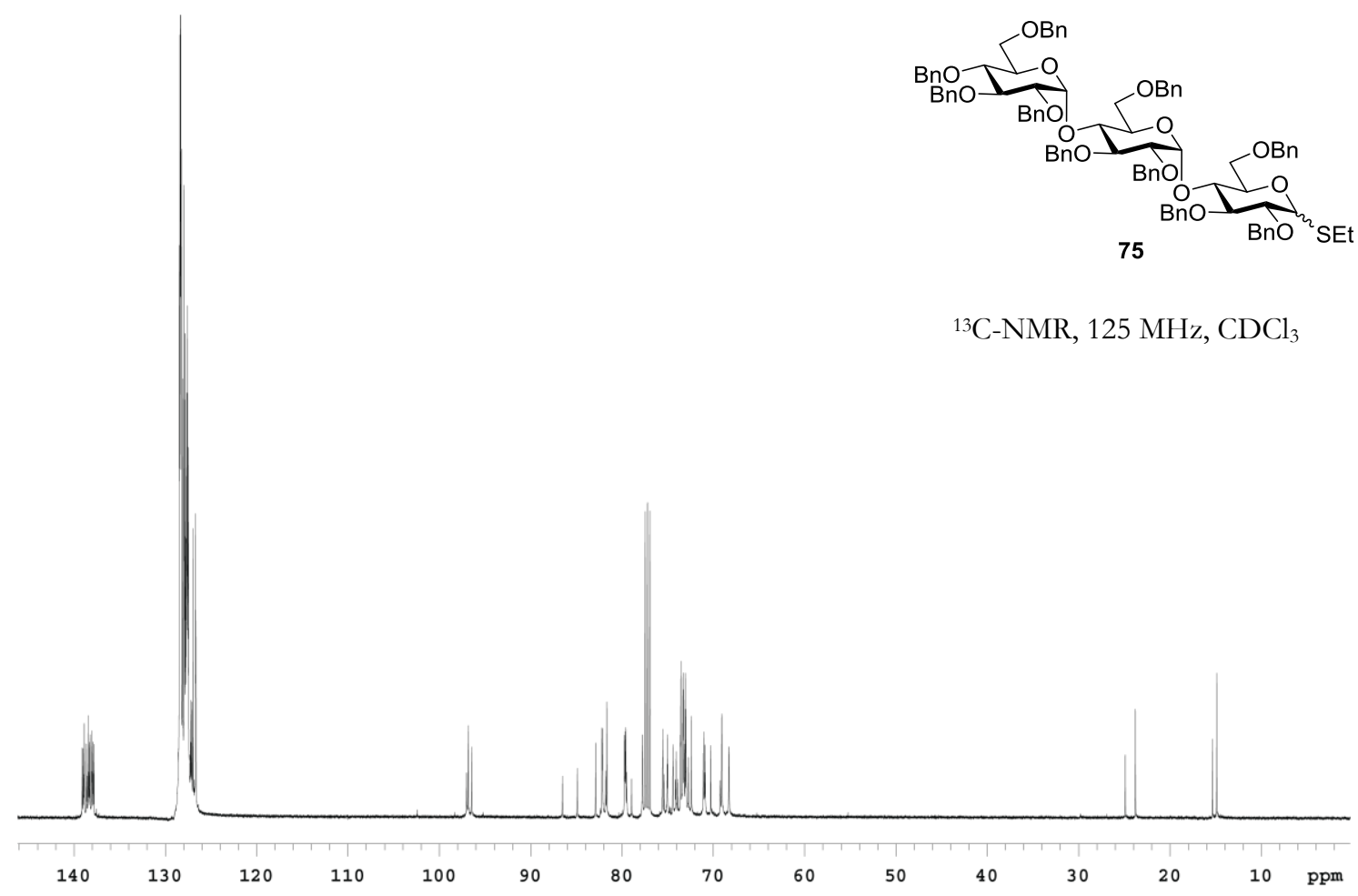

